\title{
Validação do Instrumento CICAc \\ Classificação de Idosos quanto à Capacidade para o Autocuidado
}

Maria Helena Morgani de Almeida

Tese apresentada à Faculdade de Saúde Pública da Universidade de São Paulo - Departamento de Prática de Saúde Pública para obtenção de título de doutor em Saúde Pública

Área de concentração: Serviços de Saúde Pública

Orientadora:

Profa. Titular Aracy Witt de Pinho Spínola

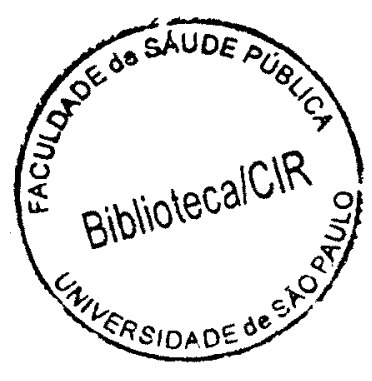


Dedico esse trabalho a meu marido Paulo, ao meu filho Paulo Henrique e a minha mãe Joana pelo incentivo dado para a sua realização, compreensão quanto aos momentos que não pude destinar a eles e que estiveram voltados ao estudo e, principalmente, por darem sentido a tudo isso. 


\section{AGRADECIMENTOS}

Meus sinceros agradecimentos a minha orientadora Profa Titular Aracy Witt de Pinho Spínola pela orientação clara, precisa e objetiva. A segurança, experiência, competência e incentivo, transmitidos ao longo desta caminhada, fizeram com que eu me sentisse sempre muito bem acompanhada.

Aos idosos, funcionários e diretoria das instituições por fornecerem informações preciosas ao trabalho e condições para sua realização.

Aos colegas terapeutas ocupacionais pela valiosa parceria nessa empreitada.

As alunas Roberta I. S. Okura, Paula S. Iwamizu e professores Antonio Carlos P. Lima e Lúcia P. Barroso, pela realização da análise estatística com competência, agilidade e respeito ao pesquisador e aos propósitos da pesquisa.

À Profa Dra Alice Moreira Derntl pelo exemplo, inspiração e apoio permanentes.

À Profa Dra Helena Akemi W. Watanabe pelo ombro amigo e continente e pelas preciosas sugestões teórico práticas.

Ao Prof Dr Julio Litvoc pelo conhecimento e experiência transmitidos.

Às minhas colegas da pós-graduação Maria Lucia Beger, Janaina Balabanowa, Leonice Aparecida Doimo, Ana Maria Tucci G. B. Ferreira, Márcia Maria P. R. Mazza pela amizade, solidariedade e constante troca de idéias.

À Maria Fernanda Derntl pela ajuda no momento e na medida exata à minha necessidade.

Ao meu marido Paulo Antonio de Almeida por me auxiliar sempre e muito, com competência, segurança e amor. 
Colhamos flores, Molhemos leves As nossas mãos Nos rios calmos, Para aprendermos Calma também...

Ricardo Reis, Odes, p.15 


\section{RESUMO}

Almeida MHM. Validação do Instrumento CICAc: Classificação de Idosos quanto à Capacidade para o Autocuidado. São Paulo, 2003. [Tese de Doutorado Faculdade de Saúde Pública da USP].

Introdução: $O$ envelhecimento populacional está associado a maior prevalência de incapacidades, indicando o fortalecimento da capacidade funcional como principal medida para a promoção da saúde dos idosos. Os terapeutas ocupacionais têm adaptado modelos para avaliar a funcionalidade desta população. Com o propósito de produzir um instrumento de uso consensual e sistematizar a atuação desse profissional com idosos, especialmente em unidades básicas de saúde, elaborei o Instrumento CICAc: Classificação de Idosos quanto à Capacidade para o Autocuidado, válido em seu conteúdo somente para a população estudada. Objetivos: Estabelecer a validade de conteúdo e avaliar a confiabilidade do referido instrumento. Método: $O$ instrumento foi apreciado e ajustado por um júri de especialistas $(n=15)$ em três etapas, através da técnica Delphi, e a seguir aplicado duas vezes, com intervalo de 7 a 15 dias, a uma população de idosos $(n=30)$. Resultados: Os itens obtiveram índices médios de aprovação de 93,3\% para conteúdo e $86,7 \%$ para enunciado. Sua estabilidade foi calculada através do coeficiente Kappa que demonstrou concordância de moderada à excelente. $O$ instrumento apresentou consistência interna para as atividades básicas e instrumentais de vida diária com Alpha de Cronbach de 0,713 e $\quad 0,704$ respectivamente. Essa análise limitourse às áreas "perfil social" e "capacidade funcional" devido a características do instrumento. Conclusões: O Instrumento CICAc permite, após o processo de validação, classificar os idosos quanto à capacidade para o autocuidado e se tornará útil ao terapeuta ocupacional e em estudos e pesquisas sobre envelhecimento se divulgado, aplicado e seus resultados compartilhados.

Descritores: Avaliação. Idoso. Terapia Ocupacional. Atividades de vida diária. Autocuidado. 


\title{
ABSTRACT
}

\author{
Almeida MHM. Validação do Instrumento CICAc - Classificação de Idosos \\ quanto à Capacidade para o Autocuidado. [Validation of the CICAc Instrument: \\ classification of the aged concerning self care ability]. São Paulo, 2003. [Doctoral \\ Thesis - Faculdade de Saúde Pública da USP].
}

Introduction: Aging is related to higher prevalence of disabilities, what suggests that strengthening functional ability is the main step to promote health among the aged. Occupational therapists have been adapting models to assess functionality among this group. In order to make an instrument of general assented use and to systematize the performance of those professionals in regard to the aged, specially in basic health units, I have developed the CICAc instrument, i.e., a classification of the aged concerning self care ability. The content of this instrument applies only to the researched population group. Objectives: To establish the validity of the content of the instrument in question and to assess its reliability. Method: The instrument has been appraised and adjusted by a judging team of fifteen specialists in the field, in three phases, employing the Delphi technique. Afterwards, it has been applied twice to a group of thirty elderly people, at intervals of 7 to 15 days. Results: The items researched have achieved average rates of approval of $93,3 \%$ regarding content and $86,7 \%$ regarding statement. Its stability has been calculated using the Kappa coefficient, which showed moderate to excellent concordance. The instrument presented internal consistency concerning both basic and instrumental activities of daily living, the Alpha of Cronbach being 0,713 and 0,704 respectively. This analysis has been limited to the "social profile" and "functional ability" issues due to the characteristics of the instrument. Conclusion: After the validation process, the CICAc instrument allows classification of the elderly concerning self care ability and, as long as it is spread out and applied, and as its results are shared, it will be useful to the occupational therapist and to studies and researches about aging.

Keywords : Assessment. Aged. Occupational therapy. Daily living activities. Self care. 


\section{SIGLAS}

ABVDs Atividades Básicas de Vida Diária

AIVDs Atividades Instrumentais de Vida Diária

AOTA Associação Americana de Terapia Ocupacional

AVDs Atividades de Vida Diária

CCT [Clock Completion Test]

CICAc Instrumento para a Classificação de Idosos quanto à Capacidade para o Autocuidado

CIF Classificação Internacional de Funcionalidade, incapacidade e saúde

ICIDH Classificação Internacional de Deficiênciass, Incapacidades e Desvantagens

OMS Organização Mundial da Saúde

OPAS Organização Pan Americana de Saúde

PNI Politica Nacional do Idoso

PNSI Política Nacional de Saúde do Idoso

T.O Terapeuta Ocupacional/ Terapia Ocupacional

UBSs Unidades Básicas de Saúde 


\section{LISTA DE TABELAS, QUADROS E FIGURAS}

Quadro 1: Atividades de vida diária segundo inclusão em instrumentos com validade e confiabilidade estabelecidas.

Tabela 1: População idosa participante da avaliação de confiabilidade do Instrumento CICAc segundo faixa etária e sexo. São Paulo, 2003.

Quadro 2: Caracterização profissional dos juizes participantes do Estudo Delphi.

Tabela 2: Juizes participantes do estudo Delphi segundo tempo de experiência na área e cursos de pós-graduação.São Paulo, 2003.

Quadro 3: Julgamento dos especialistas sobre o Instrumento CICAC - versão estruturada 60

Tabela 3: Criticas dos especialistas quanto à forma e conteúdo, por área do Instrumento CICAcversão estruturada.São Paulo, 2003.

Tabela 4: Sugestões dos especialistas quanto à forma e conteudo do Instrumento CICAc - Versão Estruturada. São Paulo, 2003.

Tabela 5: Críticas e sugestões dos especialistas referentes à atribuição de pontuação ao idoso nas áreas do Instrumento CICAc - Versão Estruturada. São Paulo, 2003.

Quadro 4: Julgamento dos especialistas sobre a $l^{a}$ versão grupal do Instrumento CICAc. 72

Tabela 6: Sugestões dos especialistas relativas à definição de termos no Instrumento CICAc $-1^{a}$ Versão Grupal. São Paulo, 2003.

Tabela 7: Sugestões dos especialistas relativas à organização de itens no Instrumento CICAc - $1^{a}$ Versão Grupal. São Paulo, 2003.

Quadro 5: Pontuação atribuida por 10 especialistas às formas adotadas pelos idosos para compensar dificuldades. Instrumento CICAc $1^{a}$ versão grupal.

Quadro 6: Julgamento dos especialistas sobre a $2^{a}$ versão grupal Instrumento CICAc. 81

Quadro 7: Pontuação atribuida por 15 especialistas às formas adotadas pelos idosos para compensar dificuldades. Instrumento $C I C A c 2^{a}$ versão grupal.

Figura 1: Produto resultante do estudo Delphi em três etapas. 84

Quadro 8: Agrupamento de respostas às questões 13 e $14.3^{a}$ versão grupal do CICAc 88

Quadro 9: Agrupamento de respostas à questão 15.1: "Porque as atividades são importantes"? (a que necessidades elas estão relacionadas). $3^{a}$ versão grupal do CICAC.

Quadro 10: Agrupamento de respostas às questões $16.1 .3^{a}$ versão grupal do CICAc. 89

Quadro 11: Agrupamento de respostas às questões 17,18,19. $3^{a}$ versão grupal do CICAc 89

Quadro 12: Agrupamento de respostas às questões 20,21. $3^{a}$ versão grupal do CICAC. 89

Quadro 13: Categorias utilizadas para as formas imaginadas de realizar as atividades desejadas.. 90 
Tabela 8: Medidas resumo para os coeficientes Kappa obtidos na análise de estabilidade. Instrumento CICAC.2003.

Tabela 9: Concordância entre teste e reteste para a questão 5-Grau de satisfação do idoso com a relação que mantém com os amigos. Instrumento CICAc, 2003.

Tabela 10: Concordância entre teste e reteste para a questão 15.1-Motivo para considerar importante as atividades instrumentais que realiza: responsabilidade social.Instrumento CICAc,2003.

Tabela 11: Concordância entre teste e reteste para as questões 13 e 14-O idoso faz ou não atividade como: uso de telefone (atividade instrumental). Instrumento CICAc,2003.

Tabela 12: Concordância entre teste e reteste para a questão 17-O idoso apresenta dificuldade proveniente de ambiente social e fisico para atividades de lazer com interesses diversos. Instrumento CICAC, 2003.

Tabela 13: Medidas resumo do coeficiente Kappa por área de investigação.Instrumento CICAc, 2003.

Figura 2: Box-plot de todos os coeficientes Kappa obtidos no instrumento. .94

Figura 3: Box-plot dos coeficientes Kappa obtidos por área do instrumento .94

Tabela 14: Medidas resumo do coeficiente Kappa por questão.instrumento CICAc,2003 96

Quadro 14: Escala utilizada para a verificação de consistência interna na área de Perfil social...... 98

Quadro 15: Escala utilizada para a verificação de consistência interna na área de Capacidade funcional.

Tabela 15: Valores do coeficiente Alpha de Cronbach por bloco de atividade na área de Capacidade funcional e número de idosos utilizado para o cálculo. Instrumento CICAc,2003

Quadro 16: Ajustes do Instrumento CICAc durante o processo de validação de seu conteúdo e avaliação de sua confiabilidade.

Quadro 17: Pontuação atribuída ao idoso segundo nivel funcional.

Figura 4: Posicionamento do idoso com base em sua capacidade funcional para as ABVDs 


\section{ÍNDICE}

1. INTRODUÇÃO ................................................................................................... 1

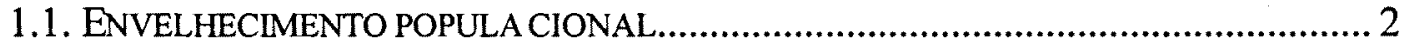

1.2. PROMOÇÃO DA SAÚDE DOS IDOSOS: CAPACIDADE FUNCIONALNOS MODELOS

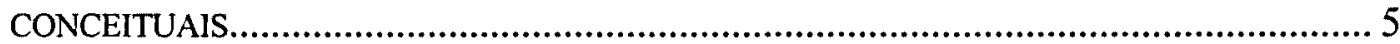

1.2.1. Envelhecimento bem sucedido ................................................................9

1.2.2. Adaptação bem sucedida ....................................................................... 10

1.2.3 Autocuidado ............................................................................................ 12

1.2.4. Modelo ecológico de envelhecimento........................................................ 14

1.2.5. Classificação Internacional de deficiências, incapacidades e

desvantagens.......................................................................................................... 15

1.2.6. Classificação Internacional de funcionalidade, incapacidade e saúde... 17

1.3. AVALIAÇÃO DA CAPACIDADE FUNCIONAL .............................................. 18

1.4. OCUPAÇÃO HUMANA : OBJETO DE ATENÇÃO EM TERAPIA OCUPACIONAL .......... 24

1.5. TERAPIA OCUPACIONAL COM IDOSOS: CAPACIDADE FUNCIONAL ..................... 30

1.6. INSTRUMENTOS DE AVALIAÇÃO DE TERAPIA OCUPACIONAL EM

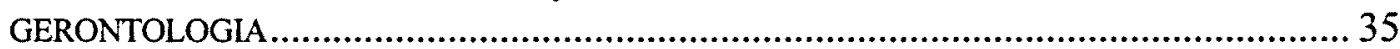

1.7. CONSIDERAÇÕES SOBRE CONFIABILIDADE E VALIDADE .............................. 41

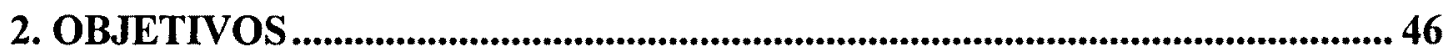

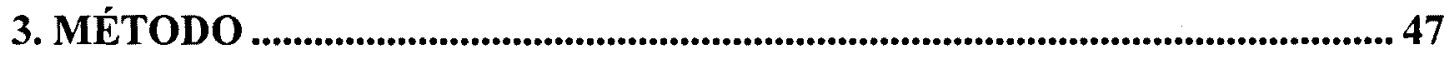

3.1. ESTRATÉGIAS PARA AVAUAR A CONFIABLIDADE E ESTABELECER A VALIDADE

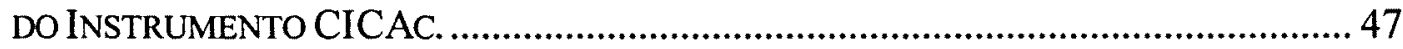

3.2.VALIDAÇÃO DE CONTEÚDO DO INSTRUMENTO CICAC .................................. 49

3.2.1. A Técnica Delphi................................................................................ 49

3.2.2. População ........................................................................................... 52

3.2.3. Coleta de dados................................................................................. 53

3.3. AvALIAÇÃO DE CONFIABILIDADE DO INSTRUMENTO CICAC .......................... 54

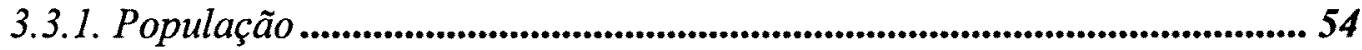

3.3.2. Coleta de dados............................................................................. 56

4. RESULTADOS E DISCUSSÃO: VALIDAÇÃO DE CONTEÚDO ................ 57

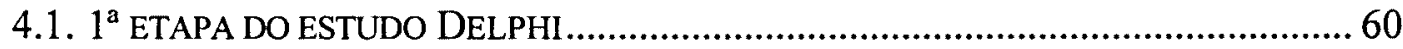

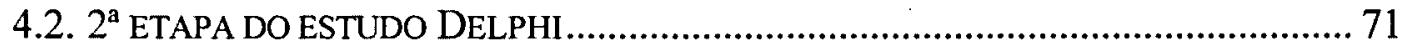

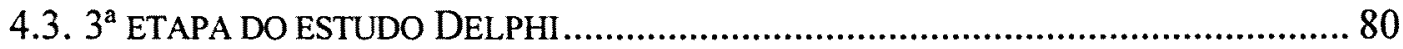

5. RESULTADOS E DISCUSSÃO: AVALIAÇÃO DE CONFIABILIDADE... 85

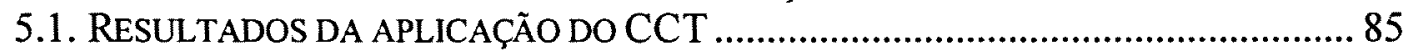

5.2. CONSIDERAÇÕES INICIAIS SOBRE A ANÁLISE ESTATISTICA ............................. 85

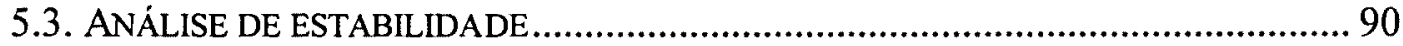

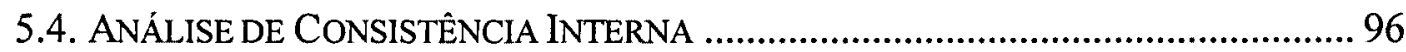

5.5. CONSIDERAÇÕES FINAIS SOBRE A ANÁLISE ESTATÍSTICA............................... 99

6. CONSIDERAÇÕES FINAIS SOBRE A VALIDAÇÃO DO INSTRUMENTO

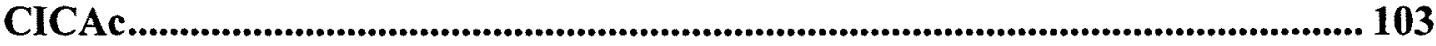

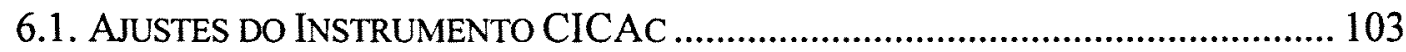


6.2. A VERSÃO SIMPLIFICADA DO INSTRUMENTO CICAC

REFERÊNCIAS BIBLIOGRÁFICAS ............................................................. 120

ANEXO 1 - VERSÕES DO INSTRUMENTO CICAc......................................... A-1

1.1. $1^{\mathrm{a}}$ VERSÃO - INSTRUMENTO CICAC............................................................. A-2

1.2. ESTRUTURAÇÃO DO INSTRUMENTO CICAC …….....................................

1.3. VERSÃo ESTRUTURADA DO INSTRUMENTO CICAC .................................... A-19

1.4. $1^{\text {a }}$ VERSÃo GRUPAL DO INSTRUMENTO CICAC............................................. A-25

1.5. $2^{\mathrm{a}}$ VERSÃO GRUPAL DO INSTRUMENTO CICAC.......................................... A-33

1.6. $3^{\mathrm{a}}$ VERSÃO GRUPAL DO INSTRUMENTO CICAC.............................................. A-44

ANEXO 2 - DIVERSOS...................................................................................... A-55

2.1. MATRIZ DE TERMINOLOGIA UNIFORME EM TERAPIA OCUPACIONAL_............. A-56

2.2. SOLICITAÇÃO AOS TERAPEUTAS OCUPACIONAIS PARA PARTICIPAR DO

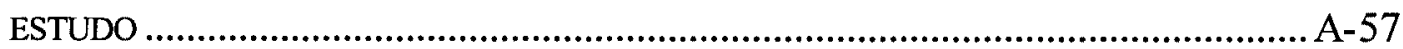

2.3. SOLICITAÇÃO AOS TERAPEUTAS OCUPACIONAIS PARA PARTICIPAR DO

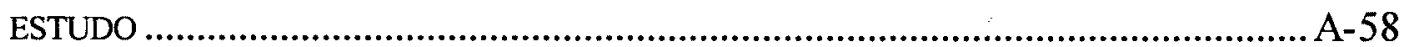

2.4. TERMO DE CONSENTIMENTO LIVRE E ESCLARECIDO AOS TERAPEUTAS

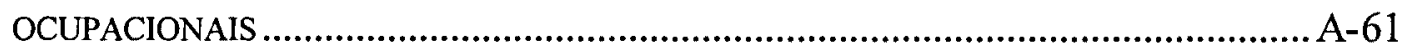

2.5. INSTRUÇÕES AOS TERAPEUTAS OCUPACIONAIS NAS TRÊS ETAPAS DO

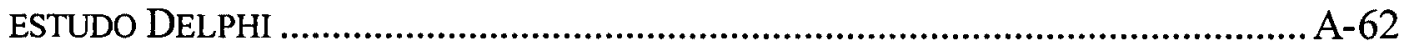

2.6. QUESTIONÁRIO DE PARTICIPAÇÃO EM PESQUISA ………............................A-68

2.7. PROPOSTA DE ENCONTRO ENTRE ESPECIALISTAS......................................... A-70

2.8. CONSIDERAÇÕES SOBRE O TESTE DO RELÓGIO [CLOCK COMPLETION TEST] A-71

2.9. TERMO DE CONSENTIMENTO PARA APLICAÇÃO DO TESTE DO RELÓGIO [CLOCK

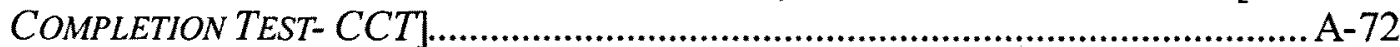

2.10. PROTOCOLO PARA APLICAÇÃO DO CCT - TESTE DO RELÓGIO....................... A-73

2.11. TERMO DE CONSENTIMENTO LIVRE E ESCLARECIDO AOS IDOSOS-AVALIAÇÃO

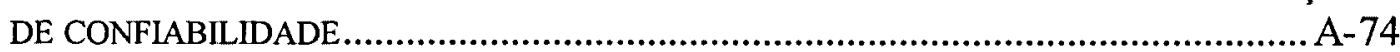

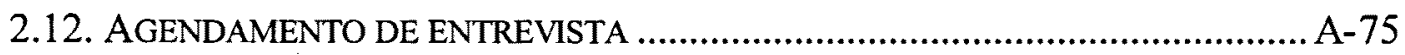




\section{INTRODUÇÃO}

Buscando sistematizar a atuação do terapeuta ocupacional (T.O) junto à população idosa em Unidades Básicas de Saúde (UBS), identifiquei a necessidade de adoção consensual por esses profissionais de um instrumento de avaliação do idoso em seu fazer cotidiano, uma vez que "não existe consenso entre os T.O.s quanto ao instrumento a ser adotado" (ALMEIDA 1997, p.2).

A idéia de construir um instrumento específico de T.O junto a essa população teve origem em minha experiência profissional. A recente inserção do T.O em UBS gera dificuldades, basicamente para identificação de demanda e de recursos para área. Considero que a utilização de um instrumento específico compõe a sistematização da atenção ao idoso pelo T.O. o que, por sua vez, deverá minimizar as dificuldades mencionadas.

Elaborei, com essa finalidade, o Instrumento CICAc: Classificação de Idosos quanto à Capacidade para o Autocuidado. Conclui sua $1^{2}$ Versão construída em três fases: Roteiro Preliminar, Roteiro Ajustado e $1^{a}$ Versão do Instrumento (ALMEIDA 1997).

Considero que a metodologia de construção do Instrumento CICAc conferiu a ele validade de face e de conteúdo para a população estudada. Para que possa fornecer informações mais válidas e confiáveis sobre o universo de idosos que vivam na comunidade, em especial sobre aqueles atendidos em UBS, deverá ser submetido a um novo processo de validação.

Através do presente estudo submeto o Instrumento CICAc a procedimentos formais de validação que contribuirão para torná-lo ferramenta útil para o propósito maior de sistematização da atenção do terapeuta ocupacional em unidades básicas junto idosos. Ao permitir avaliar e classificar idosos de forma sucinta e simplificada, o processo de validação contribuirá para utilização do instrumento em estudos e pesquisas na área de Saúde Pública e Envelhecimento Humano (ALMEIDA 1997). 


\subsection{Envelhecimento populacional}

O envelhecimento populacional é considerado um fenômeno mundial. Nos países desenvolvidos a transição demográfica ocorreu lentamente e foi acompanhada pela elevação da qualidade de vida das populações urbanas e rurais (GORDILHO e col. 2000).

A queda das taxas de fecundidade e mortalidade iniciadas no século passado em países desenvolvidos decorre da ampliação dos sistemas de proteção social e melhorias de condições gerais de vida (CHAIMOWICZ 1997).

No Brasil o declínio da mortalidade, que deu início à transição demográfica, tem ocorrido a partir das primeiras décadas do século $\mathrm{XX}$ e de forma desigual nas diferentes regiões e classes sociais. A queda das taxas de mortalidade tem se dado mais por intervenção do Estado do que por mudanças estruturais da sociedade (CHAIMOWIZC 1997).

Há que se observar no entanto que o envelhecimento populacional resulta mais da queda das taxas de fecundidade do que de mortalidade. Ao contrário dessa última, a queda da fecundidade abrange todas as regiões do país e tem provocado o envelhecimento da população brasileira de forma rápida desde a década de 60 (CHAIMOWICZ 1997; GORDILHO e col. 2000).

A fecundidade experimentou no Brasil, no período entre 1960 e 1991, uma redução de $60 \%$, atingindo o valor de 2,5. Esse fenômeno contribui para o crescimento cada vez mais expressivo da população idosa que supera o crescimento da população geral (BERQUÓ 1996).

Segundo o Censo do Ano 2000 (FUNDAÇÃO IBGE 2000), a população de idosos no Brasil corresponde a 9,1 \%. Dos 169.544.443 cidadãos recenseados, cerca de 14.400 milhões são idosos. 
De acordo com KALACHE e col. (1987) a população brasileira crescerá 5 vezes até 2025 enquanto a população maior de 60 anos crescerá 15 vezes atingindo quase 30 milhões de pessoas nessa faixa etária e posicionando o Brasil em $6^{\circ}$ lugar no mundo em número absoluto de idosos .

Considero que o aumento do número de idosos na população brasileira impõe desafios aos diversos setores da sociedade, uma vez que essa população pode ser considerada de risco por preencher grande parte dos seguintes critérios definidos pela Organização Mundial da Saúde (OMS) e citados por MORALES MARTíNEZ (1994):

- os muito idosos (de 80 anos e mais);

- os que moram sozinhos;

- as mulheres idosas, sobretudo as solteiras e as viúvas;

- os que estão socialmente isolados;

- os idosos sem filhos;

- os que têm limitações severas ou incapacidades;

- os casais de idosos em que um deles é incapacitado ou está muito doente;

- os que contam com recursos econômicos muito escassos;

- aqueles que apresentam alguma forma de incapacidade funcional mas que lhes permite permanecer no domicílio.

Segundo BERQUÓ (1996), a maior parte dos idosos brasileiros são mulheres, viúvas, morando sozinhas, na casa dos filhos ou chefiando famílias monoparentais, geralmente vivem em cond ições de pobreza decorrente da baixa escolaridade e baixo rendimento econômico. Vale destacar que problemas econômicos e baixa escolaridade são enfrentados, em nosso meio, especialmente por mulheres.

Soma-se a isso o fato de que estudos sobre capacidade funcional, conduzidos no Brasil na década de 90 , encontram altas prevalências de incapacidades para, pelo menos, uma atividade de vida diária, variando de $28,18 \%$ a $61 \%$ (LITVOC e DERNTL 2002). 
Estudos diversos demonstram que a incapacidade funcional aumenta de prevalência conforme a idade avança (LITVAK 1990; RAMOS e col. 1990; BALTES e col. 1993; VERBRUGGE 1995; MARKIDES e col. 1996; DERNTL 2002).

Esse fato deverá adquirir uma importância crescente, com repercussão para o setor social, especialmente o setor saúde, visto que a camada mais velha da população é a que apresenta maior ritmo de crescimento.

Segundo dados divulgados pela ORGANIZAÇÃO MUNDIAL DA SAÚDE (1998) o envelhecimento populacional na maioria dos países do mundo caracterizase pelo crescimento mais rápido da camada mais velha da população ou seja indivíduos de 75 anos ou mais. Em 1990 esse grupo representava 21,5 milhões de pessoas, e o seu número aumentará mais do que o dobro a cada 20 anos chegando em 2020 a 45,9 milhões.

A mudança no perfil epidemiológico "configura-se um desafio para as autoridades sanitárias, em especial no que tange à implantação de novos modelos e métodos para o enfrentamento do problema" (GORDILHO e col. 2000, p. 16).

Segundo LITVAK (1990), a susceptibilidade para enfermidades crônicas e incapacidades decorrentes do envelhecimento aumenta a demanda por serviços médicos, sociais e econômicos, configurando-se como problemas a serem enfrentados por meio de política e programas nacionais e internacionais. $\mathrm{O}$ autor considera imprescindível colocar em prática planos que incluam medidas específicas de prevenção de enfermidades da idade avançada e promoção da saúde. 


\subsection{Promoção da saúde dos idosos: capacidade funcional nos modelos conceituais}

Autores diversos, profissionais da saúde e população em geral têm percebido a saúde como "resultante de um conjunto de fatores sociais, econômicos, políticos, culturais, ambientais, comportamentais e biológicos" a ser equacionado por um modelo de atenção abrangente e explicativo que supere a concepção clínicoassistencial para uma compreensão da saúde como um processo (MINISTÉRIO DA SAÚDE 1996, p.12).

O paradigma da Promoção da saúde tem alcançado consenso em todo o mundo. A primeira Conferência Internacional sobre Promoção da Saúde ocorreu em Ottawa em 1986. No documento resultante desta Conferência, denominado Carta de Carta de Ottawa, Promoção da saúde é conceituada como "o processo de capacitação da comunidade para atuar na melhoria de sua qualidade de vida e saúde, incluindo uma maior participação no controle desse processo" (MINISTÉRIO DA SAÚDE 1996, p.12).

$\mathrm{Na}$ Carta de Ottawa foram identificados alguns comportamentos conducentes à saúde a serem desenvolvidos pelos indivíduos e grupos: identificar aspirações, satisfazer necessidades e modificar favoravelmente o meio ambiente. Neste paradigma a saúde passa a ser vista não mais como um ideal utópico mas como um " recurso para desenvolvimento social, econômico e pessoal, referindo-se a capacidade de desenvolver o projeto potencial pessoal de vida e responder de forma positiva aos estímulos do meio" (MINISTÉRIO DA SAÚDE 1996, p.12).

Segundo RESTREPO (1994) a promoção da saúde compreende medidas fundamentais como comunicação social, disseminação de informações, educação para a saúde, promoção de políticas públicas, reorientação dos serviços e desenvolvimento de habilidades pessoais. Com estes mecanismos trata-se de aumentar o nível de consciência sobre os problemas de saúde prevalentes e a necessidade de efetuar mudanças comportamentais individuais e sociais assim como 
obter compromisso de todos os setores e atores sociais para levar a cabo essas mudanças.

Segundo LIVTOC e DERNTL (2002) na Carta de Ottawa "coloca-se em relevo o papel das organizações, dos sistemas e das comunidades, bem como a valorização dos comportamentos e das capacidades individuais, como as de autocuidado, na criação de opções e oportunidades para promover a saúde e o desenvolvimento populacional" (p.277).

Segundo o grupo de trabalho sobre promoção de saúde dos idosos, reunido em Londres (1987) e citado por RESTREPO (1994), seis princípios devem ser incorporados às ações de promoção da saúde para idosos:

- velhice não é uma enfermidade, e sim uma etapa evolutiva da vida;

- a maioria das pessoas com 60 anos e mais estão em boas condições físicas e de saúde, mas perdem a capacidade de se recuperarem das enfermidades com rapidez tornando-se mais propensas a se debilitarem e a necessitarem de ajuda para seus cuidados pessoais;

- é possível fortalecer a capacidade funcional mediante capacitação e estímulos, ou evitando fatores de risco para a saúde;

- os idosos são mais heterogêneos que os jovens, do ponto de vista psicossocial;

- a promoção da saúde na velhice deveria encaminhar-se para a estimação de um bom funcionamento mental, fisico e social, e para a prevenção de enfermidades e incapacidades;

- muitas medidas que afetam a saúde dos idosos transcendem esse setor, orientando os profissionais da saúde e do bem estar social a trabalhar conjuntamente.

De acordo com GORDILHO e col. (2000), o princípio de fortalecimento da capacidade funcional do idoso encontra-se, claramente incorporado as principais políticas públicas para o idoso no Brasil como a Política Nacional do Idoso (PNI) e Política Nacional de Saúde do Idoso (PNSI), compondo o paradigma da promoção da saúde para esta parcela da população. 
A capacidade funcional refere-se "a capacidade de manter as habilidades fisicas e mentais necessárias a uma vida independente e autônoma" (GORDILHO e col. 2000, p.20).

A promoção do envelhecimento saudável e da manutenção da capacidade funcional pelo maior tempo possível é foco da PNSI. Para os idealizadores dessa política a capacidade funcional surge como um novo conceito de saúde mais adequado para instrumentalizar e operacionalizar a atenção à saúde do idoso, que deverá objetivar a manutenção, melhora ou recuperação da capacidade funcional. (GORDILHO e col. 2000).

Segundo PAULA e col. (1998) ainda que o diagnóstico de uma doença seja fundamental para a correta intervenção terapêutica, não tem se mostrado suficiente para a definição do conjunto de medidas a serem empreendidas para o restabelecimento da saúde do idoso. Fatores relacionados e doença e o impacto da mesma sobre a qualidade de vida ou sua repercussão sobre a capacidade funcional deverão ser considerados. Ainda segundo os autores, o diagnóstico da doença pode não significar tanto para o paciente quanto saber sobre a severidade, possíveis seqüelas e prejuízo às suas atividades cotidianas.

A capacidade funcional deve ser o centro de atenção em geriatria, dada sua importância para a "saúde, bem-estar e na determinação de potenciais necessidades de serviços para idosos" (KANE e col. 1994, p.62).

Para que as ações em saúde para idosos ganhem efetividade deverão incorporar a complexidade do conceito de capacidade funcional incluindo seu contraponto, ou seja, a incapacidade e fatores relacionados. 
De acordo com LITVOC e DERNTL (2002) a multiplicidade de fatores determinantes da incapacidade funcional podem ser classificados como doenças e não-doenças.

A partir de uma extensa revisão da literatura, STUCK e col. (1999) identificaram 78 estudos longitudinais conduzidos entre 1985 e 1997 que focalizavam fatores de risco para declínio funcional ou dificuldade para atividades de vida diária - autocuidado, domésticas e atividades físicas. As mais fortes evidências para risco de declínio funcional foram atribuídas a prejuízo cognitivo, depressão, comorbidade, aumento e diminuição de massa corpórea, limitações funcionais de extremidades, baixa freqüência de contato social e de atividade física, pobre autoavaliação de saúde, tabagismo e prejuizo visual.

Segundo BALTES e col.(1993) a competência para a vida diária é um "constructo multidimensional relacionado a uma larga extensão de recursos"(p. 660).

Esses autores distinguem dois tipos de competência para vida diária: básica (relativa ao autocuidado) e expandida (relativa às atividades instrumentais, de lazer $\mathrm{e}$ sociais) e afirmam que a "competência básica está fortemente relacionada aos recursos relativos a saúde enquanto a competência expandida está fortemente relacionada aos recursos sociais, psicológicos e comportamentais" (p.657).

KANE (1993) também admite a complexidade do conceito ao identificar três componentes relacionados a ele. Segundo o autor a capacidade funcional é produto de três influências básicas: fatores intrínsecos do cliente (incluindo aspectos biológicos e comportamentais), cuidados recebidos (formais e informais) e ambiente do cliente (incluindo ambiente físico, psicológico e social).

Muitos modelos conceituais foram gerados para tornar o processo de envelhecimento satisfatório para o indivíduo e sociedade. Alguns são específicos, outros podem ser adaptados para favorecer a compreensão deste processo. Apresentarei a seguir dois modelos especificos de envelhecimento e que descrevem 
esse processo sem e com incapacidades (envelhecimento bem sucedido e de adaptação bem sucedida), dois modelos que admitem a experiência de viver e envelhecer com incapacidades (do autocuidado e ecológico de envelhecimento) e dois não específicos que se propõem a desenvolver o conceito de capacidade/incapacidade em sua complexidade e classificá-la em suas diversas formas (ICIDH e CIF). Todos os modelos selecionados incluem a capacidade funciomal como componente essencial da saúde e nos orientam a preservá-la, recuperá-la plenamente ou compensar sua perda, enquanto estratégias para promoção da saúde dos idosos.

\subsubsection{Envelhecimento bem sucedido}

A Organização Pan Americana de Saúde (OPAS) vem exortando, desde 1980, os Estados Membros a instituir programas e serviços para idosos, aprimorar os dados sobre o envelhecimento e desenvolver recursos para atender a essa população. A OPAS define como enfoque conceitual o pressuposto de que o envelhecimento bemsucedido depende da prevenção de doenças e deficiências, da manutenção de altas funções físicas e cognitivas ou seja manutenção da capacidade funcional e da participação constante em atividades sociais e produtivas (ORGANIZAÇÃO MUNDIAL DA SAÚDE 1998).

De acordo com LITVOC e DERNTL (2002) a promoção de saúde dos idosos no Brasil e no mundo deve basear-se nos mesmos princípios. Esses compõem o "modelo de envelhecimento bem sucedido" que apresento, em linhas gerais, a seguir.

Elaborado por ROWE e KAHN (1998), ele tem como premissa que o envelhecimento bem sucedido depende de escolhas individuais e comportamentos adotados e se refere à habilidade para manter três características ou comportamentos chaves:

- Evitar doença e incapacidade e fatores de risco relacionados, a partir de orientação preventiva, monitoramento sistemático e secundariamente medicamentos e cirurgias; 
- Manter alto nível de capacidades físicas e mentais. A habilidade para todas as atividades diárias depende da manutenção dessas funções. Considera-se que essa capacidade possa ser estimulada, mantida e até mesmo recuperada especialmente quando a perda foi causada por fatores extrínsecos como falta de atividade, com destaque para aquelas desafiadoras à mente e ao corpo;

- Manter ou recobrar engajamento com a vida através de atividades sociais e produtivas. Fazer parte de uma rede social é um dos mais importantes preditores de longevidade. Através de uma rede social pode-se obter suporte sócioemocional (afeto, respeito e estima) e instrumental (assistência direta). O tamanho da rede social e a qualidade dos relacionamentos são determinantes de bem-estar e qualidade de vida. O conceito de atividades produtivas nessa abordagem inclui todas atividades remuneradas ou não, que geram bens e serviços de valor econômico e produtivo.

As três características ou comportamentos apresentados parecem obedecer a uma ordem seqüencial, ou seja a ausência de doenças favorece a manutenção da função física e mental que por sua vez favorece o engajamento ativo com a vida. Contudo o modelo de envelhecimento bem sucedido admite também perdas funcionais e salienta que embora existam perdas inevitáveis (intrinsecamente relacionadas à idade avançada) outras, representando a maioria das perdas, podem ser evitadas, revertidas ou compensadas uma vez se tratam de perdas causadas por fatores comportamentais.

\subsubsection{Adaptação bem sucedida}

Segundo BALTES M (1996) qualquer modelo para envelhecimento bem sucedido, deverá admitir perdas e ganhos ligados ao envelhecimento e descrever adaptações bem sucedidas a essas perdas.

BALTES P citado por BALTES M (1996) enumerou algumas características em idosos que influenciam essas adaptações: 
- Heterogeneidade : baseia-se na idéia da vida como processo de individuação e especialização

- Plasticidade: refere-se ao potencial latente ativado quando o ambiente é favorável, estimulante e desafiador

- Reserva : ainda que possa encontrar-se reduzida pela crescente vulnerabilidade biológica e outras demandas da vida, pode-se lançar mão de estratégias como aumentar o suporte do ambiente ou reduzir a demanda a fim de ajudar a manter a reserva do organismo ou desacelerar a perda desta reserva.

Componentes do modelo de adaptação bem sucedida:

- Selecão: refere-se a restrição de vida a poucos domínios como conseqüência ou em antecipação às perdas pessoais e ambientais. Essa tarefa adaptativa implica em concentrar-se em ou selecionar domínios, tarefas, metas e expectativas prioritárias e convergir esforços para fazer frente a elas.

- Compensação: esse mecanismo é xionado quando capacidades ou habilidades são perdidas ou reduzidas, abaixo do grau requerido para um funcionamento adequado. Requer uso de comportamentos existentes ou aquisição de novas habilidades ou maneiras ainda não pertencentes ao repertório do idoso. Difere da seleção uma vez que a tarefa, o domínio, a meta são mantidas mas novas maneiras de compensar o comportamento deficiente são adotadas, a fim de otimizar ou manter o funcionamento prévio. A seleção envolve estratégias mentais e tecnologia assistiva.

- Otimizacão: processo de enriquecimento de reservas ou recursos e melhora funcional em domínios específicos. Podem significar resgate ou desenvolvimento de metas e expectativas, incluindo a aceitação da própria mortalidade. Estudos sugerem que muitos idosos têm recursos e reservas para otimizar funções mas a restrição ou super proteção, muitas vezes presentes no ambiente social, pode vir a inibir a otimização.

Segundo BALTES M (1996) os componentes do modelo de adaptação bem sucedida devem combinar-se resultando em otimização seletiva com compensação. 
A combinação destes componentes gera diferenças entre os indivíduos e os fortalece em sua busca pelo envelhecimento bem sucedido. Considera-se que as perdas e crescente vulnerabilidade possam até mesmo acionar estes componentes.

\subsubsection{Autocuidado}

A Promoção da Saúde, reconhece o autocuidado como estratégia fundamental para a promoção da capacidade funcional de idosos a ser incorporada na atenção prestada a eles pelos diversos profissionais uma vez que através dele o idoso poderá exercer controle sobre sua saúde e seus ambientes (LITVOC e DERNTL 2002).

OREM (1991) define autocuidado como "prática de atividades que indivíduos iniciam e desempenham em seu próprio benefício para manter a vida, saúde e bemestar" e concebe o homem como um ser capaz de refletir sobre si mesmo e o ambiente onde está inserido, e desenvolver habilidades para auto cuidar-se e cuidar de familiares e indivíduos dependentes (p.117).

Segundo LEVIN (1981) o autocuidado inclui cuidados prestados por amigos e familiares e configura-se como forma mais utilizada de cuidado primário à saúde nos Estados Unidos. Segundo o autor, estima-se que cerca de $65 \%$ a $85 \%$ de todo o cuidado em saúde seja provido pelo próprio indivíduo ou familiares, abrangendo atividades relacionadas com promoção de saúde, prevenção e tratamento de doenças, administração de doenças crônicas e reabilitação.

Ainda segundo LEVIN (1981) o autocuidado é efetivo, seguro e acessível às necessidades de saúde. $\mathrm{O}$ autor o posiciona como ingrediente essencial no cuidado à saúde, a ser complementado por recursos técnicos e profissionais.

CHOMPRÉ (1994) identifica o autocuidado como uma das propostas que contempla participação ativa e efetiva do indivíduo e comunidade no controle $\mathrm{d}$ processo saúde-doença e acrescenta que, enquanto modelo conceitual, ele fundamenta uma organização de ações que torna o indivíduo parceiro ativo e coresponsável no processo de atenção a sua saúde. 
Acredito que as definições e considerações sobre autocuidado apresentadas por OREM (1991), LEVIN (1981) e CHOMPRÉ (1994) o relacionam com o conceito de autonomia. De acordo com BEAUCHAMP e CHILDRESS (1985) autonomia é um termo derivado do grego autos (eu) e nomos (regra, governo, lei) e significa faculdade para governar a si mesmo.

Segundo LORYS (1995) autonomia implica em capacidade para tomar decisões e aceitar as responsabilidades pessoais derivadas de suas escolhas.

A administração de dificuldades e do próprio cotidiano pelo indivíduo compreende autonomia para a tomada de decisões e empreendimento de ações, configurando-se com prática de autocuidado. (ALMEIDA 1997).

A teoria do autocuidado de OREM (1991) desenvolve e articula conceitos tais como requisitos, competência, déficits entre outros. Estes conceitos podem tornar-se ferramentas úteis na sua operacionalização como estratégia de promoção da saúde dos idosos.

Segundo a teoria de OREM (1991) os requisitos de autocuidado, podem ser organizados em três grupos:

- Universais : comuns a todos os homens durante todos os estágios do ciclo de vida como respiração, hidratação, alimentação, eliminação, atividade e repouso, recolhimento e interação social e prevenção de riscos à vida, ao funcionamento e desenvolvimento humano;

- Desenvolvimentais: relacionados a determinados estágios de desenvolvimento humano e eventos associados a esses estágios, e relacionados, ainda, a eventos adversos que podem afetar o desenvolvimento e

- Relacionados aos desvios de saúde: associados aos defeitos genéticos e constitucionais, aos desvios estruturais e de funcionamento do organismo e aos efeitos desses desvios, bem como aos efeitos dos tratamentos empregados a eles. 
Ainda de acordo com OREM (1991), o indivíduo é competente para seu autocuidado quando desenvolve capacidades para discernir fatores que devem ser controlados ou administrados a fim de regular seu próprio funcionamento e desenvolvimento, para decidir o que pode e deve ser feito com respeito à regulação, para planejar os componentes de sua demanda terapêutica de autocuidado requisitos, tecnologias, medidas de cuidados - e finalmente desempenhar as medidas designadas para alcançar esses requisitos. Para a autora, o autocuidado requer atividades orientadas internamente, dirigidas para o controle do comportamento, e também comportamento orientado externamente, dirigido para o controle do ambiente.

De acordo com NEUFELD e HOBBS (1985), alguns requisitos e déficits de autocuidado podem ser gerados pelo processo de envelhecimento, muitos dos quais relacionam-se a competência para as atividades de vida diária.

Segundo NORRIS (1974) essas atividades incluem-se no conjunto das práticas de autocuidado como atividades que suportam processos de vida.

Alguns estudos têm se ocupado em identificar práticas de autocuidado adotadas por idosos e/ou cuidadores para minimizar ou corrigir déficits nas atividades de vida diária. Mudanças comportamentais, ambientais e uso de dispositivos auxiliares incluem-se nessas práticas. Esses estudos advogam o modelo do autocuidado como estratégia de atenção, e fundamentam-se no modelo ecológico do envelhecimento (NORBURN e col. 1995; ALMEIDA 1997; GILL e col. 1999; MESSECAR 2000; GITLIN e col. 2002).

\subsubsection{Modelo ecológico de envelhecimento}

Elaborado por LAWTON e NAHENOW'S (1973) citado por PUTNAM (2002), o modelo ecológico de envelhecimento estabelece que a incapacidade é gerada por uma lacuna ou incongruência entre a capacidade individual e a demanda do ambiente. Segundo ele existe um ponto de equilíbrio entre o ambiente a pessoa 
onde um funcionamento ótimo é alcançado. Uma mudança nessa relação devida a crescente pressão do ambiente ou redução da capacidade da pessoa resulta na incapacidade.

Uma revisão deste modelo introduz a percepção do ambiente pelo indivíduo como fator determinante para o desempenho e propõe o conceito de ambiente próativo para descrever o potencial do individuo para superar incapacidade ou criar demanda (PUTNAM 2002).

\subsubsection{Classificação Internacional de deficiências, incapacidades e desvantagens}

Existe um outro modelo conceitual proposto pela Organização Mundial da Saúde (WHO, 1980) denominado ICIDH - Classificação Internacional de Deficiências, Incapacidades e Desvantagens - que, acredito, represente um contraponto ao "modelo de envelhecimento bem sucedido" e até mesmo ao "modelo de adaptação bem sucedida" uma vez que se focaliza nas incapacidades e suas conseqüências. Esse modelo será apresentado a seguir.

Segundo a OMS as doenças crônicas vêm ocupando uma posição dominante na sociedade e desafiando os serviços de saúde a fazer frente a elas. A OMS propõe o modelo classificatório ICIDH como um esquema conceitual a ser adotado consensualmente por clientes, profissionais e planejadores de políticas públicas, no sentido de favorecer a compreensão acerca das conseqüências das doenças crônicas e o compartilhar de experiências, requisitos fundamentais para a determinação de ações de saúde mais efetivas (WHO 1980).

De acordo com esse modelo, as alterações funcionais são classificadas em três estágios geralmente seqüenciais:

- Deficiência [impairment] - refere-se a redução das capacidades físicas e/ou mentais. São geralmente distúrbios no nível orgânico, podem ou não ser visíveis (exteriorizadas) e ter ou não conseqüências adversas ao indivíduo, pois podem ser corrigidos. Deficiência é caracterizada por perda ou anormalidade que pode ser 
temporária ou permanente e inclui a existência ou ocorrência de uma anomalia, defeito, ou perda de um membro, órgão, tecido ou outra estrutura do corpo, ou um defeito no sistema funcional físico ou mental.

- Incapacidade [disability] - resulta de deficiências cujos efeitos não foram corrigidos e refere-se a restrição nas habilidades do indivíduo para o desempenho de uma função de uma maneira considerada normal. A incapacidade pode ser temporária ou permanente, reversível ou irreversível. Pode ser conseqüência direta de uma deficiência ou uma resposta psicológica do indivíduo a sua ocorrência. A incapacidade representa a objetivação de uma deficiência e reflete perturbações ao nível da pessoa. A incapacidade pode ou não limitar a habilidade do indivíduo para preencher um papel social normal - dada sua severidade ou a aquilo que a pessoa deseja fazer

- Desvantagem [handicap] - resulta de deficiências ou incapacidades, referindo-se a desvantagem social quando as incapacidades impedem o desempenho do papel social. Representa a socialização de uma deficiência ou incapacidade e reflete as conseqüências culturais, sociais, econômicas e ambientais das mesmas para o indivíduo.

FILLENBAUM (1996) exemplifica a progressão de deficiências em direção a incapacidades e desvantagens informando que condições ou deficiências como redução da visão, audição, compreensão, ou capacidade de movimentar-se, podem resultar em crescente dificuldade em desempenhar atividades de vida diária e papéis sociais.

O valor da compreensão da funcionalidade em estágios reside na possibilidade de intervir sobre um estágio com vistas a modificar estágios subseqüentes.

Considero que o modelo ICIDH conduza nosso raciocínio para um melhor entendimento das consequiências das doenças crônicas e nos convide a planejar ações que interrompam ou mesmo evitem esse processo. 
O modelo ICIDH prevê, no entanto, a complexidade dessa conceituação em estágios e admite que, embora os três níveis de alterações funcionais sugiram uma progressão linear, isto nem sempre ocorre. A desvantagem social pode resultar de uma deficiência sem a mediação de uma incapacidade, por exemplo uma deformidade estrutural na mão pode eventualmente não gerar prejuízo funcional e incapacidade mas representar uma desvantagem social dependendo do valor atribuído a isso pelo indivíduo ou grupo social ao qual pertence.

O modelo ICIDH inclui três esquemas classificatórios suplementares, em forma de sistemas de códigos, para cada um dos principais conceitos. Essa classificação suplementar permite um detalhamento de alterações individuais e seu registro de forma padronizada.

Segundo FILLENBAUM (1980) o modelo ICIDH representa um sistema classificatório extremamente importante para descrever a desvantagem, isto é, conseqüência social e ambiental da presença de deficiências e incapacidades.

A classificação proposta pelo modelo ICIDH tem recebido críticas. Por ser muito próxima do modelo médico, diagnósticos e procedimentos de reabilitação ficam subordinados a esse profissional. Considera-se ainda que o modelo não contempla a diversidade de situações relativas às conseqüências das doenças (AMIRALIAN 2000).

\subsubsection{Classificação Internacional de funcionalidade, incapacidade e saúde}

A OMS revisou o modelo ICIDH e o re-nomeou para CIF. Esse modelo pode ser considerado como um modelo social de incapacidade à semelhança do modelo ICIDH, por partirem da premissa que a incapacidade não é inerente à pessoa mas uma função da interação entre a pessoa e o ambiente resultando de uma lacuna entre as capacidades individuais e as demandas ambientais (PUTNAM 2002). 
Vale ressaltar que essa premissa nos reporta ao modelo ecológico de envelhecimento.

Segundo o modelo CIF, "fatores pessoais e ambientais interagem com condições de saúde e influenciam estruturas e funções corporais, atividades e participação nos distintos domínios da vida"(PUTNAM 2002, p. 803).

Esse modelo representa um avanço ao modelo anterior pois inclui o ambiente físico e social como elemento crucial na produção de incapacidades. A incapacidade é identificada nas distintas situações de vida da pessoa (trabalho, escola, comunidade, lazer) e o ambiente é avaliado quanto à influência que exerce sobre sua vida: arquitetura, comunicação, políticas e atitudes ambientais. (LOLLAR 2002).

Reitero a importância da integração dos diversos modelos apresentados pois, em conjunto se propõem a explicar a experiência do envelhecimento sem e com incapacidade, oferecendo perspectivas mais amplas para a promoção da saúde dos idosos nos diferentes níveis de atenção.

\subsection{Avaliação da capacidade funcional}

De acordo com PAULA e col. (1998) o termo capacidade funcional é aplicado na área gerontológica para designar a capacidade para as atividades de vida diária.

FILLENBAUM $(1984,1996)$ considera que, quando se trata de idosos, informações sobre habilidades funcionais devem focalizar-se sobre as atividades de vida diária, uma vez que a capacidade para elas relaciona-se à saúde física, mental e bem-estar social desta população e possibilita aos idosos manterem-se na comunidade.

Além de serem críticas para a continuidade de uma vida com independência, informações sobre essas atividades permitem avaliar o impacto da reabilitação e 
conseqüentemente dos serviços necessários à independência e bem estar pessoal (FILLENBAUM 1996).

Segundo McDOWELL e NEWELL (1987) quando a reabilitação passou a focalizar o retorno do paciente à comunidade, a avaliação física tornourse insuficiente. Os primeiros instrumentos informavam sobre capacidades físicas como equilíbrio, movimentos e habilidades sensoriais, mais tarde, sobre o autocuidado físico e depois, sobre papéis sociais, habilidades para o trabalho e tarefas domésticas.

Muitas escalas foram produzidas para informar sobre as atividades de vida diária. Ainda que apresentem alguma variabilidade em seus itens e denominações, considero que se prestam a informar sobre o mesmo objeto de estudo.

FILLENBAUM (1984) revisou e organizou questionários com indicação de confiabilidade e validade segundo presença de itens.

Quadro 1: Atividades de vida diária segundo inclusão em instrumentos com validade e confiabilidade estabelecidas

\begin{tabular}{|c|c|c|c|c|c|c|c|}
\hline itens & KATZ & CARE & BARTHEL & MAI & $\begin{array}{l}\text { LAWTON } \\
\text { \& BRODY }\end{array}$ & OARS & KENNY \\
\hline \multicolumn{8}{|c|}{ Básicas } \\
\hline Banho & + & + & + & + & + & $t$ & $t$ \\
\hline Vestir-se & + & + & + & + & + & + & + \\
\hline Uso do toalete & + & + & + & & + & & + \\
\hline Transferências Posturais & + & & + & t & + & $t$ & + \\
\hline Continência & + & + & + & + & & $t$ & + \\
\hline Alimentar-se & + & & + & + & + & $t$ & + \\
\hline Locomoção & & + & + & + & + & + & $t$ \\
\hline Arrumar-se & & + & + & + & + & + & + \\
\hline Cortar unhas & & + & & + & & & + \\
\hline \multicolumn{8}{|c|}{ Instrumentais } \\
\hline Uso do telefone & & + & & + & + & + & \\
\hline Uso de meios de transporte & & \pm & & + & + & + & \\
\hline Fazer compras & & $\overline{+}$ & & + & $\bar{t}$ & $T$ & \\
\hline Preparar comida & & + & & + & + & + & \\
\hline Fazer tarefas domésticas & & + & & + & + & + & \\
\hline Lavar roupas & & + & & + & + & & \\
\hline Trabalho manual & & & & + & & & \\
\hline Tomar seus medicamentos & & + & & + & + & + & \\
\hline Administrar finanças & & + & & + & + & + & \\
\hline
\end{tabular}

Fonte: FILLENBAUM GG. The wellbeing of the elderly: approaches to multidimensional assessment. Geneva: World Health Organization; 1984. (WHO, Offset Publication, 84)

A partir de extensa revisão, McDOWELL e NEWELL (1987) selecionaram, num contexto de mais de 50 escalas de atividades básicas de vida diária somente 7 
com informação sobre confiabilidade e validade. As denominações para essas atividades diferem de autor para autor. MAHONEY e BARTHEL (1955) as designaram atividades de cuidado pessoal e mobilidade, MOSKOWITZ e McCANN (1957) autocuidado e mobilidade, KATZ (1959) vida diária, SCHOENING e col.(1965) autocuidado, LAWTON e BRODY (1969) físicas de auto-manutenção, FORER (1981) vida diária e STEWART (1992) autocuidado e mobilidade.

As atividades instrumentais de vida diária foram assim designadas por LAWTON e BRODY (1969). De acordo com FILLENBAUM (1984) a maioria das escalas de atividades instrumentais de vida diária é derivada de trabalhos destes autores.

Adotarei neste trabalho a Classificação proposta pelo INSTITUTO DE REABILITAÇÃO DE CHICAGO (1991) citada por HILL (1998) que categoriza as atividades de vida diária em básicas e instrumentais. As básicas referem-se ao cuidado de si mesmo e as instrumentais, às habilidades para viver em comunidade, cuidar de idosos e crianças e tarefas de casa.

Em conjunto, as atividades de vida diária (AVDs) - básicas e instrumentais abarcam cuidados pessoais, tarefas domésticas e atividades ligadas ao acesso a bens e serviços (uso de meios de transporte, compras, administração de finanças). (KIELHOFNER 1998).

Sobre as atividades básicas de vida diária é possível afirmar que são universais, ou seja apresentam pouca variabilidade nos passos requeridos, estão relacionadas à sobrevivência, focalizam aspectos motores, sensoriais e cognitivos e parecem menos influenciadas pela motivação e oportunidade quando comparada às atividades instrumentais (BALTES 1993).

LAWTON (1969) citado por CULLER (1998) foi quem introduziu o termo atividades instrumentais de vida diária reconhecendo sua complexidade em relação às atividades básicas, segundo ele essas requerem um nível de maturidade e 
organização neuropsicológica mais alto quando comparadas às básicas de vida diária, envolvem socialização e podem ser mais influenciadas pela motivação e oportunidade.

Segundo GONÇALVES (1996) “desconhece-se, em nosso meio, instrumentos práticos padronizados de avaliação da capacidade funcional do idoso" (p. 3).

A referida autora sugere o uso experimental de três instrumentos cuja tradução foi concedida a ela pelo escritório de publicação da OMS: o índice de KATZ (1959), a escala OARS (1984) e o modelo GERONTE (1983). Segundo a autora são escalas de fácil utilização e indicadas, respectivamente, para clientes com maior dependência física, independentes e ambos.

LITVOC e DERNTL (2002) relatam que escalas como as de KATZ (1959) e OARS (1984) são muito utilizadas com idosos, assim como as escalas de LAWTON e BRODY (1969) e de FRAMINGHAM (1981).

Apresento a seguir, em linhas gerais e segundo os autores acima, algumas dessas escalas devido à sua importância em estudos em nosso meio.

A escala de KATZ (1959) avalia independência para 6 (seis) atividades básicas de vida diária em três níveis, a partir dos quais o idoso seria classificado em uma de oito categorias possíveis. Essa classificação é complexa por considerar não somente o número de alterações mas para quais atividades o idoso apresenta incapacidade. Têm-se optado por valorizar somente o número de alterações, o que posiciona o idoso em uma escala de 6 pontos que vai de 0 (zero) para o idoso independente ou sem alteração até 6 (seis). (KATZ e col. 1992; LITVOC e DERNTL 2002; McDOWELL e NEWELL 1987).

A escala de LAWTON e BRODY (1969) avalia independência para 6 atividades básicas denominadas pelos autores como físicas de vida diária e 8 
atividades instrumentais para mulheres e 5 para homens, em 3 a 5 níveis. Há duas possibilidades de pontuação uma que considera a pontuação em cada atividade e outra que considera a pontuação total.

A escala OARS (1984) de atividades de vida diária compõe um instrumento multidimensional, incorpora os itens da escala de LAWTON e BRODY (1969), a pontuação é semelhante mas, neste caso inclui o mesmo número de atividades para homens e mulheres com a diferença que a ênfase nessa escala é dada à habilidade (capacidade de fazer) e não ao desempenho (faz). (LITVOC e DERNTL 2002).

Segundo McDOWELL e NEWELL (1987) algumas escalas de AVDs informam sobre o desempenho atual das atividades de vida diária enquanto outras, a semelhança da escala contida em OARS (1984), informam sobre a capacidade para realizá-las. Ambas as formas de abordagem trazem vantagens e desvantagens. A primeira forma pode subestimar a capacidade funcional visto que muitas vezes 0 paciente é capaz de realizar a atividade mas não a realiza por fatores distintos da incapacidade física. A segunda forma pode superestimar a capacidade em $15 \%$ a $20 \%$, no entanto esse forma tem sido empregada com freqüência para avaliar atividades instrumentais de vida diária, uma vez que essas atividades estão mais susceptíveis ao viéses decorrentes da primeira abordagem.

LAWTON e BRODY (1969) consideram que os comportamentos evidenciados a partir da aplicação de uma escala oferecem uma base preliminar para o estabelecimento de metas de tratamento. A incapacidade objetivada pode ser atribuída a vários fatores, como doenças, deficiências ou fatores ambientais, esses também deverão ser identificados e considerados no tratamento assim com a melhora funcional.

A aplicação sistemática das escalas elaboradas por eles demonstrou que, ao focalizarem o comportamento concreto em uma linguagem cotidiana, as escalas permitem sua utilização por diferentes profissionais e serviços e a comunicação entre eles. Os autores reconheceram ainda que sua re-aplicação em intervalos regulares, 
estima mudanças no tempo, permite avaliar resultados do tratamento e sua reformulação.

As escalas construídas por esses autores são ordinais, em sua maioria de 5 pontos, possibilitando a identificação de pequenas mudanças funcionais para cada atividade ao longo do tempo. Segundo os autores escalas sensíveis a pequenas mudanças são mais apropriadas aos idosos pois se baseiam no seu real potencial e, progressos ainda que sutis, podem ser compartilhados com eles encorajando-os a prosseguir no tratamento. Por fim, os autores consideram que as escalas possam ser aplicadas não somente na área clínica mas também administrativa fornecendo critérios de elegibilidade e contribuindo para o planejamento de recursos humanos, ambientais e materiais.

Embora muitas escalas de atividades de vida diária tenham sido testadas em sua confiabilidade e validade e isso as credencie para uso nas áreas clínica, administrativa e de pesquisa; poucos esforços têm sido feitos para estabelecer as bases teóricas destes instrumentos e para definir termos chaves como resultados, independência, deficiências, incapacidades e desvantagens (KEITH 1995).

Segundo LITVOC e DERNTL (2002) os instrumentos de KATZ (1959) e LAWTON e BRODY (1969) são os possuem maior base teórica.

A falta de uniformização de conceitos na área da deficiência compromete a prática clínica, os resultados de pesquisa, além de impedir a sua comparação e utilização pelos diversos pesquisadores (AMIRALIAN 2000).

O aprofundamento de teorias sobre capacidade funcional, e conseqüentemente, a identificação de conceitos relacionados e definição de termos empregados devem cursar com estudos de confiabilidade e validade, para o aprimoramento de instrumentos nesta área (LITVOC e DERNTL 2002). 


\subsection{Ocupação humana: objeto de atenção em terapia ocupacional}

A ocupação configura-se como "a atividade principal dos seres humanos" e "um meio através do qual os seres humanos dão sentido às suas vidas" (CLARK e LARSON 1998, p.50).

A importância da ocupação na vida humana para o funcionamento pessoal e social foi descrita por um dos precursores da terapia ocupacional. MEYER (1922) a concebia como a totalidade das experiências do homem e esse como "um organismo que se mantém e se equilibra no mundo por estar em vida ativa usando intencionalmente seu tempo, em harmonia com sua própria natureza e com a natureza ao seu redor" (p. 641).

Os cientistas ocupacionais reconhecem que, embora pareça trivial, a ocupação é infinitamente complexa. Sua natureza complexa, freqüência e valor intrínseco foram expressas por BEN-ZE'EV citado por CLARK E LARSON (1998) nesta definição " ocupação é um padrão complexo e repetido de ações cujo valor não se limita ao valor dos seus resultados externos" (p.50).

GRAY (1998) refere-se à ocupação como atividade com propósito, significado individual, começo, meio e fim inerentes a ela, e que envolve o ser humano em seus múltiplos sistemas - emocional, cognitivo, perceptivo e físico - em interação com seu ambiente.

Segundo FRANCISCO (1988) a ocupação vem sendo empregada como forma de tratamento há muito tempo. As civilizações clássicas utilizavam jogos, música e exercícios fisicos com essa finalidade.

A ocupação estruturou-se, tornando-se amplamente aceita para o tratamento do doente mental, nos séculos XVIII e XIX, na Europa, sob um esquema denominado Tratamento Moral. Essa escola de pensamento enfatizava a importância do ambiente como organizador do comportamento humano empregando atividades 
de autocuidado, trabalho e jogos para o restabelecimento desse comportamento (KIELHOFNER e BURKE 1977).

No Brasil empregava-se a ocupação com doentes mentais e tuberculosos em instituições totais, a partir da metade do século XIX até meados deste século, com o objetivo de "reduzir os efeitos desfavoráveis da hospitalização sobre o comportamento dos internos" (SOARES 1991, p 140).

Segundo a autora acima, a ocupação era empregada no final do processo de reabilitação, como forma de preparo do indivíduo para o trabalho uma vez que exigia iniciativa, responsabilidade, estabilidade emocional e tolerância para o trabalho.

Segundo SOARES (1991) o uso da ocupação como forma de tratamento passou a ser empregada no Brasil a partir da década de 40, especialmente em decorrência do Movimento Internacional de Reabilitação - resposta de entidades da sociedade civil às falhas das diversas instituições sociais na atenção aos incapacitados. Esse Movimento impulsionou a desenvolvimento de programas para esta parcela da população transformando a reabilitação no $3^{0}$ nível de atenção à saúde.

Geralmente a terapia ocupacional voltava-se para indivíduos com prejuízo em seu desempenho ocupacional como resultado de uma lesão ou enfermidade, mas pode também atuar preventivamente, quando existe uma interrupção potencial da ocupação. Em qualquer momento o objetivo será ajudar a pessoa a obter um equilíbrio de atividades significativas em sua vida diária. (KNOX 1998)

Considero que a filosofia holística que ampara o surgimento da terapia ocupacional como profissão, possibilite ao terapeuta atuar da prevenção à reabilitação e ocupar-se da amplitude de questões relacionadas à ocupação humana em seu cotidiano. 
De acordo com essa filosofia o homem deve ser visto em seu todo, com suas dificuldades e capacidades, e a atividade humana, em sua potencialidade para dar preenchimento e plenitude ao homem. (NEISTADT e SEYMOUR 1995)

Essa base filosófica tem sido resgatada por alguns estudiosos e profissionais e parece orientar a definição de terapia ocupacional proposta pela Associação Americana de Terapia Ocupacional (AOTA) citada por HANSEN E ATCHINSON (2000). De acordo com a "terminologia uniforme para a terapia ocupacional - $3^{\mathrm{a}}$ edição" elaborada por essa Associação a terapia ocupacional refere-se ao "uso de atividades intencionais para promover saúde e alcançar funcionalidade ou seja desenvolver, manter, melhorar e/ou recuperar o mais alto nível de independência possível em pessoas limitadas por doença ou injúria, disfunções cognitivas, psicossociais, doença mental, distúrbios de aprendizagem ou ligados ao desenvolvimento ou condições ambientais adversas" (p.344).

Segundo NEISTADT e SEYMOUR (1995) a ocupação vem sendo entendida basicamente de duas formas: como meta a ser alcançada pelo tratamento ou na atenção direta ao cliente. Os terapeutas denominam essas abordagens respectivamente de corretiva e adaptativa. A primeira abordagem compreende o treino da pessoa nas habilidades em déficits e que componham as atividades ocupacionais, tais como força, percepção visual, coordenação, habilidades cognitivas, entre outras. A segunda abordagem compreende o treino da pessoa nas atividades ocupacionais, para as quais a pessoa apresenta dificuldades, integrando habilidades intactas e deficitárias. Essa abordagem mostra-se mais consistente com a filosofia holística da terapia ocupacional.

Alguns estudos têm demonstrado que a abordagem com base na correção de déficits tem alcance limitado sobre a ocupação diária, ou seja habilidades aprendidas fora do contexto não são rapidamente ou eficazmente transferidas para as atividades diárias, enquanto que a abordagem que envolve atividades, tarefas e papéis dirigidos às metas funcionais da pessoa está mais estreitamente relacionada às necessidades de 
vida diária, favorecendo seu desempenho. (NEISTADT e SEYMOUR 1995; GRAY 1998; JÖNSSON 1999).

Com base na abordagem adaptativa, a avaliação e o tratamento em terapia ocupacional devem ser dirigidos à "restauração da vida ocupacional do cliente, incluindo análise e intervenção sobre o desempenho das ocupações, o uso do tempo, os hábitos e rotinas diárias, as atividades relacionadas ao desenvolvimento contínuo, e necessidades relacionadas a sua natureza ocupacional como criatividade, competência e desafio" (GRAY 1998, p. 357-8).

GRAY (1998) refere que quando as metas ocupacionais são estabelecidas em conjunto com a pessoa há possibilidade de integrar as duas formas de abordagens, uma vez que o envolvimento do paciente em atividades ou ações significativas aumenta a oportunidade para transferências de habilidades.

Parece oportuno reiterar que, ao envolver a pessoa atendida ativa e integralmente no processo de atenção à sua saúde, o terapeuta ocupacional estará atuando de acordo com a filosofia e prática do autocuidado e com o paradigma da promoção da saúde.

HOPKINS (1998) afirma que "a intervenção da terapia ocupacional se concentra nas áreas de desempenho funcional do autocuidado, trabalho e lazer considerando o ambiente humano e não humano, cultural e social dentro do qual funciona a pessoa" (p. 4).

Segundo KIELHOFNER (1998) essas áreas de desempenho são de natureza principalmente ocupacional. Uma vez que os homens realizam essas atividades, especialmente trabalham e jogam, por motivos pessoais, por necessidade de exploração e domínio, independentemente das demandas imediatas por sobrevivência. Além disso, as atividades de autocuidado, produtividade e lazer ocupam a maior parte do tempo humano, possuem validade intrínseca, são 
interdependentes e quando combinadas geram diferentes formas de comportamento ocupacional.

Considero que essas atividades ocupacionais possam ser definidas como atividades cotidianas por envolverem o homem inteiro de forma intencional e significativa. Segundo HELLER (1970), o homem envolve em seu fazer cotidiano "todos os sentidos, movimentos, intelecto, sentimentos, idéias, paixões, ideologias" de forma espontânea e ainda assim pragmática ( $\mathrm{p} 17)$.

Sobre o lazer é possível afirmar que se refere à "atividade, a parte das obrigações de trabalho, familiares e sociais; para a qual o indivíduo se volta com a intenção de relaxamento, diversão ou desenvolvimento de sua participação social e livre exercício de sua capacidade criadora" (DUMAZEDIER 1967, p.16-17).

Considero que as atividades de lazer possam ser classificadas de acordo com o interesse predominante do indivíduo para se engajar na mesma, como interesses artísticos, intelectuais, manuais, físicos e sociais. O lazer está presente ao longo da vida, de formas distintas segundo a idade. O brincar constitui-se como principal atividade na infância. Através do brincar a criança explora seu meio, adquiri habilidades e incorpora valores. Na adolescência e vida adulta as atividades de lazer diminuem em quantidade, transformando-se em passatempo, recreação social, celebração cultural. Quando as pessoas alcançam a meia idade e os filhos deixam a casa dos pais, aumenta o tempo disponível para o lazer, os interesses são menos centrados na casa e família e mais voltados para atividades externas até o advento da aposentadoria quando a redução de recursos econômicos e o rompimento com o papel de trabalhador são geralmente acompanhados por uma redução das atividades de lazer e um retorno às atividades no lar.

O lazer tem sido reconhecido como fonte de identidade para indivíduos após a aposentadoria, especialmente quando essas atividades envolvem participação social. (ATCHLEY 1971; PALMORE e KIVETT 1977 citados por TEAFF 1990). 
Segundo ROELOFS (1999) o lazer permite a idosos alcançar satisfação e melhorar sua qualidade de vida. $\mathrm{O}$ autor nomeia algumas necessidades comuns a idosos e satisfeitas pelo lazer como contato com amigos, passatempo, resgate e desenvolvimento de novas experiências e auto-realização.

O trabalho compreende todas as atividades produtivas, remuneradas ou não. O produto do trabalho pode ser um serviço, uma comodidade e até mesmo novas habilidades, idéias, conhecimentos, que mantêm a sociedade e a faz avançar. $O$ trabalho é geralmente considerado importante, reconhecido pelo ambiente social e fonte de identidade. Estudo, tarefas domésticas e voluntariado também devem ser considerados como trabalho (KIELHOFNER 1998).

O trabalho não cabe somente a adultos sadios, mostrando-se relevante para todas as pessoas e durante todo o ciclo de vida (JACOBS 1998).

Reitero que o modelo de envelhecimento bem sucedido, apresentado anteriormente, tem como premissa que envelhecer bem depende de comportamentos tais como manter ou recobrar engajamento com a vida através de atividades sociais e produtivas.

A intervenção da terapia ocupacional nas áreas de desempenho funcional do autocuidado, trabalho e lazer pode ser descrita de forma sucinta, nas seguintes citações.

O papel do terapeuta ocupacional sobre o desempenho da pessoa nas atividades de autocuidado (básicas de vida diária) é único e específico, embora muitas pessoas possam influir nesse desempenho "somente o terapeuta ocupacional possui treinamento para avaliar e analisar o desempenho de funções da pessoa determinando o método e grau de participação da mesma em seu cuidado pessoal" (HILL 1998, p.192). 
A partir da avaliação dos fatores psicossociais, sensoriomotores, cognitivos, perceptuais, médicos, ambientais envolvidos nas atividades e considerando as opções de tratamento tais como técnicas adaptadas para a realização das atividades, adoção de equipamentos adaptados, entre outros; o terapeuta ocupacional estará apto em conjunto com a pessoa para tomar decisões sobre o tratamento (HILL 1998).

Considero que o terapeuta ocupacional atue sobre as demais áreas de desempenho ocupacional de forma emelhante: analisando habilidades e atitudes pessoais e condições ambientais, tanto restritivas quanto facilitadoras das atividades de lazer e produtivas, auxiliará a pessoa a eleger e desenvolver atividades que correspondam aos seus interesses e potencialidades, empregando quando necessário método e técnicas apropriados para essa finalidade.

O terapeuta deverá ter sempre como foco a orquestração do conjunto de atividades da pessoa, a fim de que ela possa alcançar satisfação a partir delas (JÖNSSON 1999).

\subsection{Terapia ocupacional com idosos: capacidade funcional}

A atuação do terapeuta ocupacional com idosos, justifica-se na presença ou ausência de incapacidades. As perdas, sejam de ordem física, emocionais ou sociais, são inerentes ao processo de envelhecimento e afetam habitualmente o equilíbrio das atividades cotidianas. $\mathrm{O}$ terapeuta ocupacional poderá atuar em antecipação ou na vigência das perdas, auxiliando a pessoa idosa a manter ou recobrar o equilíbrio de atividades significativas em seu cotidiano, tomando como referência, por exemplo, os componentes descritos por BALTES (1996) para uma adaptação bem sucedida.

Segundo HASSELKUS (1998) a prática da T.O em geriatria poderá dar ênfase à prevenção, recuperação ou adaptação.

Quando enfoca a prevenção, o T.O dirige-se à prevenção de acidentes no domicílio e na comunidade, e à promoção de atividades. Tornar o ambiente mais seguro, confortável e estimulante para idosos, sejam eles independentes ou não, 
parece favorecer a interação desses com o ambiente, além de prevenir a ocorrência de quedas e outras injúrias.

A promoção de atividades mostra-se muito oportuna nesta fase da vida considerando-se o risco de inatividade entre idosos - por problemas de saúde, institucionalização e atitudes sociais - e conseqüente prejuizo para a sua funcionalidade (HASSELKUS 1998).

De acordo com FERRARI e col (1994) "o momento é de nova proposta, não de guarda, abrigo, proteção que levam o indivíduo a dependências." (p.31).

$\mathrm{Na}$ existência de incapacidades o terapeuta ocupacional poderá atuar na recuperação (reversão) e/ou adaptação (compensação) das incapacidades.

Em geral, quando o idoso é portador de incapacidades potencialmente reversiveis ou temporárias, decorrentes de enfermidades agudas ou lesões traumáticas, o terapeuta ocupacional trabalhará com a equipe médica e de reabilitação com vistas ao restabelecimento dos níveis funcionais anteriores a ocorrência. Um programa de recuperação deverá focalizar as condições próprias do idoso, integrar habilidades intactas às deficitárias e incluir treinamento funcional para as atividades ocupacionais (HUSSELKUS 1998).

Quando o idoso é portador de incapacidades de caráter permanente, decorrentes de injúrias ou doenças crônicas, objetiva-se a capacitação adaptada ou compensação de incapacidades, adotando-se como principal estratégia redução das demandas do ambiente físico e/ou social, com vistas a minimizar as lacunas existentes entre essas demandas e as capacidades remanescentes do idoso. Essa estratégia deverá possibilitar ao idoso a realização das atividades da forma mais segura e independente possível. (LAWTON 1969; MENEZES 1994; KEITH 1995; HILL 1998; HUSSELKUS 1998; PUTNAM 2002). 
Com idosos portadores de incapacidades, o T.O. deve ir além da normalização do processo auxiliando-os a elaborar as perdas e lidar com as limitações para o encontro de alternativas realistas ao alcance do maior grau de autonomia e independência possíveis (BALTES 1996; ALMEIDA 1997).

O terapeuta ocupacional deverá adotar como premissa, seja em programas com enfoque recuperativo ou adaptativo, o reforço das capacidades do idoso. O T.O deverá estimular, ao máximo, o uso e ampliação de recursos próprios do indivíduo como motivações, estratégias, movimentos e sentidos a serem complementadas pela redução das demandas do ambiente, dispositivo auxiliar e/ou assistência quando necessário.

As principais estratégias adotadas por idosos e reforçadas por terapeutas ocupacionais para preservar ou melhorar a independência para as atividades de vida diária são modificações comportamentais, ambientais e uso de tecnologia assistiva. (ALMEIDA 1997; HILL 1998; CULLER 1998).

Segundo HILL (1998) o terapeuta ocupacional pode utilizar-se de técnicas adaptadas para a realização de atividades (mudanças comportamentais) ou equipamento adaptado para capacitar a pessoa ao desempenho da tarefa, mas acrescenta que a desvantagem possa ser ainda impedida requerendo-se assistência ou delegando-se a realização da tarefa a outra pessoa.

O uso de técnicas adaptadas é preferível ao uso de equipamentos pois as técnicas conferem à pessoa maior flexibilidade enquanto equipamentos implicam em custo, reparos, transporte e aceitação por parte do usuário (HILL 1998; CULLER 1998).

Segundo CULLER (1998) as modificações ambientais também se constituem em estratégias compensatórias e abarcam desde reformas e instalações de barras e corrimãos até medidas simples como retiradas de obstáculos. 
De acordo com a Technology-Related Assistance for Individuals With Disabilities Act of 1988 (Tech Act) (Public Law 100-407) citado por MANN e col. (1995), dispositivo assistivo ou dispositivo tecnológico assistivo é definido como "qualquer item, peça de equipamento ou sistema, quer adquirido comercialmente, modificado ou customizado; usado para aumentar, manter ou melhorar a capacidade funcional de indivíduos com incapacidades" (p.811).

Muitos estudos reiteram a importância dessas estratégias para manter ou aumentar a independência para a vida diária e as conceituam como práticas de autocuidado. Alguns desses estudos enfatizam a adoção dessas práticas por idosos (NORBURN e col. 1995; GILL e col. 1999; ALMEIDA 1997) enquanto outros enfatizam a adoção dessas práticas por cuidadores (MESSECAR 2002; GITLIN e col. 2002).

Estudo conduzido por NORBURN e col. (1995), ilustra práticas de autocuidado adotadas por idosos com e sem incapacidades com vistas a manterem-se na comunidade com independência. As práticas utilizadas abarcavam mudanças comportamentais, ambientais e uso de dispositivos auxiliares, e eram empregadas para prevenir incapacidades ou corrigi-las. As práticas eram definidas segundo tipo e severidade das incapacidades. Para dificuldade de mobilidade e nas atividades básicas de vida diária os idosos em geral adotavam uma ampla extensão de práticas, enquanto que para atividades instrumentais de vida diária os idosos adotavam mais freqüentemente mudanças de comportamento aliada à assistência de outras pessoas.

Os resultados de estudo, conduzido por GILL e col. (1999), demonstram a alta prevalência de determinados riscos ambientais em domicílios de idosos sem e com incapacidades, tais como cadeiras com alturas inadequadas, vasos sanitários instáveis, obstrução de passagens e tapetes soltos; e focalizam-se sobre esses fatores dada sua relevância sobre a vida diária, possibilidade de minimização com intervenção e evidências de que sua redução reduz o risco de queda. Os autores sugerem que novos estudos focalizem o papel do ambiente nas atividades de vida diária. 
ALMEIDA (1997) com o objetivo de elaborar instrumento para classificação de idosos quanto à capacidade para o autocuidado, identificou estratégias de autocuidado que, de forma isolada ou combinada, compensavam parcial ou totalmente dificuldades: mudanças comportamentais, ambientais, uso de dispositivos e ajuda de outra pessoa. Os idosos entrevistados apresentavam dificuldades para realizar mais freqüentemente atividades instrumentais de vida diária seguidas por atividades de lazer e básicas de vida diária.

MESSECAR (2002) desenvolveu estudo com cuidadores de idosos portadores de demência, com a finalidade de identificar fatores que afetam a habilidade desses cuidadores para implementar modificações ambientais definidas como mudanças estruturais, equipamento especial, mudanças comportamentais e uso de dispositivos auxiliares. Os fatores identificados incluíram atributos do idoso, do ambiente, da relação cuidador-idoso, habilidades e recursos pessoais do cuidador e suporte formal e informal disponivel.

GITLIN e col. (2002) procuraram avaliar as propriedades psicométricas de um instrumento designado para identificar ações desenvolvidas por cuidadores de pacientes portadores de demências com a finalidade de simplificar as tarefas de vida diária destas pessoas. Os autores consideram que a simplificação de tarefas constitui importante estratégia para auxiliar as pessoas com demência a participarem de seu autocuidado.

Sobre as estratégias ou práticas de autocuidado acima mencionadas é possível afirmar que se ajustam à abordagem adaptativa em terapia ocupacional, atualmente preconizada, e que se relacionam estreitamente ao alcance de metas de prevenção, recuperação ou adaptação estabelecidas para atuação desse profissional em gerontologia.

MENEZES (1994) considera que treinamento para o autocuidado, para o cuidado complementar prestado ao idoso pelo cuidador e a adequação ambiental à 
capacidade funcional do idoso "são tão ou mais importantes pelos resultados satisfatórios de um tratamento do que à receita médica" (p. 69).

A autora acrescenta que a opção por uma ou mais estratégias deriva da avaliação funcional.

\subsection{Instrumentos de avaliação de terapia ocupacional em gerontologia}

Segundo HOPKINS (1998) a avaliação em terapia ocupacional deve considerar tanto áreas quanto componentes de desempenho, ou seja o profissional deverá identificar para quais atividades a pessoa apresenta déficits e quais são esses déficits: sensório-motor, cognitivo, psicológico, psicossocial.

A prática atual da terapia ocupacional procura ir além de áreas e componentes de desempenho para incorporar aspectos contextuais do mesmo, enquanto situações ou fatores que influenciam o engajamento e funcionalidade das pessoas nas áreas de desempenho. Esses aspectos podem ser subdivididos em temporais (idade cronológica e desenvolvimental e estado de saúde) e ambientais (físico, social e cultural) e deverão ser contemplados no processo de avaliação (AOTA 1994).

A partir de revisão da literatura, SMITH (1998) afirma que a área da terapia ocupacional lança mão de provas padronizadas - como os índices de Katz (1959) e o índice de BARTHEL (1955) - e provas não padronizadas, para a avaliação do desempenho funcional, porém possui poucos instrumentos específicos de terapia ocupacional que embasem o tratamento.

A Associação Americana de Terapia Ocupacional (1989) citada por DUNN e McGOURTY (1998) propõe a "matriz de terminologia uniforme" (ANEXO 2.1) a partir da qual se identifica capacidades e limitações nos componentes de desempenho e seus resultados sobre as áreas de desempenho. Esse instrumento provê um marco de referência para o planejamento do programa de atenção em terapia ocupacional geral. 
TROMBLY e SCOTT (1977) desenvolveram um instrumento para avaliar o desempenho funcional de portadores de disfunção física, em cada uma das tarefas que compõe as atividades básicas e instrumentais de vida diária. Esse instrumento pode ser aplicado por meio de observação de comportamento e/ou entrevista. O instrumento prevê 5 (cinco) níveis de desempenho: faz com independência, faz com equipamento, faz com supervisão, faz com assistência, não faz. As autoras privilegiam seu instrumento para uso clínico em lugar de índices tais como os índices de KATZ (1959) e BARTHEL (1955), que oferecem um escore total do paciente, podem ser aplicados em pesquisa mas carecem de detalhes necessários para o planejamento do tratamento em terapia ocupacional.

Segundo HASSELKUS (1998) o terapeuta ocupacional em geriatria deverá dar ênfase ao desempenho funcional enquanto comportamento resultante da interação entre a pessoa e o ambiente.

HASSELKUS (1998) considera que os terapeutas devam adotar uma combinação de instrumentos a fim de avaliar os vários aspectos envolvidos no desempenho funcional de idosos. A autora propõe a adoção de escalas de atividades de vida diária, instrumentos específicos para avaliar as áreas deficitárias tais como visão e motricidade, instrumentos para avaliar os recursos disponíveis do cliente, considerando que esses recursos combinados com níveis de destreza resultam numa avaliação de risco. A autora sugere ainda o emprego de avaliações especificas sobre o ambiente que contemplem aspectos físicos, culturais e psicossociais do mesmo.

Ainda segundo a autora acima ao eleger um instrumento para uso clínico em terapia ocupacional em geriatria o profissional deverá considerar critérios tais como amplitude de itens, se esses itens são apropriados para idosos que vivem na comunidade e como atribuir pontuação ao avaliado. A escala também deverá ser de fácil administração, sensível às mudanças no tempo, válida e confiável, além de favorecer a comunicação entre os membros da equipe. 
CLEMSON e FITZGERALD (1998), em estudo com terapeutas ocupacionais, identificaram que a maioria dos profissionais valoriza o uso de instrumentos com evidências de confiabilidade e validade desde que sejam úteis aos seus propósitos clínicos. Os autores acrescentam a importância do desenvolvimento de manual adequado para a utilização desses instrumentos.

Em nosso meio, MIOSHI (2003) desenvolveu uma pesquisa com 25 terapeutas ocupacionais objetivando identificar critérios e instrumentos de avaliação utilizados por esses profissionais na atenção ao idoso. A autora identificou 17 critérios tais como histórico de vida e ocupacional, atividades de vida diária e outras atividades que o idoso desenvolve atualmente, funções envolvidas nas atividades, ambiente, diagnóstico médico e uso de dispositivo auxiliar.

Quanto ao uso de instrumentos de avaliação por T.Os, 17 (68\%) utilizam algum tipo de instrumento, tais como escalas de AVDs (44\%), avaliação de cognição (32\%), instrumento específico de T.O. (24\%), avaliação de depressão $(20 \%)$, de qualidade de vida (4\%) e de aspectos sociais (4\%) (MIOSHI 2003).

Dois achados na pesquisa desenvolvida por MIOSHI (2003) são particularmente importantes: embora nem todos adotem instrumentos, um significativo número de T.Os o faz, o que evidencia a importância dos mesmos para orientar a prática profissional; vale ressaltar ainda que somente dois instrumentos especificos de T.O foram relatados, a saber: Loewenstein Occupational Therapy Cognitive Assessment - LOTCA (KATZ e AVERBUCH 1992); e Auto-avaliação do funcionamento ocupacional - SAOF (TEDESCO 2000). Considero que, embora esses instrumentos sejam úteis e aplicáveis a idosos, não foram concebidos para uso específico nesta área.

Considero que a adoção de modalidades combinadas de instrumentos traz vantagens e desvantagens. Embora forneçam ampla gama de informações sobre o objeto em estudo, no caso o desempenho funcional do idoso, os conceitos que embasam esses instrumentos podem ser distintos e dificultarem a interpretação, 
integração e utilização das medidas obtidas. Acrescento que a pouca padronização no processo de avaliação reduz a possibilidade de comparação de resultados e conseqüentemente sua utilização em estudos e pesquisas.

O interesse do terapeuta ocupacional no que se refere à avaliação não deve limitar-se ao diagnóstico mas fundamentalmente apoiar a intervenção. De acordo com ROGERS (1996) para ser eficiente, a avaliação deverá responder a quatro exigências: 1) identificar atividades dificeis ou impossiveis para a pessoa realizar; 2) porque ou quais as causas do problema; 3) qual o potencial para reabilitação poderá a funcionalidade ser mantida, restaurada ou adaptada? 4) como melhorar o desempenho, ou seja quais as melhores opções de intervenção.

Empregando, basicamente, a "terminologia uniforme da terapia ocupacional" (AOTA 1994) a avaliação profissional deverá fornecer informações combinadas sobre áreas e componentes de desempenho para as quais a pessoa apresenta dificuldade, aspectos contextuais, enfoque do tratamento (prevenção, recuperação ou adaptação) e abordagem a ser adotada (corretiva ou adaptativa).

A identificação de fatores que motivem o idoso a iniciar e prosseguir com o tratamento é crítico em terapia ocupacional nesta área, devendo também ser contemplada no processo de avaliação. $\mathrm{O}$ emprego de atividades significativas, geralmente configura-se como fator importante de motivação para o idoso. Antigas habilidades e/ou atividades de interesse poderão ser resgatadas e integradas ao tratamento conferindo a ele o equilíbrio entre o familiar e o novo, o que sabe/quer e o que ainda não sabe fazer.

Segundo HORGAS e col.(1998) o conhecimento sobre a diversidade das atividades praticadas pelo idoso é importante pois provê informações sobre metas, motivações, habilidades, preferências, necessidades e desejos, bem como restrições e oportunidades. 
De acordo com o modelo de envelhecimento bem sucedido, uma diversidade le atividades é importante para idosos além das atividades de básicas de vida diária $\mathrm{e}$ ncluem aquelas que envolvem o ambiente externo, outras pessoas e atividades igadas à auto-realização (HORGAS 1998; ROWE e KAHN 1998).

Acrescento a importância ainda, no processo de avaliação do idoso, não somente do reconhecimento de práticas de autocuidado já adotadas - e contempladas, em parte pelo instrumento de TROMBLY e SCOTTY (1997) - mas também o reconhecimento de práticas que o idoso imagina que possa vir a adotar. Em conjunto, elas indicam o potencial do idoso para a reabilitação e são consistentes com o modelo ecológico de envelhecimento e do autocuidado.

Em síntese, considero que, para que o processo de avaliação do terapeuta ocupacional em gerontologia ampare o planejamento da atenção profissional deverá fornecer informações válidas e confiáveis sobre o desempenho funcional (áreas e componentes incluindo os aspectos do ambiente fisico e social do idoso), as atividades significativas e práticas de autocuidado, já empregadas ou imaginadas, para manter capacidades, recuperar ou compensar incapacidades.

Acredito que um instrumento especifico de T.O em gerontologia possa reunir parte dessas informações, minimizando a necessidade do uso de uma diversidade de instrumentos e desvantagens decorrentes (já apresentadas nesse capítulo).

Considero ainda que esse instrumento deva ser sensível às mudanças no tempo e prover instruções para aplicação, facilitando sua administração, interpretação e o compartilhar de resultados.

Com essas finalidades, elaborei ao longo do mestrado, um instrumento para uso especifico do terapeuta ocupacional com idosos especialmente em unidades básicas de saúde ao qual denominei Instrumento CICAc - Classificação de Idosos quanto a Capacidade para o Autocuidado. O produto resultante do mestrado foi a $\mathbf{1}^{\mathbf{a}}$ versão do Instrumento (ANEXO 1.1), construída em três fases: Roteiro Preliminar, 
Roteiro Ajustado e $1^{a}$ Versão do Instrumento (ALMEIDA 1997). As etapas de elaboração do instrumento podem ser descritas, de forma sucinta, conforme figura abaixo.

Figura 1: Fases de elaboração da $1^{a}$ versão do instrumento CICAc

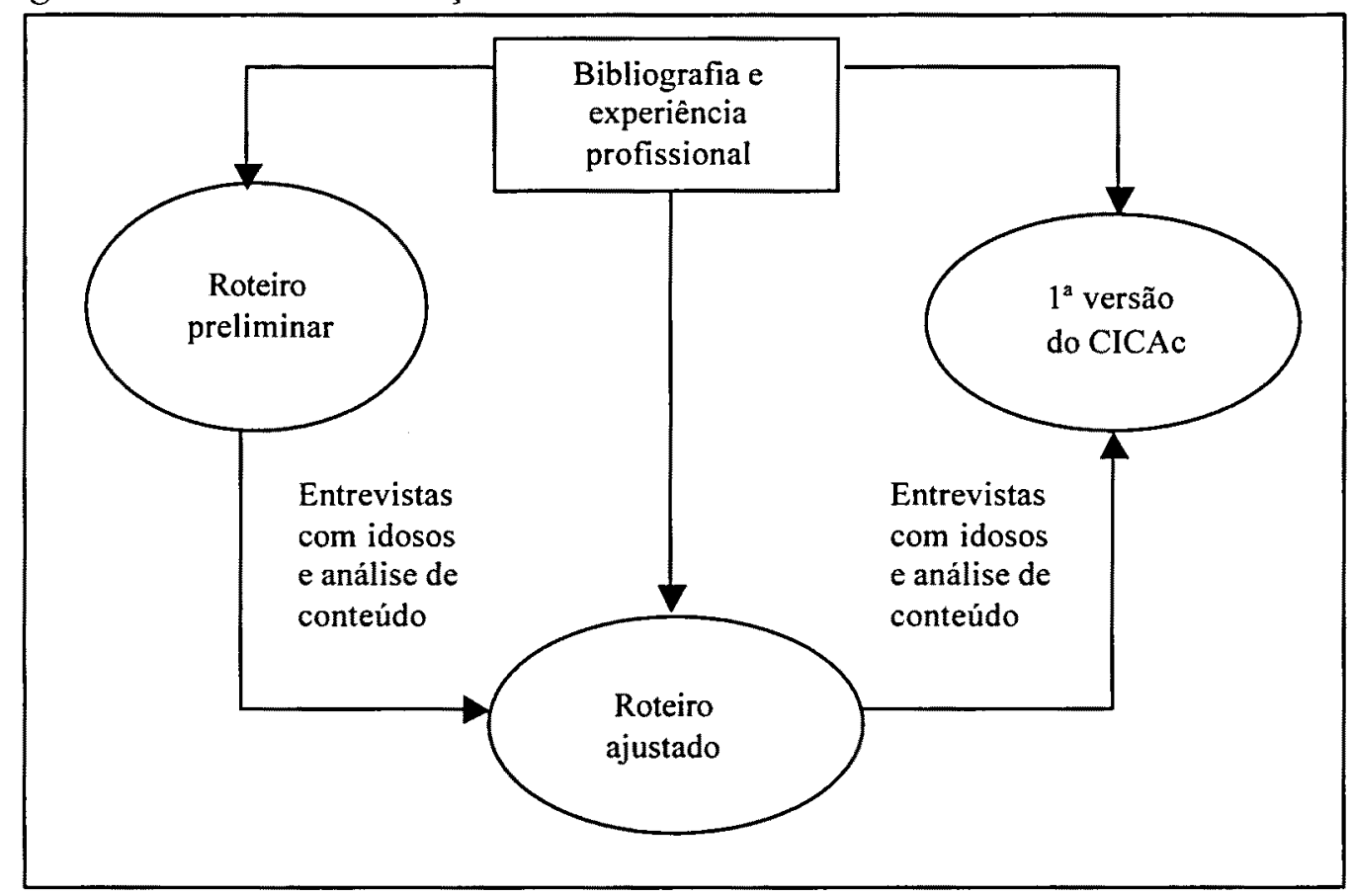

Fonte: Almeida MHM. CICAc: Instrumento para Classificação de Idosos quanto à Capacidade para o Autocuidado. São Paulo; 1997. [Dis sertação de Mestrado - Faculdade de Saúde Pública da Universidade de São Paulo].

Considero que ao pautar a construção da $\mathbf{1}^{\text {a }}$ versão do instrumento CICAc (ANEXO 1.1) em conhecimentos teóricos e práticos da terapia ocupacional e concepção teórica do autocuidado, eu tenha indicado sua validade de face e ao incorporar a ele, referenciais da população idosa entrevistada procurei dar validade ao seu conteúdo. Embora se admita que a população entrevistada seja representativa da população idosa habitualmente atendida em unidades básicas de saúde, considero que a $1^{\text {a }}$ versão do Instrumento CICAc (ANEXO 1.1) adquiriu validade de conteúdo somente para a população estudada. Estes conceitos serão apresentados no Capítulo 1.7: Considerações sobre validade e confiabilidade. 
A fim de que o instrumento CICAc possa fornecer informações de maior validade e confiabilidade sobre a população idosa, especialmente sobre aquela atendida em UBSs deverá ser submetido a um novo processo de validação, durante o qual poderá sofrer ajus tes, se necessário.

\subsection{Considerações sobre confiabilidade e validade}

Considero oportuno apresentar o conjunto das estratégias formalmente empregadas para indicar validade e avaliar confiabilidade de instrumentos e que pautaram a tomada de decisão sobre as estratégias adotadas.

Confiabilidade e validade são critérios habitualmente adotados para julgar instrumentos ou procedimentos de coleta de dados, conferindo credibilidade aos dados obtidos (McSWEENY e CREER 1995).

Confiabilidade refere-se a capacidade de um instrumento ou procedimento não variar em seus resultados, seja em sua utilização por diferentes aplicadores (admitindo-se que as condições de aplicação sejam as mesmas), seja em sua utilização em momentos distintos pelo mesmo aplicador (admitindo-se que as características do individuo pesquisado também não sofra modificações) (ALMEIDA FILHO 1989).

De acordo com FLETCHER e col. (1996), confiabilidade varia em graus, sendo determinada pela extensão em que medidas repetidas de um fenômeno relativamente estável situam-se próximas umas das outras.

A noção de erro está presente na definição de confiabilidade dada por McSWEENY e CREER (1995), referindo-se a quantidade de erro presente em um instrumento de avaliação.

Depreende-se que a correlação entre medidas obtidas a partir de duas ou mais aplicações do instrumento será sempre diferente de 1 e quanto mais próximo a esse valor, mais consistente, estável e acurado o instrumento será avaliado. 
A confiabilidade pode ser verificada de quatro maneiras McSWEENY e CREER 1995):

- Teste-reteste: é uma medida de estabilidade do instrumento, na ausência de mudanças tanto nos procedimentos de aplicação quanto nas características a serem avaliadas. Um instrumento é administrado duas vezes a um mesmo grupo de indivíduos, com um lapso de tempo entre uma e outra aplicação (habitualmente de uma a duas semanas) e os resultados são correlacionados. Se houver pouca mudança entre as aplicações, a ferramenta é considerada estável. (McSWEENY e CREER, 1995 e McDOWELL e NEWELL 1987). Segundo ALMEIDA FILHO (1989) o pesquisador poderá manter as condições de aplicação estáveis treinando a equipe para sua aplicação e acrescenta que instrumentos estruturados oferecem resultados mais confiáveis.

- Consistência interna: Para que o instrumento seja considerado consistente, deve conter questões que meçam a mesma dimensão ou constructo. Quando os itens entre si e em relação ao total da dimensão ou instrumento, mostram-se congruentes diz-se que o instrumento possui consistência interna. Essa medida é relevante se for possivel admitir que um instrumento ou domínio contenha grupos de itens homogêneos. Essa medida poderá ser obtida com uma única aplicação do instrumento a um número significativo de indivíduos.

- Confiabilidade inter-juízes: O instrumento de avaliação será consistente quando dois ou mais juízes usando-o de forma independente concordarem com seus achados. De acordo com ALMEIDA FILHO (1989) essa forma de estabelecer confiabilidade é a mais complicada pois sugere que os avaliadores tenham a mesma fundamentação para avaliar o instrumento e que a variação entre essas avaliações possa ser atribuída exclusivamente ao instrumento. 
- Formas alternativas: é uma medida que se aplica somente se houver formas paralelas de um instrumento. Quando as duas formas forem aplicadas e produzirem resultados idênticos ou similares essa forma de confiabilidade será demonstrada.

VERAS (1994) sugere que se adote mais do que uma maneira para verificar confiabilidade, uma vez que possuem vantagens e desvantagens fazendo com que as vantagens de uma compense as desvantagens da outra.

Validade refere-se à capacidade de um instrumento medir aquilo a que se propôs (McSWEENY e CREER 1995).

Segundo ALMEIDA FILHO (1989) pode-se abordar a questão da validade de um instrumento pela análise de seu componente conceitual e pela análise de seu componente pragmático e operacional.

Ainda segundo o autor a validade conceitual é teórica e impossível de ser avaliada por meio de testes comuns de validação, sendo que estratégias de pesquisa qualitativa são mais apropriadas para estabelecer esse tipo de validade já que ela não é mensurável mais demanda estreita ligação entre construção teórica e processo de pesquisa.

A validade operacional ou pragmática deve estar ao alcance de uma avaliação sistemática e dispor de um padrão contra o qual seja possível um estudo comparativo de desempenho (ALMEIDA FILHO 1989).

Para FLETCHER e col. (1996), a semelhança da confiabilidade, a validade também varia em graus referindo-se ao grau pelo qual os resultados de uma aferição correspondem aos estado verdadeiro dos fenômenos que estão sendo medidos.

Freqüentemente se pode estabelecer uma relação entre confiabilidade e validade, mas embora a confiabilidade seja necessária ela não é suficiente para 
estabelecer validade, uma vez que não garante a utilidade ou validade da medida. (McSWEENY e CREER 1995).

Segundo FLETCHER e col. (1996) é possivel ainda ter um instrumento valido mas não confiável pois seus resultados são muito dispersos em torno do valor real (como um aparelho de laboratório ou mesmo um questionário).

Considero que as afirmações acima relacionam confiabilidade e validade, especificamente em seu componente pragmático e operacional.

Existem algumas estratégias para se estabelecer validade (McSWEENY e CREER 1995):

- Validade de face: refere-se a evidência superficial da integridade da medida. "Um instrumento que é bom e faz sentido tem validade de face". Este tipo de estratégia para estabelecer validade não se constitui em técnica formal não devendo ser tomada como único critério para julgar a validade da medida (p.18).

- Validade de conteúdo: assegura que os itens de um instrumento cobrem e representam, adequadamente, o que é medido. Itens incluídos no instrumento devem refletir uma amostra de itens relevantes para cada domínio, essa amostra pode ser obtida a partir do uso de questionários com pacientes, itens sugeridos por especialistas ou através de literatura. Aspectos de validade de conteúdo incluem propriedade, clareza e abrangência dos itens. (McSWEENY e CREER 1995; McDOWELL e NEWELL 1987). ALMEIDA FILHO (1989) afirma que para ter validade de conteúdo "é preciso que os itens do instrumento de fato se relacionem com o objeto de pesquisa" e "tenham um poder discriminatório aceitável" (p. 45).

- Validade de critério: constitui-se no método mais popular para determinar validade e descreve uma relação empírica entre uma medida e um critério confiável de algum tipo. Há três tipos de validade de critério: 
- Validade concorrente: indicada pela comparação entre valores obtidos por dois instrumentos: um instrumento sob avaliação e um outro com validade já estabelecida

- Validade discriminante: indicada pela extensão pela qual uma medida pode diferenciar distintos grupos.

- Validade preditiva : permite predizer o futuro comportamento de um paciente com base no escore obtido pelo instrumento.

- Validade de constructo : Constructo refere-se a um sumário de termos referentes a comportamentos ou classe de comportamentos relacionados entre si segundo uma determinada teoria. Diz-se que um instrumento possui validade de construto quando for capaz de aferir esse conjunto de comportamentos. Esse tipo de validade é estabelecido a partir de uma pesquisa hipotético-dedutiva com o instrumento. Ex: transpiração, apreensão e taquicardia constituem parte do constructo da ansiedade e, pessoas que exibem esses comportamentos devem receber pontuação mais alta do que aquelas que os não exibem ou os exibem em graus menores.

Segundo FLETCHER e col (1996) é possivel armar evidências sobre a validade de uma de escala, nas condições em que ela é usada e a partir do emprego de estratégias como validação de conteúdo, constructo e critério, no entanto é preciso ter claro que esse processo de validação não se mostrará tão seguro quanto à confirmação de acurácia de um teste laboratorial, ou seja não se pode afirmar que uma escala é ou não é válida, mas sim se ela é mais ou menos válida, a partir dos resultados das estratégias usadas. 


\section{OBJETIVOS}

1. Estabelecer a validade de conteúdo do Instrumento CICAc - Classificação de Idosos quanto à Capacidade para o Autocuidado

2. Avaliar a confiabilidade do Instrumento CICAc - Classificação de Idosos quanto à Capacidade para o Autocuidado 


\section{MÉTODO}

\subsection{Estratégias para avaliar a confiabilidade e estabelecer a validade do Instrumento CICAC.}

A partir do conhecimento de possíveis estratégias a serem empregadas para avaliar confiabilidade e estabelecer validade de instrumentos, optei por aquelas que melhor atendessem aos objetivos propostos no estudo e ainda fossem factíveis quanto a custos e prazos.

As estratégias adotadas para o alcance dos objetivos propostos nesse estudo foram validação de conteúdo e avaliação da confiabilidade. A confiabilidade foi avaliada através das medidas de estabilidade e consistência interna do instrumento.

Ao conduzir a validação de conteúdo do instrumento procurei atribuir-lhe validade conceitual ou ajustá-lo em seu conteúdo e forma por meio da técnica Delphi (a ser apresentada no Capítulo 3.3.: Validação de conteúdo do Instrumento CICAc), a seguir procurei submetê-lo a mensuração de sua estabilidade e consistência interna, avaliando, desta forma, sua confiabilidade.

O estudo consta, basicamente, de duas fases a primeira qualitativa e a segunda quantitativa. A cada fase corresponde uma população de estudo; sendo de T.Os para a validação do conteúdo do instrumento CICAc e, de idosos para a avaliação de sua confiabilidade. Nos capítulos 3.3. e 3.4.: Validação de conteúdo do Instrumento CICAc e Avaliação de confiabilidade do Instrumento CICAc, - serão descritos os procedimentos metodológicos para a coleta de dados em cada fase da pesquisa.

Antes de submeter o Instrumento a essas estratégias conduzi sua estruturação sob a forma de escalas nominais, uma vez que instrumentos mais estruturados 
ajustam-se a algumas abordagens formais e permitem classificar indivíduos segundo as características pesquisadas.

Segundo ALMEIDA FILHO (1989) instrumentos estruturados oferecem resultados mais confiáveis desde que se padronize sua forma de aplicação.

O processo de estruturação resultou na Versão estruturada do Instrumento CICAc. Os detalhes deste processo e a Versão estruturada do instrumento estão apresentados nos ANEXOS 1.2 e 1.3, respectivamente.

Vale destacar que instrumentos compostos por escalas nominais, embora apresentem as vantagens apontadas acima, não permitem quaisquer operações matemáticas, ou seja não possibilitam mensurar caracteristicas ou realizar análise estatística, uma vez que os números são utilizados nesse tipo de escala de forma arbitrária e apenas como códigos (McDOWELL e NEWELL 1987).

Segundo os autores acima, nas escalas ordinais os números passam a refletir uma ordem crescente de categorias e embora não se possa afirmar com essas escalas a distância constante entre as categorias, elas são largamente usadas na área de saúde e pelas ciências sociais para mensuração de características, atribuição de pontuações e comparação entre grupos.

A partir da validação de conteúdo do instrumento (apresentada a seguir) foi possível não somente imprimir modificações ao instrumento, que o tornassem abrangente, claro e objetivo para cobrir aspectos fundamentais para o conhecimento da capacidade do idoso para o autocuidado, mas também atribuir níveis de capacidade para o autocuidado ao idoso, ou seja foi possível transformar algumas das escalas nominais contidas no instrumento em escalas ordinais. A consistência interna foi avaliada somente para as escalas ordinais, pois somente este tipo de escala ajustase aos procedimentos formais requeridos para esse tipo de análise (como veremos no Capítulo 5.4: Análise da consistência interna) 


\subsection{Validação de conteúdo do Instrumento CICAc}

\subsubsection{A Técnica Delphi}

A fim de se obter uma amostra de itens relevante para os distintos domínios que componham um instrumento, e a partir disso validar seu conteúdo, deve-se questionar pacientes, especialistas e consultar a literatura sobre aspectos que incluam propriedade, clareza e abrangência dos itens. (McDOWELL e NEWELL 1987; Gil 1995b).

De acordo com PASQUALI (1998) ao ouvirmos a opinião de membros da população ao qual o instrumento se destina e peritos na área estaremos conduzindo a análise sobre a compreensão dos itens e sua pertinência respectivamente. Ainda segundo o autor a análise de pertinência é às vezes chamada validação de conteúdo. Considero oportuno ressaltar que a elaboração do Instrumento CICAc tem sido pautada em consultas sistemáticas a idosos (ALMEIDA 1997) e profissionais.

Optei pelo emprego da técnica Delphi para conduzir a validação de conteúdo do Instrumento CICAc, por se configurar em uma estratégia sistemática de ouvir e analisar opiniões de especialistas com possibilidade de gerar no final dessa análise um produto validado (FARO 1995).

A técnica Delphi "debruça-se sobre o julgamento de um grupo de especialistas consistindo essencialmente em questioná-los sobre questões ou assuntos específicos" (WILLIAMS e WEBB 1994, p. 181).

Segundo SPINOLA (1984) a técnica Delphi é usada, em especial quando há falta de acordo ou há conhecimentos incompletos sobre determinado assunto, geralmente de natureza técnico-científica. 
Esta técnica tem sido largamente utilizada por uma variedade de áreas de conhecimento como economia, administração, saúde e outras (SPÍNOLA 1984)

SILVA e TANAKA (1999) destacam a utilização da técnica na área de educação para selecionar competências, objetivos e conteúdos de cursos e disciplinas. Os autores adotaram a técnica para identificar competências requeridas de médicos e enfermeiros na atenção primária à saúde a serem consideradas na reestruturação curricular destas carreiras.

FARO (1997) informa que diversas pesquisas na área de enfermagem têm aplicado a técnica Delphi para validação de condutas e diagnósticos nessa área. A referida autora empregou essa técnica de consenso para validação de intervenções de enfermagem aos lesados medulares, dado os questionamentos e conflitos vivenciados por enfermeiros para a atuação junto a essa clientela.

Segundo GROBE e HUBES (1993) citados por FARO (1995) o termo validade conceitual é freqüentemente utilizado em ciências sociais e do comportamento significando verdade, poder e valor. Os autores estudaram a validade conceitual para uma taxonomia de intervenções de enfermagem produzindo um arcabouço teórico para uma abordagem metodológica dessa taxonomia.

Considero que a técnica Delphi seja apropriada para ampliar a validade conceitual, mais especificamente de conteúdo do Instrumento CICAc que poderá vir a ser adotado como instrumento de uso consensual pelo T.O especialmente se considerarmos que até o momento não existe consenso entre T.Os quanto ao instrumento a ser adotado com idosos (ALMEIDA 1997).

Algumas qualidades próprias da técnica favorecem a obtenção do consenso grupal, como construção participativa sem contato face a face e seleção criteriosa dos juízes. 
De acordo com SPÍNOLA (1984) o questionário é considerado o instrumento mais adequado para a produção das informações com o emprego desta técnica. Esses devem ser cuidadosamente elaborados com vistas a atenderem os objetivos propostos no estudo, não existindo um modelo padronizado para sua construção.

Os questionários Delphi são componentes chaves no desenvolvimento da técnica. Um conjunto seqüencial de questionários cuidadosamente construídos, intercalados com sumários de informações derivadas de questionários anteriores ampara a coleta sistemática de dados e atribuição de julgamento de especialistas sobre um determinado assunto (DELBEC 1995 citado por SPÍNOLA 2002).

Segundo POLIT (1987) parte-se de uma interrogação individual cujas respostas em forma de resumo são compartilhadas entre todo o grupo, em prosseguimento segue novo interrogatório (amparado pelas respostas dos especialistas) e as respostas a esse são novamente compartilhadas até a obtenção de um consenso.

O número de interrogatórios ou questionários a serem enviados pode ser préfixado a depender da natureza do problema de investigação, seus determinantes e previsão de custo (SPÍNOLA 1984)

Segundo POLIT (1987) esse processo de julgamento pelos especialistas, análise e resposta pelo pesquisador é usualmente repetido três vezes até a obtenção do consenso.

A técnica Delphi objetiva alcançar o consenso, sem desprezar a visão da minoria, particularmente em estágio inicial do estudo. Embora muitos pesquisadores não estabeleçam o grau de consenso a priori mas a partir dos dados obtidos, importantes pesquisas que empregam essa técnica estabelecem o índice de 0,70 ou $70 \%$ como satisfatório e de concordância. (WILLIAMS e WEBB 1994; FARO 1995; SPÍNOLA 2002). 
Alguns cuidados no emprego da técnica Delphi podem favorecer a obtenção de resultados válidos e confiáveis.

Com o objetivo de melhorar a confiabilidade de resultados, os questionários construídos em todas as etapas devem possuir padronização suficiente para permitir a comparação e verificação de resultados finais e ainda devem possuir coerência com o problema a ser investigado.

A validade interna dos resultados obtidos é facilitada a princípio pelo fato da técnica Dephi possuir características de painel e corresponder a estudo do tipo longitudinal, no entanto alguns cuidados devem ser tomados pelo pesquisador ao longo do processo com vistas a não introduzir viés de interpretação e a manter a qualidade e quantidade de informantes (SPÍNOLA 1984).

A validade externa dos resultados pode ser indicada a partir dos critérios adotados pelo pesquisador para a seleção dos informantes, se de fato forem peritos no assunto em questão, os resultados obtidos poderão estender-se, com possibilidade de outras predições (SPÍNOLA 1984).

\subsubsection{População}

Para validar o conteúdo do instrumento CICAc foi necessário compor um painel de juízes, seguindo-se os pressupostos da técnica Delphi. Com essa finalidade, adotei os seguintes critérios de inclusão.

\section{Critérios de inclusão:}

1. Serem terapeutas ocupacionais;

2. Com atuação na área de gerontologia - assistência e/ou ensino e/ou pesquisa - por um período igual ou superior a 2 anos;

3. Residentes e atuantes no Estado de São Paulo;

4. Com interesse expresso em termo de consentimento, em colaborar com o estudo (ANEXO 2.4). 
A partir de cadastro de profissionais fornecido pela Sociedade Brasileira de Geriatria e Gerontologia/Seção São Paulo (SBGG) e de terapeutas ocupacionais indicados por esses profissionais, elaborei um cadastro de 22 profissionais. Selecionei, de acordo com os critérios de inclusão, 17 terapeutas ocupacionais, para participar do estudo. Optei por buscar os T.Os na SBGG por possuir cadastro atualizado de diferentes categorias profissionais atuando na área de gerontologia.

Embora tenha feito contato e confirmado o interesse dos 17 profissionais selecionados, 2 (dois) deles não devolveram a documentação enviada na primeira etapa e foram excluídos do estudo. Assim participaram efetivamente do mesmo 15 terapeutas ocupacionais.

\subsubsection{Coleta de dados}

Convidei os terapeutas ocupacionais a participar do estudo - por telefone e através de carta-convite enviada pelo correio (ANEXOS 2.2 e 2.3) - e solicitei que fornecessem informações profissionais a fim de caracterizar o grupo de juízes.

No que se refere especificamente ao Instrumento solicitei aos juízes que opinassem individual e confidencialmente sobre o Instrumento CICAc - versão estruturada (ANEXO1.3) ( $1^{\mathrm{a}}$ etapa do estudo delphi) quanto às áreas, questões, formas de aplicação e possibilidade de conversão das escalas nominais em escalas ordinais, ou atribuição de pontuação dos idosos segundo área de investigação. $O$ julgamento dos especialistas foi apreendido por meio de escala de opinião de 5 (cinco) pontos e por meio de comentários e sugestões.

Elaborei o primeiro questionário de opinião - com característica exploratória objetivando gerar novos itens, excluir ou modificar os existentes e questionar especialistas sobre a possibilidade de converter escalas nominais em escalas ordinais; diferindo dos demais questionários de opinião ( $2^{\mathrm{a}}$ e $3^{\mathrm{a}}$ etapas do estudo Delphi) que buscaram basicamente obter o julgamento dos especialistas quanto à propriedade $\mathrm{e}$ clareza das questões e tópicos do instrumento. 
$\mathrm{Na} 1^{\mathrm{a}}$ etapa do estudo procurei contemplar a contribuição de todos os especialistas ao tema em estudo, independente da sua freqüência, uma vez que se tratava de uma etapa exploratória, nas $2^{\mathrm{a}}$ e $3^{\mathrm{a}}$ etapas do estudo foram mantidos no instrumento somente itens aprovados por $70 \%$ ou mais dos especialistas.

Vale frisar que o corte de $70 \%$ não foi estabelecido a priori mas a partir dos primeiros resultados e do aprofundamento teórico, uma vez que esse índice tem sido apontando como satisfatório e de concordância em importantes pesquisas que desenvolveram a técnica (WILLIAMS e WEBB 1994; FARO 1995; SPÍNOLA 2002).

O índice proposto no início do estudo era de $55 \%$ e foi definido com base em estudo na área de enfermagem conduzido por ORTON (1981) e citado por WILLIAMS e WEBB (1994) que estabeleceu esse índice para consenso relacionado à aprendizagem de cuidados em enfermagem.

\subsection{Avaliação de confiabilidade do Instrumento CICAc}

A confiabilidade do Instrumento CICAc foi avaliada segundo duas medidas: estabilidade e consistência interna.

\subsubsection{População}

Para avaliar a estabilidade e consistência interna do Instrumento CICAc ele foi aplicado a idosos, adotei, nessa fase da pesquisa os critérios que seguem.

\section{Critérios de inclusão:}

1. Ter 60 anos e mais;

2. Ser inscrito no Grupo de manutenção de idosos do Centro de Saúde Escola Geraldo de Paula Souza; ou

3. Ser inscrito no Grupo de idosos do Centro de Convivência Clube Popular Chico Mendes (Zona Norte do Município de São Paulo); ou ainda 
4. Ser inscrito no "Grupo Amizade", mantido pela Coordenação Regional de Obras da Promoção Humana (CROPH) com Sede na Zona Norte do Município de São Paulo;

5. Mostrar capacidade de compreensão e expressão de idéias;

6. Mostrar disposição e consentir em participar do estudo (ANEXO 2.11), incluindo a realização do Teste do relógio (CCT) [Clock Completion Test] (ANEXO 2.9);

7. Ter apresentado desempenho satisfatório no CCT (ANEXO 2.10).

Conforme critérios de 1 a 5 identifiquei 40 idosos para participar do estudo, 8 recusaram-se, ou seja não atenderam ao critério número 6 , em decorrência da necessidade de realização de duas entrevistas, especialmente considerando-se a época do ano próxima das festas de final de ano e férias escolares, quando estariam comprometidos com outras atividades.

Dos 32 idosos que se dispuseram a participar do estudo, 2 foram excluídos por não corresponderem aos critérios número 6 (no tocante a realização do teste do relógio) e número 7. Algumas considerações sobre o teste do relógio serão apresentadas no ANEXO 2.8.

Conforme exposto obtive uma amostra de conveniência constituída por 30 idosos, descrita segundo sexo e faixa etaria na Tabela 1.

Tabela 1: População idosa participante da avaliação de confiabilidade do Instrumento CICAc segundo faixa etária e sexo. São Paulo, 2003.

\begin{tabular}{l|c|c|c}
\hline \multicolumn{1}{c|}{ Faixa Etária / Sexo } & Fem. & Masc. & Total \\
\hline 60 a 69 anos & 13 & - & 13 \\
70 a 79 anos & 10 & 1 & 11 \\
80 anos ou mais & 5 & 1 & 6 \\
\hline Total & 28 & 2 & 30 \\
\hline
\end{tabular}

- 20 idosos inscritos no Centro de Saúde Escola Geraldo de Paula Souza;

- 10 idosos inscritos nos dois Centros de Convivência localizados na Zona Norte do Município de São Paulo.

Vale frisar que estudos importantes para a avaliação de confiabilidade de escalas de atividades de vida diária empregaram amostras em números que variaram de 18 a 11.000, exemplos incluem a avaliação de confiabilidade inter-juízes da $15^{\mathrm{a}}$ 
versão do índice de Barthel, conduzida por SHINAR e col. (1987) que empregaram uma amostra de 18 pacientes; estudo da confiabilidade inter-juízes da escala RDRS [Rapid Disability Rating Scale] conduzido por LINN (1967) que empregou uma amostra de 20 pacientes e a avaliação da estabilidade teste-reteste do HAQ [Health Assessment Questionnaire] por FRIES (1980) que utilizou uma amostra de 37 idosos. Todos os estudos mencionados foram apresentados por McDOWELL e NEWELL (1987).

Em nosso meio, posso citar estudo de confiabilidade e validade do "Family Apgar de Smilkstein - versão para o português", conduzido por DUARTE (2001), o teste-reteste foi realizado pela autora a partir de uma amostra de conveniência de 27 idosos (primeira aplicação) e 23 idosos (segunda aplicação com intervalo de uma semana).

\subsubsection{Coleta de dados}

A partir de cadastro fornecido pelos coordenadores dos grupos, contatei os idosos por telefone, quando eram:

- Convidados a para participar do estudo;

- Informados sobre:

- objetivo do estudo;

- instituição a que o estudo estava vinculado;

- razões pelas quais eles foram escolhidos para participar deste estudo

- Motivados a participar com base na importância de sua colaboração;

- Assegurados do anonimato quanto à autoria das respostas e

- Assegurados sobre a devolução dos resultados do estudo, sob a forma de orientação às suas principais dificuldades.

Convidei, através de contato telefônico, os idosos para participar do estudo. Dos 32 idosos que se dispuseram a participar, 20 preferiram ser entrevistados no próprio domicilio, a fim de otimizarem seu tempo. Foram necessárias algumas remarcações mas nenhuma delas ultrapassou o intervalo de 15 dias. 
Embora o procedimento teste-reteste seja habitualmente acompanhado de perda de participantes (VERAS 1994), o presente estudo não cursou com nenhuma perda. Considero que alguns fatores contribuíram para a motivação dos idosos em permanecer no estudo: credibilidade da instituição ao qual o estudo estava vinculado e principalmente a expectativa por parte do entrevistado de receber orientação quanto às suas principais dificuldades no dia a dia (ao término da $2^{\mathrm{a}}$ entrevista).

Conforme acordado com os idosos, coordenadores dos grupos e diretorias das instituições as quais estão vinculados, forneci orientações gerais aos idosos individualmente e em reunião de grupo - para a adoção ou reforço de práticas de autocuidado que preservassem ou melhorassem sua independência no dia a dia.

No dia da entrevista individual apliquei os seguintes instrumentos:

- CCT aplicado para avaliar a capacidade cognitiva (ANEXOS 2.9 e 2. 10), sendo que o desempenho no teste foi utilizado como critério de inclusão/exclusão para participação no estudo

- Termo de consentimento para participação no estudo de avaliação de confiabilidade da $3^{\mathrm{a}}$ versão grupal do Instrumento CICAc (ANEXO 2.11)

- $3^{\mathrm{a}}$ versão grupal do Instrumento CICAc (ANEXO 1.6)

Neste mesmo dia agendei a segunda e última entrevista individual (ANEXO 2.12), quando foi reaplicada a $3^{\text {a }}$ versão grupal do Instrumento CICAc (ANEXO 1.6)

O tempo para a aplicação da $3^{a}$ versão do Instrumento CICAc (ANEXO 1.6), foi de 45 minutos a 1 (uma) hora, tanto na primeira como na segunda entrevista.

\section{RESULTADOS E DISCUSSÃO: VALIDAÇÃO DE CONTEÚDO}

Os resultados obtidos nesta pesquisa serão apresentados seguindo-se as fases e etapas do estudo. Inicialmente serão apresentados os resultados pertinentes à 
validação de conteúdo: Caracterização dos juízes e apreciação do Instrumento CICAc por eles em 3 etapas.

A caracterização profissional dos juízes pode ser descrita conforme Quadro 2.

Quadro 2: Caracterização profissional dos juizes participantes do Estudo Delphi

\begin{tabular}{|c|c|c|c|c|c|c|c|}
\hline \multirow[t]{2}{*}{ Juízes } & \multirow{2}{*}{$\begin{array}{c}\text { Formado } \\
\text { em } \\
\text { Escola... }\end{array}$} & \multirow{2}{*}{$\begin{array}{l}\text { Tempo de } \\
\text { formado } \\
\text { (anos) }\end{array}$} & \multicolumn{3}{|c|}{ Pós - graduação na área } & \multirow{2}{*}{$\begin{array}{c}\text { Experiência na } \\
\text { área: Tempo (e m } \\
\text { anos) e esfera de } \\
\text { atuação }\end{array}$} & \multirow{2}{*}{$\begin{array}{c}\text { Trabalha } \\
\text { atualmente em } \\
\text { instituição... }\end{array}$} \\
\hline & & & Especialização & Mestrado & Doutorado & & \\
\hline 1 & Pública & 11 & $\bar{S}$ & $\bar{N}$ & $\bar{N}$ & 3 anos $-A$ & Privada \\
\hline 2 & Pública & 16 & $\mathrm{~S}$ & $\mathrm{~S}$ & Em curso & $\begin{array}{l}16 \text { anos }-A \\
13 \text { anos }-E \\
10 \text { anos }-P\end{array}$ & Pública \\
\hline$\overline{3}$ & Pública & 2 & $\overline{\mathrm{S}}$ & $\mathrm{N}$ & $\mathrm{N}$ & $2 \operatorname{anos}-A$ & Privada \\
\hline 4 & Pública & $\overline{4}$ & $\mathrm{~S}$ & Em curso & $\bar{N}$ & $\begin{array}{l}4 \operatorname{anos}-A \\
2 \operatorname{anos}-E \\
2 \operatorname{anos}-P\end{array}$ & Privada e Pública \\
\hline 5 & Pública & 37 & $S$ & $\mathbf{N}$ & $\mathrm{N}$ & $18 \operatorname{anos}-\mathrm{A}$ & Privada e Pública \\
\hline 6 & Privada & 10 & $\bar{S}$ & Em curso & $\bar{N}$ & $\begin{array}{l}10 \text { anos }-\bar{A}, E, P \\
\text { atua }-\mathbf{A}, \mathbf{P}\end{array}$ & Pública \\
\hline 7 & Privada & 13 & $\overline{\mathrm{N}}$ & $\mathrm{N}$ & $\mathrm{N}$ & 13 anos $-A$ & Privada \\
\hline 8 & Pública & 37 & $\mathrm{~S}$ & $\mathrm{~S}$ & $\bar{S}$ & $\begin{array}{l}21 \text { anos }-A, E, P \\
\text { atua }-\mathbf{A}, \mathbf{E}\end{array}$ & Privada \\
\hline 9 & Pública & 34 & $\mathrm{~S}$ & $\mathrm{~N}$ & $\mathrm{~N}$ & $\begin{array}{l}34 \text { anos }-A \\
16 \text { anos- } E\end{array}$ & Privada \\
\hline 10 & Pública & 14 & $\bar{S}$ & $\mathrm{~N}$ & $\bar{N}$ & $\begin{array}{l}10 \text { anos }-\mathrm{A} \\
2 \text { anos }-\mathrm{E}\end{array}$ & Privada e Pública \\
\hline 11 & Pública & 19 & $\bar{S}$ & $\mathrm{~N}$ & $\mathrm{~N}$ & 3 anos $-A, E$ & Privada e Pública \\
\hline 12 & Privada & 11 & $\bar{S}$ & $\mathrm{~N}$ & $\mathrm{~N}$ & $\begin{array}{l}1 \text { ano }-E \\
9 \text { anos- } A\end{array}$ & Privada e Pública \\
\hline 13 & Pública & 2 & $\mathrm{~N}$ & $N$ & $\mathrm{~N}$ & 2 anos- $A$ & Privada e Pública \\
\hline 14 & Privada & 15 & $\bar{S}$ & $\mathrm{~N}$ & $\mathrm{~N}$ & $\begin{array}{l}13 \text { anos }-\mathrm{A}, \mathrm{P} \\
11 \text { anos }-\mathrm{E} \\
\text { atua }-\mathbf{A}, \mathbf{E}\end{array}$ & Pública \\
\hline 15 & Pública & 17 & $\overline{\mathrm{S}}$ & $\overline{\mathrm{S}}$ & Em curso & $\begin{array}{l}16 \text { anos }-A \\
10 \text { anos- } P \\
2 \text { anos }-E\end{array}$ & Privada \\
\hline
\end{tabular}

Legenda:

A: assistência

E: Ensino

P: Pesquisa 
Considero que algumas informações sobre a caracterização profissional dos juízes sejam especialmente importantes para o processo de validação de conteúdo do Instrumento CICAc. Como ilustra a Tabela 2, grande parte dos profissionais possui cursos de pós-graduação na área (87\%), sendo que para alguns a capacitação formal mestrado e doutorado - inscreve-se como objetivo alcançado ou a ser alcançado $(33 \%)$.

Ainda segundo Tabela 2 se nota que $50 \%$ dos profissionais com mais de 10 anos de experiência na área cursam doutorado ou já o concluíram, mostrando que a capacitação formal é um importante aliado para a atuação assistencial e na área de ensino. Vale destacar que todos os profissionais com capacitação formal, em curso ou concluída (33\%), atuam na área de ensino (27\%) ou já o fizeram ( $7 \%$ ).

Conforme EMMEL e LANCMAN (1998) a capacitação formal - mestrado e doutorado - compõe atualmente os objetivos da T.O especialmente para aqueles ligados à docência na área. Alguns fatores contribuem para isso como a mudança no caráter da profissão que passou do nível técnico ao universitário e a exigência de formação didática e de pesquisador para docentes nos cursos de graduação.

Tabela 2: Juizes participantes do estudo Delphi segundo tempo de experiência na área e cursos de pós-graduação.São Paulo, 2003.

\begin{tabular}{l|l|l|l|l}
\hline \multirow{2}{*}{ Juízes do estudo Delphi } & \multicolumn{3}{|c}{ Tempo de experiência na área } \\
\cline { 2 - 5 } & \multicolumn{1}{c|}{2 a 5 anos } & 6 a 10 anos & 11 a 37 anos & Total \\
\hline Com cursos de pós -graduação & $4 * *$ & $3^{* *}$ & $6^{*}$ & $13(87 \%)$ \\
Sem cursos na área & 1 & 0 & 1 & $2(13 \%)$ \\
\hline Total & $5(33 \%)$ & $3(20 \%)$ & $7(47 \%)$ & $15(100 \%)$ \\
\hline
\end{tabular}

\footnotetext{
* a essa categoria pertencem $3(20 \%)$ profissionais com mestrado concluído sendo 1 (7\%) com doutorado concluído e $2(13 \%)$ com doutorado em andamento.

$* *$ a essas duas categorias pertencem $2(13 \%)$ profissionais com mestrado em andamento
} 


\section{1. $1^{\text {a }}$ etapa do estudo Delphi}

Quadro 3: Julgamento dos especialistas sobre o Instrumento CICAC-versão estruturada

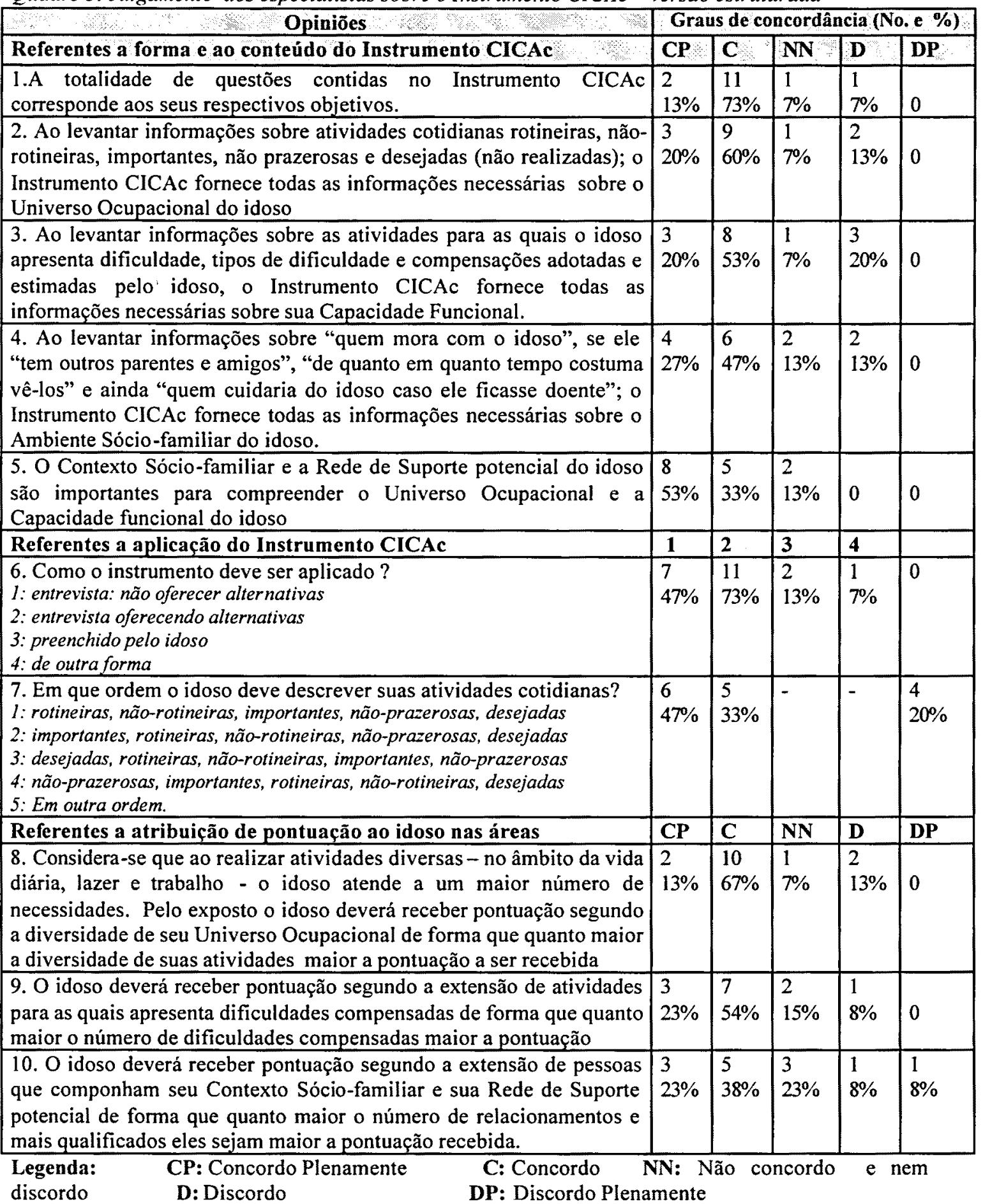


Sumário de graus de concordância, comentários e observações

Apesar do alto grau de concordância geral em relação à composição do Instrumento CICAc versão estruturada (ANEXO 1.3) e a proposta de atribuição de pontuação ao idoso nas diversas áreas (73\% ou mais), os especialistas tecem comentários e observações que designamos como críticas e sugestões. Estas foram organizadas por área do instrumento, muitas delas foram incorporadas a $\mathbf{1}^{\mathbf{a}}$ versão grupal do instrumento CICAc (ANEXO 1.4) e serão apresentadas a seguir.

Tabela 3: Criticas dos especialistas quanto à forma e conteúdo, por área do Instrumento CICAcversão estruturada. São Paulo, 2003.

\begin{tabular}{|c|c|c|}
\hline Áreas & Críticas & Freg. \\
\hline $\begin{array}{l}\text { Ambiente } \\
\text { sócio- } \\
\text { familiar }\end{array}$ & $\begin{array}{l}\text { Questões insuficientes e inadequadas para conhecer contexto sócio- } \\
\text { familiar/ rede de suporte potencial } \\
\text { Questões insuficientes para levantar informações sobre o Ambiente } \\
\text { sócio-familiar, devendo incluir questões sobre: } \\
\text { filhos e netos (1), recursos financeiros (1), relações familiares (2), se } \\
\text { reside em instituição (1) e socialização (1) } \\
\text { Questões insuficientes para levantar informações sobre o Ambiente } \\
\text { sócio-familiar qualitativamente } \\
\text { Perguntas (e objetivos) não correspondem às alternativas de resposta } \\
\text { Questões não são válidas para o idoso: Requerem memória preservada } \\
\text { (1) podem não informar aquilo que se propõe (1) }\end{array}$ & $\begin{array}{l}1 \\
1 \\
2\end{array}$ \\
\hline $\begin{array}{l}\text { Universo } \\
\text { ocupacional }\end{array}$ & $\begin{array}{l}\text { Faltaram algumas categorias de atividades } \\
\text { Faltaram algumas atividades às categorias existentes } \\
\text { Alguns nomes empregados para designar categorias e itens não são } \\
\text { adequados }\end{array}$ & $\begin{array}{l}3 \\
4 \\
2\end{array}$ \\
\hline $\begin{array}{l}\text { Capacidade } \\
\text { Funcional }\end{array}$ & $\begin{array}{l}\text { Questões referentes à CF são complexas (em seu conteúdo) } \\
\text { Quadros resumos para registro de respostas são de dificil compreensão } \\
\text { Itens contidos na área CF são insuficientes para documentar alterações } \\
\text { de desempenho } \\
\text { Itens contidos não medem CF } \\
\text { Perguntar especificamente o que o idoso deixou de fazer }\end{array}$ & $\begin{array}{l}1 \\
3 \\
1 \\
1 \\
1\end{array}$ \\
\hline $\begin{array}{l}\text { Instrumento } \\
\text { em sua } \\
\text { totalidade }\end{array}$ & $\begin{array}{l}\text { Questões insuficientes para fornecer dados qualitativos: caracteriza o } \\
\text { autocuidado quantitativamente } \\
\text { Incongruência entre perguntas e alternativas de resposta } \\
\text { Pode não informar aquilo que se propõe } \\
\text { Termos empregados não deixam clara a relação entre questões e } \\
\text { objetivos } \\
\text { Dificuldade de compreensão das questões quanto à linguagem utilizada } \\
\text { Linguagem pouco usada no meio terapêutico-ocupacional }\end{array}$ & $\begin{array}{l}1 \\
2 \\
2 \\
1 \\
1\end{array}$ \\
\hline Total & & 36 \\
\hline
\end{tabular}


Tabela 4: Sugestões dos especialistas quanto à forma e conteúdo do Instrumento CICAc - Versão Estruturada. São Paulo, 2003.

\begin{tabular}{l|c}
\hline \multicolumn{1}{c|}{ Sugestões } & Freq. \\
\hline Acrescentar uma questão sobre autonomia & 1 \\
Acrescentar questões que identifiquem e contemplem o idoso institucionalizado & 2 \\
Acrescentar questão de extensão às atividades importantes (ainda que pergunte por que são & 1 \\
importantes, propõe perguntar em que sentido são importantes) & \\
Acrescentar novas categorias de atividades: profissionais (principais e prévias), educacionais, & 2 \\
o que ele mais gosta & \\
Acrescentar itens (atividades) as categorias: atividades rotineiras//não rotineiras, & 4 \\
importantes... & \\
Renomear categorias e itens & 2 \\
Evitar abreviações & 1 \\
Evitar uso excessivo de parênteses & 1 \\
Substituir palavras de duplo sentido na formulação das questões & 1 \\
Confeccionar manual de instrução & 4 \\
Questões devem obedecer à ordem numérica & 3 \\
Modificar questões & 1 \\
Modificar quadros-resumo & 3 \\
Definição de termos & 5 \\
Substituir ambiente sócio- familiar por ambiente relacional - familiar & 1 \\
Retirar alternativas "ninguém"e eparentesco" (alternativas de resposta às questões 2 e 3) & 2 \\
Registrar em colunas separadas rotineiras e não-rotineiras & 1 \\
Pode ser aplicado a cuidadores & 2 \\
\hline Total & 37 \\
\hline
\end{tabular}


Tabela 5: Críticas e sugestões dos especialistas referentes à atribuição de pontuação ao idoso nas áreas do Instrumento CICAc-Versão Estruturada. São Paulo, 2003

\begin{tabular}{|c|c|c|}
\hline AREAS & Criticas e sugestões & Freq. \\
\hline $\begin{array}{l}\text { Ambiente sócio - } \\
\text { familiar }\end{array}$ & $\begin{array}{l}\text { Concorda desde que sejam feitos alguns acertos } \\
\text { Extensão de pessoas insuficiente para determinar pontuação, há } \\
\text { necessidade de incluir: } \\
\quad \text { - Qualidade das relações, extensão do suporte } \\
\quad \text { - Numero de pessoas de um grande parentesco direto } \\
\quad \text { - Concorda com reserva devido às peculiaridades do idoso } \\
\text { Termo qualificado é dúbio } \\
\text { Quantidade não é realmente significativo } \\
\text { Se o enfoque da avaliação é independência e autonomia, o idoso não deve } \\
\text { receber pontuação nesta área } \\
\text { Dados numéricos não trazem qualidade } \\
\text { Não se deve avaliar a rede e sim o idoso } \\
\text { Os critérios de avaliação da rede devem ser claros. }\end{array}$ & $\begin{array}{l}2 \\
1 \\
1 \\
1 \\
1 \\
1 \\
1 \\
1 \\
1\end{array}$ \\
\hline $\begin{array}{l}\text { Universo } \\
\text { ocupacional }\end{array}$ & $\begin{array}{l}\text { Na condição que inclua atividades realizadas por compensação } \\
\text { Questiona validade do questionário com um todo para o idoso com } \\
\text { comprometimento cognitivo } \\
\mathrm{Na} \text { condição que se considere as limitações impostas pela } \\
\text { institucionalização } \\
\text { Diversidade do Universo Ocupacional (UO) é insuficiente para } \\
\text { determinar pontuação ao idoso na área U.O: } \\
\text { - devendo considerar particularidades do idoso } \\
\text { Diversidade do Universo Ocupacional (UO) é insuficiente para } \\
\text { determinar pontuação ao idoso na área U.O: } \\
\text { - devendo associar à complexidade das atividades e condições } \\
\text { externas } \\
\text { Diversidade não merece pontuação } \\
\text { - A rede de informações a associações que as atividades criam } \\
\text { merece pontuação } \\
\text { - mais importante verificarmos a importância atribuída à } \\
\text { pontuação deve considerar o interesse em determinadas } \\
\text { atividades e a execução das mesmas }\end{array}$ & $\begin{array}{l}1 \\
1 \\
1\end{array}$ \\
\hline $\begin{array}{l}\text { Capacidade } \\
\text { funcional }\end{array}$ & $\begin{array}{l}\text { Na condição que estejam incluídas as atividades realizadas por } \\
\text { compensação } \\
\text { Número de dificuldades compensadas é insuficiente para determinar } \\
\text { pontuação ao idoso segundo CF } \\
\text { - devendo considerar particularidades do idoso (1) } \\
\text { Número de dificuldades compensadas é insuficiente para determinar } \\
\text { pontuação ao idoso segundo CF } \\
\text { - devendo distinguir formas de compensação: com tecnologia } \\
\text { assistiva, com auxilio de outras pessoas e em que grau (1) } \\
\text { Número de dificuldades compensadas não merece pontuação e sim quais } \\
\text { atividades são compensadas e porquê, para posteriormente interpretando } \\
\text { mudanças em função do ambiente } \\
\text { Treinamento para atribuição da pontuação }\end{array}$ & $\begin{array}{l}1 \\
1\end{array}$ \\
\hline \multicolumn{2}{|l|}{ Total } & 22 \\
\hline
\end{tabular}




\section{Discussão de resultados}

Como foi dito anteriormente parte significativa das críticas e sugestões foram incorporadas a $1^{\text {a }}$ versão grupal do Instrumento CICAc (ANEXO 1.4) independente da freqüência em que foram expressas, dada a sua relevância para o aprimoramento do instrumento, com vistas a sua aplicação, especialmente junto à população idosa usuária de unidades básicas de saúde. As principais propostas de modificação serão apresentadas a seguir.

\section{Instrumento como um todo}

- Orientações gerais sobre o instrumento:

- Onde pode ser utilizado;

- Quais as informações que pode fornecer;

- Sugestão quanto à periodicidade de aplicação.

- Instruções para aplicação do instrumento e registro de respostas preferencialmente no corpo do instrumento - favorecendo e assegurando a consulta das mesmas;

- Ajuste da terminologia empregada, incluindo definição de termos:

- Substituição de palavras com compreensão duvidosa;

- Definição de termos técnicos.

- Objetivos definidos por extenso:

- retirada dos códigos - úteis somente para tabulação e análise de resultados;

- retirada de abreviações.

\section{Área Ambiente sócio-familiar}

Apesar da maior parte dos especialistas (86\%) concordarem com a importância desta área para a compreensão do universo ocupacional e da capacidade funcional do idoso e $74 \%$ concordarem total ou parcialmente com questões que compõe o Instrumento CICAc- versão estruturada (ANEXO 1.3) nesta área, 80\% expressa crítica quanto à quantidade insuficiente ou validade das questões para fornecer informações sobre o contexto sócio-familiar do idoso e sua rede de suporte. As críticas dos especialistas concordam com a literatura. As questões do 
Instrumento CICAc versão estruturada (ANEXO 1.3) se limitam a descrever quem mora ou não com o idoso, não informando sobre a qualidade de sua rede social. Segundo FILLENBAUM (1984) aspectos da saúde social incluem a quantidade e qualidade de relacionamentos interpessoais e a extensão do envolvimento com a comunidade. Fazer parte de uma rede social é um dos mais importantes indicadores de longevidade, uma vez que através dela o idoso pode obter suporte sócio-emocional e instrumental. (ROWE e KAHN 1998).

Os especialistas sugerem que o instrumento informe sobre escolaridade, atividades profissionais e recursos financeiros do idoso. Considero oportunas essas sugestões uma vez que, de acordo com a literatura, essas variáveis estão relacionadas com o universo ocupacional e a capacidade funcional de idosos.

$\mathrm{O}$ idoso mantém e recobra engajamento com a vida através de atividades sociais e produtivas incluindo atividades remuneradas, por sua vez o engajamento dos idosos nessas atividades sofre a influência de fatores tais como a escolaridade (ROWE e KAHN 1998). De acordo com BALTES (1993) a competência para atividades instrumentais, de lazer e sociais está fortemente relacionada aos recursos sociais. Pelo exposto, as atividades remuneradas e escolaridade deverão ser contempladas na $1^{\mathrm{a}}$ versão grupal do Instrumento CICAc (ANEXO 1.4).

Recursos financeiros, assim com escolaridade e atividades profissionais são contemplados ainda em instrumentos importantes em gerontologia como o OARS versão para o português (RAMOS 1987). Depreende-se que os recursos financeiros possam associar-se ao envolvimento de idosos em determinadas atividades, devendo também ser incorporado ao instrumento.

Com base nessa apreciação, as modificações que a serem incorporadas à $\mathbf{1}^{\mathrm{a}}$ versão grupal do Instrumento CICAc (ANEXO 1.4) referem-se a:

\section{Desdobramento da área Ambiente sócio-familiar do idoso em:}

- Arranjo doméstico e Potencial rede de suporte: 
- com objetivo de descrever o arranjo doméstico e familiar do idoso e potencial rede de suporte deverá incluir itens que descrevam mais detalhadamente esse arranjo e convidem o idoso a avaliar seus relacionamentos quanto ao apoio que eles possam ou não representar

- Perfil social

- com objetivo de traçar um breve perfil social deverá incluir questões que caracterizem brevemente o idoso socialmente como escolaridade, atividades remuneradas e recursos financeiros.

Treze especialistas respondem a questão quanto à pontuação, e ainda que $62 \%$ dos especialistas concordem total ou parcialmente com a atribuição de pontuação ao idoso nesta área, $85 \%$ consideram que a extensão de pessoas que componham o Contexto Sócio-familiar e Rede de Suporte potencial do idoso não são critérios suficientes (38\%) ou adequados (38\%) para atribuição dessa pontuação.

Com base nessa apreciação, devo afirmar que a atribuição de valores ao idoso segundo esses critérios não atingiu o consenso entre os especialistas. Nosso esforço deve voltar-se, portanto, ao aprimoramento do instrumento para que ele possa melhor caracterizar o ambiente social e familiar do idoso.

\section{Área Universo ocupacional}

Oitenta $(80 \%)$ dos especialistas concordam total ou parcialmente com as questões que informam sobre o U.O no entanto $47 \%$ acrescentariam itens e $13 \%$ dariam novos nomes a alguns itens. As sugestões dos especialistas buscam tornar o instrumento consistente com o objeto de atenção da terapia ocupacional, ou seja a ocupação humana em suas distintas áreas: atividades de autocuidado (básicas de vida diária), lazer e trabalho (atividades produtivas remuneradas e não remuneradas). Segundo HORGAS e col. (1998) informações sobre as diversas atividades de vida diária além das básicas provêem conhecimento sobre metas e motivações do idoso, restrições e oportunidades, a serem consideradas numa perspectiva de envelhecimento bem sucedido. Em concordância com tais sugestões incorporei e modifiquei itens no instrumento a serem julgados. 
Oitenta $(80 \%)$ dos especialistas concordam total ou parcialmente com a atribuição de pontuação ao idoso nessa área, no entanto $33 \%$ desses especialistas apontam condições a serem consideradas tais como o ambiente onde essas atividades se realizam e peculiaridades do idoso. Para os $20 \%$ que não concordam nem discordam da pontuação ou discordam dessa, a extensão e a diversidade das atividades são insuficientes (7\%) ou não merecem pontuação (13\%), sendo que a complexidade, a importância das atividades que o idoso realiza ou a rede de associações que as atividades determinam é o que merece portuação.

Pelo exposto depreende-se que a extensão e diversidade de atividades não foram consideradas pelos especialistas como critério suficiente para atribuição de pontuação ao idoso nessa área. A maioria dos especialistas (53\%) considera que essa informação deva ser combinada com outras informações para ganhar algum significado.

\section{Área Capacidade funcional}

Setenta e três $(73 \%)$ dos especialistas concordam total ou parcialmente com as questões desta área, mas $53 \%$ fazem críticas e sugestões especialmente no que se refere a complexidades das questões e quadros resumos, os $27 \%$ que não concordam nem discordam ou discordam das questões também fazem críticas aos quadros resumo $(7 \%)$, ou consideram que as questões sejam insuficientes $(7 \%)$ ou ainda não medem a capacidade funcional $(7 \%)$.

Treze especialistas respondem a questão quanto à atribuição de pontuação nesta área, $78 \%$ dos quais admite essa possibilidade. Para os $22 \%$ que não discordam nem concordam ou discordam da pontuação, o número de dificuldades compensadas é insuficiente para determinar pontuação ao idoso devendo distinguir formas de compensação: com tecnologia assistiva, com auxílio de outras pessoas e em que grau. Mesmo o especialista que considera que o número de dificuldades compensadas não merece pontuação admite que se forem consideradas quais atividades são compensadas (se importantes ou não para o idoso), a informação teria 
mais valor. Esse especialista no entanto acha que essa informação só adquire real importância em função do tempo e do ambiente, ou seja se ao reaplicar o instrumento constatarmos mudanças na capacidade funcional e em qual contexto essa mudança se insere.

A sugestão de um especialista para a determinar pontuação ao idoso de acordo com a forma(s) de compensação adotada(s) tem amparo na literatura. TROMBLY e SCOTT (1977) prevêem 5 (cinco) niveis de desempenho para atividades diárias que incluem a realização de atividades com equipamento e com ajuda, índices como os de KATZ (1959) e BARTHEL (1955), embora incluam menos níveis, distinguem a realização de atividades de forma independente ou com ajuda.

Pelo exposto considero que o idoso possa ser posicionado segundo presença e grau de incapacidade para suas atividades desde que cheguemos a um consenso quanto às formas de compensação e ainda possamos ordená-las em graus de dependência/independência.

Corroborando com a sugestão de um dos especialistas, considero que a informação sobre nível de independência combinada com a informação sobre atividades importantes poderia ser um dos critérios para a definição de prioridades em T.O

\section{Formas e aplicação do instrumento}

Quanto às formas de aplicação do instrumento, o número de opinião (21) supera o número de especialistas (15) uma vez que alguns especialistas consideram que não exista uma forma única de aplicação do instrumento, e esta deverá ser escolhida de acordo com características da clientela e objetivos da aplicação. A técnica de entrevista foi sugerida por todos os especialistas, oferecendo alternativas de resposta ao entrevistado (73\%) ou não oferecendo essas alternativas (47\%). Estas sugestões estão de acordo com a literatura. 
McDOWELL e NEWELL (1987) sugerem a importância da técnica de entrevista aplicada nas ciências sociais e de saúde a partir das afirmações de que muitos índices têm optado pelo uso de informações colhidas por meio de entrevistas e que o julgamento subjetivo em ciências sociais e de saúde amplifica dados estatísticos, sinaliza problemas de dor, sofrimento e depressão, informa se indivíduos procuram ou não cuidados, reflete aspectos de boa saúde e é pouco custoso, prático, configurando-se como maneira sistemática de ouvir os indivíduos.

Ainda segundo esses autores as pessoas podem fazer julgamentos acurados e consistentes acerca de estímulos, o que equivale a dizer que entrevistas poderão fornecer informações válidas e confiáveis.

Segundo SMITH (1998) a entrevista em terapia ocupacional atende a vários propósitos de forma privilegiada: fornece informações valiosas sobre o paciente para a definição de objetivos e plano de tratamento, favorece a compreensão do paciente acerca do processo de terapia ocupacional e oferece a oportunidade para que o paciente comente sua situação e pense sobre planos para modificá-la. Considero que essas entrevistas possam ter frmato estruturado desde que contemple os aspectos mencionados acima, o que favoreceria comparar resultados de re-aplicação e comparações entre indivíduos.

O emprego da entrevista não se opõe a outras técnicas de coleta de informações, o terapeuta deverá lançar mão de uma ampla gama de fontes apropriadas de informação a fim de apoiar o processo terapêutico, como obtenção de história clínica, observação, provas padronizadas de função motora, inteligência, habilidade sensório-motora entre outras. (SMITH 1998)

De acordo com LODI (1991) outras técnicas de coleta de informações - tais como consultas a documentos e observações de comportamento - são complementares à técnica de entrevistas e devem, sempre que possível, ser empregadas. 
Conforme BENNETT (1999) as escalas de atividades de vida diária, empregadas por meio de entrevistas, não deveriam ser usadas como medida única de desempenho devido a problemas de estabelecimento de escores totais, por se tratarem de informações auto-referidas, especialmente por idosos que podem negar dificuldades de desempenho, especialmente em estágios iniciais, e ainda pelo fato das escalas sofrerem adaptações quando usadas por distintas populações. A autora sugere a obtenção de informações complementares baseadas em testes de desempenho.

Em concordância com BENNETT (1999), observo que grande parte das escalas atribui pontuação total aos avaliados desconsiderando a condição funcional para cada uma das atividades, quando se sabe que incapacidade para algumas atividades contribui mais para a dependência do que a incapacidade para outras. Há que se observar ainda que classificação funcional em três níveis, habitual em escalas de avaliação funcional, embora possibilite o encontro mais fácil de tendências, muitas vezes despreza diferenças entre os indivíduos, cujo conhecimento é fundamental para a orientação do processo terapêutico.

Espero que o processo de validação de conteúdo e avaliação da confiabilidade do instrumento possa gerar como produto um instrumento que identifique diferenças funcionais entre as atividades diárias, mesmo para dificuldades em estágios iniciais, além de outros aspectos relevantes da capacidade para o autocuidado de idosos. 


\section{2. $2^{\mathrm{a}}$ etapa do estudo Delphi}

Convidei os especialistas, confidencial e individualmente - através de questionário enviado pelo correio - a opinar sobre a $\mathbf{1}^{\mathbf{a}}$ versão grupal do Instrumento CICAc (ANEXO 1.4) quanto à propriedade e clareza de:

- cada questão que compõe o Instrumento;

- orientações gerais para sua aplicação;

- instruções para preenchimento e

- definição de termos.

Enfatizo que imediatamente após a apresentação de cada item do instrumento o juiz era convidado a opinar sobre a propriedade e clareza do mesmo.

Reafirmo que o nível de concordância estabelecido para confirmação dos itens no instrumento foi de $70 \%$ para conteúdo e enunciado.

Nesta etapa do estudo os especialistas foram convidados ainda a construir uma escala ordinal a partir das formas adotadas pelo idoso para compensar dificuldades, com vistas a estabelecer níveis de comprometimento da capacidade funcional a partir delas. 


\section{Resultados}

Quadro 4: Julgamento dos especialistas sobre a $1^{a}$ versão grupal do Instrumento CICAc.

\begin{tabular}{|c|c|c|c|c|c|c|}
\hline \multirow{3}{*}{$\begin{array}{c}\text { Queståo por área de investigaçằo } \\
\begin{array}{c}\text { Área de investigação: Arranjo doméstico e potencial rede } \\
\text { de suporte }\end{array}\end{array}$} & \multicolumn{4}{|c|}{ Aprovada quanto ao } & \multicolumn{2}{|c|}{$\begin{array}{l}\text { Nao julgada = } \\
\text { Sim E Não } \\
\text { assinaladas ou } \\
\text { EM BRANCO }\end{array}$} \\
\hline & \multicolumn{2}{|c|}{ Conteúdo } & \multicolumn{2}{|c|}{ Enunciado } & \multirow{2}{*}{$\begin{array}{l}\text { Conteú } \\
\text { do }\end{array}$} & \multirow{2}{*}{$\begin{array}{l}\text { Enun- } \\
\text { ciado }\end{array}$} \\
\hline & Sim & Não & Sim & Năo & & \\
\hline $\begin{array}{l}\text { Questão } 1 \text {-O(a) } \mathrm{Sr}(\mathrm{a}) \text { mora com outras pessoas na } \\
\text { mesma casa? Sim ( ) Não ( ) Com quem o(a) } \mathrm{Sr}(\mathrm{a}) \\
\text { mora? } \\
\text { Identifique todas as pessoas que moram, atualmente, com } \\
\text { o(a) idoso(a). Acompanha quadro para registro de nome, } \\
\text { tipo de relacionamento, sexo e idade das pessoas que } \\
\text { moram com o(a) idoso(a) }\end{array}$ & $\begin{array}{l}15 \\
100 \%\end{array}$ & 0 & $\begin{array}{l}15 \\
100 \%\end{array}$ & 0 & 0 & 0 \\
\hline $\begin{array}{l}\text { Questão } 2-\mathrm{O}(\mathrm{a}) \mathrm{Sr}(\mathrm{a}) \text { tem (outros) filhos? } \\
\text { Sim ( ) Não ( ) } \\
\text { ldentifique todos os filhos vivos que não moram com or a) } \\
\text { idoso(a). Acompanha quadro para registro de nome, sexo, } \\
\text { idade e onde residem os filhos vivos do(a) idoso(a) }\end{array}$ & $\begin{array}{l}13 \\
86,7 \%\end{array}$ & & $\begin{array}{l}13 \\
86,7 \%\end{array}$ & $\begin{array}{l}2 \\
13,3 \%\end{array}$ & $\begin{array}{l}2 \\
13,3 \%\end{array}$ & \\
\hline $\begin{array}{l}\text { Questão } 3 \text { - Com que freqüência o(a) Sr(a) se } \\
\text { relaciona com: } \\
\text { Preencha a coluna correspondente à freqüència segundo } \\
\text { legenda. Acompanha quadro para registro das freqũências } \\
\text { com que o(a) idoso(a) se relaciona com distintas pessoas e } \\
\text { legenda referente às frequências }\end{array}$ & $\begin{array}{l}14 \\
93,3 \%\end{array}$ & & $\begin{array}{l}14 \\
93,3 \%\end{array}$ & $\begin{array}{l}1 \\
6,7 \%\end{array}$ & $\begin{array}{l}1 \\
6,7 \%\end{array}$ & \\
\hline $\begin{array}{l}\text { Questão } 4 \text { - } \mathrm{O}(\mathrm{a}) \mathrm{Sr}(\mathrm{a}) \text { está satisfeito(a) com a } \\
\text { freqüência com se relaciona com: } \\
\text { Assinale com um X o grau de satisfação corresponde a cada } \\
\text { um dos tipos de relacionamento. Acompanha quadro para } \\
\text { registro dos graus de satisfação do(a) idoso(a) quanto à } \\
\text { frequência com que se relaciona com distintas pessoas }\end{array}$ & $\begin{array}{l}14 \\
93,3 \%\end{array}$ & & $\begin{array}{l}12 \\
80,0 \%\end{array}$ & $\begin{array}{l}3 \\
20,0 \%\end{array}$ & $\begin{array}{l}1 \\
6,7 \%\end{array}$ & \\
\hline $\begin{array}{l}\text { Questão } 5 \text { - Como o(a) } \operatorname{Sr}(\text { a) se sente com a relação } \\
\text { que mantém com: } \\
\text { Assinale com um } X \text { o grau de satisfação correspondente a } \\
\text { cada um dos tipos de relacionamento. Acompanha Quadro } \\
\text { para registro dos graus de satisfação quanto aos } \\
\text { relacionamentos }\end{array}$ & $\begin{array}{l}15 \\
100 \%\end{array}$ & 0 & $\begin{array}{l}12 \\
80,0 \%\end{array}$ & $\begin{array}{l}3 \\
20,0 \%\end{array}$ & & \\
\hline $\begin{array}{l}\text { Questão } 6 \text { - Tem alguém que cuida do(a) Sr(a) caso } \\
\text { quando o(a) Sr(a) fica doente? Sim ( ) Não ( ). Quem } \\
\text { é ou quais são essa(s) pessoa(s) } \\
\text { ldentifique todas as pessoas que cuidam do(a) idoso(a) em } \\
\text { caso de doença. Acompanha quadro para registro de nome, } \\
\text { tipo de relacionamento sexo e idade das pessoas que } \\
\text { cuidam do(a) idoso(a) em caso de doença }\end{array}$ & $\begin{array}{l}15 \\
100 \%\end{array}$ & 0 & $\begin{array}{l}14 \\
93,3 \%\end{array}$ & $\begin{array}{l}1 \\
6,7 \%\end{array}$ & & \\
\hline \multicolumn{7}{|c|}{ Área de investigaça: Perfil social } \\
\hline $\begin{array}{l}\text { Questão 7- } \mathrm{O}(\text { a) } \mathrm{Sr}(\mathrm{a}) \text { freqüentou escola? Até que ano } \\
\text { estudou? } \\
\text { Assinale com um } X \text { a escolaridade do entrevistado na coluna } \\
\text { à direita. Acompanha quadro para registro do grau de } \\
\text { escolaridade do(a) idoso(a) }\end{array}$ & $\begin{array}{l}15 \\
100 \%\end{array}$ & 0 & $\begin{array}{l}14 \\
93,3 \%\end{array}$ & $\begin{array}{l}1 \\
6,7 \%\end{array}$ & & \\
\hline $\begin{array}{l}\text { Questão } 8 \text { - Qual sua atividade profissional principal ? } \\
\text { Preencha o campo abaixo: }\end{array}$ & $\begin{array}{l}15 \\
100 \% \\
\end{array}$ & 0 & $\begin{array}{l}12 \\
80,0 \%\end{array}$ & $\begin{array}{l}3 \\
20,0 \% \\
\end{array}$ & & \\
\hline $\begin{array}{l}\text { Questão } 9 \text { - } \mathrm{O}(\text { a) } \mathrm{Sr}(\mathrm{a}) \text { exerce essa atividade } \\
\text { profissional atualmente? ( ) Sim ( ) Não } \\
\text { Se a resposta for negativa, aplique a questão } 10\end{array}$ & $\begin{array}{l}15 \\
100 \%\end{array}$ & 0 & $93,3 \%$ & $6,7 \%$ & & \\
\hline
\end{tabular}




\begin{tabular}{|c|c|c|c|c|c|c|}
\hline $\begin{array}{l}\text { Questão } 10-O(a) \operatorname{Sr}(\text { a) } \text { tem trabalho remunerado } \\
\text { atualmente? ( ) } \operatorname{Sim}() \text { Não. Qual ? }\end{array}$ & $\begin{array}{l}13 \\
86,7 \%\end{array}$ & $\begin{array}{l}2 \\
13,3 \%\end{array}$ & $\begin{array}{l}11 \\
73,3 \%\end{array}$ & $\begin{array}{l}4 \\
26,7 \%\end{array}$ & & \\
\hline 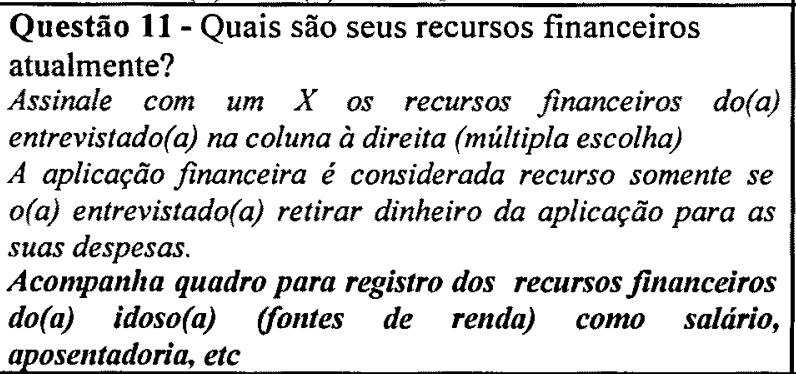 & $100 \%$ & 0 & $93,3 \%$ & $6,7 \%$ & & \\
\hline $\begin{array}{l}\text { Questão } 12 \text { - Com a sua situação econômica atual de } \\
\text { que forma o(a) Sr(a) satisfaz suas necessidades de } \\
\text { alimentação, moradia, saúde, etc? } \\
\text { Assinale com um X X forma com o(a) idoso(a) satisfaz suas } \\
\text { necessidades, na coluna à direita. } \\
\text { Acompanha quadro para registro do grau de satisfação } \\
\text { do(a) idoso(a) com sua situação econômica atual }\end{array}$ & $\begin{array}{l}14 \\
93,3 \%\end{array}$ & & $86,7 \%$ & $6,7 \%$ & $6,7 \%$ & $\begin{array}{l}1 \\
6,7 \%\end{array}$ \\
\hline \multicolumn{7}{|c|}{ Area: Universo Ocupacional } \\
\hline $\begin{array}{l}\text { Questão 13 - O que o(a) Sr(a) faz todos os dias, desde } \\
\text { a hora acorda até a hora que vai dormir? Procure } \\
\text { contar todas as coisas faz. } \\
\text { Utilize o Quadro l para registro das respostas }\end{array}$ & 15 & 0 & $\begin{array}{l}13 \\
86,7 \%\end{array}$ & $13,3 \%$ & & \\
\hline $\begin{array}{l}\text { Questão } 14 \text { - Tem alguma coisa que o(a) Sr(a) faça só } \\
\text { de vez em quando? } \\
\text { Utilize o Quadro I para registro das respostas }\end{array}$ & $93.3 \%$ & 0 & $80,0 \%$ & 2 & $6,7 \%$ & 1 \\
\hline $\begin{array}{l}\text { Questão } 15 \text { - Das coisas que o(a) } \operatorname{Sr}(\text { a) faz, quais o(a) } \\
\text { Sr(a) acha que são importantes para o(a) } \operatorname{Sr}(\text { a) ? } \\
\text { 15.1. Por quê?? } \\
\text { Utilize o Quadro I para registro das respostas à questão } 15 \\
\text { e, o Quadro } 2 \text { para registro de respostas à questão } 15.1\end{array}$ & 15 & 0 & $86,7 \%$ & $13,3 \%$ & & \\
\hline $\begin{array}{l}\text { Questão } 16 \text { - Das coisas que o(a) Sr(a) faz, de quais } \\
\text { gosta menos? } \\
16.1 \text { Por quê? } \\
\text { Utilize o Quadro } 1 \text { para registro das respostas à questão } 16 \\
\text { e Quadro } 3 \text { para registro de respostas à questão 16.1 }\end{array}$ & $\begin{array}{l}15 \\
100 \%\end{array}$ & 0 & $93,3 \%$ & $6,7 \%$ & & \\
\hline $\begin{array}{l}\text { Questão } 17 \text { - Tem alguma coisa que o(a) Sr(a) } \\
\text { gostaria de ter feito em sua vida mas nunca fez ou fez } \\
\text { há algum tempo atrás e gostaria de voltar a fazer? Por } \\
\text { que não faz? } \\
\text { Utilize o Quadro I para registro das respostas à questão } 17 \\
\text { e Quadro } 4 \text { para registro das respostas à questão 17.1. }\end{array}$ & $100 \%$ & 0 & $80,0 \%$ & $20,0 \%$ & & \\
\hline $\begin{array}{l}\text { Quadro1: Quadro resumo para registro de respostas às } \\
\text { questões } 13,14,15,16 \text { el } 7 \\
\text { Identifíque todas as atividades que componham a vida } \\
\text { cotidiana do(a) idoso(a), assinalando com X na(s) coluna(s) } \\
\text { correspondente(s) a sua caracterização Esse quadro } \\
\text { permite caracterização das atividades básicas e } \\
\text { instrumentais de vida diária, lazer, trabalho remunerado e } \\
\text { não remunerado (linhas) enquanto atividades cotidianas } \\
\text { rotineiras, näo rotineiras, importantes, não prazerosas e } \\
\text { desejadas (colunas). }\end{array}$ & $100 \%$ & 0 & $86,7 \%$ & $\begin{array}{l}2 \\
13,3 \%\end{array}$ & & \\
\hline
\end{tabular}




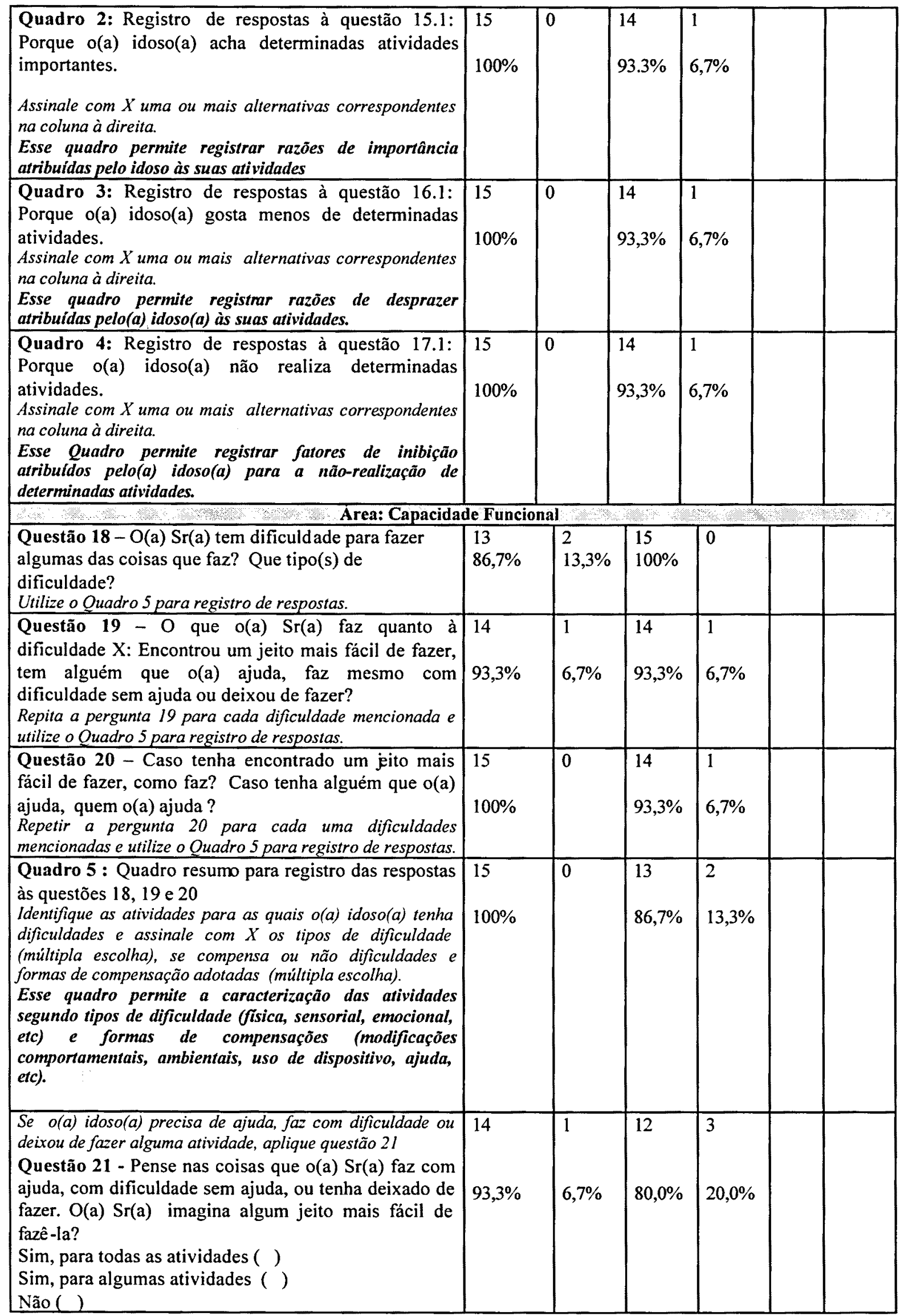




\begin{tabular}{|c|c|c|c|c|c|c|}
\hline $\begin{array}{l}\text { Se a resposta for afirmativa para todas ou para algumas } \\
\text { atividades, aplique a questão } 22 \text { e registre as respostas no } \\
\text { Quadro } 6 . \\
\text { Questão } 22 \text { - Como poderia ser feito? }\end{array}$ & $\begin{array}{l}13 \\
86,7 \%\end{array}$ & $\begin{array}{l}2 \\
13,3 \%\end{array}$ & $\begin{array}{l}13 \\
86,7 \%\end{array}$ & $\begin{array}{l}2 \\
13,3 \%\end{array}$ & & \\
\hline $\begin{array}{l}\text { Quadro 6: Registro das respostas à questão } 22 \\
\text { Nomeie todas as atividades que o(a) idoso(a) faz com ajuda, } \\
\text { com dificuldade sem ajuda, ou tenha deixado de fazer e para } \\
\text { as quais ele(a) imagina compensações. Assinale com um X } \\
\text { as formas de compensação imaginadas (múltipla escolha). } \\
\text { Esse quadro permile a caracterização de atividades para as } \\
\text { quais o(a) idoso(a) precisa de ajuda, faz com dificuldade } \\
\text { sem ajuda, ou tenha deixado de fazer segundo as formas } \\
\text { de compensação imaginadas. }\end{array}$ & $\begin{array}{l}13 \\
86,7 \%\end{array}$ & $\begin{array}{l}2 \\
13,3 \%\end{array}$ & $\begin{array}{l}13 \\
86,7 \%\end{array}$ & $\begin{array}{l}2 \\
13,3 \%\end{array}$ & & \\
\hline $\begin{array}{l}\text { Questão } 23 \text { - Pense nas coisas que o(a) Sr(a) gostaria } \\
\text { de ter feito em sua vida mas nunca fez ou fez há muito } \\
\text { tempo atrás e gostaria de voltar a fazer. O(a) } \operatorname{Sr}(\text { a) } \\
\text { imagina algum jeito de vir a fazê-las? }\end{array}$ & $\begin{array}{l}12 \\
80,0 \%\end{array}$ & $\begin{array}{l}3 \\
20,0 \%\end{array}$ & $\begin{array}{l}12 \\
80,0 \%\end{array}$ & $\begin{array}{l}3 \\
20,0 \%\end{array}$ & & \\
\hline $\begin{array}{l}\text { Quadro 7: Registro das atividades desejadas (resposta à } \\
\text { questâo i7), acompanhadas das respectivas formas } \\
\text { imaginadas para sua realização(resposta à questão } 23 \text { ). } \\
\text { Repita nesse quadro as atividades desejadas e introduza as } \\
\text { formas imaginadas de realização na coluna à direita. }\end{array}$ & $\begin{array}{l}12 \\
80,0 \%\end{array}$ & $\begin{array}{l}2 \\
13,3 \%\end{array}$ & $\begin{array}{l}13 \\
86,7 \%\end{array}$ & $\begin{array}{l}1 \\
6,7 \%\end{array}$ & $\begin{array}{l}1 \\
6,7 \\
\%\end{array}$ & $\begin{array}{l}1 \\
6,7 \%\end{array}$ \\
\hline Orientações gerais para aplicação do Instrumento & $\begin{array}{l}12 \\
80 \%\end{array}$ & $\begin{array}{l}1 \\
6,7 \%\end{array}$ & $\begin{array}{l}11 \\
73,3, \%\end{array}$ & $\begin{array}{l}2 \\
13,3 \%\end{array}$ & $\begin{array}{l}2 \\
13,3 \\
\% \\
\end{array}$ & $\begin{array}{l}2 \\
13,3 \%\end{array}$ \\
\hline Definição de termos & $\begin{array}{l}11 \\
73,3 \%\end{array}$ & $\begin{array}{l}1 \\
6,7 \%\end{array}$ & $\begin{array}{l}10 \\
66,7 \%\end{array}$ & $\begin{array}{l}1 \\
6,7 \%\end{array}$ & $\begin{array}{l}3 \\
20,0 \\
\% \\
\end{array}$ & $\begin{array}{l}4 \\
26,7 \%\end{array}$ \\
\hline
\end{tabular}

Quanto ao conteúdo, a $1^{\mathrm{a}}$ versão grupal do Instrumento (ANEXO 1.4) obteve a aprovação do conjunto dos especialistas para a totalidade dos itens que o compõe (incluindo quadros para registro de respostas, orientações gerais para aplicação do instrumento e definição de termos), variando de 73,3\% a 100\%.

\section{Quanto ao enunciado, a $1^{\text {a }}$ versão grupal do Instrumento (ANEXO 1.4)}

obteve a aprovação para a quase totalidade dos itens mantendo-se a mesma variação observada no julgamento do conteúdo, exceto para a definição de termos que foi aprovada em seu enunciado por 10 juízes $(66,7 \%)$, ficando abaixo do índice de aprovação desejado de $70 \%$.

Vale ressaltar que as posições neutras e opiniões discordantes foram assumidas com mais freqüência por profissionais com capacitação formal (doutorado) em curso, seguida por profissionais com mais tempo de experiência na área (30 anos ou mais) e por um profissional com 30 anos e mais de experiência e 
doutorado concluído. Há que se observar, no entanto, que as posições contrárias ao instrumento referem-se menos ao conteúdo (24\%) e concentram-se nos enunciados e organizações das questões e tópicos (76\%), expressando-se na reprovação, nesta etapa, do tópico Definição de termos. Os especialistas foram ouvidos e considerados nas seguintes sugestões.

Tabela 6: Sugestões dos especialistas relativas à definição de termos no Instrumento CICAc - $1^{a}$ Versão Grupal. São Paulo, 2003.

\begin{tabular}{|c|c|}
\hline Sugestões & Freqüência \\
\hline Definição das formas de compensação empregadas & 3 \\
\hline Definição da potencial rede de suporte & 2 \\
\hline $\begin{array}{l}\text { Contemplar outros tipos de dificuldade, e que se destine espaço para sua } \\
\text { especificação; }\end{array}$ & 2 \\
\hline $\begin{array}{l}\text { Redefinição de objetivos para as questões sobre breve perfil social - sugerem que } \\
\text { estas questões informam sobre perfil econômico; }\end{array}$ & 2 \\
\hline $\begin{array}{l}\text { Definição de termos como arranjo doméstico e familiar, tipos de dificuldade e } \\
\text { incapacidade; }\end{array}$ & 1 \\
\hline Exemplos sobre formas de compensacão & 1 \\
\hline Total & 11 \\
\hline
\end{tabular}

Tabela 7: Sugestões dos especialistas relativas à organização de itens no Instrumento CICAc- $1^{a}$ Versão Grupal. São Paulo, 2003.

\begin{tabular}{l|c}
\hline \multicolumn{1}{c|}{ Sugestões } & Freqüência \\
\hline Questão 23 complementar a questão 17, devendo se colocar como extensão dessa, ou & 3 \\
vice e versa & 3 \\
Quadro 7 (para registro da resposta a questão 23) complementar ao quadro 1 & 1 \\
Questões 18,19 e 20 são complementares, devem ser enunciadas como uma única & \\
pergunta para que o entrevistado tenha a oportunidade de falar de forma seqüencial & \\
sobre sua dificuldade, se compensa ou não e de que forma para a seguir discorrer & \\
Sobre a próxima eventual dificuldade & \\
Relacionar com mais clareza e precisão as questões em geral aos quadros & 4 \\
correspondentes & 3 \\
Relacionar com mais clareza a questão 10 ao quadro 1 & 2 \\
Quadros devem começar e terminar na mesma página incluindo legenda & 1 \\
Enumerar as páginas & 1 \\
Objetivos sejam apresentados antes das respectivas questões & 1 \\
Legendas sejam apresentadas antes dos respectivos quadros & 19 \\
\hline Total & \\
\hline
\end{tabular}

\section{A construção da escala ordinal}

Os especialistas foram convidados a atribuir números às formas adotadas pelo idoso para compensar dificuldades, de maneira que os números refletissem graus de dependência ou níveis de comprometimento da independência funcional. $O$ número 1 deveria acompanhar o menor comprometimento da independência 
funcional, na opinião do especialista e assim por diante. Admitiu-se a atribuição do mesmo número a uma ou mais categorias a ainda a existência de categorias ou formas de compensação não mencionadas pelo pesquisador.

Somente 10 juízes construíram a escala, os demais informaram que a solicitação de construção de uma escala passou desapercebida no corpo da $1^{\mathrm{a}}$ versão grupal do instrumento (ANEXO 1.4). A pontuação média que cada categoria recebeu as posicionou em uma ordem crescente correspondente a estabelecida pelo pesquisador, exceto para a categoria Faz com dificuldade que recebeu a pontuação média de 3.5 posicionando-a no $4^{\circ}$ nível da escala (ocupava a $6^{a}$ posição na escala original).

Quadro 5: Pontuação atribuida por 10 especialistas às formas adotadas pelos idosos para compensar dificuldades. Instrumento CICAc $1^{a}$ versão grupal.

\begin{tabular}{|c|c|c|c|c|c|c|c|c|c|c|c|c|c|c|}
\hline Item & $\begin{array}{c}\text { Juiz } \\
1\end{array}$ & $\begin{array}{c}\text { Juiz } \\
\mathbf{2}\end{array}$ & $\begin{array}{c}\text { Juiz } \\
\mathbf{3}\end{array}$ & $\begin{array}{c}\text { Juiz } \\
4\end{array}$ & $\begin{array}{c}\text { Juiz } \\
5\end{array}$ & $\begin{array}{c}\text { Juiz } \\
6\end{array}$ & $\begin{array}{c}\text { Juiz } \\
7\end{array}$ & $\begin{array}{c}\text { Juiz } \\
8\end{array}$ & $\begin{array}{c}\text { Juiz } \\
9\end{array}$ & Juiz 10 & Total & $\begin{array}{c}\text { Médi } \\
\mathbf{a}\end{array}$ & $\begin{array}{c}\text { Median } \\
\text { a }\end{array}$ & Modal \\
\hline Mc & 3 & 1 & 1 & 2 & 1 & 2 & 1 & 1 & 1 & 3 & 16 & 1.6 & 1 & 1 \\
\hline Ma & 1 & 2 & 2 & 4 & 2 & 3 & 1 & 2 & 1 & 1 & 19 & 1.9 & 2 & 1 \\
\hline $\mathbf{D a}$ & 2 & 3 & 3 & 3 & 4 & 4 & 1 & 3 & 1 & 2 & 25 & 2.5 & 3 & 3 \\
\hline Fd & 4 & & 6 & 1 & 4 & 1 & 7 & 6 & 1 & 5 & 35 & 3.5 & 4 & 1 \\
\hline Su & 5 & 4 & 4 & 5 & 5 & 5 & 1 & 4 & 2 & 4 & 39 & 3.9 & 4 & 4 \\
\hline As & 6 & 5 & 5 & 6 & 6 & 6 & 7 & 5 & 4 & 6 & 56 & 5.6 & 6 & 6 \\
\hline Df & 7 & 6 & 7 & 7 & 7 & 7 & 7 & 7 & 7 & 7 & 69 & 6.9 & 7 & 7 \\
\hline
\end{tabular}

Legenda:

Mc: Encontrou um jeito mais fácil de fazer sozinho: Mudança Comportamental

Ma: Encontrou um jeito mais fácil de fazer sozinho: Mudança Ambiental

Da: Encontrou um jeito mais fácil de fazer sozinho: Dispositivo Auxiliar

Fd: Faz sozinho com dificuldade

Su: Alguém que ajude: supervisão

As: Alguém que ajude: assistência física direta

Df: Deixou de fazer

\section{Discussão}

Considero as críticas e sugestões à definição de termos pertinentes, uma vez que não foram definidos pelo pesquisador alguns dos termos e expressões empregados, foi somente dado exemplos. O consenso dos juízes aponta a necessidade de definirmos termos e conceitos empregados com absoluta clareza, contribuindo para a homogeneidade no processo de aplicação do instrumento e interpretação das informações.

O tópico definição de termos foi reapresentado com novo enunciado na $\mathbf{2}^{\mathbf{a}}$ versão grupal do Instrumento CICAc (ANEXO 1.5) a partir das sugestões dos 
especialistas e novamente julgado quanto ao seu conteúdo e enunciado, na $3^{\mathrm{a}}$ etapa do estudo Delphi.

Há que se observar ainda preocupação dos especialistas quanto à abrangência dos itens do instrumento a fim de que contemplem a diversidade de tipos de dificuldade (fatores associados às dificuldades). A busca por abrangência fundamenta-se no próprio objeto de atenção em terapia ocupacional, ou seja no desempenho funcional, que compreende basicamente, áreas e componentes do desempenho e seus aspectos contextuais (AOTA 1994). Ressalto ainda que a literatura gerontológica relaciona uma multiplicidade de fatores como associados à incapacidade funcional, basicamente de ordem biológica, comportamental, psicológica e social (BALTES e col. 1993; KANE 1993; STUCK e col. 1999; LITVOC E DERNTL 2002).

Em síntese, a $1^{\text {a }}$ versão grupal do Instrumento CICAc (ANEXO 1.4) alcançou elevado índice de aprovação, mas 10 juízes (66\%) - com ênfase para os mais experientes e com capacitação formal na área - tecem um ou mais comentários especialmente relacionados ao enunciado de algumas questões e tópicos e à organização dos itens no instrumento.

Os comentários sobre o tópico definição de termos foram de grande utilidade para a sua reformulação.

As sugestões dadas à organização dos itens $(22,5 \%)$ referem-se a mudanças na seqüência de questões e quadros, instruções para preenchimento e atribuição de códigos aos itens do instrumento. Essas sugestões foram incorporadas a $2^{\mathbf{a}}$ versão grupal do instrumento (ANEXO 1.5) uma vez que:

- Não implicam em mudanças no conteúdo e enunciados já aprovados pelos especialistas;

- Abreviam o tempo de aplicação do instrumento - fundamental quando se pensa em utilização de instrumentos em serviços de saúde pública;

- Facilitam o preenchimento do instrumento pelo T.O.e 
- Relacionam com maior precisão as respostas às questões, contribuindo para a tabulação e análise dos dados.

Sobre a escala ordinal, a ordem estabelecida pelos juízes para a sua construção e que reflete níveis de comprometimento funcional, corresponde às citações da literatura bem como o expresso em instrumentos específicos ou não de terapia ocupacional devendo compor a $2^{a}$ versão grupal do Instrumento CICAc (ANEXO 1.5) (TROMBY e SCOTT 1977; KATZ 1959; BARTHEL 1955; LAWTON e BRODY 1969; HILL 1998; CULLER 1998). 


\section{3. $\quad 3^{\text {a }}$ etapa do estudo Delphi}

Convidei os especialistas a opinar, confidencial e individualmente, sobre os seguintes tópicos da $2^{\mathbf{a}}$ versão grupal do Instrumento CICAc (ANEXO 1.5), resultantes da $2^{\mathrm{a}}$ etapa do estudo Delphi, quanto à propriedade e clareza :

- Definição de termos visto que foi considerado pelo conjunto dos especialistas apropriado em seu conteúdo mas sem clareza de enunciado, sofreu modificações e, portanto deverá ser julgado novamente em seu conteúdo e enunciado.

- Quadro 6. Três especialistas (20\%) consideram que as informações sobre atividades desejadas, fatores de inibição e formas imaginadas de realização devam ser levantadas em seqüência, uma logo após a outra, para evitar que a aplicação do instrumento se torne demorada e repetitiva. O Quadro 6 representa uma tentativa de agrupar todas essas informações logo após a aplicação das questões.

Os especialistas foram ainda convidados a construir uma escala ordinal ou rever a escala já construída, uma vez que para 5 (33\%) especialistas, esta solicitação passou desapercebida em etapa anterior. 


\section{Resultados finais}

Todos os itens e tópicos da $\mathbf{2}^{\mathbf{a}}$ versão grupal do Instrumento CICAc (ANEXO 1.5) foram aprovados em seu:

- Conteúdo: índice médio de aprovação de 93,3\% (com variação entre $80 \%$ e $100 \%)$;

- Enunciado: índice médio de aprovação de $86,7 \%$ (com variação entre $73,3 \%$ e $100,0 \%)$.

Quadro 6: Julgamento dos especialistas sobre a $2^{a}$ versão grupal Instrumento CICAc

\begin{tabular}{|c|c|c|c|c|c|c|}
\hline \multirow{3}{*}{$\begin{array}{c}\text { Questão por área de investigação } \\
\text { Arranjo doméstico e potencial rede de } \\
\text { suporte }\end{array}$} & \multicolumn{4}{|c|}{ Aprovada quanto ao } & \multicolumn{2}{|c|}{$\begin{array}{l}\text { Não julgada }= \\
\text { Alternativas } \\
\text { Sim E Não assinaladas ou } \\
\text { deixadas EM BRANCO }\end{array}$} \\
\hline & \multicolumn{2}{|c|}{ Conteúdo } & \multicolumn{2}{|c|}{ Enunciado } & \multirow{2}{*}{ Conteúdo } & \multirow{2}{*}{ Enunciado } \\
\hline & $\operatorname{sim}$ & Não & Sim & Não & & \\
\hline Questão 1 & $\begin{array}{c}15 \\
100 \%\end{array}$ & 0 & $\begin{array}{c}15 \\
100 \%\end{array}$ & 0 & & \\
\hline Questão 2 & $\begin{array}{c}13 \\
86,7 \%\end{array}$ & & $\begin{array}{c}13 \\
86,7 \%\end{array}$ & $\begin{array}{c}2 \\
13,3 \%\end{array}$ & $\begin{array}{c}2 \\
13,3 \%\end{array}$ & \\
\hline Questão 3 & $\begin{array}{c}14 \\
93,3 \%\end{array}$ & & $\begin{array}{c}14 \\
93,3 \%\end{array}$ & $\begin{array}{c}1 \\
6,7 \%\end{array}$ & $\begin{array}{c}1 \\
6,7 \%\end{array}$ & \\
\hline Questão 4 & $\begin{array}{c}14 \\
93,3 \% \\
\end{array}$ & & $\begin{array}{c}12 \\
80,0 \% \\
\end{array}$ & $\begin{array}{c}3 \\
20,0 \% \\
\end{array}$ & $\begin{array}{c}1 \\
6.7 \%\end{array}$ & \\
\hline Questão 5 & $\begin{array}{c}15 \\
100 \%\end{array}$ & 0 & $280,0 \%$ & $\begin{array}{c}3 \\
20,0 \%\end{array}$ & & \\
\hline Questão 6 & $\begin{array}{c}15 \\
100 \%\end{array}$ & 0 & $\begin{array}{c}14 \\
93,3 \%\end{array}$ & $\begin{array}{c}1 \\
6,7 \%\end{array}$ & & \\
\hline 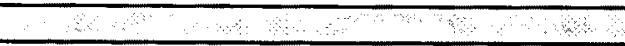 & Perf & ial & क & & $\mathrm{ser}$ & 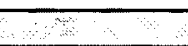 \\
\hline Questão 7 & $\begin{array}{c}15 \\
100 \% \\
\end{array}$ & 0 & $\begin{array}{c}14 \\
93.3 \% \\
\end{array}$ & $\begin{array}{c}1 \\
6,7 \% \\
\end{array}$ & & \\
\hline Questão 8 & $\begin{array}{c}15 \\
100,0 \% \\
\end{array}$ & 0 & $\begin{array}{c}12 \\
80,0 \% \\
\end{array}$ & $\begin{array}{c}3 \\
20,0 \% \\
\end{array}$ & & \\
\hline Questão 9 & $\begin{array}{c}15 \\
100 \% \\
\end{array}$ & 0 & $\begin{array}{c}14 \\
93,3 \%\end{array}$ & $\begin{array}{c}1 \\
6,7 \%\end{array}$ & & \\
\hline Questão 10 & $\begin{array}{c}13 \\
86,7 \% \\
\end{array}$ & $\begin{array}{c}2 \\
13,3 \% \\
\end{array}$ & $\begin{array}{c}11 \\
73,3 \% \\
\end{array}$ & $\begin{array}{c}4 \\
26,7 \% \\
\end{array}$ & & \\
\hline Questão 11 & $\begin{array}{c}15 \\
100 \% \\
\end{array}$ & 0 & $\begin{array}{c}14 \\
93.3 \% \\
\end{array}$ & $\begin{array}{c}1 \\
6.7 \%\end{array}$ & & \\
\hline Questão 12 & $\begin{array}{c}14 \\
93,3 \% \\
\end{array}$ & & $\begin{array}{c}13 \\
86,7 \% \\
\end{array}$ & $\begin{array}{c}1 \\
6,7 \% \\
\end{array}$ & $\begin{array}{c}1 \\
6,7 \% \\
\end{array}$ & $\begin{array}{c}1 \\
6,7 \% \\
\end{array}$ \\
\hline $8 \mathrm{n}$ & Univer & cupacio & & & 8 & 4 \\
\hline Questão 13 & $\begin{array}{c}15 \\
100 \% \\
\end{array}$ & 0 & $\begin{array}{c}13 \\
86,7 \% \\
\end{array}$ & $\begin{array}{c}2 \\
13,3 \%\end{array}$ & & \\
\hline Questão 14 & $\begin{array}{c}14 \\
93.3 \% \\
\end{array}$ & 0 & $\begin{array}{c}12 \\
80,0 \% \\
\end{array}$ & $\begin{array}{c}2 \\
13,3 \% \\
\end{array}$ & $\begin{array}{c}1 \\
6,7 \% \\
\end{array}$ & $\begin{array}{c}1 \\
6,7 \% \\
\end{array}$ \\
\hline Questão 15 & $\begin{array}{c}15 \\
100 \% \\
\end{array}$ & 0 & $\begin{array}{c}13 \\
86,7 \% \\
\end{array}$ & $\begin{array}{c}2 \\
13,3 \% \\
\end{array}$ & & \\
\hline Questão 16 & $\begin{array}{c}15 \\
100 \% \\
\end{array}$ & 0 & $\begin{array}{c}14 \\
93,3 \% \\
\end{array}$ & $\begin{array}{c}1 \\
6,7 \% \\
\end{array}$ & & \\
\hline Questão 17 & $\begin{array}{c}15 \\
100 \% \\
\end{array}$ & 0 & $\begin{array}{c}12 \\
80.0 \% \\
\end{array}$ & $\begin{array}{c}3 \\
20,0 \% \\
\end{array}$ & & \\
\hline Quadrol & $\begin{array}{c}15 \\
100 \% \\
\end{array}$ & 0 & $\begin{array}{c}13 \\
86,7 \% \\
\end{array}$ & $\begin{array}{c}2 \\
13.3 \% \\
\end{array}$ & & \\
\hline
\end{tabular}




\begin{tabular}{|c|c|c|c|c|c|c|}
\hline Quadro 2 & $\begin{array}{c}15 \\
100 \%\end{array}$ & 0 & $\begin{array}{c}14 \\
93.3 \% \\
\end{array}$ & $\begin{array}{c}1 \\
6,7 \% \\
\end{array}$ & & \\
\hline Quadro 3 & $\begin{array}{c}15 \\
100 \%\end{array}$ & 0 & $\begin{array}{c}14 \\
93,3 \%\end{array}$ & $\begin{array}{c}1 \\
6,7 \%\end{array}$ & & \\
\hline Quadro 4 & $\begin{array}{c}15 \\
100 \% \\
\end{array}$ & 0 & $\begin{array}{c}14 \\
93,3 \% \\
\end{array}$ & $\begin{array}{c}1 \\
6,7 \% \\
\end{array}$ & & \\
\hline \multicolumn{7}{|c|}{ Area: capacidade funcional } \\
\hline 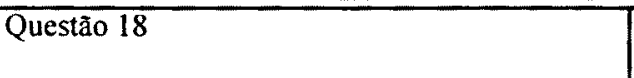 & $\begin{array}{c}13 \\
86.7 \%\end{array}$ & $\begin{array}{c}2 \\
13.3 \%\end{array}$ & $\begin{array}{c}15 \\
100 \%\end{array}$ & 0 & & \\
\hline Questão 19 & $\begin{array}{c}14 \\
93,3 \%\end{array}$ & $\begin{array}{c}1 \\
6,7 \% \\
\end{array}$ & $\begin{array}{c}14 \\
93,3 \%\end{array}$ & $\begin{array}{c}1 \\
6,7 \% \\
\end{array}$ & & \\
\hline Questão 20 & $\begin{array}{c}15 \\
100 \%\end{array}$ & 0 & $\begin{array}{c}14 \\
93,3 \%\end{array}$ & $\begin{array}{c}1 \\
6.7 \%\end{array}$ & & \\
\hline Quadro 5 & $\begin{array}{c}15 \\
100 \%\end{array}$ & 0 & $\begin{array}{c}13 \\
86.7 \%\end{array}$ & $\begin{array}{c}2 \\
13.3 \%\end{array}$ & & \\
\hline Questão 21 & $\begin{array}{c}14 \\
93,3 \%\end{array}$ & $\begin{array}{c}1 \\
6,7 \%\end{array}$ & $\begin{array}{c}12 \\
80,0 \%\end{array}$ & $\begin{array}{c}3 \\
20,0 \%\end{array}$ & & \\
\hline Questão 22 & $\begin{array}{c}13 \\
86,7 \%\end{array}$ & $\begin{array}{c}2 \\
13,3 \%\end{array}$ & $\begin{array}{c}13 \\
86,7 \%\end{array}$ & $\begin{array}{c}2 \\
13,3 \%\end{array}$ & & \\
\hline Quadro 6 & $\begin{array}{c}13 \\
86,7 \%\end{array}$ & $\begin{array}{c}2 \\
13.3 \%\end{array}$ & $\begin{array}{c}13 \\
86,7 \%\end{array}$ & $\begin{array}{c}2 \\
13,3 \%\end{array}$ & & \\
\hline Questão 23 & $\begin{array}{c}12 \\
80.0 \%\end{array}$ & $\begin{array}{c}3 \\
20.0 \%\end{array}$ & $\begin{array}{c}12 \\
80,0 \%\end{array}$ & $\begin{array}{c}3 \\
20.0 \%\end{array}$ & & \\
\hline Quadro 7 & $\begin{array}{c}12 \\
80,0 \%\end{array}$ & $\begin{array}{c}2 \\
13.3 \%\end{array}$ & $\begin{array}{c}13 \\
86,7 \%\end{array}$ & $\begin{array}{c}1 \\
6,7 \%\end{array}$ & $\begin{array}{c}1 \\
6,7 \%\end{array}$ & $\begin{array}{c}1 \\
6,7 \%\end{array}$ \\
\hline $\begin{array}{l}\text { Quadro: Registro de atividades desejadas, } \\
\text { dos "porquês" o idoso não faz e se imagina } \\
\text { algum jeito de vir a fazêtas * }\end{array}$ & $\begin{array}{c}13 \\
86,7 \%\end{array}$ & $\begin{array}{c}2 \\
13,3 \%\end{array}$ & $\begin{array}{c}13 \\
86,7 \%\end{array}$ & 22 & & \\
\hline $\begin{array}{l}\text { Orientações gerais para aplicação do } \\
\text { Instrumento }\end{array}$ & $\begin{array}{c}12 \\
80 \%\end{array}$ & $\begin{array}{c}1 \\
6,7 \%\end{array}$ & $\begin{array}{c}11 \\
73,3 \%\end{array}$ & $\begin{array}{c}2 \\
13,3 \%\end{array}$ & $\begin{array}{c}2 \\
13,3 \%\end{array}$ & $\begin{array}{c}2 \\
13,3 \%\end{array}$ \\
\hline Definição de Termos * & $\begin{array}{c}13 \\
86,7 \%\end{array}$ & $\begin{array}{c}2 \\
13,3 \%\end{array}$ & $\begin{array}{c}12 \\
80 \%\end{array}$ & $\begin{array}{c}2 \\
13.3 \%\end{array}$ & & $\begin{array}{c}1 \\
6,7 \%\end{array}$ \\
\hline
\end{tabular}

* julgados em etapa anterior (3" etapa do Estudo)

\section{A construção da escala ordinal}

Nesta etapa a totalidade dos juizes (15) construiu a escala. A pontuação média que cada categoria recebeu as posicionou na mesma ordem estabelecida pelos especialistas em etapa anterior.

Quadro 7: Pontuação atribuida por 15 especialistas às formas adotadas pelos idosos para compensar dificuldades. Instrumento CICAc $2^{a}$ versão grupal.

\begin{tabular}{|c|c|c|c|c|c|c|c|c|c|c|c|c|c|c|c|c|c|c|}
\hline Itens & 1 & 2 & 3 & 4 & 5 & 6 & 7 & 8 & 9 & 10 & 11 & 12 & 13 & 14 & 15 & Média & Mediana & Modal \\
\hline $\mathrm{MC}$ & 1 & 7 & 1 & 1 & 1 & 1 & 1 & 1 & 2 & 1 & 2 & 3 & 1 & 3 & 3 & 1,9 & $\mathrm{I}$ & 1 \\
\hline $\mathbf{M A}$ & $\overline{3}$ & 7 & 2 & 3 & 2 & 2 & 2 & 2 & 1 & 2 & 3 & 1 & 2 & 1 & 2 & 2,4 & 2 & 2 \\
\hline$\overline{\mathbf{D A}}$ & 2 & 7 & 3 & 2 & 3 & 3 & 3 & 3 & 2 & 3 & 1 & 2 & 3 & 2 & 1 & 2,6 & 3 & 3 \\
\hline FD & 4 & 6 & 4 & 4 & 4 & 4 & 4 & 4 & 1 & 4 & 4 & 4 & 4 & 4 & 4 & 3,9 & 4 & 4 \\
\hline $\mathrm{SU}$ & 5 & 5 & 5 & 5 & 5 & 5 & 5 & 5 & 3 & 5 & 5 & 5 & 5 & 5 & 1 & 4.6 & 5 & 5 \\
\hline AS & 6 & & 6 & 6 & 6 & 6 & 6 & 6 & 4 & 6 & 6 & 6 & 6 & 6 & 2 & 5.6 & 6 & 6 \\
\hline$\overline{\mathbf{D F}}$ & 7 & 1 & 7 & 7 & 7 & 7 & 7 & 7 & 7 & 7 & 7 & 7 & 7 & 7 & 3 & 6,3 & 7 & 7 \\
\hline
\end{tabular}

\section{Legenda}

MC: Encontrou um jeito mais fácil de fazer Mudança Comportamental

MA: Encontrou um jeito mais fácil de fazer Mudança Ambiental

DA: Encontrou um jeito mais fácil de fazer Dispositivo Auxiliar

FD: Faz com dificuldade

SU: Alguém que ajude: supervisão

AS : Alguém que ajude: assistência física direta

DF: Deixou de fazer 
Ainda bastante relevante à qualidade do processo, são alguns comentários expressos por parte dos especialistas (6) quando questionados sobre como se sentiram durante o estudo (ANEXO 2.6). Os especialistas se sentiram valorizados por poder contribuir com a elaboração de um instrumento na área de T.O e satisfeitos com o resultado do trabalho, conforme expresso nestas falas:

"construindo um instrumento junto com a pesquisadora me senti importante, valorizado"

"acho válido e importante termos um instrumento destes que também poderá ser aplicado em consultório"

Um especialista considerou ainda que o estudo possibilitou a ele rever condutas terapêuticas adotadas em sua prática diária.

Sobre a percepção da atuação da pesquisadora, os 6 (seis) especialistas em conjunto a consideraram ética, alerta, interessada, compreensiva, flexível e cuidadosa, ao justificar as modificações a serem feitas e aquelas que não caberiam no momento. Tranqüila, aberta, clara, extremamente séria em sua pesquisa, preocupada com a fidedignidade dos dados, conduzindo o processo com as exigências e o rigor necessário.

\section{Discussão}

Considero que o emprego da técnica Delphi em 3 etapas, tenha conferido ao produto final - $3^{a}$ versão grupal do Instrumento CICAc (ANEXO 1.6) - validade de conteúdo, visto que a quantidade de informantes foi mantida ao longo do processo e o índice de aprovação para a totalidade dos itens que compõe o instrumento ficou bem acima do estabelecido como satisfatório e de concordância ( $70 \%)$.

Os resultados finais foram enviados, pelo correio, aos 15 especialistas. Nessa correspondência procuro enfatizar que o produto resultante do estudo Delphi $-\mathbf{3}^{\mathbf{a}}$ versão grupal do Instrumento CICAc (ANEXO 1.6) já pode ser aplicado por todos 
nós, embora outros testes formais deverão ser conduzidos ainda como parte do projeto de doutorado.

Ainda nesta mesma correspondência lanço proposta de encontro entre especialistas (ANEXO 2.7) com as finalidades de nos conhecermos pessoalmente, iniciarmos troca de experiências profissionais especialmente com idosos, e discutirmos questões referentes à adoção do Instrumento CICAc entre outros instrumentos, na prática clinica e de pesquisa. Vale ressaltar que dois especialistas expressam, em momentos anteriores do estudo, o desejo de conhecer os T.Os que participaram do júri de especialistas. Os seis especialistas que responderam a essa correspondência concordaram com o encontro, informando suas disponibilidades.

Após a conclusão da avaliação da confiabilidade do Instrumento CICAc, enviarei um novo convite aos 15 especialistas para encontro no qual pretendo apresentar os resultados desse estudo e atender as demais finalidades já mencionadas acima.

Figura 1: Produto resultante do estudo Delphi em três etapas

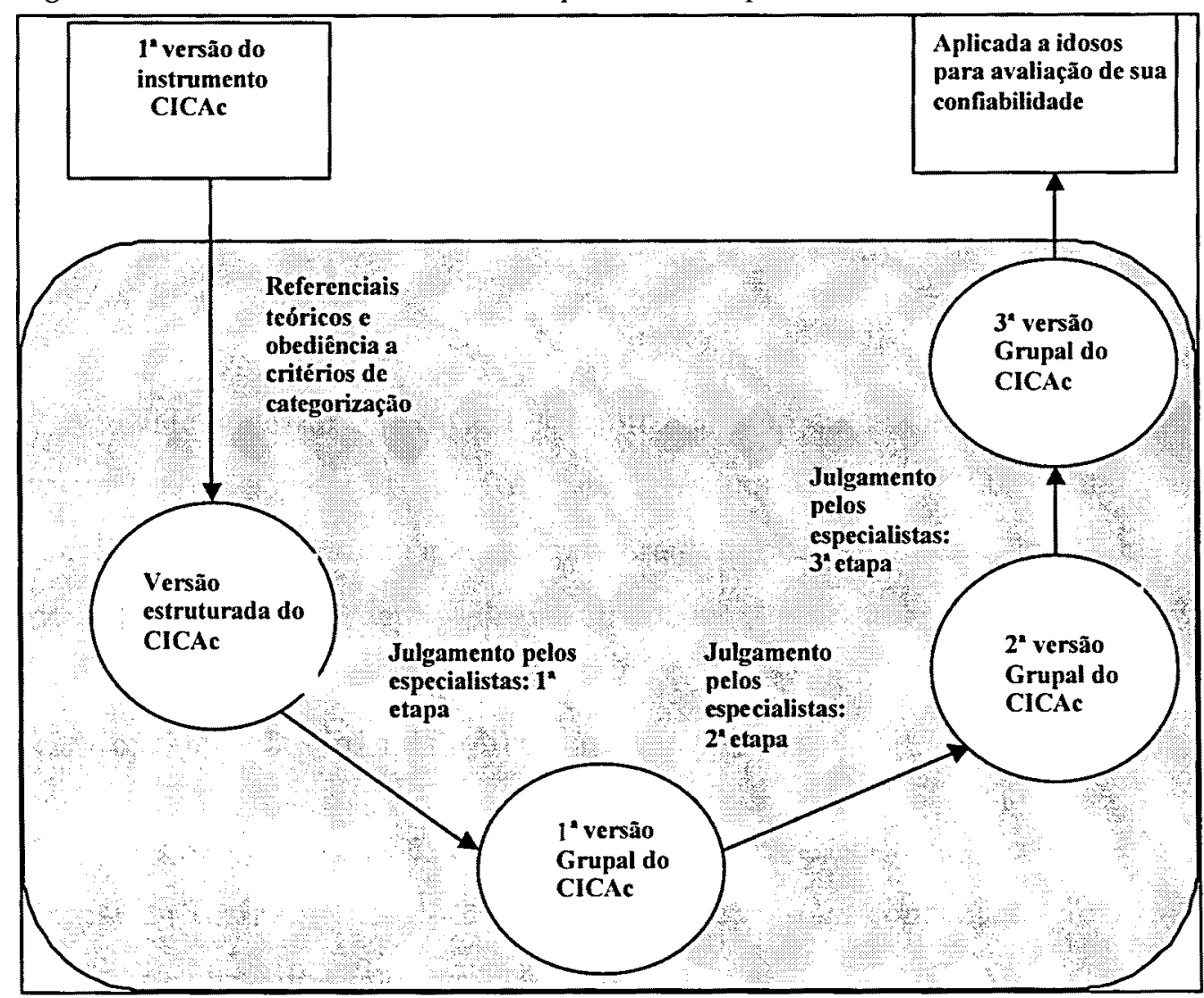




\section{RESULTADOS E DISCUSSÃO: AVALIAÇÃO DE CONFIABILIDADE}

Conforme descrito no MÉTODO, além da $3^{\mathbf{a}}$ versão grupal do Instrumento CICAc (ANEXO 1.6), foi aplicado na primeira entrevista aos idosos o Teste do relógio [Clock Completion Test- CCT] para avaliar sua capacidade cognitiva. Considerações sobre o teste serão apresentadas no ANEXO 2.8, termo de consentimento e protocolo de aplicação para o mesmo, nos ANEXOS 2.9 e 2.10. O desempenho nesse teste foi utilizado como critério de inclusão/exclusão para participação no estudo.

\subsection{Resultados da aplicação do CCT}

O teste foi aplicado antes da aplicação do Instrumento CICAc, mas no mesmo dia, dado a rapidez e praticidade de aplicação. $\mathrm{O}$ círculo em papel foi entregue ao idoso, sugerido a ele que o imaginasse como um relógio e o completasse somente com números, não se preocupando com a confecção dos ponteiros. $O$ idoso poderia usar o tempo que julgasse necessário para a realização do teste procurando entretanto evitar rasuras. Houve boa receptividade ao teste pelos idosos em geral e ele foi concluído em média em um minuto. Somente uma idosa recusourse em realizá-lo pois estava sem óculos e uma idosa obteve resultado insatisfatório no mesmo.

Vale enfatizar que o CCT foi utilizado com critério de inclusão/exclusão em pesquisa com população idosa desenvolvida por DOIMO (2003), com resultados semelhantes. Neste estudo a autora procura descrever a estruturação da vida diária de idosas a partir do recordatório dessas atividades pelas entrevistadas.

\subsection{Considerações iniciais sobre a análise estatística}

As análises, tanto da estabilidade quanto da consistência interna da $3^{\mathbf{a}}$ versão grupal do Instrumento CICAc (ANEXO 1.6), foram conduzidas por LIMA e col. (2003) membros do Centro de Estatística Aplicada da USP (CEA-USP) 
Antes da análise estatística propriamente dita foi necessário realizar uma série de agrupamentos de respostas a fim de possibilitar uma análise com um menor número de combinações de respostas possíveis. Segundo LIMA e col. (2003) "caso isso não fosse feito, a análise se tornaria praticamente inviável, pois o número de indíviduos amostrados seria muito pequeno para todas as opções de resposta"(p.20). O agrupamento de respostas será apresentado nos quadros de 8 a 13.

Corroborando com LIMA e col. (2003), admito que ao longo de sua elaboração e validação de conteúdo, junto à população e ao júri de especialistas, o Instrumento CICAc tornou-se complexo e abrangente reunindo uma amostra de itens relevante para os distintos domínios. Considero que o instrumento resultante tornouse apropriado para estudo de casos ao admitir a complexidade do objeto a ser avaliado.

A dificuldade em delimitar e em compreender qualquer processo ou objeto foi descrita por GIL (1995b). Segundo o autor a coleta de dados no estudo de caso é feita habitualmente mediante diversos procedimentos tais como observação, realização de entrevistas e obtenção de histórias de vida.

Embora considere a necessidade de coletar informações provenientes de várias fontes (LODI 1991; BENNETT 1999) acredito que a $\mathbf{3}^{\mathbf{a}}$ versão grupal do Instrumento CICAc (ANEXO 1.6) poderá reunir informações úteis, reduzindo a necessidade de uma combinação de questionários e formulários, que poderão dificultar ao terapeuta a interpretação e integração de resultados, conforme descrito na introdução desse trabalho.

Essa qualidade do instrumento traz outras vantagens como permitir ao terapeuta ocupacional obter informações detalhadas sobre o idoso, considerá-lo como um caso específico e apoiar, em conjunto com outras informações, o processo terapêutico além de oferecer ao idoso a oportunidade de refletir sobre seu 
autocuidado ou seja refletir sobre sua situação atual e possibilidades para modificá-la (SMITH 1998).

Se, por um lado, a aplicação da $3^{\mathbf{a}}$ versão grupal do Instrumento CICAc (ANEXO 1.6) traz as vantagens mencionadas, por outro lado, demanda um longo tempo de aplicação (cerca de uma hora), especialmente se considerarmos a rotina de uma unidade básica de saúde. Ainda que possa ser aplicado por módulos reduzindo o tempo e as exigências de aplicação, especialmente para o idoso, a $3^{\mathbf{a}}$ versão grupal do Instrumento CICAc (ANEXO 1.6) não permite a classificação de idosos quanto à capacidade para o autocuidado uma vez que ao detalhar o caso o tornará único e especifico.

A fim de possibilitar a análise estatística das informações e ainda para que o Instrumento CICAc possa classificar os idosos, de forma mais sucinta e simplificada, conforme qualidades previstas para o instrumento (ALMEIDA 1997) realizei agrupamentos de respostas.

Os agrupamentos foram feitos para a totalidade das questões do instrumento pertencentes às áreas: Universo Ocupacional e Capacidade Funcional, uma vez que essas áreas concentram um grande número de itens e ainda pela possibilidade de agrupamentos desses itens, sem perda de informações consideradas essenciais para o conhecimento do universo ocupacional do idoso e sua capacidade para o autocuidado para as atividades diárias. 
Quadro 8: Agrupamento de respostas às questões 13 e $14.3^{a}$ versão grupal do CICAc

\begin{tabular}{|c|c|c|}
\hline Questões ou ite ns & Agrupamento & $\begin{array}{l}\text { Considerações } \\
\text { teóricas/práticas }\end{array}$ \\
\hline \multicolumn{3}{|c|}{ Atividades cotidianas que faz todos os dias e que faz de vez em quando } \\
\hline $\begin{array}{l}\text { 13. O que o idoso faz todos os dias } \\
\text { 14. O que o idoso faz de vez em quando }\end{array}$ & $\begin{array}{l}13+14 \text { (questões } 13 \text { e } 14 \\
\text { representam, em conjunto, tentativa } \\
\text { de tornar o levantamento de } \\
\text { atividades cotidianas exaustivo) }\end{array}$ & $\begin{array}{l}\text { OREM (1991), MEYER (1922), } \\
\text { KEITH (1995), HORGAS (1998) } \\
\text { admitem a complexidade da vida } \\
\text { diária e salientam que o } \\
\text { equilibrio entre as diversas } \\
\text { atividades é fundamental para a } \\
\text { saúde e qualidade de vida. }\end{array}$ \\
\hline \multicolumn{3}{|c|}{ Lazer } \\
\hline $\begin{array}{l}\text { Caminhar (26)/ Dançar (31)/ Praticar } \\
\text { esporte (44) }\end{array}$ & \begin{tabular}{|l} 
Atividades de lazer com \\
predomínio de interesse físico
\end{tabular} & \multirow{7}{*}{$\begin{array}{l}\text { Segundo critérios de análise de } \\
\text { atividades, as atividades de lazer } \\
\text { podem ser classificadas de } \\
\text { acordo com o interesse } \\
\text { predominante do individuo para } \\
\text { se engajar na mesma, como } \\
\text { interesses artísticos, intelectuais, } \\
\text { manuais, fisicos e sociais. }\end{array}$} \\
\hline $\begin{array}{l}\text { Bordado/tricô/crochê (25)/ Cuidar de } \\
\text { plantas (29)/Costurar (46) }\end{array}$ & $\begin{array}{l}\text { Atividades de lazer com } \\
\text { predomínio de interesse manual }\end{array}$ & \\
\hline Leituras (39)/Participar de cursos (41) & $\begin{array}{l}\text { Atividades de lazer com } \\
\text { predomínio de interesse intelectual }\end{array}$ & \\
\hline $\begin{array}{l}\text { Conversar com amigos/sair com amigos } \\
\text { (28)/ Fazer visitas a familiares } \\
\text { (34)/Fazer visitas a doentes (35)/Jogar } \\
\text { (jogos de salão) (38)/ Participar de } \\
\text { grupos (42)/Viajar (45)/ Passear (46) }\end{array}$ & $\begin{array}{l}\text { Atividades de lazer com } \\
\text { predominio de interesse social }\end{array}$ & \\
\hline $\begin{array}{l}\text { Fazer orações }(32) / \text { Ir a missa ou } \\
\text { reunião religiosa (36)/ }\end{array}$ & \begin{tabular}{|l} 
Atividades de lazer com \\
predomínio de interesse religioso
\end{tabular} & \\
\hline $\begin{array}{l}\text { Cantar (27)/Ir ao cinema/teatro (37)/ } \\
\text { Pintar (43) }\end{array}$ & $\begin{array}{l}\text { Atividades de lazer com } \\
\text { predomínio de interesse artístico }\end{array}$ & \\
\hline $\begin{array}{l}\text { Assistir televisão (24)/Cuidar de } \\
\text { pequenos animais (30)/ Fazer pequenos } \\
\text { consertos em casa } \\
\text { música/rádio (40) } \\
\end{array}$ & $\begin{array}{l}\text { Atividades de lazer com interesses } \\
\text { diversos }\end{array}$ & \\
\hline \multicolumn{3}{|c|}{ Trabalho remunerado } \\
\hline Informal (47) & Informal & \multirow{5}{*}{$\begin{array}{l}\text { Considerando resultados do } \\
\text { teste-reteste }\end{array}$} \\
\hline $\begin{array}{l}\text { Cargo técnico ou } \\
\text { administrativo/profissão liberal (48) }\end{array}$ & $\begin{array}{ll}\text { Cargo } & \text { técnico } \\
\text { administrativo/profissão liberal }\end{array}$ & \\
\hline Empregada doméstica (49) & \multirow[t]{3}{*}{ Outro: especifique } & \\
\hline Operário (50) & & \\
\hline Outro: especifique (51) & & \\
\hline \multicolumn{3}{|c|}{ Atividades instrumentais de vida diária } \\
\hline $\begin{array}{l}\text { Pequenas compras (14) } \\
\text { Grandes compras (de mês) (15) }\end{array}$ & $\begin{array}{l}\text { Pequenas compras }+ \text { Grandes } \\
\text { compras }\end{array}$ & $\begin{array}{l}\text { Baseada em leituras de alguns } \\
\text { instrumentos com validade } \\
\text { indicada }\end{array}$ \\
\hline $\begin{array}{l}\text { Tarefas domésticas (limpeza pesada) } \\
\text { (17) } \\
\text { Tarefas domésticas (manutenção da } \\
\text { limpeza da casa) (18) }\end{array}$ & $\begin{array}{l}\text { Tarefas domésticas } \text { (limpeza } \\
\text { pesada) + Tarefas domésticas } \\
\text { (manutenção da limpeza da casa) }\end{array}$ & \\
\hline $\begin{array}{l}\text { Lavar roupas (19) } \\
\text { Passar roupas (20) }\end{array}$ & Lavar roupas + Passar roupas & \\
\hline $\begin{array}{l}\text { Tomar medicamentos } \\
\text { receitados (21) } \\
\text { Comparecer as consultas ou outros } \\
\text { tratamentos (22) }\end{array}$ & $\begin{array}{l}\text { Tomar medicamentos conforme } \\
\text { receitados }+ \text { Comparecer as } \\
\text { consultas ou outros tratamentos }\end{array}$ & \\
\hline
\end{tabular}


Quadro 9: Agrupamento de respostas à questão 15.1: "Porque as atividades são importantes"? (a que necessidades elas estão relacionadas). $3^{a}$ versão grupal do CICAc

\begin{tabular}{|c|c|c|}
\hline Itens & Agrupamento & Considerações teóricas e práticas \\
\hline Trazem prazer & \multirow[t]{10}{*}{ Satisfação pessoal } & \multirow{16}{*}{$\begin{array}{l}\text { As classificações das necessidades } \\
\text { humanas descritas OREM (1991) e } \\
\text { MASLOW (1987) }\end{array}$} \\
\hline Mantêm as pessoas ativas & & \\
\hline Distraem & & \\
\hline Ocupam o tempo & & \\
\hline Mantém pessoa atualizada & & \\
\hline Alimentam a vaidade & & \\
\hline Diminuem a solidão e a carência afetiva & & \\
\hline Trazem satisfação espiritual & & \\
\hline Trazem oportunidade de descansar & & \\
\hline Mantém a privacidade & & \\
\hline Promovem senso de utilidade & \multirow[t]{2}{*}{ Responsabilidade social } & \\
\hline desempenham comportamentos esperados & & \\
\hline São benéficas à saúde física e/ou mental & \multirow{3}{*}{$\begin{array}{l}\text { Prevenção de riscos a vida, ao } \\
\text { funcionamento e } \\
\text { desenvolvimento }\end{array}$} & \\
\hline Estimulam o exercício da independência & & \\
\hline Estão relacionadas com a sobrevivência & & \\
\hline Outras razões : Especifique & Outras & \\
\hline
\end{tabular}

Quadro 10: Agrupamento de respostas às questões 16.1. $3^{a}$ versão grupal do CICAc

\begin{tabular}{|l|l|}
\hline \multicolumn{1}{|c|}{ Itens } & \\
\hline Acima das capacidades do idoso & Intrínsecas \\
\hline Não atende as necessidades do idoso & \\
\hline Realizada em condições adversas & Extrínsecas \\
\hline Outras & Outras \\
\hline
\end{tabular}

Quadro 11: Agrupamento de respostas às questões 17,18,19. $3^{a}$ versão grupal do CICAc

\begin{tabular}{|c|c|c|}
\hline \multicolumn{3}{|c|}{ Tipos de dificuldade } \\
\hline Itens & Agrupamento & $\begin{array}{c}\text { Considerações teóricas e } \\
\text { práticas }\end{array}$ \\
\hline $\begin{array}{l}\text { Tipos de dificuldade: Física, Sensorial, Cognitiva, } \\
\text { Emocional e Restrições clínicas }\end{array}$ & $\begin{array}{l}\text { Fatores Biológicos } \\
\text { comportamentais }\end{array}$ & $\begin{array}{l}\text { A capacidade funcional é } \\
\text { produto de: fatores }\end{array}$ \\
\hline $\begin{array}{l}\text { Tipos de dificuldade: Social, Econômica, Cultural } \\
\text { (entre outros) e relativas ao ambiente físico }\end{array}$ & $\begin{array}{l}\text { Fatores do ambiente social e } \\
\text { físico }\end{array}$ & $\begin{array}{lrr}\text { intrínsecos } & \text { do } & \text { cliente } \\
\text { (biológicos } & & \mathrm{e}\end{array}$ \\
\hline Outros tipos de dificuldade & Outros fatores & $\begin{array}{l}\text { comportamentais), cuidados } \\
\text { (formais e informais) e } \\
\text { ambiente(fisico, psicológico } \\
\text { e social). KANE (1993) }\end{array}$ \\
\hline \multicolumn{3}{|c|}{ Formas de compensação às dificuldades } \\
\hline & Não apresenta dificuldade & \multirow{8}{*}{$\begin{array}{l}\text { TROMBLY e SCOTT (1997) } \\
\text { adotam níveis semelhantes, } \\
\text { atribuídos a cada atividade } \\
\text { O idoso "não apresenta } \\
\text { dificuldade" se não citou } \\
\text { dificuldade para a atividade } \\
\text { fazendo ela parte do seu } \\
\text { universo ocupacional. }\end{array}$} \\
\hline Compensa com Modificação Comportamental & \multirow{3}{*}{$\begin{array}{l}\text { apresenta dificuldade } \\
\text { compensa com uma ou mais } \\
\text { estratégias }\end{array}$} & \\
\hline Compensa com Dispositivo Auxiliar & & \\
\hline Compensa com Modificação Ambiental & & \\
\hline Faz com dificuldade & $\begin{array}{llll}\begin{array}{l}\text { apresenta } \\
\text { dificuldade }\end{array} & \text { faz } & \text { com } \\
\end{array}$ & \\
\hline Faz com ajuda - supervisão & \multirow{2}{*}{$\begin{array}{ll}\text { apresenta dificuldade } \\
\text { compensa com ajuda }\end{array}$} & \\
\hline Faz com ajuda - assistência física direta & & \\
\hline Deixa de fazer & $\begin{array}{l}\text { apresenta dificuldade - } \\
\text { deixa de fazer }\end{array}$ & \\
\hline
\end{tabular}

Quadro 12: Agrupamento de respostas às questões 20,21. $3^{a}$ versão grupal do CICAc

\begin{tabular}{|l|l|l|}
\hline \multicolumn{1}{|c|}{ Itens } & \multicolumn{1}{|c|}{ Agrupamento } & \multicolumn{1}{c|}{ Considerações teóricas e práticas } \\
\hline Modificação Comportamental & Sozinho & \\
\cline { 1 - 1 } Dispositivo Auxiliar & & $\begin{array}{l}\text { Instrumento como de TROMBLY e SCOTT (1977) } \\
\text { propõe níveis semelhantes de capacidade funcional }\end{array}$ \\
\cline { 1 - 1 } Modificação Ambiental & & \\
\cline { 1 - 2 } Ajuda de alguém & Ajuda de alguém & \\
\hline Outra forma & Outra forma & \\
\hline
\end{tabular}


Quadro 13: Categorias utilizadas para as formas imaginadas de realizar as atividades desejadas.

\begin{tabular}{|l|l|}
\hline \multicolumn{1}{|c|}{ Formas imaginadas de realizar as atividades desejadas } & \multicolumn{1}{|c|}{ Consideraçōes teóricas e práticas } \\
\hline Instituição que ofereça & $\begin{array}{l}\text { Categorias estabelecidas a partir dos resultados do } \\
\text { teste }\end{array}$ \\
\hline Tempo Livre & \\
\hline Mudança de comportamento & \\
\hline Recursos financeiros & \\
\hline Ajuda de alguém &
\end{tabular}

Os agrupamentos de respostas possibilitaram a elaboração de uma versão sucinta e simplificada da $3^{\mathrm{a}}$ versão grupal do istrumento CICAc a qual denominei Versão simplificada do Instrumento CICAc a ser apresentada no capítulo 6: Considerações finais sobre a validação do Instrumento CICAc)

Com base nesta versão simplificada foram realizadas as análises de estabilidade e consistência interna do Instrumento.

\subsection{Análise de estabilidade}

Os resultados, tanto da análise de estabilidade quanto da consistência interna do Instrumento CICAc são da autoria de LIMA e col. (2003) e serão apresentados, em síntese, a seguir.

Para a realização da análise de concordância entre as respostas do teste e do reteste adotourse o coeficiente Kappa, medida adequada para grande parte das variáveis presentes no instrumento, ou seja variáveis nominais. Para as variáveis ordinais adotourse o coeficiente Kappa ponderado, uma vez que esse coeficiente privilegia as classificações que possam ser discordantes porém próximas.

Para discutir os graus de concordância, LIMA e col. (2003) utilizourse o critério sugerido em STOKES e col. (1995) segundo o qual para valores de Kappa:

- abaixo de 0,4 a concordância é considerada fraca;

- entre 0,4 e 0,8 a concordância é considerada moderada e

- acima de 0,8 a concordância é considerada excelente.

Segundo o critério adotado, grande parte das medidas calculadas obteve concordância de moderada à excelente, já que $60,14 \%$ são maiores que 0,8 e apenas $7,17 \%$ são menores ou iguais a 0,4 . 
Tabela 8: Medidas resumo para os coeficientes Kappa obtidos na análise de estabilidade. Instrumento CICAC.2003

\begin{tabular}{ccccccccc}
\hline & \multicolumn{1}{c}{ Medidas Resumo } \\
\cline { 2 - 9 } & $\mathbf{N}$ & Média & Mediana & DP & Mínimo & Máximo & Q1 & Q3 \\
\hline \multirow{2}{*}{ Kappa } & 248 & 0,80 & 1,00 & 0,27 & $-0,09$ & 1,00 & 0,65 & 1,00 \\
\hline
\end{tabular}

LIMA e col. Relatório de análise estatística sobre o projeto "Validação do Instrumento CICAc (Classificação de Idosos quanto à Capacidade para o Autocuidado)" São Paulo, IME-USP, 2003.

Ao analisar os dados da Tabela 8, verificourse que, em média, o coeficiente Kappa foi alto, uma vez que $75 \%$ dos coeficientes calculados foram superiores a 0,65 e mais de $50 \%$ deles foi igual a um, indicando uma concordância perfeita. $\mathrm{O}$ menor valor dos coeficientes calculados foi de $-0,09$. Outros valores muito baixos foram obtidos, no entanto, quando se observa as tabelas de freqüência correspondentes não se nota grande discordância das respostas. Como exemplo cito a tabelas 9 e 10 .

Tabela 9: Concordância entre teste e reteste para a questão 5-Grau de satisfação do idoso com a relação que mantém com os amigos. Instrumento CICAc, 2003.

\begin{tabular}{|c|c|c|c|c|c|}
\hline \multirow[b]{2}{*}{ Teste } & \multicolumn{4}{|c|}{ Reteste } & \multirow[b]{2}{*}{ Total } \\
\hline & $\begin{array}{c}\text { Muito } \\
\text { Satisfeito }\end{array}$ & Satisfeito & Insatisfeito & $\begin{array}{c}\text { Muito } \\
\text { Insatisfeito }\end{array}$ & \\
\hline Muito Satisfeito & 4 & 9 & 0 & 0 & 13 \\
\hline Satisfeito & 4 & 11 & 0 & 0 & 15 \\
\hline Insatisfeito & 0 & 0 & 0 & 0 & 0 \\
\hline Muito Insatisfeito & 0 & 0 & 0 & 0 & 0 \\
\hline Total & 8 & 20 & 0 & 0 & 28 \\
\hline
\end{tabular}

LIMA e col. Relatório de análise estatística sobre o projeto "Validação do Instrumento CICAc (Classificação de Idosos quanto à Capacidade para o Autocuidado)" São Paulo, IME-USP, 2003.

Kappa $=0,04$

Tabela 10: Concordância entre teste e reteste para a questão 15.1 - Motivo para considerar importante as atividades instrumentais que realiza: responsabilidade social.Instrumento CICAc, 2003.

\begin{tabular}{cccc}
\hline \multirow{2}{*}{ Teste } & \multicolumn{2}{c}{ Reteste } & \multirow{2}{*}{ Total } \\
\cline { 2 - 3 } & Não & Sim & \\
\hline Não & 25 & 2 & 27 \\
Sim & 3 & 0 & 3 \\
\hline Total & 28 & 2 & 30
\end{tabular}

LIMA e col. Relatório de análise estatística sobre o projeto "Validação do Instrumento CICAc (Classificação de Idosos quanto à Capacidade para o Autocuidado)” São Paulo, IME-USP, 2003.

Kappa $=-0,09$

Não entraram no cálculo das Medidas Resumo da Tabela 8, casos em que a tabela apresentava colunas ou linhas iguais a zero. Nessas situações observa-se alta 
concordância entre o teste e o reteste, no entanto o coeficiente Kappa não é adequado para essa análise pois o valor de Kappa resulta em zero (0). Houveram 16 situações como essa ao longo do processo. Para ilustrar considero as tabelas 11 e 12.

Tabela 11: Concordância entre teste e reteste para as questões 13 e 14-O idoso faz ou não atividade como: uso de telefone (atividade instrumental). Instrumento CICAC, 2003.

\begin{tabular}{cccc}
\multirow{2}{*}{ Teste } & \multicolumn{2}{c}{ Reteste } & \multirow{2}{*}{ Total } \\
\cline { 2 - 3 } & Não & Sim & \\
\hline Não & 0 & 1 & 1 \\
Sim & 0 & 29 & 29 \\
\hline Total & 0 & 30 & 30
\end{tabular}

LIMA e col. Relatório de análise estatística sobre o projeto "Validação do Instrumento CICAc (Classificação de Idosos quanto à Capacidade para o Autocuidado)” São Paulo, IME-USP, 2003.

A tabela apresenta $97 \%$ de respostas concordantes.

Tabela 12: Concordância entre teste e reteste para a questão 17 - $O$ idoso apresenta dificuldade proveniente de ambiente social e fisico para atividades de lazer com interesses diversos. Instrumento $C I C A C, 2003$.

\begin{tabular}{|c|c|c|c|}
\hline \multirow{2}{*}{ Teste } & \multicolumn{2}{|c|}{ Reteste } & \multirow{2}{*}{ Total } \\
\hline & Não & $\mathrm{Sim}$ & \\
\hline Não & 29 & 0 & 29 \\
\hline Sim & 1 & 0 & 1 \\
\hline Total & 30 & 0 & 30 \\
\hline
\end{tabular}

LIMA e col. Relatório de análise estatística sobre o projeto "Validação do Instrumento CICAc (Classificação de Idosos quanto à Capacidade para o Autocuidado)” São Paulo, IMEUSP, 2003.

A tabela apresenta $97 \%$ de respostas concordantes.

A Tabela 13 abaixo permite enfatizar alguns resultados:

- o valor médio do coeficiente Kappa foi menor que 0,7 apenas para a área Arranjo doméstico e Potencial rede de suporte.

- 75\% dos coeficientes Kappa calculados para a área Perfil social apresentaram valores maiores que 0,8 que, segundo critério adotado pelos autores, sugere excelente estabilidade.

Tabela 13: Medidas resumo do coeficiente Kappa por área de investigação.Instrumento CICAc, 2003.

\begin{tabular}{lcccccc}
\hline \multicolumn{1}{c}{ Área } & $\mathbf{N}$ & Média & Mínimo & Máximo & Q1 & Q3 \\
\hline 1. Arranjo doméstico e & 16 & 0,68 & 0,04 & 1,00 & 0,56 & 0,87 \\
Potencial rede de suporte & 13 & 0,90 & 0,50 & 1,00 & 0,86 & 1,00 \\
2. Perfil social & 74 & 0,75 & $-0,09$ & 1,00 & 0,58 & 1,00 \\
3. Universo ocupacional & 145 & 0,83 & $-0,03$ & 1,00 & 0,71 & 1,00 \\
4. Capacidade funcional & $\mathbf{2 4 8}$ & $\mathbf{0 , 8 0}$ & $-0,09$ & 1,00 & - & - \\
\hline Total &
\end{tabular}

LIMA e col. Relatório de análise estatística sobre o projeto "Validação do Instrumento CICAc (Classificação de Idosos quanto à Capacidade para o Autocuidado)” São Paulo, IME-USP, 2003. 
Observa-se que $145(58,5 \%)$ dos coeficientes Kappa foram calculados somente para a área da capacidade funcional. As questões que informam sobre compensações imaginadas obtiveram coeficiente Kappa médio de 0,67 enquanto as questões que informam sobre tipos de dificuldade e formas de compensação adotadas receberam coeficiente Kappa médio de 0,87 .

O comportamento da estatística Kappa observado nas Tabelas 8 e 13 pode ser visualizado nos box-plots das Figuras 2 e 3 . As figuras mostram alguns pontos discrepantes (marcados com asteriscos), que correspondem a alguns valores baixos do coeficiente Kappa. Esses pontos estão associados à questões em que a estatística Kappa não representava bem a concordância, conforme já discutido anteriormente. A figura 4 sugere também que a área de Universo ocupacional apresenta a maior variabilidade com relação aos Kappa calculados, enquanto a área de Perfil social apresenta a menor. 
Figura 2: Box-plot de todos os coeficientes Kappa obtidos no instrumento

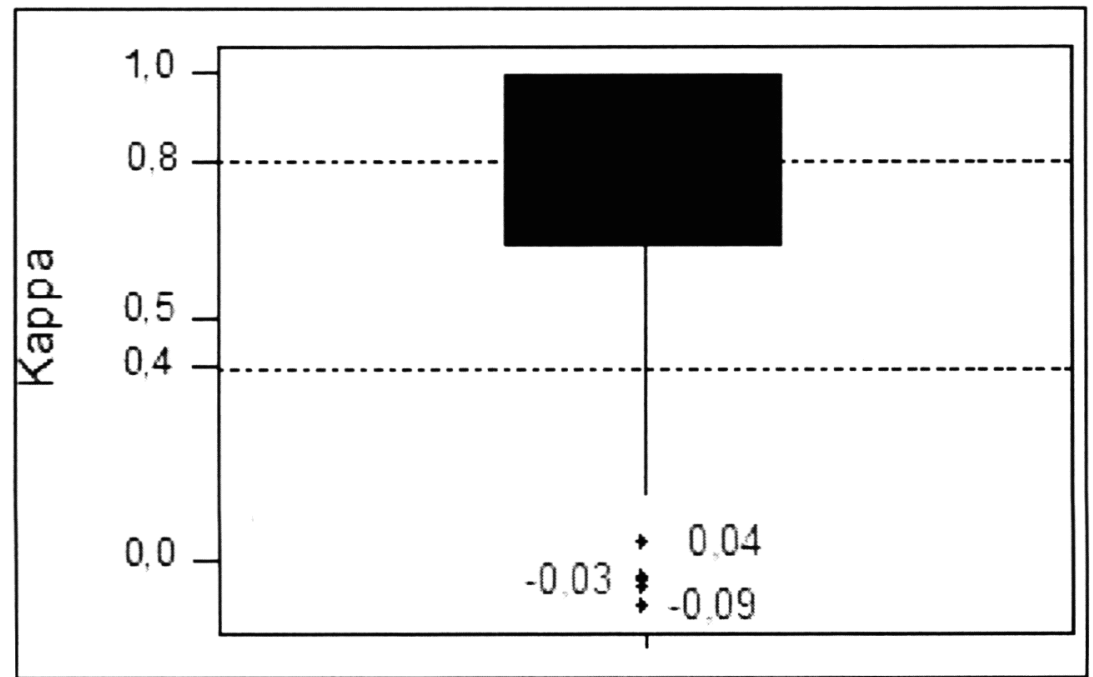

Figura 3: Box-plot dos coeficientes Kappa obtidos por área do instrumento

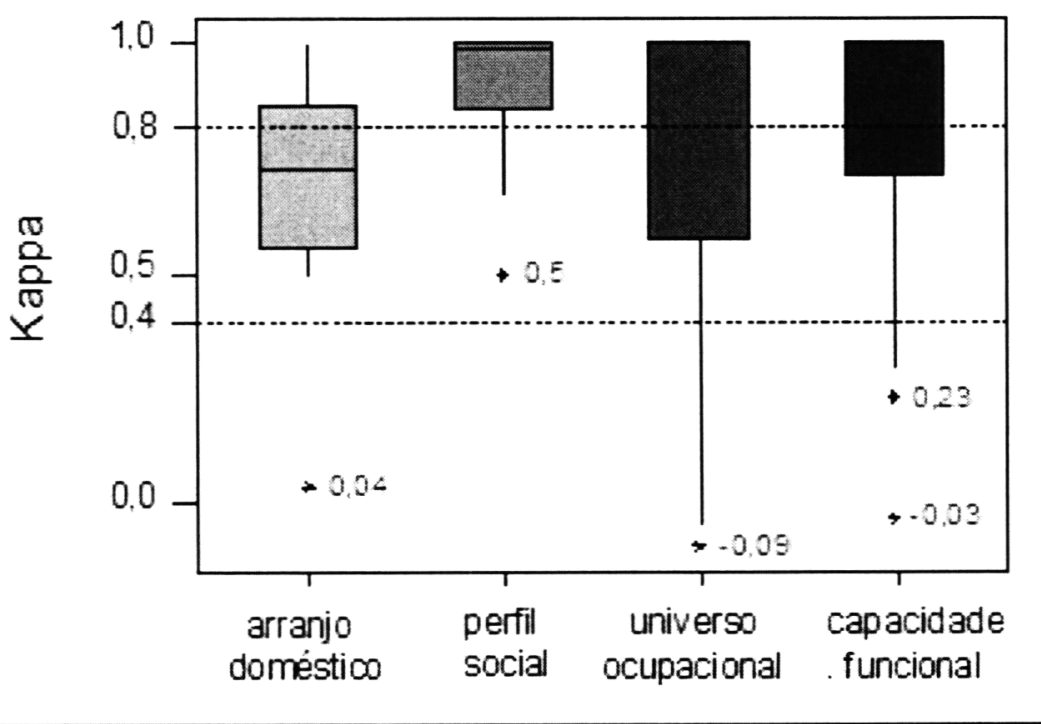

Analisando a Tabela 14 abaixo, pode-se verificar que a concordância entre teste e reteste resultou em:

- Valor médio acima de 0,8 para as questões: 4, 6, 7, 8, 9, 10, 11, 13 e 14, 16, 17, 21

- Valor médio abaixo de 0,8 e acima de 0,4 para as questões $\mathbf{3}, \mathbf{5}, \mathbf{1 2}, \mathbf{1 5}, \mathbf{1 6 . 1}$, $18 / 19,20,22,22.1$ e 22.2

- valor médio abaixo de 0,4 somente para a questão $15.1(0,34)$, ou seja só houve um caso, de acordo com o critério adotado, em que a concordância foi fraca. Essa 
questão busca informar por que (ou quais as razões) o idoso considera determinadas atividades mais importantes que outras.

Vale frisar que para algumas questões os valores médios obtidos estiveram acima mas próximos ao valor 0,4 . Observo que estas questões informam sobre opiniões: graus de satisfação, por que o idoso considera determinadas atividades menos importantes e possibilidade ou não de superar dificuldades.

Embora para algumas questões que informem opinião a concordância ficou em torno de 0,4 para outras a concordância ficou em torno de 0,7 .

Vale destacar que os idosos foram mais consistentes em informar sobre as atividades que gostam menos $(0,95)$ do que sobre aquelas mais importantes e que incluem as que gostam mais $(0,66)$.

Os idosos foram mais consistentes para informar sobre formas imaginadas de superar dificuldades e realizar atividades desejadas $(0,8$ e 0,73$)$ do que para informar sobre a existência ou não de possibilidades para superar dificuldades. 
Tabela 14: Medidas resumo do coeficiente Kappa por questão.instrumento CICAc,2003.

\begin{tabular}{|c|c|c|c|c|}
\hline Questão & $\mathbf{N}$ & Média & Mínimo & Máximo \\
\hline \multicolumn{5}{|l|}{ Área Arranjo doméstico e potencial rede de suporte } \\
\hline 3. Freqüência com que se relaciona com outras pessoas & 5 & 0,70 & 0,50 & 0,89 \\
\hline $\begin{array}{l}\text { 4. Satisfação com a freqüência com que se relaciona com outras } \\
\text { pessoas }\end{array}$ & 5 & 0,80 & 0,65 & 0,91 \\
\hline $\begin{array}{l}\text { 5. Satisfação com a qualidade do relacionamento que mantém } \\
\text { com outras pessoas }\end{array}$ & 4 & 0,42 & 0,04 & 0,80 \\
\hline 6. Ajuda nos casos de doença & 2 & 0,90 & 0,79 & 1,00 \\
\hline \multicolumn{5}{|l|}{ Área Perfil social } \\
\hline 7. Nivel de escolaridade mencionado & 1 & 0,97 & 0,97 & 0,97 \\
\hline 8. Principal (profrssão) mencionada & 1 & 1,00 & 1,00 & 1,00 \\
\hline 9. Exercício atual da profissão & 1 & 0,90 & 0,90 & 0,90 \\
\hline 10. Exerce trabalho remunerado atualmente & 1 & 1,00 & 1,00 & 1,00 \\
\hline 11. Fontes de renda atuais & 8 & 0,91 & 0,67 & 1,00 \\
\hline 12. Satisfação com a situação econômica atual & 1 & 0,50 & 0,50 & 0,50 \\
\hline \multicolumn{5}{|l|}{ Área Universo Ocupacional } \\
\hline $\begin{array}{l}13 \text { e } 14 \text {. Atividades e freqüência relativas ao universo } \\
\text { ocupacional }\end{array}$ & 21 & 0,92 & 0,59 & 1,00 \\
\hline 15. Importância percebida das atividades do universo ocupacional & 17 & 0,66 & $-0,04$ & 1,00 \\
\hline 15.1. Justificativa da importância percebida & 12 & 0,34 & $-0,09$ & 1,00 \\
\hline 16. Atividades menos apreciadas do universo ocupacional & 20 & 0,95 & 0,59 & 1,00 \\
\hline 16.1. Justificativa da(s) atividade(s) menos apreciada(s) & 4 & 0,56 & $-0,05$ & 0,90 \\
\hline \multicolumn{5}{|l|}{ Área Capacidade funcional } \\
\hline 17. Dificuldades para realização de atividades & 95 & 0,89 & $-0,03$ & 1,00 \\
\hline $\begin{array}{l}18 \text { e 19. Características das formas de compensação adotadas } \\
\text { para superar as dificuldades }\end{array}$ & 33 & 0,74 & 0,29 & 1,00 \\
\hline 20. Possibilidade de superar dificuldades & 1 & 0,41 & 0,41 & 0,41 \\
\hline 21. Formas imaginadas para superar as dificuldades & 3 & 0,80 & 0,58 & 1,00 \\
\hline 22. Atividades desejadas que atualmente não realiza & 1 & 0,72 & 0,72 & 0,72 \\
\hline 22.1. Fatores de inibição das atividades desejadas & 7 & 0,60 & 0,40 & 1,00 \\
\hline 22.2. Formas imaginadas para realizar as atividades desejadas & 5 & 0,73 & 0,42 & 1,00 \\
\hline Total & 248 & 0,80 & $-0,09$ & $1,00-$ \\
\hline
\end{tabular}

LIMA e col. Relatório de análise estatística sobre o projeto "Validação do Instrumento CICAc (Classificação de Idosos quanto à Capacidade para o Autocuidado)" São Paulo, IME-USP, 2003.

\subsection{Análise de Consistência Interna}

A análise de consistência interna permite verificar se os itens que compõem o instumento medem de forma semelhante o que o nstrumento (ou cada área dentro dele) mede no total. A consistência interna baseia-se na homogeneidade dos itens.

Para estimar a consistência interna do Instrumento CICAc foi utilizado o coeficiente Alpha de Cronbach. NUNNALLY (1978) citado por LIMA e col (2003) 
sugere que valores do coeficiente Alpha de Cronbach maiores ou iguais a 0,70 são adequados para concluir se há consistência interna.

Esse coeficiente só poderá ser calculado quando o instrumento (ou a parte que será analisada dentro dele) for composto por itens dispostos em escala ordinal e com um mesmo número de pontos, de maneira que a soma desses itens resulte num valor total que mede algum constructo de interesse. É importante observar que esse coeficiente não pode ser calculado se existirem valores omissos [missing] em um ou mais dos itens que compõem a soma da escala.

No Instrumento CICAc, nem sempre foi possível o calculo do Alpha de Cronbach por algumas razões:

- A existência de muitas escalas nominais, mantidas pelos especialistas ao longo do processo de validação de conteúdo;

- A impossibilidade de agrupar ou desdobrar niveis em determinadas escalas ordinais, a fim de que tivessem o mesmo número de pontos. Como exemplo cito a área Arranjo doméstico e familiar do idoso e potencial rede de suporte que possue algumas questões com escalas ordinais de 4 e 5 pontos. A modificação dos niveis dessas escalas não ganhou respaldo teórico, e se configuraria como uma arbitrariedade;

- A existência de valores omissos.

Vale ressaltar que, embora a questão 17 admita como resposta do idoso "não apresenta dificuldade", o quadro resumo para registro de respostas não contempla essa opção. Para afirmar que o idoso "não apresente dificuldade" houve necessidade de cotejar informações das áreas universo ocupacional e capacidade funcional. Quando a atividade faz parte do universo ocupacional e o idoso não informa dificuldade, concluisse que ele "não apresenta dificuldade". Caso a atividade não foi assinalada no universo ocupacional e tão pouco nos níveis de dificuldade LIMA e col. (2003) consideraram valores omissos [missing] para a(s) atividade(s) 
Segundo esses critérios, a análise da consistência interna do instrumento foi realizada somente para as áreas Perfil social (utilizando metade das questões) e Capacidade funcional (atividades básicas e instrumentais de vida diária). Foram utilizados apenas os resultados do teste, ou seja, da primeira aplicação do instrumento.

Nos quadros 14 e 15 apresento os agrupamentos e as escalas que foram utilizados na análise de consistência interna.

Quadro 14: Escala utilizada para a verificação de consistência interna na área de Perfil social.

\begin{tabular}{|c|c|}
\hline Questão & Escala ordinal \\
\hline 7. Escolaridade & $\begin{array}{l}\text { 1 - Analfabeto } \\
2 \text { - Sabe ler / Escrever ou Primário Incompleto } \\
3 \text { - Primário Completo ou Ginásio In completo } \\
4 \text { - Ginásio Completo ou Colegial Incompleto } \\
5 \text { - Colegial Completo ou Curso Superior Incompleto + Superior } \\
\text { Completo }\end{array}$ \\
\hline 11. Renda & $\begin{array}{l}1 \text { - até } 3 \text { salários mínimos } \\
2 \text { - } 3 \text { a } 5 \text { salários } \\
3 \text { - } 5 \text { a } 7 \text { salários } \\
4 \text { - } 7 \text { a } 9 \text { salários } \\
5 \text { - } 9 \text { salários ou mais }\end{array}$ \\
\hline 12. Satisfação & $\begin{array}{l}\text { 1- Muito mal } \\
2 \text { - Mal } \\
3 \text { - Mais ou menos } \\
\text { 4- Bem } \\
\text { 5- Muito bem }\end{array}$ \\
\hline
\end{tabular}

Quadro 15: Escala utilizada para a verificação de consistência interna na área de Capacidade funcional.

\begin{tabular}{|l|l|}
\hline \multicolumn{1}{|c|}{ Questão } & \multicolumn{1}{c|}{ Escala } \\
\hline & 1 - Deixou de fazer a atividade \\
17 e 18. Dificuldades e Formas de & 2 - Compensa a dificuldade com ajuda (Su + As) \\
compensação & - Faz sozinho com dificuldade \\
& 4- Compensa sozinho adotando uma ou mais \\
& estratégias (MC + MA + DA) \\
& 5 - Não apresenta dificuldade \\
\hline
\end{tabular}

MC : modificações comportamentais

MA : modificações ambientais

DA : dispositivo auxiliar

Su : supervisão

As : assistência fisica direta

$\mathrm{Na}$ área de Perfil social, o valor de Alpha de Cronbach foi igual a -0,078, calculado para 29 idosos. Uma idosa foi excluída desse cálculo, pois apresentava valor omisso na questão 11 (renda mensal), que ela preferiu não responder. 
A Tabela 15 apresenta os resultados do coeficiente Alpha de Cronbach para os blocos de atividades básicas e instrumentais da área de Capacidade funcional.

A coluna " $\mathrm{N}$ " corresponde ao número de idosos que foram utilizados no cálculo do coeficiente. Quando esse valor é menor que 30 (total de idosos amostrados) significa que alguns indíviduos foram descartados do cálculo por apresentarem valores omissos [missing] em um ou mais itens. No caso em que o número de respostas omissas em pelo menos um dos itens foi igual a 30 , não foi possível calcular o coeficiente Alpha para o bloco (isso ocorreu para alguns itens dos blocos de atividades de trabalho e lazer).

Tabela 15: Valores do coeficiente Alpha de Cronbach por bloco de atividade na área de Capacidade funcional e número de idosos utilizado para o cálculo. Instrumento CICAc,2003.

\begin{tabular}{ccc}
\hline Atividades & Alpha de Cronbach & $\mathbf{N}$ \\
\hline Básicas & 0,713 & 30 \\
Instrumentais $\left(^{*}\right)$ & 0,704 & 16 \\
\hline Total & & 46
\end{tabular}

LIMA e col. Relatório de análise estatística sobre o projeto "Validação do Instrumento CICAc (Classificação de Idosos quanto à Capacidade para o Autocuidado)" São Paulo, IME-USP, 2003.

$\left(^{*}\right)$ O Alpha de Cronbach foi calculado excluindo os indivíduos que apresentavam valores omissos [missing] em um ou mais itens.

\subsection{Considerações finais sobre a análise estatística}

$\mathrm{Na}$ análise de cada uma das áreas de investigação, LIMA e col. (2003) afirmam que Arranjo doméstico e Potencial rede de suporte e o Universo ocupacional apresentaram estabilidade moderada, com valores médios de $0,68 \mathrm{e}$ 0,75, respectivamente. Já as áreas referentes ao Perfil social e Capacidade funcional, com coeficientes Kappa médios de 0,90 e 0,83, possuem estabilidade considerada excelente, segundo os autores.

Os autores ressaltam que valores baixos do coeficiente não implicam, necessariamente, em baixa concordância $\mathrm{e}$, nesses casos, recomendam uma análise criteriosa das tabelas de freqüência, além disso os coeficientes que não foram 
incluídos nos cálculos, por serem iguais a zero, apresentaram no mínimo $90 \%$ de respostas concordantes.

LIMA e col. (2003) concluíram, segundo o critério adotado que, de um modo geral, o instrumento possui estabilidade excelente, pois apresentou coeficiente Kappa médio superior a 0,8 em mais de $60 \%$ dos coeficientes calculados, sendo que esses valores representam ainda uma análise subestimada da estabilidade do instrumento em decorrência da limitação do coeficiente para análise de determinadas situações (já discutidas).

Para a realização da análise da consistência interna, era necessário que a área estudada fosse composta de itens com escalas ordinais de mesmo número de categorias. Como isso não acontecia no instrumento em geral, a consistência só foi estudada dentro de parte da áreas Perfil social e Capacidade funcional.

O estudo da consistência interna do Instrumento CICAc mostrou, de acordo com o critério adotado pelos autores, a existência de consistência no bloco de atividades básicas e instrumentais da vida diária na área de Capacidade funcional.

\section{Discussão de resultados}

$\mathrm{Na}$ análise da estabilidade, vale frisar que embora algumas questões que informam opinião estejam dentro do critério adotado por LIMA e col (2003) para estabilidade moderada, essas questões obtiveram valores médios mais baixos do que aquelas que informam o comportamento atual do idoso. Isso me parece razoável uma vez que os comportamentos foram concretizados enquanto as opiniões, embora preditoras do comportamento não atingiram o nível da concretude.

Esse fato não torna as opiniões menos importantes num instrumento que se propõe a classificar idosos quanto a capacidade para o autocuidado. Segundo a concepção teórica do autocuidado, a competência (ou capacidade) para o autocuidado inclui a habilidade para discernir sobre fatores que possam ser 
controlados e administrados a fim de regular o funcionamento e desenvolvimento humano. Considero que as questões que fornecem informações tais como graus de satisfação do idoso em relação a rede de suporte social e renda e compensações imaginadas referem-se a essa dimensão do autocuidado.

Os idosos foram mais consistentes para informar sobre formas imaginadas de superar dificuldades e realizar atividades desejadas do que para informar sobre a existência ou não de possibilidades para superar dificuldades. Depreende-se que os idosos entrevistados oscilaram em reconhecer a existência de possibilidade para superar determinadas dificuldades mas, uma vez que eles reconhecem essa possibilidade, identificam formas para isso. As formas imaginadas são quase sempre as mesmas que os idosos já adotam, ou seja já se configuram como práticas de autocuidado.

$\mathrm{Na}$ análise da consistência interna obteve-se valores baixos para a área perfil social, o que pode ser uma indicação de que as variáveis escolaridade, renda e satisfação não estejam medindo o Perfil social de forma homogênea, salientando que a satisfação com a renda é um conceito abstrato e não necessariamente corresponde à renda do indivíduo. Conforme ilustram a seguintes falas:

"Na qualidade de pobre estou bem" (referindo-se a como satisfaz suas necessidades)".

"Estou muito mal pois ajudo minha filha desempregada e meus dois netos que moram no interior" (referindo-se a como satisfaz suas necessidades)".

Vale frisar que a primeira fala é de um idoso que está posicionado na categoria 2 para renda e categoria 4 para satisfação com renda. Enquanto a segunda fala pertence a uma idosa que está posicionada na categoria 5 para renda e 1 para satisfação com renda

Admito que houve por parte de toda a equipe - pesquisador e estatísticos - um forte desejo de corrigir os valores omissos, que possibilitasse o cálculo do coeficiente alpha para um maior número de atividades da área capacidade funcional. Considero 
que, para atribuir escores a essas atividades, o doso deveria ter sido questionado sobre a capacidade potencial em realizá-las sem ou com dificuldades.

Segundo McDOWELL e NEWELL (1987) questionar o paciente sobre o que ele pode fazer gera respostas hipotéticas, no entanto esse forma de abordagem tem sido bastante utilizada em instrumentos para avaliar atividades instrumentais de vida diária, visto que essas atividades são familiares, muitas vezes o idoso é capaz de realizá-las mas não as realiza atualmente por fatores diversos, não relacionados à saúde.

Considero que o questionamento sistemático sobre capacidade potencial do idoso para as atividades instrumentais de vida diária, que não componham seu universo ocupacional possa vir a mostrar-se uma abordagem adequada para evitar valores omissos para esse bloco de atividades.

Quanto à correção dos valores omissos para as atividades de lazer e trabalho, considero que o questionamento sobre a capacidade potencial para realizá-las implicaria em duas dificuldades:

- Ao avaliar todos os idosos com base num mesmo universo de atividades de lazer e trabalho, estaria admitindo uma homogeneização do processo de envelhecimento, contrariando os referenciais teóricos adotados nesta pesquisa que consideram o envelhecimento como um processo de individuação, caracterizado pela heterogeneidade daqueles que envelhecem e pela diversidade nas escolhas de suas atividades. (RESTREPO 1994, BALTES P citado por BALTES M 1996, HORGAS e col 1998)

- Ao questionar o idoso sobre a possibilidade de realizar com ou sem dificuldade uma gama de atividades, por vezes bastante estranha ao seu universo ocupacional, o instrumento estaria obrigando o idoso a raciocinar e informar sobre situações distantes de sua realidade e estaria valorizando essas informações. 


\section{CONSIDERAÇÕES FINAIS SOBRE A VALIDAÇÃO DO INSTRUMENTO CICAC}

\subsection{Ajustes do Instrumento CICAc}

O Instrumento CICAc sofreu ajustes durante o processo de validação de seu conteúdo e avaliação de sua confiabilidade que podem ser resumidos conforme quadro a seguir: 
Quadro 16: Ajustes do Instrumento CICAc durante o processo de validação de seu conteúdo e avaliação de sua confiabilidade

\begin{tabular}{|c|c|c|c|c|c|c|c|}
\hline \multirow{2}{*}{\begin{tabular}{|l|} 
Fases da \\
pesquisa \\
Caracte- \\
rísticas do \\
instrumento \\
\end{tabular}} & \multirow{2}{*}{\begin{tabular}{|r|} 
Elaboração \\
(mestrado) $^{\mathbb{2} \text { versão }}$ \\
\end{tabular}} & \multicolumn{5}{|c|}{ Validação de conteúdo } & \multirow{2}{*}{\begin{tabular}{|c|}
$\begin{array}{c}\text { Avaliação } \\
\text { confiabilidade }\end{array}$ \\
Versão \\
simplificada \\
\end{tabular}} \\
\hline & & Versão estruturada & \multicolumn{2}{|c|}{$\begin{array}{l}\text { 1'versão grupal }^{\text {I'val }} \\
\text { (resultado da } 1^{\text {' }} \text { etapa Delphi) }\end{array}$} & $\begin{array}{c}2^{\boldsymbol{a}} \text { versåo grupal } \\
\text { (resultado da } 2^{\boldsymbol{a}} \text { etapa Delphi) } \\
\end{array}$ & $\begin{array}{c}3^{n} \text { versão } \\
\text { grupal (3: } \\
\text { etapa } \\
\text { Delphi) } \\
\end{array}$ & \\
\hline \begin{tabular}{|l|} 
Formato das \\
questões
\end{tabular} & $\begin{array}{l}\text { Questões } \\
\text { abertas e } \\
\text { fechadas } \\
\text { (respostas } \\
\text { dicotômicas } \\
\text { e uma escala } \\
\text { nominal) } \\
\end{array}$ & $\begin{array}{l}\text { Questðes abertas e } \\
\text { fechadas (respostas } \\
\text { dicotômicas, } \\
\text { múltiplas e escalas } \\
\text { nominais) }\end{array}$ & \multicolumn{2}{|c|}{$\begin{array}{l}\text { Questões abertas e fechadas (respostas dicotômicas, } \\
\text { múltiplas, escalas nominais e ordinais) }\end{array}$} & $\begin{array}{l}\text { Questôes abertas e fechadas (respostas } \\
\text { dicotômicas, múltiplas, escalas nominais e } \\
\text { ordinais) com destaque para inclusão de } \\
\text { escala para níveis de comprometimento da } \\
\text { capacidade funcional }\end{array}$ & $\begin{array}{l}\text { Sem alteração } \\
\text { no formato }\end{array}$ & $\begin{array}{l}\text { Sem alteração } \\
\text { no formato }\end{array}$ \\
\hline \multirow[t]{4}{*}{ Areas e itens } & $\begin{array}{l}\text { Ambiente } \\
\text { sócio- } \\
\text { familiar }\end{array}$ & $\begin{array}{l}\text { Ambiente sócio- } \\
\text { familiar }\end{array}$ & $\begin{array}{l}\text { Arranjo doméstico e } \\
\text { potencial rede de } \\
\text { suporte }\end{array}$ & $\begin{array}{l}\text { Inclusão de variáveis: satisfação } \\
\text { com frequiência de } \\
\text { relacionamentos, } \\
\text { Satisfação com relacionamentos }\end{array}$ & \multirow[t]{3}{*}{ Sem alterações nas áreas e itens } & \multirow[t]{4}{*}{\begin{tabular}{|l|} 
Sem \\
alterações \\
nas áreas e \\
itens
\end{tabular}} & \multirow{4}{*}{$\begin{array}{l}\text { Agrupamento } \\
\text { de respostas } \\
\text { para áreas: } \\
\text { Universo } \\
\text { Ocupacional e } \\
\text { Capacidade } \\
\text { funcional }\end{array}$} \\
\hline & & & Perfil social & $\begin{array}{l}\text { Inclusão de variáveis: } \\
\text { escolaridade, atividades } \\
\text { profissionais, fontes de renda, } \\
\text { satisfação com renda }\end{array}$ & & & \\
\hline & $\begin{array}{l}\text { Universo } \\
\text { ocupacional }\end{array}$ & $\begin{array}{l}\text { Universo } \\
\text { ocupacional }\end{array}$ & $\begin{array}{l}\text { Area: universo } \\
\text { ocupacional }\end{array}$ & $\begin{array}{l}\text { Inclusão de atividades tais como } \\
\text { comunicação, comparecimento às } \\
\text { consultas, pintura }\end{array}$ & & & \\
\hline & $\begin{array}{l}\text { Capacidade } \\
\text { funcional }\end{array}$ & $\begin{array}{l}\text { Capacidade } \\
\text { funcional }\end{array}$ & $\begin{array}{l}\text { Area capacidade } \\
\text { funcional }\end{array}$ & $\begin{array}{l}\text { Modificação de quadros resumos } \\
\text { para registro de respostas }\end{array}$ & $\begin{array}{l}\text { Inclusão de mais tipos de dificuldade e de } \\
\text { escala para comprometimento funcional }\end{array}$ & & \\
\hline $\begin{array}{l}\text { Instrumento } \\
\text { em geral }\end{array}$ & & & & $\begin{array}{l}\text { Inclusão de } \\
\text { - Orientação para aplicação } \\
\text { - Definição de termos } \\
\text { - Instruções para preenchimento }\end{array}$ & $\begin{array}{l}\text { Redefinição de termos/Numeração das } \\
\text { páginas/ correspondência entre questões e } \\
\text { quadros resumos, legenda do quadro } 4, \\
\text { reunião de questões sobre atividades } \\
\text { desejadas e quadro resumo (quadro } 6 \text { ) }\end{array}$ & $\begin{array}{l}\text { Sem } \\
\text { alterações }\end{array}$ & Sem alterações \\
\hline Conclusão & & & & & & $\begin{array}{l}\text { Validado em } \\
\text { seu } \\
\text { conteúdo }\end{array}$ & $\begin{array}{l}\text { estável no geral } \\
\text { e com } \\
\text { consistência } \\
\text { interna para } \\
\text { AVDs } \\
\end{array}$ \\
\hline
\end{tabular}




\subsection{A versão simplificada do Instrumento CICAc}

A $3^{a}$ versão grupal do Instrumento CICAc (ANEXO 1.6), mais apropriada para estudo de casos em sua especificidade não possibilita a classificação, sucinta e simplificada, de idosos quanto à capacidade para o autocuidado.

Sendo esta qualidade necessária para sua incorporação à rotina da terapia ocupacional, especialmente em UBS e ainda, para obtenção de tendências em pesquisa com população idosa elaborei, a partir dos agrupamentos exigidos para análise estatística, uma nova versão do Instrumento - produto final do processo de validação - ao qual denominei Versão simplificada do Instrumento CICAc.

Vale destacar que além dos agrupamentos foi acrescida nesta versão, mais especificamente ao quadro resumo para o registro das dificuldades do idoso, uma coluna para "não apresenta dificuldade". Essa coluna deverá ser preenchida em todas as linhas correspondentes às atividades do universo ocupacional do idoso para as quais ele "não apresenta dificuldade".

Se o idoso não realiza determinadas atividades instrumentais poderá ser questionado sobre a capacidade potencial em realizá-las e posicionado de acordo com a possibilidade de realizá-las com ou sem dificuldade.

A informação sistemática sobre a presença e ausência de dificuldades facilitará o emprego do instrumento em pesquisas, evitando os indesejáveis valores omissos, ao menos para os blocos das atividades básicas e instrumentais de vida diária, e facilitará a utilização clínica do instrumento pelo T.O.

O registro da informação "não apresenta dificuldade" é consistente com a atuação do T.O na esfera preventiva pois considera as dificuldades do idoso bem como suas capacidades. 
Por fim, para que um instrumento possa ser útil ele deve permitir não somente a identificação de aspectos do problema mas também de opções para seu enfrentamento. Ao descrever o universo ocupacional, o arranjo doméstico e potencial rede de suporte, perfil social e capacidade funcional do idoso, o Instrumento CICAc fornece referenciais para o terapeuta e idosos sobre opções para atender às necessidades ocupacionais do idoso. Vejo como necessário que o instrumento contemple o registro de objetivos e estratégias de intervenção em T.O, através de um espaço reservado para essa finalidade.

A Versão simplificada do instrumento CICAc será apresentada a seguir. 
Instrumento C.I.C.Ac

\section{Orientações gerais para aplicação}

A versão simplificada do Instrumento CICAc foi elaborada com alternativa a $3^{\mathrm{a}}$ versão grupal do Instrumento para aplicação especialmente em UBSs, por apresentar as seguintes características:

- Demanda menor tempo de aplicação facilitando sua incorporação à rotina da UBS (a $3^{a}$ versão grupal do Instrumento requer cerca de uma hora de aplicação ou sua aplicação por áreas de investigação em momentos distintos)

- Aplicação e registro de informações facilitado, uma vez que um menor número de alternativas deverá ser oferecida aos idosos, bem como um menor número de alternativas deverá ser selecionada pelo entrevistador para registro

- Possibilidade de caracterizar idosos segundo um menor número de características ocupacionais e funcionais

A versão simplificada do instrumento CICAc, compreende o agrupamento de respostas presentes na $3^{\mathrm{a}}$ versão grupal, especificamente nas áreas Universo Ocupacional e Capacidade Funcional. Esses agrupamentos baseiam em reflexões teóricas e nos resultados de pesquisa de validação do Instrumento e, serão apresentados a seguir.

Agrupamento de respostas às questões 13 e 14. Instrumento CICAC $3^{a}$ versão grupal::

\begin{tabular}{|l|l|}
\hline \multicolumn{1}{|c|}{ Itens } & \multicolumn{1}{c|}{ Agrupamento } \\
\hline Atividades de Lazer & Lazer com predomínio de interesse... \\
\hline Caminhar/ Dançar/ Praticar esporte & fisico \\
\hline Bordado/tricô/crochê/ Cuidar de plantas/Costurar & manual \\
\hline Leituras /Participar de cursos & intelectual \\
\hline $\begin{array}{l}\text { Conversar com amigos/sair com amigos / Fazer visitas a familiares/Fazer visitas a doentes /Jogar } \\
\text { (jogos de salão)/ Participar de grupos / Viajar/Passear }\end{array}$ & social \\
\hline Fazer orações / lr a missa ou reunião religiosa/ & religioso \\
\hline Cantar/Ir ao cinema/teatro/Pintar & artístico \\
\hline $\begin{array}{l}\text { Assistir televisão/Cuidar de pequenos animais/ Fazer pequenos consertos em casa/Ouvir } \\
\text { música/rádio }\end{array}$ & diversos \\
\hline Trabalho remunerado & \\
\hline Informal & Informal \\
\hline Cargo técnico ou administrativo/profissão liberal & $\begin{array}{l}\text { Cargo técnico ou administrativo/profissão } \\
\text { liberal }\end{array}$ \\
\hline Empregada doméstica & Empregada doméstica \\
\hline Operário & Outro \\
\hline Outro: especifique & \\
\hline
\end{tabular}

Agrupamento de respostas à questão 15.1. Instrumento CICAC $3^{a}$ versão grupal.:

\begin{tabular}{|c|c|}
\hline 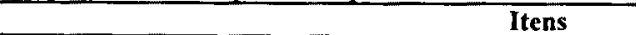 & Agrupamento \\
\hline Trazem prazer & \multirow[t]{10}{*}{ Satisfação pessoal } \\
\hline Mantêm as pessoas ativas & \\
\hline Distraem & \\
\hline Ocupam o tempo & \\
\hline Mantém pessoa atualizada & \\
\hline Alimentam a vaidade & \\
\hline Diminuem a solidão e a carência a fetiva & \\
\hline Trazem satisfação espiritual & \\
\hline Trazem oportunidade de descansar & \\
\hline Mantém a privacidade & \\
\hline Promovem senso de utilidade & \multirow[t]{2}{*}{ Responsabilidade social } \\
\hline Através delas se desempenha comportamentos esperados & \\
\hline São benéficas à saúde fisica e/ou mental & \multirow{3}{*}{$\begin{array}{l}\text { Prevenção de riscos a vida, ao } \\
\text { funcionamento e desenvolvimento }\end{array}$} \\
\hline Estimulam o exercício da independēncia & \\
\hline Estão relacionadas com a sobrevivência & \\
\hline Outras razōes: Especifique & Outras \\
\hline
\end{tabular}

Agrupamento de respostas às questões 16.1 Instrumento CICAC $3^{a}$ versão grupal

\begin{tabular}{|l|l|}
\hline \multicolumn{1}{|c|}{ Itens } & Agrupamento \\
\hline Acima das capacidades do idoso & Intrinsecas \\
\hline Não atende as necessidades do idoso & \\
\hline Realizada em condições adversas & Extrinsecas \\
\hline Outras razões: Especifique & Outras \\
\hline
\end{tabular}


Agrupamento de respostas das questôes 17,18,19: Instrumento CICAC $3^{a}$ versão grupal.

\begin{tabular}{|l|l|}
\hline Tipos de dificuldade & Agrupamento \\
\hline Física, Sensorial, Cognitiva, Emocional e Restrições clínicas & Fatores Biológicos e comportamentais \\
\hline Social, Econômica, Cultural (entre outros) e relativas ao ambiente fisico & Fatores do ambiente social e fisico \\
\hline Outros tipos de dificuldade & Outros fatores \\
\hline Formas de compensação & Agrupamento \\
\hline & Não apresenta dificuldade \\
\hline $\begin{array}{l}\text { Compensa com Modificação Comportamental } \\
\text { Compensa com Dispositivo Auxiliar } \\
\text { Compensa com Modificação Ambiental }\end{array}$ & $\begin{array}{l}\text { apresenta dificuldade - compensa com uma } \\
\text { ou mais estratégias }\end{array}$ \\
\hline Faz com dificuldade & apresenta e faz com dificuldade \\
\hline $\begin{array}{l}\text { Faz com ajuda - supervisão } \\
\text { Faz com ajuda - assistência fisica direta }\end{array}$ & apresenta dificuldade - compensa com ajuda \\
\hline Deixa de fazer & apresenta dificuldade - deixa de fazer \\
\hline
\end{tabular}

Agrupamento de respostas das questões 20.1. Instrumento CICAC $3^{a}$ versão grupal.

\begin{tabular}{|l|l|}
\hline Itens & agrupamentos \\
\hline PS : problemas de saúde & Intrinsecos \\
ANE: atitude negativa em relação ao envelhecimento & \\
PR: preocupação excessiva com atribuições/responsabilidades & \\
familiares & \\
\hline $\begin{array}{l}\text { FA: falta de apoio familiar } \\
\text { DF: dificuldade financeira }\end{array}$ & Extrínsecos \\
DRS: desconhecimento de recursos sociais & \\
\hline outros: & Outros \\
\hline
\end{tabular}

Agrupamento de respostas das questões 20.2. Instrumento CICAC $3^{a}$ versão grupal.

\begin{tabular}{|l|}
\hline \multicolumn{1}{|c|}{ Formas imaginadas de realizar as atividades desejadas } \\
\hline Instituição que ofereça \\
\hline Tempo Livre \\
\hline Mudança de comportamento \\
\hline Recursos financeiros \\
\hline Ajuda de alguém \\
\hline
\end{tabular}

Vale destacar que, na presença de incapacidades não compensadas (atividades que o idoso faz com dificuldade, com ajuda ou tem deixado de fazer), sugere-se a aplicação de questões especificas da $3^{\mathrm{a}}$ versão grupal, voltada para 0 detalhamento das incapacidades: determinação de fatores associados e formas imaginadas para sua realização. Esse detalhamento é especialmente importante quando houver perdas funcionais não compensadas para as atividades básicas e instrumentais de vida diária e atividades importantes para o idoso. 
Instrumento C.I.C.Ac

Nome do entrevistado

Versão Simplificada

$N^{\circ}$ do prontuário

Nome do entrevistador

Data de entrevista

Área de investigação: Arranjo doméstico e familiar do idoso e potencial rede de suporte

Questão 1 -O(a) sr(a) mora com outras pessoas na mesma casa? Sim ( ) Não ( ) Com quem o(a) sr(a) mora?

Identificar todas as pessoas que moram, atualmente, com o idoso

\begin{tabular}{|c|c|c|c|c|}
\hline \multirow{2}{*}{ Nome } & $\begin{array}{c}\text { Grau de parentesco/ Tipo de } \\
\text { relacionamento } \\
\text { (cônjuge, irmão, filho, neto, amigo, etc) }\end{array}$ & Masculino & Feminino & \multirow{2}{*}{ Idade } \\
\cline { 3 - 4 } & & & & \\
\hline & & & & \\
\hline & & & & \\
\hline
\end{tabular}

Questão 2 - O(a) sr(a) tem (outros) filhos? Sim ( ) Não ( )

Identificar todos os filhos vivos que não moram como idoso

\begin{tabular}{|l|l|l|l|l|}
\hline \multirow{2}{*}{ Nome } & \multicolumn{2}{|c|}{ Sexo } & \multirow{2}{*}{ Idade } & \multirow{2}{*}{ Onde reside } \\
\cline { 2 - 5 } & Masculino & Feminino & & \\
\hline & & & & \\
\hline & & & & \\
\hline & & & & \\
\hline
\end{tabular}

Questão 3 - Com que freqüência o(a) sr(a) se relaciona com:

Preencher a coluna correspondente à freqüência segundo Legenda abaixo

\begin{tabular}{|l|l|}
\hline \multicolumn{1}{|c|}{ Tipo de relacionamento } & Frequiência \\
\hline Filhos & \\
\hline Vizinhos & \\
\hline Amigos & \\
\hline Associações/Grupos/Instituições & \\
\hline Outros Parentes & \\
\hline
\end{tabular}

Legenda: Freqüência

$\begin{array}{lll}\text { Todos os dias } & \text { A cada } 15 \text { dias } & \text { l vez por ano } \\ \text { Quase todos os dias } & \text { I vez por mês } & \text { A cada } 2 \text { anos } \\ \text { 2 vezes por semana } & \text { I vez a cada } 2 \text { meses } & \text { Mais de dois anos } \\ \text { I vez por semana } & \text { I vez a cada } 6 \text { meses } & \text { Nunca }\end{array}$

I vez por semana

I vez a cada 6 meses

Mais de dois anos

Questão 4 - O(a) sr(a) está satisfeito com a freqüência com se relaciona com:

Assinale com um Xo grau de satisfação corresponde a cada um dos tipos de relacionamento

\begin{tabular}{|l|c|c|c|}
\hline \multicolumn{1}{|c|}{ Tipos de relacionamento } & \multicolumn{3}{c|}{ Grau de satisfação } \\
\cline { 2 - 4 } & Sim & Mais ou menos & Não \\
\hline Filhos & & & \\
\hline Vizinhos & & & \\
\hline Amigos & & & \\
\hline Associações/Grupos/Instituições & & & \\
\hline Outros Parentes & & & \\
\hline
\end{tabular}

Questão 5 - Como o(a) sr(a) se sente com a relação que mantém com:

Assinale com um $X$ o grau de satisfação correspondente a cada um dos tipos de relacionamento.

Se o idoso mora só assinale com X para a $I^{a}$ linha somente a coluna Mora só

\begin{tabular}{|l|c|c|c|c|c|}
\hline \multicolumn{2}{|c|}{ Tipos de relacionamento } & \multicolumn{5}{c|}{ Grau de satisfação } \\
\cline { 2 - 6 } & $\begin{array}{c}\text { Muito } \\
\text { satisfeito }\end{array}$ & Satisfeito & Insatisfeito & $\begin{array}{c}\text { Muito } \\
\text { insatisfeito }\end{array}$ & Mora só \\
\hline As pessoas da familia que moram com o(a) sr(a) & & & & & \\
\hline Pessoas da família que não vivem com o(a) sr(a) & & & & & \\
\hline Os amigos & & & & & \\
\hline Os vizinhos & & & & & \\
\hline
\end{tabular}


Questão 6 - Tem alguém que cuida do(a) sr(a) quando fica doente? Sim ( ) Não ( ).

Quem é ou quais são essa(s) pessoa(s)

Identifique todas as pessoas que cuidam do idoso em caso de doença

\begin{tabular}{|c|c|c|c|c|}
\hline \multirow{2}{*}{ Nome } & \multirow{2}{*}{$\begin{array}{c}\text { Tipo de relacionamento } \\
\text { (cônjuge, irmão, filho, neto, amigo, etc) }\end{array}$} & \multicolumn{2}{|c|}{ Sexo } & Idade \\
\cline { 4 - 5 } & & & & \\
\hline & & & & \\
\hline & & & & \\
\hline
\end{tabular}

Objetivo das questões $1,2,3,4,5, \mathrm{e} 6$ :

Descrever o arranjo doméstico e familiar do idoso e potencial rede de suporte

\section{Área de investigação: perfil social}

Questão 7 - $O$ (a) sr(a) freqüentou escola? Até que ano estudou?

Assinale com um X a escolaridade do idoso na coluna à direita

\begin{tabular}{|l|l|}
\hline Analfabeto & \\
\hline Sabe ler/escrever ou primário incompleto & \\
\hline Primário completo/ginásio incompleto & \\
\hline Ginásio completo/colegial incompleto & \\
\hline Colegial completo/curso superior incompleto & \\
\hline Superior completo & \\
\hline
\end{tabular}

Questão 8 - Qual sua atividade profissional principal ? Preencha o campo abaixo:

Questão 9 - O(a) sr(a) exerce essa atividade profissional atualmente? ( ) Sim ( ) Não Se a resposta for negativa, aplicar a questão 10

Questão 10 - O(a) sr(a) tem trabalho remunerado atualmente? ( ) Sim ( ) Não. Qual ?

Após registrar o trabalho remunerado atual, procure transportó-lo para o Quadro 1, classificando-o segundo categorias definidas para Trabalho remunerado. As questões da área "Universo Ocupacional" deverão informar sobre o significado atribuido pelo idoso a esse trabalho e as suas outras atividades cotidianas.

Questão 11 - Quais são seus recursos financeiros atualmente?

Assinale com um $X$ os recursos financeiros do idoso na coluna à direita (múltipla escolha)

- A aplicação financeira é considerada recurso somente se o idoso retirar dinheiro da aplicação para as suas despesas

\begin{tabular}{|l|l|}
\hline Salário & \\
\hline Aposentadoria & \\
\hline Pensão & \\
\hline Renda mensal vitalícia & \\
\hline Aluguel & \\
\hline Atividades informais & \\
\hline Aplicação financeira & \\
\hline Recebe ajuda em dinheiro ou espécie & \\
\hline
\end{tabular}

Questão 12 - Com a sua situação econômica atual como o(a) $\operatorname{sr(a)~satisfaz~suas~necessidades~de~alimentação,~}$ moradia, saúde, etc?

Assinale com um X a forma com o idoso satisfaz suas necessidades, na coluna à direita

\begin{tabular}{|l|l|}
\hline Muito bem & \\
\hline Bem & \\
\hline Mais ou menos & \\
\hline Mal & \\
\hline Muito mal & \\
\hline
\end{tabular}

Objetivos das questões 7,8,9,10,11 e12: Traçar um breve perfil social 


\section{Área de investigação : Universo ocupacional}

Questão 13 - O que o(a) sr(a) faz todos os dias, desde a hora que acorda até a hora que vai dormir? Procure contar todas as coisas que faz.

Utilize o Quadro I para registro das respostas (Objetivo: Conhecer as Atividades cotidianas rotineiras)

Questão 14 - Tem alguma coisa que o(a) sr(a) faz só de vez em quando ?

Utilize o Quadro 1 para registro das respostas (Objetivo: Conhecer as Atividades cotidianas não-rotineiras)

Questão 15 - Das coisas que o(a) sr(a) faz, quais acha que são importantes para o(a) $\operatorname{sr}(a)$ ? 15.1. Por quê?

Utilize o Quadro I para registro das respostas à questão 15 e, o Quadro 2 para registro de respostas à questão 15.1

Objetivo: Conhecer as atividades importantes e as necessidades a que elas correspondem

Questão 16 - Das coisas que o(a) sr(a) faz, quais gosta menos? 16.1 Por quê?

Utilize o Quadro I para registro das respostas à questão 16 e Quadro 3 para registro de respostas à questão 16.1

Objetivo: Conhecer as atividades não prazerosas e as necessidades a que elas não atendem

Quadro1: Quadro resumo para registro de respostas às questôes 13,14,15 e16

Identificar atividades que compõe a vida cotidiana do idoso, assinalando-as com X. São atribuidos códigos numéricos (I a31) às atividades para facilitar seu registro nos quadros seguintes.

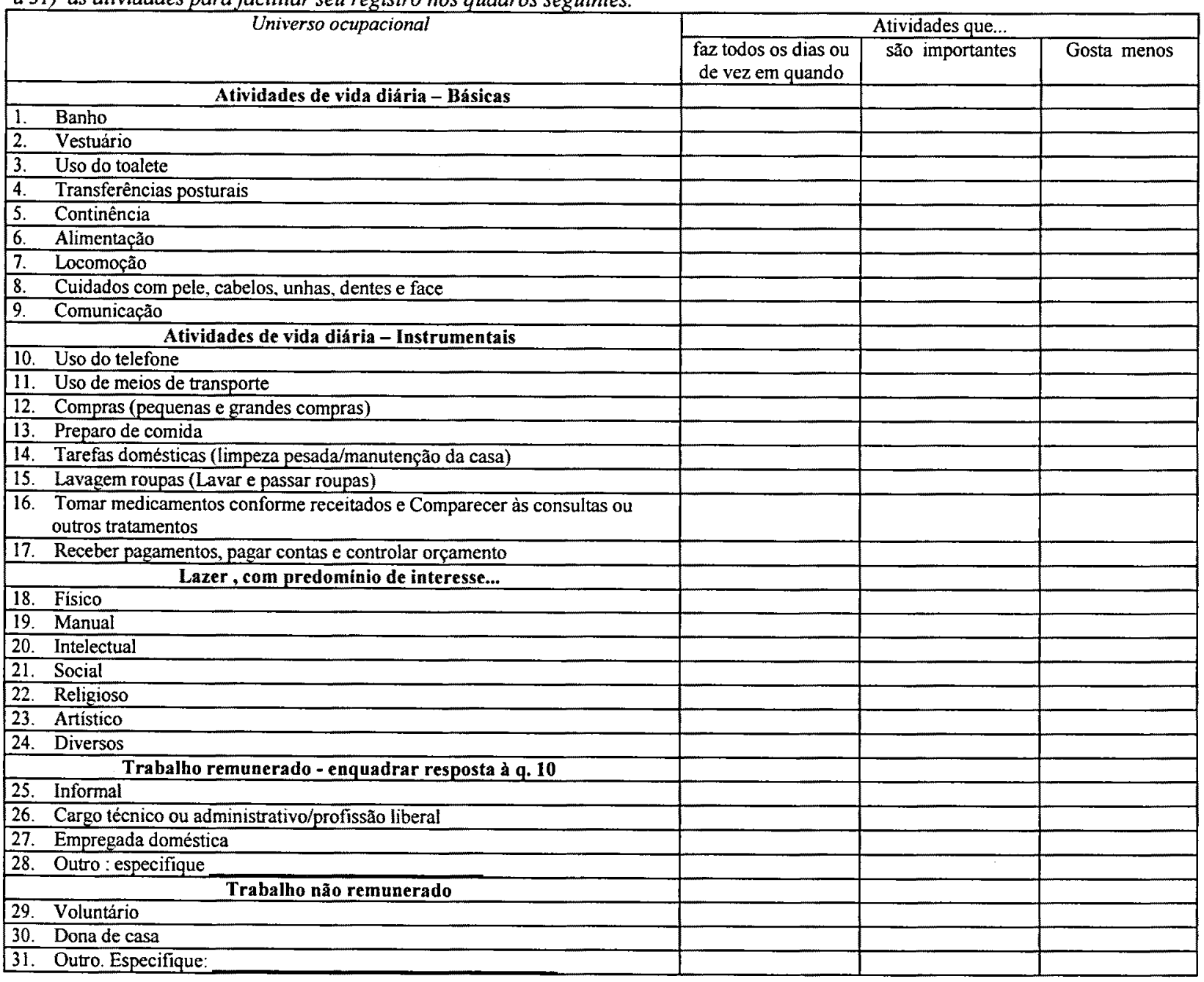


Quadro 2: Registro de respostas à questão 15.1: Porque o idoso acha determinadas atividades importantes.

Preencha a coluna à direita com os códigos numéricos correspondentes às atividades. O idoso pode atribuir importância a todas as suas atividades por uma ou mais razões, nesse caso ao invés de anotar os códigos, preencha a linha(s) correspondente(s) com a palavra todas.

\begin{tabular}{|l|l|}
\hline \multicolumn{1}{|c|}{ Porque são importantes } & Códigos numéricos das atividades \\
\hline Satisfação pessoal & \\
\hline Responsabilidade social & \\
\hline Prevenção de riscos a vida, ao funcionamento e desenvolvimento & \\
\hline Outras razōes : Especifique & \\
\hline
\end{tabular}

Quadro 3: Registro de respostas à questão 16.1: Porque o idoso gosta menos de determinadas atividades.

Preencha a coluna à direita com os códigos numéricos correspondentes às atividades. O idoso pode referir todas as suas atividades como não - prazerosas por uma ou mais razões, nesse caso ao invés de anotar os códigos, preencha a linha(s) correspondente(s) com a palavra todas.

\begin{tabular}{|l|l|}
\hline \multicolumn{1}{|c|}{ Porque não gosta (razões) } & Códigos numéricos das atividades \\
\hline Intrinsecas & \\
\hline Extrinsecas & \\
\hline Outras razões: especifique & \\
\hline
\end{tabular}

\section{Área de investigação: Capacidade funcional}

Questão 17 - O(a) sr(a) tem dificuldade para fazer algumas das coisas que faz? Que tipo(s) de dificuldade? Utilize o Quadro 4 para registro de respostas

Objetivos: Conhecer as atividades cotidianas para as quais o idoso apresenta dificuldade(s) e alguns fatores relacionados às dificuldades

Questão 18 - O que o(a) sr(a) faz quanto à dificuldade X: Encontrou um jeito mais fácil de fazer, tem alguém que o ajuda, faz mesmo com dificuldade sem ajuda ou deixou de fazer?

Repita a pergunta 18 para cada dificuldade mencionada e utilize o Quadro 4 para registro de respostas

Questão 19 - Caso tenha encontrado um jeito mais fácil de fazer, como faz? Caso tenha alguém que o ajuda, quem o ajuda?

Repita a pergunta 19 para cada dificuldade mencionada e utilize o Quadro 4 para registro de respostas

objetivo das questöes 18 e 19: identificar niveis de dificuldade do idoso e algumas formas de compensação adotadas

Legenda para preenchimento do Quadro 4:

\begin{tabular}{|l|l|}
\hline Tipos de dificuldade: & Códigos para tipos de relacionamento (quando houver \\
B/C: Fatores biológicos e comportamentais & alguém que ajude o idoso) \\
S/F: Fatores do ambiente social e fisico & $1:$ Pai,mãe, sogro(a), tio(a) \\
O: Outros fatores & $2:$ Cônjuge \\
Niveis de dificuldade e algumas formas de compensação & $3:$ Irmãos, primos, cunhados \\
N: Não apresenta dificuldade & $4:$ Filhos, enteados, sobrinhos \\
DC: Apresenta Dificuldade mas Compensa & $5:$ Genro, nora \\
com uma ou mais estratégias & $6:$ Netos \\
FD: Apresenta e Faz com Dificuldade & $7:$ Bisnetos \\
FA: Apresenta dificuldade e Faz com Ajuda & $8:$ Amigo, conhecido \\
DF: Apresenta dificuldade e Deixa de Fazer & $9:$ Cuidador formal \\
& $10:$ Outros: especifique \\
\hline
\end{tabular}


Quadro 4 : Quadro resumo para registro das respostas às questöes 17,18 e 19

Identifique as atividades para as quais o idoso tenha dificuldades, assinale com $X$ os tipos e os niveis de dificuldade para as atividades (muiltipla escolha).

\begin{tabular}{|c|c|c|c|c|c|c|c|c|}
\hline \multirow{2}{*}{\begin{tabular}{|c|} 
Universo ocupacional \\
Atividades de vida diária - Básicas \\
\end{tabular}} & \multicolumn{3}{|c|}{$\begin{array}{c}\text { Tipos de } \\
\text { dificuldade }\end{array}$} & \multicolumn{5}{|c|}{$\begin{array}{l}\text { Niveis de dificuldade e algumas formas } \\
\text { de compensação }\end{array}$} \\
\hline & $\mathrm{B} / \mathrm{C}$ & $\mathbf{S} / \mathbf{F}$ & $\mathbf{O}$ & $\mathbf{N}$ & DC & FD & FA & DF \\
\hline & & & & & & & & \\
\hline 2. Vestuário & & & & & & & & \\
\hline 3. Uso do toalete & & & & & & & & \\
\hline 4. Transferências posturais & & & & & & & & \\
\hline 5. Continência & & & & & & & & \\
\hline 6. Alimentação & & & & & & & & \\
\hline Locomoçãa & & & & & & & & \\
\hline 8. Cuidados com pele, cabelos, unhas, dentes e face & & & & & & & & \\
\hline 9. Comunicação & & & & & & & & \\
\hline Atividades de vida diária - Instrumentais & & & & & & & & \\
\hline 10. Uso do telefone & & & & & & & & \\
\hline 11. Uso de meios de transporte & & & & & & & & \\
\hline 12. Compras (pequenas e grandes compras) & & & & & & & & \\
\hline 13. Preparo de comida & & & & & & & & \\
\hline 14. Tarefas domésticas (limpeza pesada/manutenção da casa) & & & & & & & & \\
\hline 15. Lavagem roupas (Lavar e passar roupas) & & & & & & & & \\
\hline $\begin{array}{l}\text { 16. Tomar medicamentos conforme receitados e Comparecer às consultas ou } \\
\text { outros tratamentos }\end{array}$ & & & & & & & & \\
\hline 17. Receber pagamentos, pagar contas e controlar orçamento & & & & & & & & \\
\hline Lazer, com predominio de interesse... & & & & & & & & \\
\hline 18. Físico & & & & & & & & \\
\hline 19. Manual & & & & & & & & \\
\hline 20. Intelectual & & & & & & & & \\
\hline 21. Social & & & & & & & & \\
\hline 22. Religioso & & & & & & & & \\
\hline 23. Artistico & & & & & & & & \\
\hline 24. Diversos & & & & & & & & \\
\hline Trabalho remunerado - enquadrar resposta à q. 10 & & & & & & & & \\
\hline 25. Informal & & & & & & & & \\
\hline 26. Cargo técnico ou administrativo/profissão liberal & & & & & & & & \\
\hline 27. Empregada doméstica & & & & & & & & \\
\hline 28. Outro: especifique & & & & & & & & \\
\hline Trabalho não remunerado & & & & & & & & \\
\hline 29. Voluntário & & & & & & & & \\
\hline 30. Dona de casa & & & & & & & & \\
\hline 31. Outro Especifique: & & & & & & & & \\
\hline
\end{tabular}

Questão 20 - Tem alguma coisa que o(a) sr(a) gostaria de ter feito em sua vida mas nunca fez ou fez há algum tempo atrás e gostaria de voltar a fazer?

Questão 20.1 - Por que não faz?

Questão 20.2 - O(a) sr(a) imagina algum jeito de vir a fazê-las?

Utilize o Quadro 5 para registro das respostas à questão $20,20.1$ e 20.2

Objetivo das questões 20, 20.1 e 20.2 : Conhecer as Atividades desejadas, Fatores de Inibição para essas atividades e Formas imaginadas para realizar as atividades desejadas

Quadro 5 Registro das Atividades desejadas (resposta à questão 20), dos Por quês o idoso não faz (resposta à questão 20.1) e se imagina algum jeito de vir a fazê-las (resposta à questão 20.2).

Registre as atividades desejadas ( $I^{a}$ coluna), assinale com um $X$ a(s) coluna(s) correspondente(s) aos fatores de inibição (porque não faz) e as formas imaginadas de realização.

\begin{tabular}{|c|c|c|c|c|c|c|c|c|c|}
\hline $\begin{array}{c}\text { Atividades } \\
\text { desejadas }\end{array}$ & \multicolumn{3}{|c|}{ Porque não faz } & \multicolumn{5}{c|}{ Formas imaginadas para realização } \\
\cline { 2 - 8 } & Intrinsecos & Extrínsecos & Outros & $\begin{array}{l}\text { Instituição } \\
\text { que ofereça }\end{array}$ & $\begin{array}{l}\text { Tempo } \\
\text { livre }\end{array}$ & $\begin{array}{l}\text { Mudança de } \\
\text { comportamento }\end{array}$ & $\begin{array}{l}\text { Recursos } \\
\text { financeiros }\end{array}$ & $\begin{array}{l}\text { jjuda de } \\
\text { alguém }\end{array}$ & outras \\
\hline & & & & & & & & & \\
\hline
\end{tabular}

\section{Objetivos:}

\section{Estratégias de intervenção em T.O:}




\subsection{Qualidades da versão simplificada do Instrumento CICAc}

Como dito anteriormente a versão simplificada, além de ter possibilitado a análise estatística mostra-se mais apropriada à rotina do terapeuta ocupacional, especialmente em UBSs, por apresentar as seguintes características:

- Demanda menor tempo de aplicação (a $3^{\mathrm{a}}$ versão grupal do Instrumento requer cerca de uma hora de aplicação ou sua aplicação por áreas de investigação em momentos distintos)

- Aplicação e registro de informações facilitados uma vez que um menor número de alternativas deverá ser oferecido aos idosos, bem como um menor número de alternativas deverá ser selecionado pelo entrevistador para registro

- Possibilidade de identificar idosos segundo um menor número de características ocupacionais e funcionais.

Vale destacar entretanto que na presença de incapacidades não compensadas (atividades que o idoso faz com dificuldade, com ajuda ou tem deixado de fazer), a aplicação de questões específicas da $3^{\mathfrak{a}}$ versão grupal do Instrumento CICAc (ANEXO 1.6) se faz necessária pois estas questões permitem a identificação de aspectos das incapacidades como fatores associados e formas imaginadas para sua compensação; o que permitirá que a avaliação responda a algumas exigências citadas por ROGERS (1996) no Capítulo: Instrumentos de avaliação de terapia ocupacional em gerontologia.

1) porque ou quais as causas das incapacidades

2) qual o potencial para reabilitação - poderá a funcionalidade ser mantida, restaurada ou adaptada?

3) como melhorar o desempenho, ou seja quais as melhores opções de intervenção

O detalhamento das incapacidades será especialmente importante para as atividades significativas para o idoso (aquelas que ele considera importantes) e ainda para as atividades básicas e instrumentais de vida diária, pela importância dessas atividades para a saúde e bem-estar dos idosos, conforme descrito nos Capítulos 1.3. 
e 1.4: Avaliação da capacidade funcional e Ocupação humana: objeto de atenção em terapia ocupacional.

O Instrumento CICAc, após os ajustes sofridos ao longo de seu processo de validação, oferece a possibilidade de:

- Caracterizar idosos quanto alguns aspectos relevantes de seu universo ocupacional, arranjo doméstico/familiar e potencial rede de suporte e, perfil social;

- Classificar idosos quanto à capacidade funcional para cada uma das atividades que componham seu universo ocupacional separadamente

- Classificar idosos quanto à capacidade funcional para os blocos das atividades básicas e instrumentais de vida diária também separadamente

O instrumento CICAc versão simplificada avalia a capacidade funcional para 17 atividades de vida diária, sendo 9 básicas e 8 instrumentais, com base no desempenho atual ou capacidade potencial. A capacidade potencial será levada em consideração especificamente para as atividades instrumentais. $O$ instrumento permite ainda a avaliação da capacidade funcional do idoso para cada uma das atividades de lazer e trabalho que componham o seu universo ocupacional.

Este instrumento avalia a capacidade funcional, para cada atividade, em 5 níveis, e atribui pontuação segundo o nível funcional para cada uma delas, conforme quadro abaixo:

Quadro 17: Pontuação atribuida ao idoso segundo nível funcional.

\begin{tabular}{|l|l|}
\hline Pontuação & \\
\hline 5 & Não apresenta dificuldade \\
\hline 4 & apresenta dificuldade - compensa com uma ou mais estratégias \\
\hline 3 & apresenta e faz com dificuldade \\
\hline 2 & apresenta dificuldade - compensa com ajuda \\
\hline 1 & apresenta dificuldade - deixa de fazer \\
\hline
\end{tabular}

Com relação às atividades básicas e instrumentais de vida diária, o instrumento CICAc oferece duas possibilidades de pontuação: uma que considera a pontuação em cada atividade e outra que considera a pontuação total por bloco de atividade. 
Uma pontuação total por bloco poderá ser atribuída uma vez que foi demonstrada razoável consistência interna entre os itens que compõe essas escalas e que valores omissos possam ser evitados para as atividades instrumentais, questionando-se os idosos sobre a capacidade potencial para realizá-las (quando não façam parte de seu universo ocupacional).

A atribuição de pontuações totais pode mostrar-se útil em pesquisa e mesmo na área administrativa, enquanto que na área clinica considero que se deva considerar fundamentalmente a condição funcional do idoso para cada uma das atividades, pois a incapacidade para determinadas atividades pode gerar maior desvantagem social do que a incapacidade para outras, condição essa a ser equacionada no tratamento terapêutico-ocupacional.

Com base na pontuação recebida, o idoso poderá ser posicionado num "continuum" em relação às atividades básicas de vida diária (ABVDs), que irá de 9 (deixou de fazer todas as ABVDs, que passaram a ser realizadas por outros) até 45 pontos (não apresenta dificuldade para nenhuma ABVDs) e num "continuum" que irá de 8 até 40 pontos em relação às atividades instrumentais de vida diária (AIVDs).

Pelo exposto, a aplicação do instrumento CICAc possibilita, até o momento, posicionar em linhas contínuas a capacidade funcional do idoso para cada atividade e para os blocos das atividades básicas e instrumentais e, através destes posicionamentos identificar uma distância aproximada em relação aos pontos extremos das linhas: "não apresenta dificuldade para (nenhuma) atividade" (independente) até "deixou de fazer (todas) a(s) atividade(s) (dependente) " conforme figura abaixo:

Figura 4: Posicionamento do idoso com base em sua capacidade funcional para as ABVDs

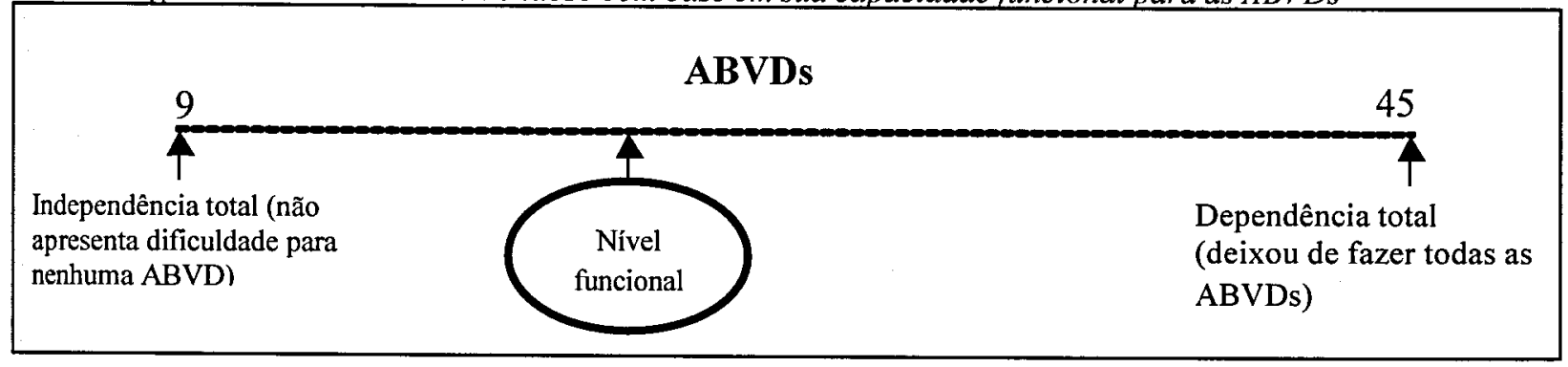


Embora possibilite situar a capacidade funcional do idoso em um ponto do "continuum" considero que o Instrumento CICAc não permita ainda determinar diferenças entre os idosos classificando-os em grupos tais como idosos com discreta, moderada ou severa incapacidade. Novos estudos deverão ser conduzidos para análise e alcance desse propósito.

Vale lembrar que o instrumento alcançou validade conceitual, mais especificamente de conteúdo, e ainda demonstrou ser ferramenta estável e com consistência interna para algumas áreas. Com essas qualidades poderá ser incorporado à prática da T.O especialmente em UBSs, apoiando o planejamento terapêutico. A partir de sua aplicação sistemática, considero que possamos reunir informações valiosas sobre sua utilidade clínica, administrativa e em pesquisa dando suporte a novos estudos sobre sua validade pragmática e operacional. 


\section{CONCLUSÕES}

O estudo Delphi gerou como produto um instrumento válido em seu conteúdo e os resultados obtidos nos testes de estabilidade e consistência interna the conferiram ainda mais credibilidade.

Ao conduzir a validação de conteúdo do Instrumento CICAc, esse sofreu ajustes significativos, basicamente quanto à clareza de enunciado, pertinência e organização das questões, resultando na $3^{\mathrm{a}}$ versão grupal do Instrumento CICAc.

Abrangente e complexa, a semelhança do objeto de estudo - capacidade de idosos para o autocuidado nas atividades diárias - a $3^{\mathrm{a}}$ versão grupal do Instrumento possibilita o conhecimento pelo terapeuta ocupacional de componentes relevantes do desempenho funcional do idoso, embasando, juntamente com outros instrumentos, o planejamento e desenvolvimento da atenção profissional.

Embora forneça elementos importantes para a atuação do T.O, a $3^{\mathrm{a}}$ versão grupal do instrumento CICAc demanda longo tempo de aplicação especialmente se considerarmos a rotina de atendimento em UBSs

A Versão simplificada do Instrumento CICAc, organizada a partir do agrupamento de respostas foi avaliada como confiável. Considero essa versão também mais apropriada à rotina diária da terapia ocupacional, especialmente em UBS e, em estudos e pesquisas sobre envelhecimento por permitir a classificação sucinta e simplificada de idosos quanto à capacidade para o autocuidado nas atividades diárias.

Acredito que a $3^{\mathrm{a}}$ versão grupal poderá ser utilizada de forma complementar à Versão simplificada e particularmente na vigência de incapacidades, fornecendo alguns detalhes sobre as mesmas e apoiando o processo terapêutico. 
A elaboração e validação do Instrumento CICAc configuroutse como pesquisa laboriosa, desenvolvida em várias fases e etapas. Sua construção aliou referenciais teóricos e práticas de autocuidado referidas pela população ao qual o instrumento se destina, esta população foi ouvida de forma sistemática em três etapas. Sua validação ocorreu em duas fases, na primeira fase o instrumento foi apreciado por um júri de especialistas também em três etapas sofrendo ajustes em todas elas e, na segunda fase foi submetido a testes formais de confiabilidade durante a qual também sofreu modificação. Em síntese o instrumento foi construido e validado através de oito versões, todas elas elaboradas com base em critérios teóricos e metodológicos.

A partir dos resultados desta extensa pesquisa, o Instrumento ClCAc poderá ser empregado pelo T.O em gerontologia fornecendo referenciais válidos e confiáveis sobre a capacidade do idoso para o autocuidado nas atividades diárias, importantes para o planejamento e intervenção nesta área.

Para que, de fato, o Instrumento CICAc se torne ferramenta útil ao terapeuta ocupacional e em estudos e pesquisas sobre envelhecimento - propósito maior desse estudo - o Instrumento CICAc deverá ser divulgado, aplicado de forma sistemática e os resultados compartilhados. 


\section{REFERÊNCIAS BIBLIOGRÁFICAS}

Almeida Filho N. Epidemiologia sem números: uma introdução crítica à ciência epidemiológica. Rio de Janeiro: Editora Campos; 1989.

Almeida MHM. CICAc: Ins trumento para Classificação de Idosos quanto à Capacidade para o Autocuidado. São Paulo; 1997. [Dissertação de Mestrado Faculdade de Saúde Pública da Universidade de São Paulo].

[AOTA] American Occupational Therapy Association. Uniform terminology for occupational therapy, third edition. Am J Occup Therapy 1994; 48:1047-54.

Amiralian MLT, Pinto EB, Ghirardi MIG, Lichtig I, Masini EFS, Pasqualin L. Conceituando deficiência. Rev Saúde Pública 2000; .34: 97-103.

Baltes MM, Mayr U, Borchelt M, Maas I, Wilms HU. Everday competence in Old and very old age: And inter-disciplinary perspective. Aging Soc 1993; 13:657-80.

Baltes MM. Successful ageing. In: Ebrahim S, Kalache A. Epidemiology in old age. London: BMJ Publishing Group; 1996. p. 163-7.

Bardin L. Análise de conteúdo. Lisboa: Edições 70; 1977.

Beauchamp TL, Childress JF. Principles of medical ethics. 2. ed. New York: Oxford University Press; 1985.

Bennett JA. Activities of daily living. Old fashioned or still useful? J Gerontological Nurs 1999; 25(5): 22-29.

Berquó E. Algumas considerações demográficas sobre o envelhecimento da população no Brasil. [Apresentado ao Seminário Internacional sobre Envelhecimento Populacional: uma agenda para o fim do século; 1996; Brasília (DF)]. 
Chaimowicz F. A saúde dos idosos brasileiros às vésperas do século XXI: problemas, projeções e alternativas. Rev Saúde Pública 1997; 31: 184 -2000.

Chompré RR. Autocuidado: necessidade ou responsabilidade? Rev Baiana Enferm 1994; 7: 153-61.

Clark F, Larson E. Desarollo de una disciplina académica: la ciencia de la ocupación. In: Hopkins HL, Smith HD. Terapia ocupacional de Willard \& Spackmann. 8. ed. Madrid: Panamericana; 1998. p 44-57.

Clemson L, Fitzgerald MH. Understanding assessment concepts within the occupational therapy context. OccupTher Int 1998; 5:17-33.

Culler KH. Áreas de ejecución en terapia ocupacional. In: Hopkins HL, Smith HD. Terapia ocupacional de Willard \& Spackmann. 8. ed. Madrid: Panamericana; 1998. p 207-26.

Derntl AM, Litvoc J, Castro CGJ, Watanabe HAW, Almeida MHM. Características de idosos segundo comprometimento no autocuidado (ac): subsídios para um programa de assistência no domicilio. [Apresentado ao $5^{\circ}$ Congresso Brasileiro de Epidemiologia; 2002. Mar 23-27; Curitiba].

Doimo LA. O Uso do tempo e o fazer diário de mulheres idosas. São Paulo; 2003. [Tese de doutorado - Faculdade de Saúde Pública da Universidade de São Paulo].

Duarte YAO. Familia: rede de suporte ou fator estressor. A ótica de idosos e cuidadores familiares. São Paulo; 2001. [Tese de doutorado - Escola de Enfermagem da Universidade de São Paulo].

Dumazedier J. Toward a society of leisure. New York: The Free Press; 1967. 
Dunn W, McGourty L. Aplicación de la terminologia uniforme a la practica profesional: apendices. In: Hopkins HL, Smith HD. Terapia ocupacional de Willard \& Spackmann. 8. ed. Madrid: Panamericana; 1998. p. 894-8.

Emmel ML, Lancman S. Quem são nossos mestres e doutores? O avanço da capacitação docente em Terapia Ocupacional no Brasil. Cad. Ter. Ocup. UFSCar. 1998; 7: 29-38.

Faro ACM. Técnica Delphi na validação das intervenções de enfermagem. Rev Esc Enferm USP 1997; 31: 259-73.

Ferrari MAC, Miadaira ES, Nakagawa, CS. Aspectos de terapia ocupacional relativos à formação de cuidadores informais de idosos. São Paulo; 1993. [Texto didático para o $1^{\circ}$ Treinamento para Formação de Cuidadores Informais em Atenção à Saúde do Idoso - Secretaria Municipal de Saúde de São Paulo].

Fillenbaum GG. Functional ability. In: Ebraim S, Kalache A. Epidemiology em old age. London: BMJ Publishing Group; 1996. p. 229 -35.

Fillenbaum GG. The wellbeing of the elderly: approaches to multidimensional assessment. Geneva: World Health Organization; 1984. (WHO Offset Publication, 84).

Fletcher RH, Fletcher SW, Wagner EH. Clinical epidemiology: The essentials. Baltimore: Williams \&Wilkins; 1996.

Francisco B.R. Terapia ocupacional. Campinas: Papirus; 1988.

Fundação IBGE. Brasil em números: 2000. Rio de Janeiro; 2000. v.8.

Gil AC. Como elaborar projetos de pesquisa. São Paulo: Atlas; 1995. 
Gil AC. Métodos e técnicas em pesquisa social. São Paulo: Atlas; 1995.

Gill TM, Robison JT, Willians CS, Tinetti ME. Mismatches between the home environment and physical capabilities among community-living older persons. J Am Geriatr Soc 1999; 47:88-92.

Gitlin LN, Winter L, Dennis MP, Corcoran M, Schinfeld S, Hauck WW. Strategies used by families to simplify tasks for individuals with alzheimer's disease and related disorders: Psycometric Analysis of Task Management Strategy Index (TMSI). Gerontologist 2002; 42:61-9.

Gonçalves LHT. Instrumentos de avaliação da autonomia no desempenho das atividades de vida diária do cliente idoso. ACM Arq Catarin Med 1996; 24(4):2147.

Gordilho A, Sergio J, Silvestre J, Ramos LR, Freire MPA, Espindola A et al. Desafios a serem enfrentados no terceiro milênio, pelo setor saúde na atenção integral ao idoso. Rio de janeiro: UnAti; 2000.

Gray JML. Putting occupation into practice: occupation as ends, occupation as means. Am J Occup Ther 1998; 52(5): 354-64.

Hansen RA, Atchison B. Conditions in occupational therapy - Effect on occupational performance. 2. ed. Baltimore: Lippincott Williams e Wilkins, 2000.

Hasselkus BR. Discapacidad funcional en ancianos. In Hopkins HL, Smith HD. Terapia ocupacional de Willard \& Spackmann. 8. ed. Madrid: Panamericana; 1998. p 742-52.

Heller A. O cotidiano e a história. 2. ed. São Paulo: Paz e Terra filosofia, 1970. 
Hill J. Areas de ejecución en terapia ocupacional. In: Hopkins HL, Smith HD. Terapia ocupacional de Willard \& Spackmann. 8. ed. Madrid: Panamericana; 1998. p 192-206.

Hopkins HL. Introducción a la terapia ocupacional. In: Hopkins HL, Smith HD. Terapia ocupacional de Willard \& Spackmann. 8. ed. Madrid: Panamericana; 1998. p 3-12.

Horgas AL, Wilms HU, Baltes MM. Daily life in very old age: everyday activities as expression of successful living. Gerontologist 1998; 38:556-68.

Jacobs K. Evaluaciones y programas de trabalho. In Hopkins HL, Smith HD. Terapia ocupacional de Willard \& Spackmann. 8. ed. Madrid: Panamericana; 1998. p 226-48.

Jönsson ANL, Möller A, Grimby G. Managing occupations in every life to achieve adaptation. Am J Occup Ther 1999; 53: 353-62.

Kalache A. Veras, RP, Ramos RL. O envelhecimento da população mundial: um desafio novo. Rev Saúde Pública 1987; 21: 200-10.

Kane RL. Ouslander JG, Abrass, IB. Essential of clinical geriatrics. 3. ed. New York: McGraw-Hill; 1994.

Kane RL. The implication of assessment. J Gerontol 1993; 48 (Sp.Issue): 27-31.

Katz S, Ford AB, Moskowitz RW, Jackson BA, Jaffe MW. Estudios sobre la enfermedad en los ancianos. El indice de AVD: Medicion normalizada de la funcionalidad biologica y pscosocial. In: White KL, Frenk J, Ordonez C, Paganini JM, Starfield B. Investigaciones sobre servicios de salud: una antologia. Washington (DC): Organización Panamericana de la Salud; 1992. p.303-11 (OPS Publicación Cientifica, 534). 
Keith RA. Conceptual basis of outcome measures. Am J Phys Med Rehabil 1995; 74: $73-80$.

Kielhofner G , Burke JP. A terapia ocupacional após 60 anos: um relatório sobre a mudança de identidade e do corpo de conhecimento. Am J Occup Ther 1977; 31: 675-89.

Kielhofner G. Fundamentos del conocimiento de terapia ocupacional. In: Hopkins HL, Smith HD. Terapia Ocupacional de Willard \& Spackmann. 8. ed. España: Panamericana; 1998. p 137-44.

Knox SH. Juego y actividades de esparcimiento. In: Hopkins HL, Smith HD. Terapia ocupacional de Willard \& Spackmann. 8. ed. Madrid: Panamericana; 1998. p 260-8.

Lawton MP, Brody E. Assessment of older people: self maintining and instrumental activities od daily living. Gerontologist 1969; 9: 179-86.

Levin LS. Self-care toward fundamental changes in national strategies. Int J Health Educ 1981; 24: 219-28.

Lima ACP, Barroso LP, Iwamizu PS, Okura RIS. Relatório de análise estatística sobre o projeto "Validação do Instrumento CICAc (Classificação de Idosos quanto à Capacidade para o Autocuidado)" São Paulo: IME-USP; 2003. (RAE CEA - 03P02).

Litvak J. El envejecimiento de la población: un desafio que va más allá del año 2000. Bol Oficina Sanit Panam 1990; 109: 2-5. 
Litvoc J, Derntl AM. Capacidade funcional do idoso: significado e aplicações. In: Cianciarullo TI, Gualda DMR, Silva GTR, Cunha ICKO. Saúde na família e na comunidade. São Paulo: Robe editorial; 2002. p.268-319.

Lodi JB. A Entrevista: teoria e prática. 7. ed. São Paulo: Pioneira; 1991. (Biblioteca Pioneira de Administração e Negócios).

Lollar DJ. Public health and disability: Emerging opportunities. Public Health Rep 2002; 117: 131-5.

Lorys FO, Enhancing patients' autonomy. Dimens Crit Care Nurs 1994; 13: 60-8.

Mann WC, Hurren D., Machiko T. Assistive devices used by home-based elderly persons with arthrits. Am J Occup Ther 1995; 49: 810-20.

Markides K, Stroup-Benham CA, Goodwin JS, Perkowski LC, Lichtenstein M, Ray LA. The effect of medical conditions on the functional limitations of MexicanAmerican elderly. Ann Epidemiol 1996; 6: 386-91.

Maslow A. Motivation and personality. 3 ed. New York: Harper \& Row; 1987.

McDowell I, Newell C. Measuring health: a guide to rate scales and questionnaires. Oxford: Oxford University Press; 1987.

McSweeny AJ, Creer TL. Health-related quality-of life assessment in medical care. Dis Mon 1995; 41: 16-20.

Menezes AK. Avaliação funcional do idoso versus avaliação clínica tradicional. In: Sociedade Brasileira de Geriatria e Gerontologia, organizador. Caminhos do envelhecer. Rio de Janeiro: Revinter; 1994. p. 63-70. 
Messecar DC Caregivers' ability to make environmental modifications. J Gerontol Nurs 2000; 26 (12): 32-42.

Meyer A, The philosophy of occupation therapy. Arch Occup Ther 1922; 1: 1-10.

Ministério da Saúde. Fundação Oswaldo Cruz. Promoção da saúde. Brasília (DF); 1996.

Mioshi E. Proposta de sistematização de critérios de avaliação e matriz de raciocínio clínico em terapia ocupacional para o idoso. São Paulo; 2003. [Dissertação de Mestrado - Faculdade de Medicina da Universidade de São Paulo].

Morales Martínez F. Evaluación integral del anciano In: Perez EA, Galinsk D, Martinez ARS, Ayéndez MS. La atención de los ancianos: un desafio para los años noventa.. Washington (DC): OMS/OPS; 1994. (OPS - Publicación Cientifica, 546).

Neistadt ME, Seymour SG. Treatment activity preferences of occupational therapists in adult physical dysfunction settings. Am. J Occup Ther 1995; 49: 437-43.

Neufeld A, Hobbs H. Self-care in high-rise for seniors. Nurs Outlook 1985; 33: 298-301.

Norburn JEKI. Bernard SL, Konrad TR, Woomert A, DeFriese GH, Kalsbeek WD et al. Self-care and assistance from others in coping with functional status limitations among a national sample of older adults. J Gerontol B Psychol Sci Soc Sci 1995; 50: 101-9.

Norris CM. Self-care. Am J Nurs 1979; 79: 486-9.

Orem DE. Nursing: concepts of practice. 4. ed. St. Louis: Mosby Year Book; 1991. Self-care, self-care requisites, therapeutic self-care demand; p. 117-43. 
Organização Mundial da Saúde. Organização Pan Americana da Saúde. 25 Conferência Sanitária Pan-Americana e 50 Sessão do Comitê Regional. Saúde dos Idosos. Washington (DC); 1998.

Pasquali, L: Princípios de elaboração de escalas psicológicas. Rev Psiquiatr Clin (São Paulo) 1998; 25 (5): 206-213.

Paula JAM, Tavares, MCGF, Diogo MJD. Avaliação funcional em gerontologia. Rev Gerontol 1998; 6 (20): 81-8.

Polit D. Nursing research: principles and methods. 3 ed. Philadelphia: J.B. Lippincott Company; 1987.

Putnam M. Linking aging theory and disability models: Increasing the potenctial to explore aging with physical impairment. Gerontologist 2002; 42:799-806.

Ramos LR. Growing old in São Paulo Brazil: assessment of health status and social support of elderly people from different socio-economic strata living in community. London; 1987. [PhD Thesis - London School of Hygiene and Tropical Medicina. University of London].

Ramos RL, Saad PM. Morbidade da população idosa. In:Fundação SEADE. O idoso na Grande São Paulo. São Paulo; 1990. p 161-72.

Restrepo HE, Perez EA. Promoción de la salud de los ancianos. In: Perez E,A, Galinsk D, Martinez ARS, Ayéndez, MS. La atención de los ancianos: un desafio para los años noventa.. Washington (DC): OMS/OPS; 1994 (POS - Publicación Cientifica, 546).

Roelofps LH, The meaning of leisure. J Gerontol Nurs 1999; 25 (10): 32-9. 
Rogers JC, Holm MB, Stone RG. Evaluation of daily living tasks: the home care advantage. Am J Occup Ther 1997; 51: 410-22.

Rowe JW, Kahn RL. Successful aging. New York: Dell Publishing; 1998. The struture of successful aging; p. 36 - 52.

Sherman FT. Functional assessment.Easy-to-use screening tools speed initial office work-up. Geriatrics 2001; 56(8):36-40.

Silva RF, Tanaka OY. Técnica Delphi: identificando as competências gerais de médicos e de enfermeiros que atuam em atenção primária de saúde. Rev. Esc. Enferm.USP. 1999; 33(3): 207-16.

Smith H. Evaluación total y evaluación específica en terapia ocupacional: consideraciones generales. In: Hopkins HL, Smith HD. Terapia ocupacional de Willard \& Spackmann. 8. ed. Madrid: Panamericana; 1998. p. 169-91.

Soares LBT. Terapia ocupacional: lógica do capital ou do trabalho? São Paulo: Hucitec; 1991. (Saúde em Debate 42).

Spínola AWP. Delphos: proposta tecnológica alternativa. São Paulo: Faculdade de Saúde Pública da USP; 1984.

Spínola AWP. Técnica prospectiva Delphi.. Vitória; 2002. [Apostila do Curso de mestrado interinstitucional. FSP-USP - FAESA].

Stuck AE, Walthert JM, Nikolaus T, Bula CJ, Hohmann C, Beck JC. Risk factors for functional status decline in community - living elderly people: systematic literature review. Soc Sci Med 1999; 48: 445-69.

Teaff JD, editor Leisure services with the elde rly. Carbondale: Waveland Press; 1990. Leisure and aging; p. 43-58. 
Trombly CA, Scott AD. Occupational therapy for physical dysfunction Baltimore: The Williams \& Wilkins Company; 1977.

Tuokko H, Hadjistavropoulos T, Miller JA, Bettie BL. The Clock Test: A sensitive measure to differentiate normal elderly from those with alzheimer disease. J Am Geriatric Soc 1992; 40:579-584.

Veras R. País jovem com cabelos brancos: A saúde do idoso no Brasil. Rio de Janeiro: Relume Dumará; 1994. As escalas de deficiência cognitiva e depressão; p. $130-47$.

Verbrugge L, Patrick DL. Seven chronic conditions: their impact on US adults' activity levels and use of medical services. Am J Public Health 1995; 85:173-181.

Watson YI, Arfken CL, Birge SJ. Clock Completion: An objetive screening teste for dementia. J Am Geriatric Soc 1993; 41:1235-40.

Williams PL, Webb C. The Delphi technique: a methodological discussion. J Adv Nurs 1994; 19: 180-6.

World Health Organization. International classification of impairments, disabilities, and handicaps: a manual of classification relating to the consequences of disease. Geneva; 1980. 
ANEXO 1 - VERSÕES DO INSTRUMENTO CICAC 


\section{1. $1^{\mathrm{a}}$ Versão - Instrumento CICAc}

Nome do entrevistado: $\mathrm{N}^{0}$ do prontuário

Área Ambiente sócio-familiar: questões 1,2 e 3

1. $\mathrm{O}$ (a) $\operatorname{Sr}($ a) mora com outras pessoas na mesma casa? Sim ( ) Não ( ). Em caso afirmativo, com quem o (a) sr (a) mora?

2. $\mathrm{O}$ (a) $\mathrm{Sr}$ (a) tem (outros) parentes e amigos? Sim ( ) Não ( ). Em caso afirmativo, quem são eles e de quanto em quanto tempo costuma vê-los?

Objetivo das questões 1 e 2: Conhecer o Contexto Sócio-Familiar do idoso

3. Tem alguma(s) pessoa(s) que cuidaria(m) do(a) $\operatorname{Sr}(a)$ caso o(a) $\operatorname{Sr}(a)$ ficasse doente? Sim ( ) Não ( ). Em caso afirmativo, quem seria(m) essa(s) pessoa(s)?

Objetivo: Conhecer a Rede de Suporte potencial do idoso

Área Universo ocupacional: questões 4,5,6,6.1,7, 8,9 e 9.1

4. O que o(a) $\operatorname{Sr}(a)$ faz todos os dias, desde a hora que o(a) $\operatorname{Sr}(a)$ acorda até a hora que vai dormir?

Procure contar todas as coisas que o(a) Sr(a) faz.

Objetivo: Conhecer as Atividades cotidianas rotineiras

5. Tem alguma coisa que o(a) $\operatorname{Sr}(a)$ não faz todos os dias mas que de vez em quando o(a) $\operatorname{Sr}($ a) faz?

Objetivo: Conhecer as Atividades cotidianas não-rotineiras

6. Das coisas que o(a) $\operatorname{Sr}(a)$ faz, quais o(a) $\operatorname{Sr}(a)$ acha que são importantes para o(a) $\operatorname{Sr}(\mathrm{a})$ ?

6.1. Por quê?

Objetivo: Conhecer as Atividades cotidianas importantes e os requisitos a que elas correspondem

Se o(a) idoso(a) mencionar entre as atividades importantes, uma pequena parcela de atividades prazerosas, aplica-se a questão 7

7. Além de $\mathrm{X}$ e $\mathrm{Y}$ (atividades prazerosas citadas como parte das atividades importantes) tem mais alguma coisa que o(a) $\operatorname{Sr}(a)$ faz e que o(a) $\operatorname{Sr}(a)$ goste de fazer? Por quê?

Se o idoso não mencionar entre as atividades importantes atividades prazerosas, adotase a questão 8:

3. Das coisas que o(a) $\operatorname{Sr}($ a) faz, de quais o(a) $\mathrm{Sr}($ a) mais gosta? Por quê?

Objetivo: Conhecer as Atividades cotidianas prazerosas e os requisitos a que elas

correspondem 
9. Das coisas que o(a) $\operatorname{Sr}(a)$ faz, de quais o(a) $\operatorname{Sr}$ (a) menos gosta? 9.1. Por quê ? Objetivo: Conhecer as Atividades cotidianas não prazerosas e os requisitos a que elas não atendem Área Capacidade funcional: questões 10,11,12,13, 14 e 15

10. $\mathrm{O}$ (a) $\mathrm{Sr}(\mathrm{a})$ tem dificuldade física para fazer algumas das coisas que o(a) $\mathrm{Sr}$ (a) faz? $\operatorname{Sim}($ ) Não( ). Em caso afirmativo, tem dificuldade para fazer o quê? Qual a dificuldade?

Objetivo: Conhecer as Atividades para as quais apresenta dificuldade física/Fatores de Inibição

11. $\mathrm{O}$ (a) $\mathrm{Sr}(\mathrm{a})$ costuma esquecer algumas coisas que o(a) Sr(a) tenha a fazer?

$\operatorname{Sim}$ ( ) Não( ). Em caso afirmativo, o que o (a) sr (a) costuma esquecer?

Objetivo: Conhecer as Atividades para as quais apresenta dificuldade de memória/ fatores de Inibição

12. $\mathrm{O}$ (a) $\mathrm{Sr}(\mathrm{a})$ tem dificuldade para fazer mais algumas das coisas que o(a) $\operatorname{Sr}(a)$ faz? Sim ( ) Não ( ). Em caso afirmativo, tem dificuldade para fazer o quê? Que tipo de dificuldade?

Objetivo: Conhecer as Ativida des para as quais apresenta dificuldade (exceto física e de memória)/ Fatores de Inibição

13. O que o(a) $\operatorname{Sr}(a)$ faz quanto à dificuldade $X$ : encontrou um jeito mais fácil de fazer, tem alguém que o ajuda, faz mesmo com dificuldade sem ajuda ou deixou de fazer?

Como o(a) $\operatorname{Sr}$ (a) faz (caso tenha encontrado um jeito mais fácil de fazer)? Quem o ajuda e como o ajuda (caso precise e identifique ajuda)?

Repetir a pergunta para cada uma das dificuldades mencionadas

Objetivo: Conhecer os Fatores de Compensação para as Atividades cotidianas

Em caso de ocorrência de atividades que o idoso precise de ajuda, faça com dificuldade e/ou tenha deixado de fazer em função das dificuldades, aplicar a questão 14 e/ou 15 respectivamente:

14. Das coisas que o(a) $\operatorname{Sr}(a)$ faz com dificuldade ou tenha alguém que o ajude, tem alguma que o(a) $\operatorname{Sr}(a)$ gostaria de encontrar um jeito mais fácil para fazer?

$\operatorname{Sim}($ ) Não( )

Em caso afirmativo, o que seria? $\mathrm{O}(\mathrm{a}) \mathrm{Sr}(\mathrm{a})$ vê algum jeito mais fácil de fazer (repetir a atividade)? $\operatorname{Sim}($ ) Não( ). Em caso afirmativo, como poderia ser feito?

15. Das coisas que o(a) $\operatorname{Sr}(a)$ deixou de fazer pelas dificuldades que o(a) $\operatorname{Sr}(a)$ me contou, tem alguma coisa que o(a) Sr(a) gostaria de voltar a fazer? Sim ( ) Não ( ). Em caso afirmativo, o que seria? $\mathrm{O}$ (a) $\mathrm{Sr}$ (a) vê algum jeito de voltar a fazer(repetir a atividade)? Sim ( ) Não ( ). Em caso afirmativo, como poderia ser feito?

Objetivo de q.14 e q.15: Conhecer as Atividades desejadas/Fatores estimados como facilitadores 
Área Universo Ocupacional (continuação): questões 16, 17

16. Tem alguma coisa que o(a) $\operatorname{Sr}(a)$ gostaria de ter feito em sua vida mas nunca fez, ou fez há algum tempo atrás e gostaria de voltar a fazer? Sim ( ) Não ( ). Em caso afirmativo, o quê? Por que não faz?

Objetivo: Conhecer as Atividades desejadas/Fatores de Inibição

17. $\mathrm{O}$ (a) $\operatorname{Sr}(\mathrm{a})$ vê algum jeito de (aprender ou voltar a) fazer (repetir a atividade mencionada)? Sim ( ) Não ( ) (Aplicada no caso de Atividades desejadas nunca realizadas ou realizadas há algum tempo) Em caso afirmativo, como poderia (aprender ou voltar a) fazer?

Objetivo: Conhecer os Fatores Estimados como facilitadores

Observações do entrevistador:

Nome do entrevistador: Data da entrevista: 


\subsection{Estruturação do Instrumento CICAc}

\section{Considerações prévias}

A estratégia metodológica para a obtenção de informações junto aos idosos para a elaboração da $1^{\text {a }}$ Versão do Instrumento CICAc compreendeu a realização de duas etapas de entrevistas - guiadas respectivamente por um roteiro preliminar e um roteiro ajustado, ambos compostos por questões abertas - aos usuários idosos da UBS José Toledo Piza e seguidas por análise qualitativa de conteúdo (ALMEIDA 1997).

Ao priorizar o conteúdo das entrevistas para a elaboração do instrumento e as análises temática e formal descritas por BARDIN (1977) como método de apreensão e tratamento desse conteúdo, admiti que os instrumentos descritos pela literatura, os conceitos teóricos que embasam a elaboração desses instrumentos e minha experiência profissional, ainda que fossem fundamentais, não eram suficientes para embasar a elaboração de um instrumento que orientasse a prática da terapia ocupacional junto ao idoso com ênfase na capacidade para o autocuidado, enquanto estratégia de promoção da saúde dos idosos.

A Análise de Conteúdo possibilitou a elaboração da $1^{\mathrm{a}}$ versão do Instrumento CICAc (apresentado na Introdução desse trabalho). Ao debruçar novamente sobre a análise de conteúdo das entrevistas - guiadas pelo roteiro ajustado - foi possível identificar categorias de resposta a cada uma das questões e propor sua estruturação.

Nesse processo de estruturação foram identificadas ainda novas possibilidades de agrupamento de respostas. Essa re-categorização é fruto basicamente de uma reflexão sobre conhecimentos mais atualizados em terapia ocupacional e da obediência aos critérios de pertinência, mútua exclusividade, exaustividade e utilidade. 


\section{O processo de estruturação do Instrumento CICAc}

Esse processo será descrito por áreas de investigação e serão apresentadas as questões, respostas dos idosos e comentários sobre a estruturação das questões.

Área de investigação: Informações sobre o contexto sócio-familiar do idoso e potencial rede de suporte.

\section{Questão 1 e 2}

1. $\mathrm{O}$ (a) $\mathrm{Sr}(\mathrm{a})$ mora com outras pessoas na mesma casa? Sim ( ) não ( )

Em caso afirmativo, com quem o(a) $\mathrm{Sr}(\mathrm{a})$ mora?

2. $\mathrm{O}$ (a) $\operatorname{Sr}(\mathrm{a})$ tem (outros) parentes e amigos? Sim ( ) não ( ) Em caso afirmativo, quem são eles?

2.1. De quanto em quanto tempo costuma vê-los?

Objetivo das perguntas 1, 2 e 2.1: Conhecer o Contexto Sócio-familiar do idoso

Respostas de idosos à questão 1 do roteiro ajustado e categorização:

- Companheiro/ Cônjuge

- Filho (s)

- Filha (s)

- Filha, genro

- Filho, nora

- Netos

- Bisnetos

Respostas de idosos à questão 2 do roteiro ajustado e categorização

- Companheiro/ Cônjuge

- Filho(s)

- Filha (s)

- Filha, genro

- Filho, nora

- Netos

- Bisnetos

- Tios

- Sobrinhos

- Primos

- Cunhados

- Vizinhos

- Amigos

Respostas de idoso à questão 2.1 do roteiro ajustado e categorização

- Todos os dias

- Quase todos os dias

- 2 vezes por semana

- 1 vez por semana

- A cada 15 dias 
- 1 vez por mês

- 1 vez a cada 2 meses

- 1 vez a cada 6 meses

- 1 vez por ano

- A cada 2 anos

Comentário sobre a estruturação: Além das respostas dos idosos, a categoria "outros" foi adicionada na versão estruturada do Instrumento CICAc como possibilidade de respostas às questões 1 e 2 com vistas a contemplar demais graus de parentescos ou tipos relacionamentos.

\section{Questão 3}

Tem alguma(s) pessoa(s) que cuidaria(m) do(a) $\operatorname{Sr}(a)$ caso o(a) $\operatorname{Sr}(a)$ ficasse doente?

$\operatorname{Sim}($ ) não ( ). Em caso afirmativo, quem seria(m) essa(s) pessoa(s)

Objetivo: Conhecer a rede de suporte potencial do idoso

Respostas à questão 3 do roteiro ajustado e categorização

- Companheiro/ Cônjuge

- Filho (s)

- Filha (s)

- Filha, genro

- Filho, nora

- Netos

- Bisnetos

- Tios

- Sobrinhos

- Primos

- Cunhados

- Vizinhos

- Amigos

Comentários sobre a estruturação: A categoria "outros" também foi adicionada a versão estruturada do Instrumento CICAc como possibilidade de resposta à questão 3, atendendo ao critério da exaustividade.

Área de investigação (dimensão): Universo Ocupacional. Atividades que compõe o universo do idoso e como ele qualifica essas atividades - rotineiras, importantes, não prazerosas, desejadas (não realizadas). 


\section{Questões 4 e 5}

4. O que o(a) $\operatorname{Sr}(a)$ faz todos os dias, desde a hora que o(a) $\operatorname{Sr}(a)$ acorda até a hora que vai dormir? Procure contar todas as coisas que $\mathrm{o}(\mathrm{a}) \mathrm{Sr}(\mathrm{a})$ faz.

Objetivo: Conhecer as Atividades cotidianas rotineiras

5. Tem alguma coisa que o(a) $\operatorname{sr}$ (a) não faz todos os dias mas que de vez em quando o(a) $\mathrm{Sr}$ (a) faz?

Objetivo: Conhecer as Atividades cotidianas não-rotineiras

Respostas dos idosos às questões 4 e 5 do roteiro ajustado e categorização

Os idosos citaram, como resposta a essas questões, atividades diversas (cerca de 50) abrangendo atividades básicas, instrumentais de trabalho e lazer.

Comentários sobre a estruturação: Considerando as áreas de ocupação em terapia ocupacional e a nomenclatura proposta pelo Instituto de Reabilitação de Chicago, as atividades descritas foram a princípio distribuídas em cinco categorias: atividades básicas e instrumentais de vida diária, lazer e trabalho remunerado e não remunerado. (HILL 1998; HOPKINS 1998).

Para assegurar o levantamento de um universo diversificado de atividades elaborei uma "relação geral de atividades". Essa relação de atividades foi organizada segundo as categorias mencionadas acima e elaborada a partir de escalas de atividades de vida diária - com indicação de validade e confiabilidade - e atividades mencionadas pelos idosos. Considero pertinente o emprego da seguinte relação como alternativa de resposta a maior parte das questões dessa área do instrumento. A adição da categoria "outras atividades" na versão estruturada e sua especificação asseguram o cumprimento do critério de exaustividade. (FILLENBAUM 1984; McDOWELL e NEWELL 1987; RAMOS 1987; ALMEIDA 1997). 
Quadro 1: Relação geral de atividades. Instrumento CICAc versão estruturada

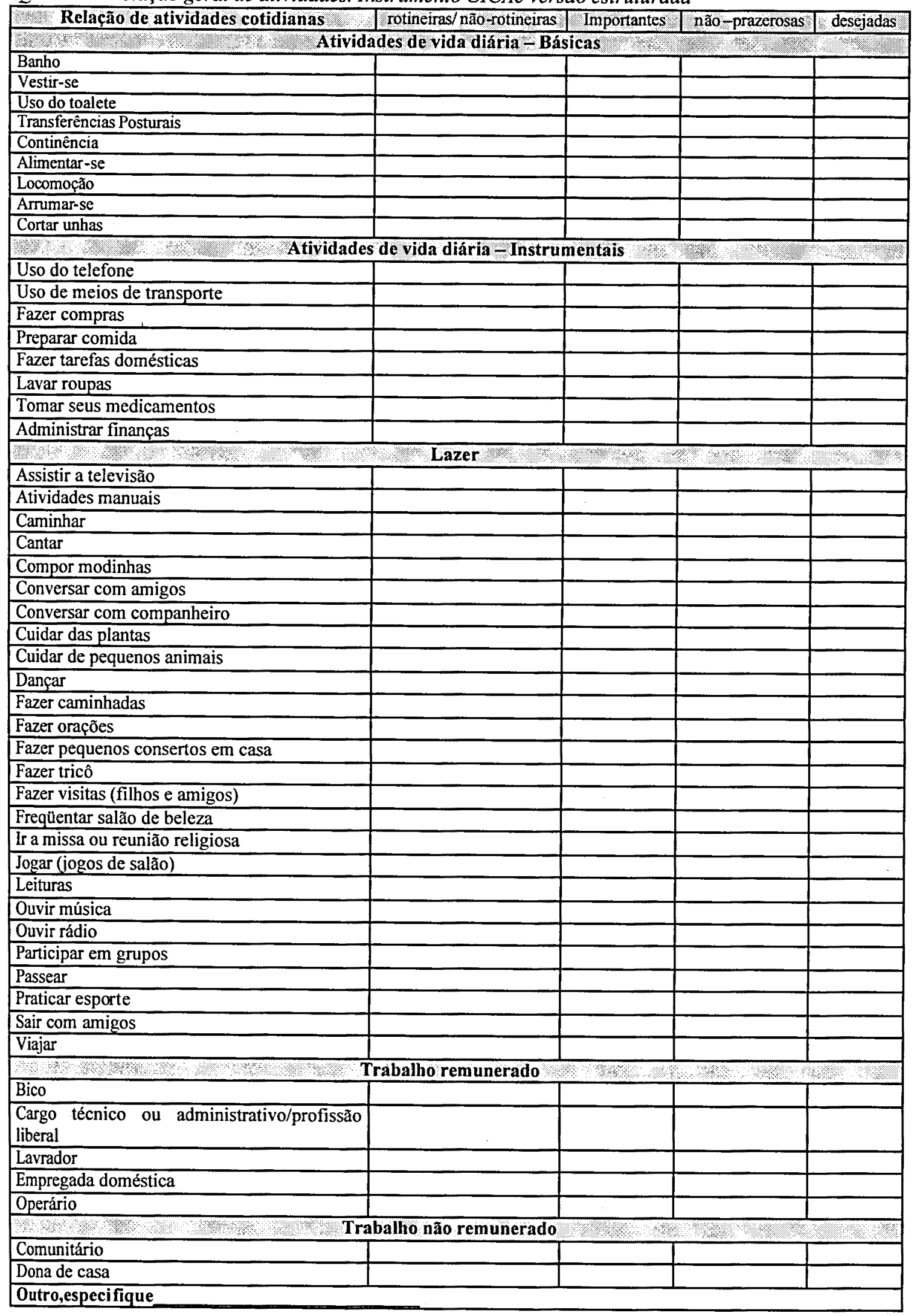


Questões 6 e 6.1

6. Das coisas que o(a) $\mathrm{Sr}$ (a) faz, quais o(a) $\mathrm{Sr}$ (a) acha que são importantes para o(a) $\mathrm{Sr}$ (a)? 6.1. Por quê? Objetivo: Conhecer as Atividades cotidianas importantes e os requisitos a que elas correspondem

Respostas de idosos à questão 6 do roteiro ajustado e categorização.

Atividades básicas de vida diária

- Tomar banho

Atividades instrumentais de vida diária

- Serviços de casa

- Preparo de comida (abrangendo preparo de lanches e pratos)

- Fazer compras

- Dirigir automóvel

- Lavagem de roupa

Trabalho não-remunerado

- Cuidado com familiares

- Visitar idosos e doentes (trabalho comunitário)

Trabalho remunerado

- Atividade remunerada (jogo do bicho)
Atividades de lazer

- Atividades religiosas (abrangendo rituais e reuniões religiosas)

- Visitas a amigos

- Pequenos consertos em casa

- Escutar rádio

- Costurar

- Plantar

- Bordar em clube de mães

- Leituras diversas (abrangendo leituras e recortes de jornais e leituras religiosas)

- Orientar amigos

- Participar em ensaios de canto religioso

- Pensar na namorada

- Caminhar

- Fazer orações

Comentários sobre a estruturação: A fim de assegurar o levantamento de atividades que o idoso considere "importantes" e por constatar que essas atividades correspondem às atividades cotidianas, proponho a "relação geral de atividades" como alternativas de resposta à questão 6

Respostas de idosos à questão 6.1 do roteiro ajustado e categorização

- Trazem prazer

- Promovem senso de utilidade (incluindo transmissão de cultura)

- Através delas as pessoas desemp enham comportamentos esperados

- Mantêm as pessoas ativas

- Distraem

- Estimulam o exercício da independência

- Estão relacionadas com a sobrevivência

- Diminuem a solidão e a carência afetiva (incluindo oportunidade de interação)

- Trazem satisfação espiritual

- Trazem oportunidade de descansar

- Ocupam o tempo

- São benéficas à saúde (melhoram a memória e circulação sanguínea)

- Mantém pessoa atualizada

- Alimentam a vaidade

- Mantêm privacidade 


\section{Questões 7 e 8}

7. Além de $\mathrm{X}$ e $\mathrm{Y}$ (atividades prazerosas citadas como parte das atividades importantes) tem mais alguma coisa que o (a) sr (a) faz e que o (a) sr (a) goste de fazer? Por quê?

Se $o$ idoso não mencionar entre as atividades importantes atividades prazerosas, adota-se a seguinte questão:

8. Das coisas que o(a) $\operatorname{Sr}(a)$ faz, de quais o(a) $\operatorname{Sr}(a)$ mais gosta? Por quê?

Objetivo: Conhecer as Atividades cotidianas prazerosas e os requisitos a que elas correspondem

Comentários sobre a estruturação: As questões 7 e 8 foram elaboradas para assegurar o levantamento sistemático das "atividades prazerosas", considero no entanto que a estruturação da questão 6.1 em categorias já apresentadas acima, acrescidas da categoria "outras" e sua especificação permitirá o levantamento sistemático e exaustivo das razões de importância das atividades inclusive o fato de proporcionar prazer, eliminando a necessidade das questões 7 e 8 na versão estruturada do Instrumento CICAc

\section{Questões 9 e 9.1}

9. Das coisas que o(a) $\mathrm{Sr}(a)$ faz, de quais o(a) $\mathrm{Sr}(a)$ menos gosta? Por quê?

Objetivo: Conhecer as atividades cotidianas não prazerosas e os requisitos a que elas não atendem

Respostas de idosos à questão 9 do roteiro ajustado e categorização

Atividades instrumentais de vida diária

- Limpeza pesada (incluindo passar pano no chão)

- Varrer casa/tirar pó

- Lavar roupa

- Passar roupa

- Cozinhar

Lazer

- Assistir a televisão

- Ficar em casa por muito tempo

- Passear

- Ir a festa

Comentários sobre a estruturação: Embora outras atividades não tenham sido mencionadas, considero a possibilidade dos idosos em geral apresentarem interesses e desinteresses por um universo diversificado de atividades. Proponho a "relação geral de atividades" como alternativas de resposta à questão 9. 
Respostas de idosos à questão 9.1 do roteiro ajustado e categorização

- Acima das capacidades do idoso

- Realizada em condições adversas

- Não atende a necessidade

Comentários sobre a estruturação: Considero que a estruturação da questão 9.1 em categorias - descritas no quadro, acrescidas da categoria "outras" e sua especificação permitirá o levantamento sistemático e exaustivo das razões que levam aos idosos a julgarem as atividades como "não-prazerosas"

Área de investigação (dimensão): Capacidade funcional. Atividades para as quais o idoso apresenta dificuldades, tipos de dificuldade e práticas de autocuidado para manter ou compensar dificuldades.

\section{Questões 10, 11 e 12}

10. O(a) $\mathrm{Sr}$ (a) tem dificuldade física para fazer algumas das coisas que o(a) $\mathrm{Sr}$ (a) faz?

$\operatorname{Sim}$ ( ) Não( ). Em caso afirmativo, tem dificuldade para fazer o quê? Qual a dificuldade?

Objetivo: Conhecer as Atividades para as quais apresenta dificuldade física/Fatores de Inibição

11. $\mathrm{O}$ (a) $\operatorname{Sr}($ a) costuma esquecer algumas coisas que o(a) $\operatorname{Sr}($ a) tenha a fazer? $\operatorname{Sim}($ ) Não( ). Em caso afirmativo, o que o(a) $\mathrm{Sr}$ (a) costuma esquecer?

Objetivo: Conhecer as atividades para quais apresenta dificuldades de memória/ fatores de inibição

12 .O(a) $\operatorname{Sr}$ (a) tem dificuldade para fazer mais algumas das coisas que o(a) $\operatorname{Sr}(a)$ faz? $\operatorname{Sim}($ ) Não ( ) Em caso afirmativo, tem dificuldade para fazer o quê? Que tipo de dificuldade?

Objetivo: Conhecer as Atividades para as quais apresenta dificuldade (exceto dificuldades físicas e de memória)/ Fatores de Inibição

As questões 10, 11, 12 apresentadas acima resultaram de desdobramento da questão 8 do roteiro ajustado, a seguir:

\section{Questão 8. Roteiro ajustado}

Q.8. O(a) $\mathrm{Sr}$ (a) tem dificuldade para fazer algumas das coisas que o(a) $\mathrm{Sr}(\mathrm{a})$ faz? Para fazer o quê? Que tipo de dificuldade?

Objetivo: Conhecer as atividades cotidianas para as quais o idoso apresenta dificuldade/ fatores de inibição 
Respostas de idosos à questão 8 (atividades) do roteiro ajustado e categorização

Atividades instrumentais de vida diária

- Serviços de casa

- Lavar roupa

- Fazer compras

- Prepara comida (inclui escolher cereais e verduras e cozinhar)

Lazer

- Leitura (inclui desde ler letreiros de ônibus até publicações)

- Costura ( manual ou máquina)

- Tricô

- Plantar

- Pequenos consertos em casa

- Bordar

- Caminhar

- Fazer visitas

- Participar de eventos recreativos

- Serrar madeira
Condições motoras

- Pegar e sustentar peso (inclui carregar grandes volumes e transferir objetos pesados de até 50 quilos)

- Subir e descer escada (inclui subir/descer escadas internas e de acesso a casa, degraus de ônibus e "domésticas")

- Fazer ginástica

Atividades básicas de vida diária

- Dormir

- Relação Sexual

- Cobrir se na cama

Trabalho remunerado

- Preencher pedidos de jogos

- Preencher pedidos de cosméticos

Condições mentais

- Identificar pessoas pelo nome

- Localizar objetos

Relacionamentos sociais

Respostas de idosos à questão 8 do roteiro ajustado (tipos de dificuldade)e categorização.

- Física

- Sensorial

- Emocional

- Sócio-cultural

- Cognitiva/mental

- Ambiental

- Financeira

Comentários sobre a estruturação: Em linhas gerais as questões 10, 11 e 12 da $1^{\text {a }}$ versão do Instrumento CICAc se propõem levantar o universo de dificuldades do idoso - atividades e tipos de dificuldade. Para a versão estruturada do Instrumento CICAc proponho a recuperação da questão 8 do roteiro ajustado desde que as alternativas de resposta privilegiem o conteúdo expresso pelas questões 10, 11 e 12: atividades para as quais o idoso apresenta dificuldade e dificuldades fisicas, mentais e outras.

As atividades para as quais os idosos apresentam dificuldades aproximam-se daquelas oferecidas como alternativas de resposta às questões 4 e 5. Proponho que a 'relação geral de atividades" seja utilizada como referência para o registro das respostas à questão 8. As respostas a essa questão, no entanto, não se limitam ao fazer, estendendo-se às condições relacionadas ao fazer as quais denominei condições motoras 
e mentais. Os idosos citam ainda dificuldades em relacionamentos sociais. Ainda que essa citação não corresponda à categoria atividades, deve ser considerado seu levantamento sistemático. A categoria de resposta: "outras atividades" - e sua especificação, poderá incorporar essas respostas e outras que não se enquadrem em alternativas anteriores. Os tipos de dificuldades apresentados no quadro acima se configuram, juntamente com a "relação de atividades", como alternativas de resposta à questão 8.

\section{Questão 13}

13. O que o(a) $\operatorname{Sr}(a)$ faz quanto à dificuldade $X$ : encontrou um jeito mais fácil de fazer, tem alguém que o ajuda, faz mesmo com dificuldade sem ajuda ou deixou de fazer? Como o(a) $\mathrm{Sr}$ (a) faz (caso tenha encontrado um jeito mais fácil de fazer)? Quem o ajuda e como o ajuda (caso precise e identifique ajuda)? Repetir a pergunta para cada uma das dificuldades mencionadas

objetivo: Conhecer os Fatores de Compensação para as Atividades cotidianas

Comentários sobre a estruturação: Considero que a questão 13 se proponha identificar a existência de fatores compensatórios às dificuldades, a que categorias pertencem e quais são esses fatores. Dada a complexidade dessa questão, proponho que seja desmembrada em duas questões:

\section{Questão 13. Instrumento CICAc versão estruturada}

$1^{2}$ - O que o(a) $\operatorname{Sr}(a)$ faz quanto à dificuldade $X$ ? Encontrou um jeito mais fácil de fazer, tem alguém que o ajuda, faz mesmo com dificuldade sem ajuda ou deixou de fazer? O X representa cada uma das atividades para as quais o idoso apresenta dificuldade. Essas atividades deverão ser mencionadas uma a uma.

$2^{2}$ - Como o(a) Sr(a) faz/ quem o(a) ajuda?

Caso o idoso tenha "encontrado um jeito mais fácil de fazer" ou "tenha alguém que o ajude", proponho alternativas de respostas - adotadas pelos idosos e confirmadas pela literatura - para compensar dificuldades: mudança de comportamento, mudanças ambientais, adoção de dispositivos auxiliares e ajuda externa. (BALTES 1996; PUTNAM 2002; GILL 1999; GITLIN 2002; MESSECAR 2000; NORBURN e col. 1995). 
As respostas previstas para as duas questões (derivadas da questão 13) poderão ser registradas juntamente com as respostas as atividades para as quais o idoso apresenta dificuldade e tipos de dificuldade - em quadro resumo. $\mathrm{O}$ quadro deverá ser preenchido com atividades correspondentes, tomando como referência "relação geral de atividades". No que se refere a "quem ajuda", o entrevistador deverá registrar no quadro resumo o grau de parentesco/tipo de relacionamento correspondente, conforme os graus de parentesco adotados no Instrumento OARS - versão em português (RAMOS 1987). Esse instrumento será utilizado como uma das referências para a estruturação do Instrumento C.I.C.Ac, por reunir as seguintes qualidades: ser especifico para idosos, possuir versão em português e indicação de validade e confiabilidade.

Os graus de parentesco adotados no Instrumento OARS (Ramos, 1987) são:

1 Pai,Mãe, sogro(a), tio(a)

2 Cônjuge

3 Irmãos, primos, cunhados

4 Filhos, enteados, sobrinhos

5 Genro, nora

6 Netos

7 Bisnetos

10 Amigo, conhecido

11 Outros. Especifique:

Quadro 2: Quadro resumo para registro das atividades para as quais o idoso apresenta dificuldades, tipos de dificuldade e compensações adotadas. Instrumento CICAc versão estruturada.

\begin{tabular}{|c|c|c|c|c|c|c|}
\hline \multirow{2}{*}{$\begin{array}{l}\text { Compensações } \\
\text { Atividades para as } \\
\text { quais o idoso tem } \\
\text { Dificuldades e tipos de } \\
\text { dificuldades }\end{array}$} & \multicolumn{4}{|c|}{$\begin{array}{l}\text { Encontrou um jeito mais fácil de fazer/ } \\
\text { Tem alguém que o ajude }\end{array}$} & \multirow[t]{2}{*}{$\begin{array}{c}\text { Faz com } \\
\text { dificuldade }\end{array}$} & \multirow[t]{2}{*}{$\begin{array}{l}\text { Deixou } \\
\text { de fazer }\end{array}$} \\
\hline & $\begin{array}{c}\text { Mudança } \\
\text { de comporta } \\
\text { mento } \\
\end{array}$ & $\begin{array}{l}\text { Mudanças } \\
\text { ambientais }\end{array}$ & $\begin{array}{c}\text { Dispositivo } \\
\text { auxiliar }\end{array}$ & $\begin{array}{c}\text { Ajuda externa } \\
\text { (grau de } \\
\text { parentesco) }\end{array}$ & & \\
\hline \multicolumn{7}{|l|}{ Física } \\
\hline \multicolumn{7}{|l|}{ Sensorial } \\
\hline \multicolumn{7}{|l|}{ Emocional } \\
\hline \multicolumn{7}{|l|}{ Cognitiva/mental } \\
\hline \multicolumn{7}{|l|}{ Sócio-cultural } \\
\hline \multicolumn{7}{|l|}{ Ambiental } \\
\hline \multicolumn{7}{|l|}{ Financeira } \\
\hline Outras dificuldades & & & & & & \\
\hline
\end{tabular}




\section{Questão 14 e 15}

Em caso de ocorrência de atividades que o idoso precise de ajuda, faça com dificuldade e/ou tenha deixado de fazer em função das dificuldades, aplicar a questão 14 e/ou 15 respectivamente:

14. Das coisas que o(a) $\mathrm{Sr}$ (a) faz com dificuldade ou tenha alguém que o ajude, tem alguma que o(a) $\operatorname{Sr}(a)$ gostaria de encontrar um jeito mais fácil para fazer? Sim( ) Não( )

Em caso afirmativo, o que seria? $\mathrm{O}$ (a) $\operatorname{Sr}($ a) vê algum jeito mais fácil de fazer (repetir a atividade)? $\operatorname{Sim}($ ) Não( ). Em caso afirmativo, como poderia ser feito?

15. Das coisas que o(a) $\operatorname{Sr}(a)$ deixou de fazer pelas dificuldades que o(a) $\operatorname{Sr}(a)$ me contou, tem alguma coisa que o(a) $\mathrm{Sr}$ (a) gostaria de voltar a fazer? $\operatorname{Sim}$ ( ) Não ( ). Em caso afirmativo, o que seria? $\mathrm{O}$ (a) $\mathrm{Sr}$ (a) vê algum jeito de voltar a fazer (repetir a atividade)? Sim ( ) Não ( )Em caso afirmativo, como poderia ser feito?

Objetivo de q.14 e q.15: Conhecer as Atividades desejadas/Fatores estimados como facilitadores

Quadro 3: Quadro resumo para registro das atividades para as quais o idoso apresenta dificuldades, tipos de dificuldade e compensações estimadas. Instrumento CICAc versão estruturada

\begin{tabular}{|r|r|r|r|r|}
\hline $\begin{array}{r}\text { Compensaçōes } \\
\text { Estimadas }\end{array}$ & $\begin{array}{r}\text { Mudança de } \\
\text { comportamento }\end{array}$ & $\begin{array}{c}\text { Mudanças } \\
\text { ambientais }\end{array}$ & $\begin{array}{c}\text { Dispositivo } \\
\text { auxiliar }\end{array}$ & $\begin{array}{c}\text { Ajuda externa } \\
\text { (grau de } \\
\text { parentesco) } \\
\text { Atividades e tipos de dif. }\end{array}$ \\
\hline Física & & & & \\
\hline Sensorial & & & & \\
\hline Emocional & & & & \\
\hline Cognitiva/mental & & & & \\
\hline Sócio-cultural & & & & \\
\hline Ambiental & & & & \\
\hline Financeira & & & & \\
\hline Outras dificuldades & & & & \\
\hline
\end{tabular}

\section{Questão 16}

16. Tem alguma coisa que o(a) $\operatorname{Sr}(a)$ gostaria de ter feito em sua vida mas nunca fez, ou fez há algum tempo atrás e gostaria de voltar a fazer? Sim ( ) Não ( ). Em caso afirmativo, o quê? Por que não faz?

Objetivo: Conhecer as Atividades Desejadas/ Fatores de Inibição 
Atividades desejadas mencionadas com resposta a questão 16 do roteiro ajustado e categorização:

Lazer

- Viajar

- Fazer tricô

- Costurar

- Praticar esportes

- Ir a festas

- Assar pratos

- Freqüentar clube de idosos

- Bordar

- Confeitar bolos

- Ir a bailes

- Cuidar da aparência
Atividades instrumentais de vida diária

- Fazer compras

- Limpar/Cuidar da casa

- Fazer consertos em casa

- Dirigir automóvel

Trabalho - remunerado ou não

- Trabalho voluntário

- Exercer algum trabalho remunerado

Atividades básicas de vida diária

- Cuidar da aparência

- Relação sexual

Comentários sobre a estruturação: Considero que as "atividades desejadas" estejam contidas na "relação geral de atividades" e em alguma medida componham o universo ocupacional do idoso: universo imaginário

Respostas do roteiro ajustado à questão 16.1 e categorização

- Problemas de saúde

- Falta de apoio familiar

- Atitude negativa em relação ao envelhecimento-própria ou da sociedade

- Preocupação excessiva com atribuições/responsabilidades familiares

- Dificuldades financeiras

- Desconhecimento de recursos sociais

Comentários sobre a estruturação: Considero que essas categorias possam ser mantidas como resposta à questão 16.1, acrescida da categoria "outras" e sua especificação.

\section{Questão 17}

17. $\mathrm{O}$ (a) $\mathrm{Sr}$ (a) vê algum jeito de (aprender ou voltar a) fazer (repetir a atividade mencionada)?

Sim ( ) Não ( ) (Aplicada no caso de A.D.s nunca realizadas ou realizadas há algum tempo) Em caso afirmativo, como poderia (aprender ou voltar a) fazer?

Objetivo : Conhecer Fatores de estimulação para as Atividades Desejadas

Comentários sobre a estruturação: Essa questão convida aos entrevistados imaginar estratégias para ampliar sua capacidade funcional. As estratégias de autocuidado já mencionadas: mudança comportamental, ambiental, uso de dispositivo e ajuda externa podem não ser suficiente para permitir a realização das atividades desejadas. Proponho que às estratégias habitualmente empregadas sejam acrescidas da categoria "outras" e 
sua especificação. $\mathrm{O}$ quadro abaixo sugere resgate e permite registro das atividades desejadas, acompanhadas dos respectivos fatores estimados para vir/voltar a praticá-las.

Quadro 4: Atividades desejadas e fatores estimados para sua realização. Instrumento CICAc versão estruturada






\title{
1.3. Versão Estruturada do Instrumento CICAc
}

\author{
Nome do entrevistado \\ $N^{N}$ do prontuário
}

\section{Área de investigação : Ambiente sócio-familiar}

Questão 1 e 2

1. $\mathrm{O}$ (a) $\mathrm{Sr}(\mathrm{a})$ mora com outras pessoas na mesma casa? Sim ( ) não ( )

Em caso afirmativo, com quem o(a) Sr(a) mora?

2. $\mathrm{O}$ (a) $\operatorname{Sr}$ (a) tem (outros) parentes e amigos? $\operatorname{Sim}($ ) não ( )

Em caso afirmativo, quem são eles?

2.1. De quanto em quanto tempo costuma vê-los?

Objetivo das perguntas 1, 2 e 2.1: Conhecer o Contexto Sócio-familiar do idoso

Questão 3

2. Tem alguma(s) pessoa(s) que cuidaria(m) do(a) $\mathrm{Sr}(a)$ caso o(a) $\mathrm{Sr}(\mathrm{a})$ ficasse doente?

$\operatorname{Sim}($ ) não ( ). Em caso afirmativo, quem seria(m) essa(s) pessoa(s)

Objetivo: Conhecer a rede de suporte potencial do idoso

Respostas à Questão 1. Preencha as alternativas correspondentes

\begin{tabular}{|l|l|}
\hline Pai, mãe,sogro(a), tio(a) & \\
\hline Cônjuge & \\
\hline Irmãos,primos, cunhados & \\
\hline Filhos, enteados, sobrinhos & \\
\hline Genro, nora & \\
\hline Netos & \\
\hline Bisnetos & \\
\hline Amigo, conhecido & \\
\hline Outros & \\
\hline
\end{tabular}

Respostas à Questão 2. Preencha as alternativas correspondentes

\begin{tabular}{|l|l|}
\hline Pai, mãe,sogro(a), tio(a) & \\
\hline Cônjuge & \\
\hline Irmãos, primos, cunhados & \\
\hline Filhos, enteados, sobrinhos & \\
\hline Genro, nora & \\
\hline Netos & \\
\hline Bisnetos & \\
\hline Amigo, conhecido & \\
\hline Outros & \\
\hline
\end{tabular}

Respostas à Questão 2.1. Preencha a alternativa correspondente

\begin{tabular}{|l|l|}
\hline Todos os dias & \\
\hline Quase todos os dias & \\
\hline 2 vezes por semana & \\
\hline 1 vez por semana & \\
\hline A cada 15 dias & \\
\hline 1 vez por mês & \\
\hline 1 vez a cada 2 meses & \\
\hline 1 vez a cada 6 meses & \\
\hline 1 vez por ano & \\
\hline A cada 2 anos & \\
\hline
\end{tabular}


Respostas à Questão 3. Preencha as alternativas correspondentes

\begin{tabular}{|l|l|}
\hline Ninguém & \\
\hline Esposo(a) ou companheiro(a) & \\
\hline Filha(s) & \\
\hline Filho (s) & \\
\hline Outros familiares & \\
\hline Amigos ou vizinhos & \\
\hline Profissional contratado (enfermeira, etc) & \\
\hline Associações beneficentes (religiosas ou não) & \\
\hline Outros (especifique & \\
\hline
\end{tabular}

\section{Área de investigação : Universo ocupacional}

\section{Questões 4 e 5}

4. O que o(a) $\operatorname{Sr}$ (a) faz todos os dias, desde a hora que o(a) $\operatorname{Sr}$ (a) acorda até a hora que vai dormir? Procure contar todas as coisas que o(a) $\mathrm{Sr}(\mathrm{a}) \mathrm{faz}$.

Objetivo: Conhecer as Atividades cotidianas rotineiras

5. Tem alguma coisa que o(a) $\operatorname{Sr}(a)$ não faz todos os dias mas que de vez em quando o(a) $\operatorname{Sr}(a)$ faz? Objetivo: Conhecer as Atividades cotidianas não-rotineiras

\section{Questões 6 e 6.1}

6. Das coisas que o(a) $\mathrm{Sr}(a)$ faz, quais o(a) $\mathrm{Sr}(a)$ acha que são importantes para o(a) $\mathrm{Sr}(\mathrm{a})$ ?

6.1. Por quê??

Objetivo: Conhecer as Atividades coti dianas consideradas importantes e os requisitos a que elas correspondem

\section{Questōes 9 e 9.1}

9. Das coisas que o(a) $\mathrm{Sr}($ a) faz, de quais o(a) $\mathrm{Sr}($ a) menos gosta? Por quê?

Objetivo: Conhecer as Atividades cotidianas não prazerosas e os requisitos a que elas não atendem

\section{Questão 16 e 16.1}

16. Tem alguma coisa que o(a) $\operatorname{Sr}(a)$ gostaria de ter feito em sua vida mas nunca fez, ou fez há algum tempo atrás e gostaria de voltar a fazer? $\operatorname{Sim}$ ( ) Não ( ). Em caso afirmativo, o quê? Por que não faz?

Objetivo: Conhecer as Atividades desejadas/Fatores de Inibição 
Quadro resumo para registro de respostas às questões 4, 5, 6, 9 e 16.

\begin{tabular}{|c|c|c|c|c|}
\hline Relação de atividades cotidianas & $\begin{array}{l}\text { Rotineiras/não- } \\
\text { rotineiras }\end{array}$ & Importantes & não-prazerosas & desejadas \\
\hline 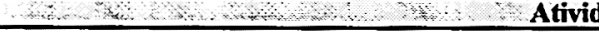 & anda- & Básicas & & 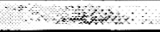 \\
\hline \multicolumn{5}{|l|}{ Banho } \\
\hline \multicolumn{5}{|l|}{ Vestir-se } \\
\hline \multicolumn{5}{|l|}{ Uso do toalete } \\
\hline \multicolumn{5}{|l|}{ Transferências Posturais } \\
\hline \multicolumn{5}{|l|}{ Continência } \\
\hline \multicolumn{5}{|l|}{ Alimentar-se } \\
\hline \multicolumn{5}{|l|}{ Locomocão } \\
\hline \multicolumn{5}{|l|}{ Amumar-se } \\
\hline \multirow{2}{*}{\multicolumn{5}{|c|}{\begin{tabular}{l|l|l|} 
Cortar unhas & & \\
\end{tabular}}} \\
\hline & & & & \\
\hline \multicolumn{5}{|l|}{ Uso do telefone } \\
\hline \multicolumn{5}{|l|}{ Uso de meios de transporte } \\
\hline \multicolumn{5}{|l|}{ Fazer compras } \\
\hline \multicolumn{5}{|l|}{ Preparar comida } \\
\hline \multicolumn{5}{|l|}{ Fazer tarefas domésticas } \\
\hline \multicolumn{5}{|l|}{ Lavar roupas } \\
\hline \multicolumn{5}{|l|}{ Tomar seus medicamentos } \\
\hline \multicolumn{5}{|l|}{ Administrar finanças } \\
\hline Wh & Lazer & s. & 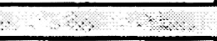 & bink \\
\hline \multicolumn{5}{|l|}{ Assistir a televisão } \\
\hline Atividades manuais & & & & \\
\hline Caminhar & & & & \\
\hline Cantar & & & & \\
\hline Compor modinhas & & & & \\
\hline Conversar com amigos & & & & \\
\hline Conversar com companheiro & & & & \\
\hline Cuidar das plantas & & & & \\
\hline Cuidar de pequenos animais & & & & \\
\hline Dancar & & & & \\
\hline Fazer caminhadas & & & & \\
\hline Fazer oraçöes & & & & \\
\hline Fazer pequenos consertos em casa & & & & \\
\hline Fazer tricô & & & & \\
\hline Fazer visitas (filhos e amigos) & & & & \\
\hline Freqüentar salão de beleza & & & & \\
\hline Ir a missa ou reunião religiosa & & & & \\
\hline Jogar (jogos de salão) & & & & \\
\hline Leituras & & & & \\
\hline Ouvir música & & & & \\
\hline Ouvir rádio & & & & \\
\hline Participar em grupos & & & & \\
\hline Passear & & & & \\
\hline Praticar esporte & & & & \\
\hline Sair com amigos & & & & \\
\hline Viajar & & & & \\
\hline 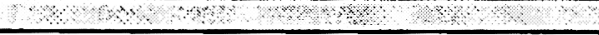 & Trabalho remunerad & .. & 2. & 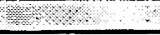 \\
\hline Bico & & & & \\
\hline Cargo técnico ou administrativo / profissão liberal & & & & \\
\hline Lavrador & & & & \\
\hline Empregada doméstica & & & & \\
\hline Operário & & & & \\
\hline Whe $\quad T$ & abalho não remunera & 10 & m & 然济 \\
\hline Comunitário & & & & \\
\hline Dona de casa & & & & \\
\hline Outro,especifique & & & & \\
\hline
\end{tabular}


Questão 6.1. Assinale com X uma ou mais alternativas correspondentes

\begin{tabular}{|l|l|}
\hline Trazem prazer & \\
\hline Promovem senso de utilidade (incluindo transmissão de cultura) & \\
\hline Através delas as pessoas desempenham comportamentos esperados & \\
\hline Mantêm as pessoas ativas & \\
\hline Distraem & \\
\hline Estimulam o exercício da independência & \\
\hline Estão relacionadas com a sobrevivência & \\
\hline Diminuem a solidão e a carência afetiva (incluindo oportunidade de interação) & \\
\hline Trazem satisfação espiritual & \\
\hline Trazem oportunidade de descansar & \\
\hline Ocupam o tempo & \\
\hline São benéficas à saúde (melhoram a me mória e circulação sanguínea) & \\
\hline Mantém pessoa atualizada & \\
\hline Alimentam a vaidade & \\
\hline Mantêm privacidade & \\
\hline $\begin{array}{l}\text { Outras razões. } \\
\text { Especifique }\end{array}$ & \\
\hline
\end{tabular}

Questão 9.1. Assinale com x uma ou mais alternativas correspondentes

\begin{tabular}{|l|l|}
\hline Acima das capacidades do idoso & \\
\hline Realizada em condições adversas & \\
\hline Não atende a necessidade & \\
\hline Outras razões & \\
\hline Especifique: & \\
\hline
\end{tabular}

Questão 16. 1. Assinale com $x$ uma ou mais alternativas correspondentes

\begin{tabular}{|l|l|}
\hline Problemas de saúde & \\
\hline Falta de apoio familiar & \\
\hline Atitude negativa em relação ao envelhecimento - própria ou da sociedade & \\
\hline Preocupação excessiva com atribuições/responsabilidades familiares & \\
\hline Dificuldades financeiras & \\
\hline Desconhecimento de recursos sociais & \\
\hline Outras razões & \\
\hline Especifique: & \\
\hline
\end{tabular}

\section{Area de investigaçâo: Capacidade funcional}

\section{Q. 8. Roteiro ajustado}

\section{8. $\mathrm{O}$ (a) $\mathrm{Sr}(a)$ tem dificuldade para fazer algumas das coisas que o(a) $\mathrm{Sr}(a)$ faz? Para fazer o quê? Que tipo de dificuldade? \\ Objetivo: Conhecer atividades cotidianas para as quais o idoso apresenta di ficuldade/ fatores de inibição}

\section{Questão 13}

13. O que o(a) $\mathrm{Sr}$ (a) faz quanto à dificuldade $\mathrm{X}$ : encontrou um jeito mais fácil de fazer, tem alguém que o ajuda, faz mesmo com dificuldade sem ajuda ou deixou de fazer? Como o(a) $\operatorname{Sr}(a)$ faz (caso tenha encontrado um jeito mais fácil de fazer)? Quem o ajuda e como o ajuda (caso precise e identifique ajuda)? Repetir a pergunta para cada uma das dificuldades mencionadas 


\section{Desmembrada em 2 questōes:}

$1^{\mathrm{a}}$ - $\mathrm{O}$ que o(a) $\operatorname{Sr}(\mathrm{a})$ faz quanto à dificuldade $\mathrm{X}$ ? Encontrou um jeito mais fácil de fazer, tem alguém que o ajuda, faz mesmo com dificuldade sem ajuda ou deixou de fazer? O X representa cada uma das atividades para as quais o idoso apresenta dificuldade. Essas atividades deverão ser mencionadas uma a uma.

$2^{\mathrm{a}}$ - Como o(a) $\operatorname{Sr}(\mathrm{a})$ faz/ quem o ajuda?

Quadro resumo para registro das respostas as questões 8 e 13

Preencha os espaços com as atividades correspondentes

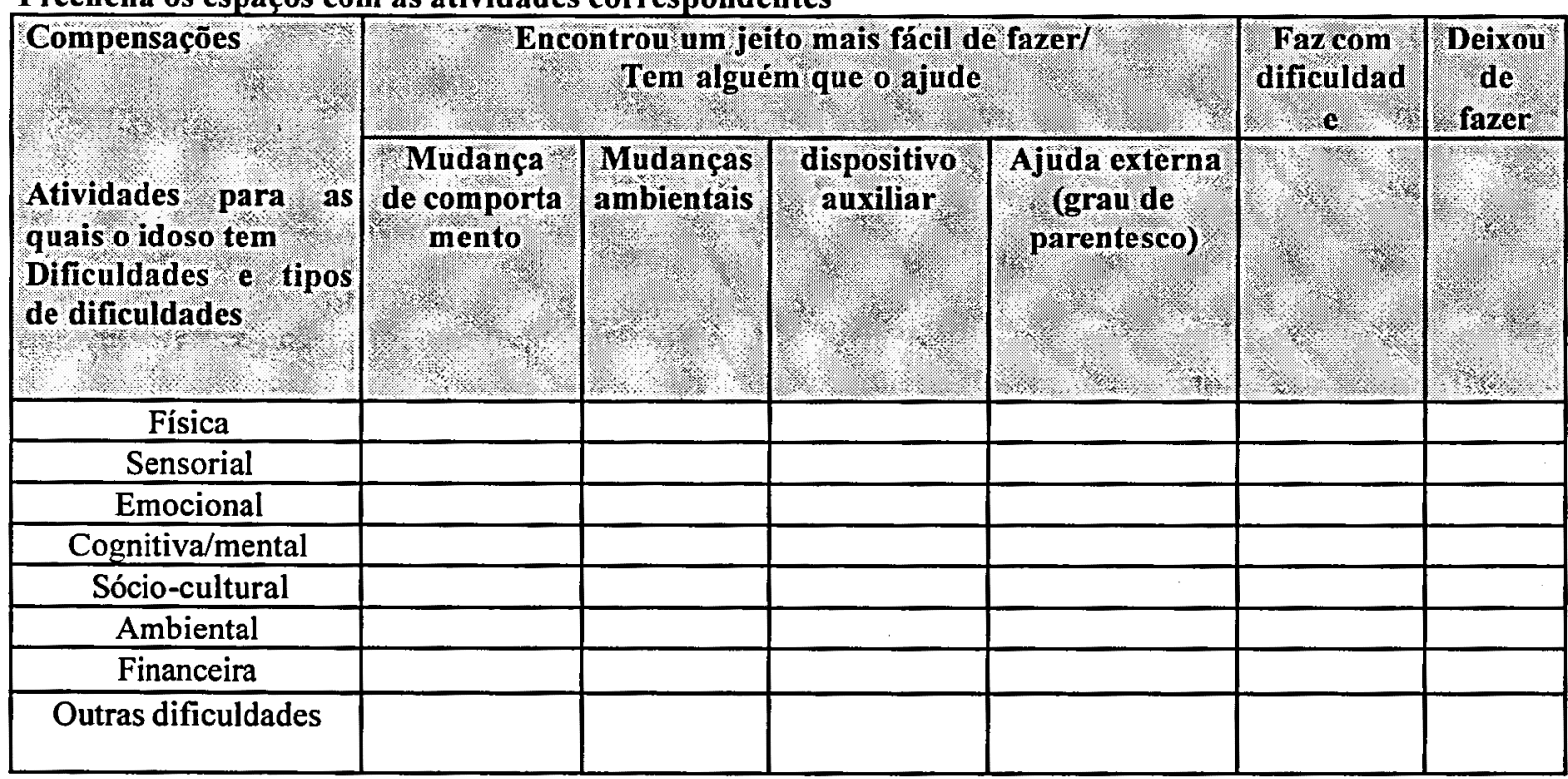

Graus de parentesco

\begin{tabular}{|ll|}
\hline 1 & Pai,Mãe, sogro(a), tio(a) \\
\hline 2 & Cônjuge \\
\hline 3 & Irmãos, primos, cunhados \\
\hline 4 & Filhos, enteados, sobrinhos \\
\hline 5 & Genro, nora \\
\hline 6 & Netos \\
\hline 7 & Bisnetos \\
\hline 10 & Amigo, conhecido \\
\hline 11 & Outros. Especifique \\
\hline
\end{tabular}

Em caso de ocorrência de atividades que o idoso precise de ajuda, faça com dificuldade e/ou tenha deixado de fazer em função das dificuldades, aplicar a questão 14 e/ou 15 respectivamente :

14. Das coisas que o(a) $\mathrm{Sr}(\mathrm{a})$ faz com dificuldade ou tenha alguém que o ajude, tem alguma que o (a) sr (a) gostaria de encontrar um jeito mais fácil para fazer? Sim( ) Não( )

Em caso afirmativo, o que seria? $\mathrm{O}$ (a) $\mathrm{Sr}$ (a) vê algum jeito mais fácil de fazer (repetir a atividade)? $\operatorname{Sim}($ ) Não( ). Em caso afirmativo, como poderia ser feito?

15. Das coisas que o(a) $\mathrm{Sr}(a)$ deixou de fazer pelas dificuldades que o(a) $\mathrm{Sr}(\mathrm{a})$ me contou, tem alguma coisa que o(a) $\operatorname{Sr}($ a) gostaria de voltar a fazer? Sim ( ) Não ( ). Em caso afirmativo, o que seria?

$\mathrm{O}(\mathrm{a}) \mathrm{Sr}(\mathrm{a})$ vê algum jeito de voltar a fazer (repetir a atividade)? Sim ( ) Não ( )

Em caso afirmativo, como poderia ser feito?

Objetivo de q.14 e q.15: Conhecer as Atividades desejadas /Fatores estimados como facilitadores 
Quadro resumo para registro das respostas às questões 14 e 15.

Preencha os espaços com atividades correspondentes

\begin{tabular}{|c|c|c|c|c|}
\hline $\begin{array}{r}\text { Compensaçóes } \\
\text { atividades e } \\
\text { tipos de dificuldade }\end{array}$ & $\begin{array}{c}\text { Mudança de } \\
\text { comportamento }\end{array}$ & $\begin{array}{c}\text { Mudanças } \\
\text { ambientais }\end{array}$ & $\begin{array}{c}\text { Dispositivo } \\
\text { auxiliar }\end{array}$ & $\begin{array}{c}\text { Ajuda externa } \\
\text { (grau de parentesco) }\end{array}$ \\
\hline Física & & & & \\
\hline Sensorial & & & & \\
\hline Emocional & & & & \\
\hline Cognitiva/mental & & & & \\
\hline Sócio-cultural & & & & \\
\hline Ambiental & & & & \\
\hline Financeira & & & & \\
\hline
\end{tabular}

\section{Questão 17}

17. O (a) sr (a) vê algum jeito de (aprender ou voltar a) fazer (repetir a atividade mencionada)? Sim ( ) Não ( ) (Aplicada no caso de A.D.s nunca realizadas ou realizadas há algum tempo) 17.1.Em caso afirmativo, como poderia (aprender ou voltar a) fazer?

Objetivo : Conhecer Fatores de estimulação para as ADs

Quadro resumo para registro das respostas às questões 17 e 17.1

Preencha os espaços com as atividades correspondentes

\begin{tabular}{|c|c|c|c|c|c|}
\hline $\begin{array}{r}\text { Fatores } \\
\text { astimados } \\
\text { Atividades } \\
\text { desejadas }\end{array}$ & $\begin{array}{c}\text { Mudança de } \\
\text { comportamento }\end{array}$ & $\begin{array}{c}\text { Mudanças } \\
\text { ambientais }\end{array}$ & $\begin{array}{c}\text { Dispositivo } \\
\text { auxiliar }\end{array}$ & $\begin{array}{c}\text { Ajuda externa } \\
\text { (graus de } \\
\text { parentesco) }\end{array}$ & $\begin{array}{c}\text { Outros } \\
\text { fatores de } \\
\text { estimulação }\end{array}$ \\
\hline & & & & & \\
\hline
\end{tabular}

Observações do entrevistador:

Data da avaliação: Profissional responsável 


\section{4. $1^{\text {a }}$ Versão Grupal do Instrumento CICAc}

Nome do entrevistado

$N^{\circ}$ do prontuário

Nome do entrevistador

Data de entrevista

\section{Área de investigação Ambiente social e familiar}

Questão 1-O(a) Sr(a) mora com outras pessoas na mesma casa? Sim ( ) Não ( )

Com quem o(a) $\mathrm{Sr}$ (a) mora?

Identifique todas as pessoas que moram, atualmente, com o idoso

\begin{tabular}{|l|l|l|l|l|l|}
\hline \multirow{2}{*}{ Nome } & \multirow{2}{*}{$\begin{array}{c}\text { Tipo de relacionamento } \\
\text { (cónjuge, irmão, filho, neto, amigo, etc) }\end{array}$} & Masculino & Feminino & . Idade \\
\hline & & & & \\
\hline & & & & \\
\hline
\end{tabular}

Questão 2-O(a) Sr(a) tem (outros) filhos? Sim ( ) Não ( )

Identifique todos os filhos vivos que não moram com o idoso

\begin{tabular}{|l|l|l|l|l|l|l|}
\hline \multirow{2}{*}{ Nome } & \multicolumn{2}{|c|}{ Sexo } & Onde reside \\
\hline & Masculino & Feminino & Idade & . \\
\hline & & & & & \\
\hline & & & & \\
\hline
\end{tabular}

Questão 3 - Com que freqüência o(a) Sr(a) se relaciona com:

Preencha a coluna correspondente à freqüência segundo Legenda abaixo

\begin{tabular}{|l|l|}
\hline Tipo de relacionamento & Freqüência \\
\hline Filhos & \\
\hline Vizinhos & \\
\hline Amigos & \\
\hline Associações/Grupos/Instituições & \\
\hline Outros Parentes & \\
\hline
\end{tabular}

Legenda: Freqüência

\begin{tabular}{|l|l|l|}
\hline Todos os dias & A cada 15 dias & I vez por ano \\
\hline Quase todos os dias & I vez por mês & A cada 2 anos \\
\hline 2 vezes por semana & I vez a cada 2 meses & Mais de dois anos \\
\hline I vez por semana & I vez a cada 6 meses & Nunca \\
\hline
\end{tabular}

Questão 4 - $\mathrm{O}$ (a) Sr(a) está satisfeito com a freqüência com se relaciona com:

Assinale com um $X$ o grau de satisfação corresponde a cada um dos tipos de relacionamento

\begin{tabular}{|l|c|c|c|}
\hline \multirow{2}{*}{ Tipos de relacionamento } & \multicolumn{2}{|c|}{ Grau de satisfação } \\
\cline { 3 - 4 } & Sim & Mais ou menos & Não \\
\hline Filhos & & & \\
\hline Vizinhos & & & \\
\hline Amigos & & & \\
\hline Associações/Grupos/Instituições & & & \\
\hline Outros Parentes & & & \\
\hline
\end{tabular}

Questão 5 - Como o(a) Sr(a) se sente com a relação que mantém com:

Assinale com um $X$ o grau de satisfação correspondente a cada um dos tipos de relacionamento

\begin{tabular}{|c|c|c|c|c|c|}
\hline \multirow{2}{*}{ Tipos de relacionamento } & \multicolumn{5}{|c|}{ Grau de satisfação } \\
\hline & $\begin{array}{l}\text { Muito } \\
\text { satisfeito }\end{array}$ & Satisfeito & Insatisfeito & $\begin{array}{l}\text { Muito } \\
\text { insatisfeito }\end{array}$ & Mora so \\
\hline \multicolumn{6}{|l|}{ As pessoas da familia que moram com o(a) $\mathrm{Sr}(\mathrm{a})$} \\
\hline \multicolumn{6}{|l|}{ Pessoas da família que não vivem com o(a) $\mathrm{Sr}(\mathrm{a})$} \\
\hline \multicolumn{6}{|l|}{ Os amigos } \\
\hline Os vizinhos & & & & & \\
\hline
\end{tabular}


Questão 6 - Tem alguém que cuida do(a) $\operatorname{Sr}(a)$ caso quando o(a) $\operatorname{Sr}(a)$ fica doente? Sim ( ) Não ( )

Quem é ou quais são essa(s) pessoa(s)

Identifique todas as pessoas que cuidam do idoso em caso de doença

\begin{tabular}{|c|c|c|c|c|}
\hline 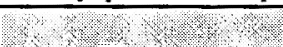 & Tipo de relacionamento & S. Ser & 0 & Idade \\
\hline Nome : & (cônjuge, irmão, filho, neto, amigo, etc) & Masculino & Feminino & \\
\hline & & & & \\
\hline & & & & \\
\hline & & & & \\
\hline
\end{tabular}

Objetivo das questões $1,2,3,4,5$, e 6: Descrever o arranjo doméstico e familiar do idoso e potencial rede de suporte

\section{Área de investigação: perfil social}

Questão 7- $\mathrm{O}$ (a) Sr(a) freqüentou escola? Até que ano estudou? Assinale com um $X$ a escolaridade do entrevistado na coluna à direita

\begin{tabular}{|l|l|}
\hline Analfabeto & \\
\hline Sabe ler/escrever ou primário incompleto & \\
\hline Primário completo/ginásio incompleto & \\
\hline Ginásio completo/colegial incompleto & \\
\hline Colegial completo/curso superior incompleto & \\
\hline Superior completo & \\
\hline
\end{tabular}

Questão 8 - Qual sua atividade profissional principal ? Preencha o campo abaixo:

Questão 9-O(a) Sr(a) exerce essa atividade profissional atualmente? ( ) Sim ( ) Não Se a resposta for negativa, aplicar a questão 10

Questão 10-O(a) $\operatorname{Sr}(a)$ tem trabalho remunerado atualmente? ( ) Sim ( ) Não. Qual ?

Questão 11 - Quais são seus recursos financeiros atualmente?

Assinale com um $X$ os recursos financeiros do entrevistado na coluna à direita (múltipla escolha)

- A aplicação financeira é considerada recurso somente se o entrevistado retirar dinheiro da aplicação para as suas despesas

\begin{tabular}{|l|l|}
\hline Salário & \\
\hline Aposentadoria & \\
\hline Pensão & \\
\hline Renda mensal vitalícia & \\
\hline Aluguel & \\
\hline Atividades informais & \\
\hline Aplicação financeira & \\
\hline Recebe ajuda em dinheiro ou espécie & \\
\hline
\end{tabular}

Questão 12 - Com a sua situação econômica atual de que forma o(a) $\operatorname{Sr}(a)$ satisfaz suas necessidades de alimentação, moradia, saúde, etc?

Assinale com um $X$ a forma com o idoso satisfaz suas necessidades, na coluna à direita

\begin{tabular}{|l|l|}
\hline Muito bem & \\
\hline Bem & \\
\hline Mais ou menos & \\
\hline Mal & \\
\hline Muito mal & \\
\hline
\end{tabular}

Objetivos das questões $7,8,9,10,11$ e12: Traçar umbreve perfil social 


\section{Área de investigação : Universo ocupacional}

Questão 13 - O que o(a) Sr(a) faz todos os dias, desde a hora acorda até a hora que vai dormir? Procure contar todas as coisas faz.

Utilize o Quadro 1 para registro das respostas

Objetivo: Conhecer as Atividades cotidianas rotineiras

Questão 14 - Tem alguma coisa que o(a) $\operatorname{Sr}(a)$ faça só de vez em quando ?

Utilize o Quadro 1 para registro das respostas

Objetivo: Conhecer as Atividades cotidianas não-rotineiras

Questão 15 - Das coisas que o(a) $\operatorname{Sr}(a)$ faz, quais o(a) $\operatorname{Sr}(a)$ acha que são importantes para o(a) $\operatorname{Sr}(a)$ ? 15.1. Por quê?

Utilize o Quadro 1 para registro das respostas à questão 15 e, o Quadro 2 para registro de respostas à questão 15.1

Objetivo: Conhecer as atividades importantes $e$ as necessidades a que elas correspondem

Questão 16 - Das coisas que o(a) $\operatorname{Sr}(a)$ faz, de quais gosta menos? 16.1 Por quê?

Utilize o Quadro 1 para registro das respostas à questão 16 e Quadro 3 para registro de respostas à questão 16.1

Objetivo: Conhecer as atividades não prazerosas e as necessidades a que elas não atendem

Questão 17 - Tem alguma coisa que o(a) $\operatorname{Sr}(a)$ gostaria de ter feito em sua vida mas nunca fez ou fez há algum tempo atrás e gostaria de voltar a fazer? Por que não faz?

Utilize o Quadro 1 para registro das respostas à questão 17 e Quadro 4 para registro das respostas à questão 17.1

Objetivo: Conhecer as Atividades desejadas e Fatores de Inibição para essas atividades

Quadro1: Quadro resumo para registro de respostas às questões 13, 14, 15, 16 e17

Identifique todas as atividades que componham a vida cotidiana do idoso, assinalando com $X$ na(s) coluna(s) correspondente(s) a sua caracterização

\begin{tabular}{|c|c|c|c|c|c|}
\hline $\begin{array}{c}\text { Universo ocupacional } \\
\end{array}$ & $\begin{array}{l}\text { cotidianas } \\
\text { rotineiras }\end{array}$ & $\begin{array}{l}\text { Cotidianas } \\
\text { não- } \\
\text { rotineiras }\end{array}$ & $\begin{array}{c}\text { cotidianas } \\
\text { importantes }\end{array}$ & $\begin{array}{c}\text { Cotidianas não } \\
\text {-prazerosas }\end{array}$ & desejad \\
\hline Atividades de vida diária - Básicas & rex & setm & - & 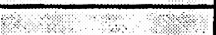 & 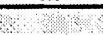 \\
\hline \multicolumn{6}{|l|}{ Banho } \\
\hline \multicolumn{6}{|l|}{ Vestuário } \\
\hline \multicolumn{6}{|l|}{ Uso do toalete } \\
\hline \multirow{2}{*}{\multicolumn{6}{|c|}{$\begin{array}{l}\text { Transferências posturais } \\
\text { Continência }\end{array}$}} \\
\hline & & & & & \\
\hline \multicolumn{6}{|l|}{ Alimentação } \\
\hline \multicolumn{6}{|l|}{ Locomoção } \\
\hline \multirow{2}{*}{\multicolumn{6}{|c|}{$\begin{array}{l}\text { Cuidados com pele, cabelos, unhas, dentes e face } \\
\text { Atividades de vida diária - Instrumentais }\end{array}$}} \\
\hline & & & & & \\
\hline \multicolumn{6}{|l|}{ Uso do telefone } \\
\hline \multicolumn{6}{|l|}{ Uso de meios de transporte } \\
\hline \multicolumn{6}{|l|}{ Compras } \\
\hline \multicolumn{6}{|l|}{ Preparo de comida } \\
\hline \multirow{2}{*}{\multicolumn{6}{|c|}{ Tarefas domésticas }} \\
\hline & & & & & \\
\hline \multicolumn{6}{|l|}{$\begin{array}{l}\text { Lavagem roupas } \\
\text { Tomar medicamentos conforme receitados }\end{array}$} \\
\hline \multicolumn{6}{|l|}{ Comparecer as consultas ou outros tratamentos } \\
\hline \multicolumn{6}{|l|}{$\begin{array}{l}\text { Receber pagamentos, pagar contas e controlar } \\
\text { orçamento }\end{array}$} \\
\hline \multirow{2}{*}{\multicolumn{6}{|c|}{ Assistir a televisão }} \\
\hline & & & & & \\
\hline \multicolumn{6}{|l|}{ Bordar } \\
\hline \multicolumn{6}{|l|}{ Caminhar } \\
\hline \multicolumn{6}{|l|}{ Cantar } \\
\hline \multicolumn{6}{|l|}{ Compor modinhas } \\
\hline \multicolumn{6}{|l|}{ Conversar com amigos/companheiro } \\
\hline \multicolumn{6}{|l|}{ Cuidar das plantas } \\
\hline \multicolumn{6}{|l|}{ Cuidar de pequenos animais } \\
\hline Dançar & & & & & \\
\hline Fazer crochế & & & & & \\
\hline
\end{tabular}




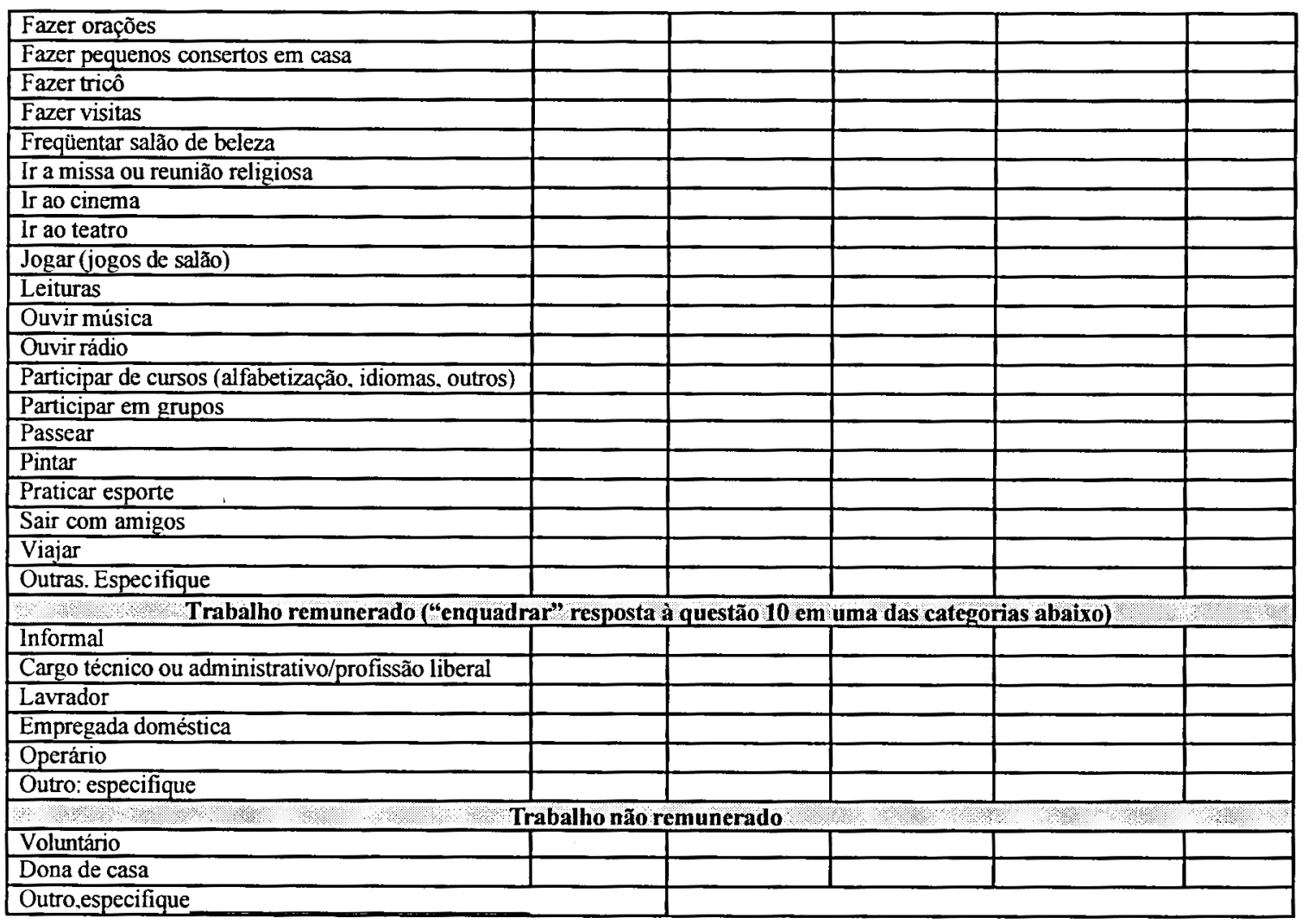

Quadro 2: Registro de respostas à questão 15.1: Porque o idoso acha determinadas atividades importantes

Assinale com $X$ uma ou mais alternativas correspondentes na coluna à direita

\begin{tabular}{|l|l|}
\hline Trazem prazer & \\
\hline Promovem senso de utilidade (incluindo transmissão de cultura) & \\
\hline Através delas as pessoas desempenham comportamentos esperados & \\
\hline Mantêm as pessoas ativas & \\
\hline Distraem & \\
\hline Estimulam o exercício da independência & \\
\hline Estão relacionadas com a sobrevivência & \\
\hline Diminuem a solidão e a carência afetiva (incluindo oportunidade de interação) & \\
\hline Trazem satisfação espiritual & \\
\hline Trazem oportunidade de descansar & \\
\hline São benéficas à saúde & \\
\hline Ocupam o tempo & \\
\hline Mantém pessoa atualizada & \\
\hline Alimentam a vaidade & \\
\hline Mantêm privacidade & \\
\hline Outras razões : Especifique & \\
\hline
\end{tabular}

Quadro 3: Registro de respostas à questão 16.1: Porque o idoso gosta menos de determinadas atividades. Assinale com $X$ uma ou mais alternativas correspondentes na coluna à direita

\begin{tabular}{|l|l|}
\hline Acima das capacidades do idoso & \\
\hline Realizada em condições adversas & \\
\hline Não atende as necessidades do idoso & \\
\hline Outras razões: especifique & \\
\hline
\end{tabular}




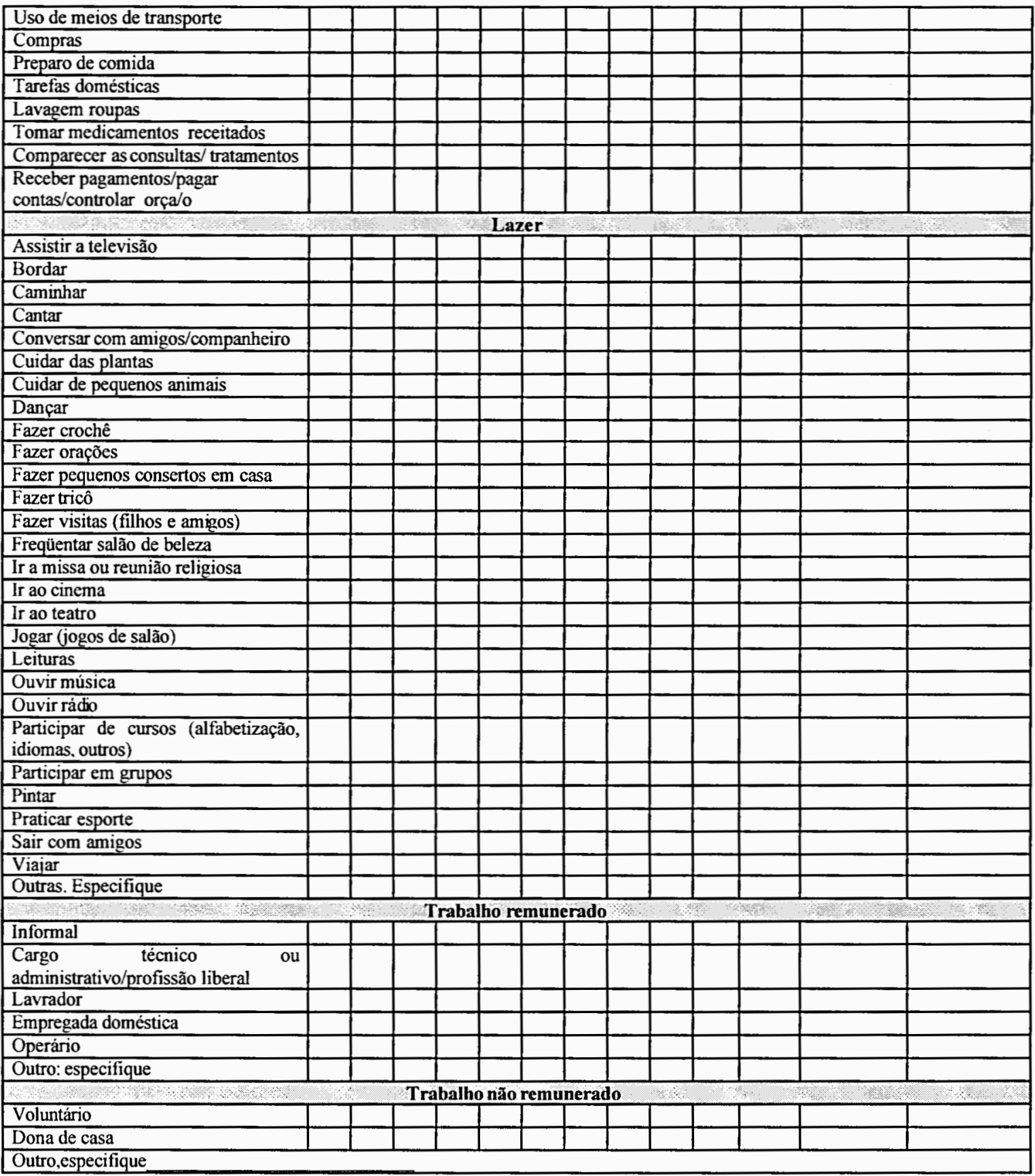

$\begin{array}{lll}\begin{array}{l}\text { Legenda - tipos de } \\ \text { dificuldade }\end{array} & \begin{array}{l}\text { Legenda - formas de } \\ \text { compensação }\end{array} & \begin{array}{l}\text { Códigos para tipos de relacionamento } \\ \text { (quando houver alguém que ajude o idoso) }\end{array} \\ \text { F:Física } & \text { MC:Mudança Comportamental } & 1: \text { Pai,mãe, sogro(a), tio(a) } \\ \text { S:Sensorial } & \text { MA:Mudança Ambiental } & 2: \text { Cônjuge } \\ \text { E:Emocional } & \text { DA:Dispositivo Auxiliar } & 3: \text { Irmãos, primos, cunhados } \\ \text { C:Cognitiva } & \text { Su: Supervisão } & 4: \text { Filhos, enteados, sobrinhos } \\ \text { So:Social } & \text { As: Assistência Física } & 5: \text { Genro, nora } \\ \text { O: Outro } & & 6: \text { Netos } \\ & & 7: \text { Bisnetos } \\ & 8: \text { Amigo, conhecido }\end{array}$

Se o(a) idoso(a) precisa de ajuda, faz com dificuldade ou deixou de fazer alguma atividade, aplique a questão 21. 
Questão 21 - Pense nas coisas que o(a) Sr(a) faz com ajuda, com dificuldade sem ajuda, ou tenha deixado de fazer. O sr imagina algum jeito mais fácil de fazê-la?

Sim, para todas as atividades ( )

Sim, para algumas atividades ( )

Não ( )

Se a resposta for afirmativa para todas ou para algumas atividades, aplique a questão 22 e registre as respostas no Quadro 6.

Questão 22 - Como poderia ser feito?

Objetivo das questões 21 e 22 : Convidar o idoso a imaginar formas para compensar algumas dificuldades

Quadro 6: Registro das res postas à questão 22

Nomeie todas as atividades que o(a) idoso(a) faz com ajuda, com dificuldade sem ajuda, ou tenha deixado de fazer e para as quais ele(a) imagina compensações. Assinale com um X as formas de compensação imaginadas (múltipla escolha)

\begin{tabular}{|l|l|l|l|l|}
\hline \multirow{2}{*}{$\begin{array}{l}\text { Atividades para as quais } \\
\text { apresenta dificuldade }\end{array}$} & \multicolumn{4}{|c|}{ Formas de compensação imaginadas } \\
\cline { 2 - 5 } & $\begin{array}{c}\text { Mudança de } \\
\text { comportamento }\end{array}$ & $\begin{array}{c}\text { Mudança } \\
\text { ambiental }\end{array}$ & $\begin{array}{c}\text { Dispositivo } \\
\text { Auxiliar }\end{array}$ & $\begin{array}{c}\text { Outra forma (especificar a(s) } \\
\text { forma(s) de compensação na } \\
\text { mesma linha da atividade) }\end{array}$ \\
\hline & & & & \\
\hline & & & & \\
\hline & & & & \\
\hline
\end{tabular}

Questão 23 - Pense nas coisas que o(a) Sr(a) gostaria de ter feito em sua vida mas nunca fez ou fez há muito tempo atrás e gostaria de voltar a fazer. $\mathrm{O}$ (a) $\mathrm{Sr}(\mathrm{a})$ imagina algum jeito de vir a fazê-las?

Objetivo da questão 23 : Convidar o idoso a imaginar formas para realizar as atividades desejadas

Quadro 7: Registro das atividades desejadas (resposta à questão 17), acompanhadas das respectivas formas imaginadas para sua realização( resposta à questão 23)

Repita nesse quadro as atividades desejadas e introduza as formas imaginadas de realização na coluna à direita.

\begin{tabular}{|c|c|}
\hline Atividades desejadas & Formas imaginadas para realização \\
\hline & \\
\hline
\end{tabular}

\section{Observações}

\section{Orientações gerais para aplicação do Instrumento CICAc}

Recomenda-se a aplicação do Instrumento CICAc, pelo terapeuta ocupacional, especialmente a idosos usuários de unidades básicas de saúde; uma vez que esse instrumento se propõe a fornecer algumas informações relevantes sobre o idoso que vive na comunidade, onde importa, basicamente, as atividades que o idoso pode ou não desempenhar, fatores compensatórios as incapacidades, o ambiente e o suporte social.

As informações obtidas pela aplicação do Instrumento CICAc deverão contribuir para o processo de avaliação em Terapia Ocupacional, integrando-se a outras informações, provenientes de: prontuários, observações de comportamento e do ambiente, percepções de familiares e cuidadores. Como exemplo da importância da integração de informações podemos citar que os tipos de dificuldade darão pistas para relacionar as incapacidades, designadas pelo idoso - em nossa pesquisa - como "atividades para as quais tem dificuldades" com determinadas patologias registradas em prontuário. Essas informações serão importantes para priorizar condutas em T.O tais como reversão de incapacidades potencialmente reversíveis e compensação de incapacidades irreversiveis. 
Ainda que um processo amplo de avaliação deva se dar de forma continua, recomenda-se a aplicação do Instrumento CICAc em intervalos não superiores há 6 meses, o tempo mínimo de intervalo deverá ser determinado pelas aquisições do idoso, isto é, sempre que o T.O. observar algum progresso no tratamento, deverá conduzir uma nova avaliação, uma vez que a verificação e informação sobre progressos ainda que sutis (não óbvios) para o idoso podem promover a sua motivação a prosseguir com o tratamento.

Sugerimos que o Instrumento CICAc seja aplicado ao familiar responsável ou cuidador, especialmente nas seguintes situações: quando as exigências da entrevista superarem as capacidades do idoso e para ampliação da compreensão do profissional acerca da capacidade funcional do idoso.

\section{Definição de termos empregados no Instrumento CICAc:}

Arranjo doméstico e familiar do idoso: Com quem mora e quem compõe sua família mesmo que não more junto

Potencial rede de suporte : $O$ arranjo doméstico, familiar e comunitário, a freqüência de contato e graus de satisfação do idoso em relação à essa rede, podem sugerir essas pessoas como possíveis suporte para o idoso

Breve perfil social: informações que caracterizem o idoso socialmente, de forma sucinta

Ajuda em espécie: ajuda em mantimentos, roupas, medicamentos, etc

Condições adversas: quando o ambiente físico ou social impõe restrições à autonomia e independência

Tipos de dificuldade: fatores que dificultem ou impeçam a realização de atividades:

- Física: restrição dos movimentos requeridos pela atividade

- Sensorial: restrição dos sentidos requeridos pela atividade

- Emocional: restrição da motivação requerida pela atividade

- Cognitiva: restrição das habilidades mentais requeridas pela atividade

- Social: restrições de ordem financeira ou falta de apoio social para desempenhar a atividade

- Outra: restrições de ordem cultural ou do ambiente físico

Formas de compensação:

- mudança comportamental: mudança na forma de realizar a atividade, ex: evitar escadas, evitar carregar objetos pesados, comprar um pouco a cada vez, fazer coisas menos freqüentemente ou mais vagarosamente etc

- dispositivo auxiliar: "qualquer item, peça de equipamento ou sistema modificado ou customizado, usado para aumentar, manter ou melhorar a capacidade funcional de individuos com incapacidades", ex: óculos, controle remoto para televisão, cadeira de rodas, telefone sem fio, lupa, números maiores para o telefone, amplificador de telefone, abridores de jarra, etc

- mudanças no ambiente: ex: mover itens de maior uso para prateleiras mais baixas, melhorar a iluminação, simplificar ambientes etc.

- assistência de outras pessoas:

- Supervisão: observar o idoso para se assegurar que de a atividade está sendo adequadamente realizada; oferecer dispositivos, utensílios utilizados na atividade; lembrá-lo quais passos tomar para completar a atividade.

- Assistência fisica direta: para iniciar ou completar a atividade. 


\section{5. $2^{\mathrm{a}}$ Versão Grupal do Instrumento CICAc}

\section{Orientações gerais para aplicação}

Recomenda-se a aplicação do Instrumento C.I.C.Ac., pelo Terapeuta Ocupacional, especialmente a idosos usuários de unidades básicas de saúde; uma vez que esse instrumento se propõe a fornecer algumas informações relevantes sobre o idoso que vive na comunidade, onde importam, basicamente, as atividades que o idoso desempenha ou não, fatores compensatórios às incapacidades, o ambiente e o suporte social.

As informações obtidas pela aplicação do Instrumento C.I.C.Ac deverão contribuir para o processo de avaliação em Terapia Ocupacional, integrando-se a outras informações, provenientes de: prontuários, observações de comportamento e do ambiente, percepções de familiares e cuidadores. Como exemplo da importância da integração de informações podemos citar que os tipos de dificuldade darão pistas para relacionar as incapacidades, designadas pelo idoso - em nossa pesquisa - como "atividades para as quais tem dificuldades" com determinadas doenças registradas em prontuário. Essas informações serão importantes para priorizar condutas em T.O tais como reversão de incapacidades potencialmente reversíveis e compensação de incapacidades irreversiveis.

Ainda que um processo amplo de avaliação deva se dar de forma contínua, recomenda-se a aplicação do instrumento C.I.C.Ac em intervalos não superiores a 6 meses, o tempo mínimo de intervalo deverá ser determinado pelas aquisições do idoso, isto é, sempre que o T.O. observar algum progresso no tratamento, deverá conduzir uma nova avaliação, uma vez que a verificação e informação sobre progressos, ainda que sutis (não óbvios) para o idoso, podem promover a sua motivação a prosseguir com o tratamento.

Sugerimos que o instrumento C.I.C.Ac seja aplicado ao familiar responsável ou cuidador, especialmente nas seguintes situações: quando as exigências da entrevista superarem as capacidades do idoso e para ampliação da compreensão do profissional acerca da capacidade funcional do idoso. 


\section{Definição de termos}

Arranjo doméstico e familiar do idoso - informações que descrevem com quem o idoso mora e quem compõe sua familia mesmo que não more junto. Essas pessoas deverão ser descritas segundo alguns atributos como grau de parentesco (ou outro tipo de relacionamento) com o idoso, sexo e idade.

Potencial rede de suporte - Algumas informações contempladas pela aplicação do instrumento podem indicar a existência de uma rede de suporte para o idoso, pelo menos em potencial, a saber: frequência de contato com familiares, amigos e comunidade, satisfação do idoso em relação às pessoas que compõe sua rede de relações, incluindo aquelas com quem mora e indicação pelo idoso de determinadas pessoas com que pode contar em caso de doença. Algumas destas pessoas poderão, a partir de critérios estabelecidos pelo serviço de saúde, ser orientadas e apoiadas com vistas a formarem uma rede de suporte efetiva.

Breve perfil social - informações que caracterizam de forma sucinta o idoso socialmente. $O$ instrumento reúne sob essa denominação questões sobre escolaridade, atividade profissional principal, trabalho remunerado e outros recursos financeiros do idoso, enquanto fatores que influenciam o Universo Ocupacional do idoso. Atividade profissional, trabalho remunerado e atividades educacionais podem ainda compor esse Universo Ocupacional.

Ajuda em espécie (alternativa de resposta à q. 11): ajuda em mantimentos, roupas, medicamentos, etc

Condições adversas (alternativa de resposta à questão 16.1, presente no quadro 3) - quando o ambiente fisico ou social impõe restrições à autonomia e independência do idoso

Autonomix termo derivado do grego: autos (eu) e nomos (regra, governo, lei) e significa faculdade para governar a si mesmo. BEAUCHAMP, T.L. e CHILDRESS, J.F. (1985)

Capacidade funcional: $O$ termo capacidade funcional, é aplicado na área gerontológica para designar a capacidade para as atividades de vida diária (PAULA e col 1998).

Segundo FILLENBAUM (1984), a capacidade funcional relaciona-se à saúde fisica, mental e bemestar social e a possibilidade do idoso manter-se na comunidade

De acordo com KANE (1993) a capacidade funcional é produto de três influências básicas: fatores intrínsecos do cliente (incluindo aspectos biológicos e comportamentais), cuidados recebidos (formais e informais) e ambiente do cliente (incluindo o ambiente físico, psicológico e social).

Tipos de dificuldhde: fatores que dificultem ou impeçam a realização de atividades. Esses fatores podem ser intrínsecos do cliente e/ou extrínsecos

- Física: restrição dos movimentos requeridos pela atividade

- Sensorial: restrição dos sentidos requeridos pela atividade

- Emocional: restrição da motivação requerida pela atividade

- Cognitiva: restrição das habilidades mentais requeridas pela atividade

- Social: falta de apoio social para desempenhar a atividade

- Econômica: falta de recursos econômicos que possibilitem a realização da atividade

- Restrições clínicas: doenças referidas pelo idoso ou efeitos dos tratamentos prescritos para essas doenças

- Ambiente físico: desenho arquitetônico do domicilio e/ou disposição de moveis e objetos que dificultem a locomoção do idoso, suas transferências posturais e o uso de objetos e utensílios de forma segura e confortável

- Outros: restrições de ordem cultural entre outras

Dificuldade (para realizar atividades) - termos empregado por alguns idosos para designar incapacidade

Doenças, incapacidades, desvantagens são conceitos relacionados de acordo com o modelo ICIDH (WHO, 1980). 
- doença ou impedimento - refere-se a redução das capacidades físicas e/ou mentais. São geralmente distúrbios ao nivel orgânico, podem não ser visiveis ou ainda não ter conseqüências adversas ao indivíduo, pois podem ser corrigidos

- incapacidade - resulta de patologias ou impedimentos cujos efeitos não foram corrigidos e refere-se a restrição nas habilidades do individuo para o desempenho de uma função de uma maneira considerada normal. Pode ser temporária ou permanente, reversível ou irreversível ou ainda progressiva ou regressiva. Pode ser consequêencia direta de uma doença ou impedimento ou uma resposta, particularmente psicológica do indivíduo, à doença ou impedimento seja ele físico, sensorial ou outro. A incapacidade pode ou não limitar a habilidade do indivíduo para preencher um papel social normal - dada sua severidade ou a aquilo que a pessoa deseja fazer.

- desvantagem - resulta de incapacidades, referindo-se a desvantagem social quando essas impedem o desempenho do papel social

Formas de compensação de dificuldades (ou incapacidades): estratégias de autocuidado empregadas por pessoas com distintos níveis de capacidade funcional com a finalidade de reduzir lacunas entre sua capacidade funcional $e$ as demandas do ambiente

- mudança comportamental: mudança na forma de realizar a atividade, ex: evitar escadas, evitar carregar objetos pesados, comprar um pouco a cada vez, fazer coisas menos freqüentemente ou mais vagarosamente etc

- dispositivo auxiliar: "qualquer item, peça de equipamento ou sistema modificado ou customizado, usado para aumentar, manter ou melhorar a capacidade funcional de individuos com incapacidades" (Mann e col, 1995).

- Exemplos de dispositivos auxiliares: adaptações simples nos utensílios e "instrumentos" de uso cotidiano (uso de colher de pau, cabo comprido ao invés de colher de metal, uso de acendedor ao invés de fósforo, óculos, controle remoto para televisão, telefone sem fio, lupa, números maiores para o telefone, amplificador de telefone, abridores de jarra, etc) órteses e próteses substitutivas - dispositivos utilizados junto ao corpo para corrigir disfunções ou deficiências - cadeira de rodas

- mudanças no ambiente físico

- Deslocamento de móveis/obstáculos: remanejamento sem exclusão, com vistas a aumentar a área de circulação e/ou facilitar o acesso de idoso, por exemplo o quarto do idoso pode ser transferido de pavimento - do superior para o inferior (temporária ou permanentemente) em caso de incapacidade para usar escada.

- Retirada/modificação de barreiras arquitetônicas: modificar o ambiente sem necessitar de reforma arquitetônica

- Alteração na estrutura arquitetônica: colocação de barras, rampas, aumento do tamanho de portas, pintura destacante das portas de ambientes, iluminação diferenciada - no rodapé do corredor, por exemplo, entre outras.

- assistência de outras pessoas:

- Supervisão: observar o idoso para se assegurar que de a atividade está sendo adequadamente realizada; oferecer dispositivos, utensílios utilizados na atividade; lembrá-lo quais passos tomar para completar a atividade.

- Assistência fisica direta: para iniciar ou completar a atividade.

Referências Bibliográficas

Beauchamp, T.L. \& Childress, J.F. Principles of medical ethics. 2nd ed. New York, Oxford University Press, 1985. p. 59-105: The principle of autonomy.

Fillenbaum GG. The wellbeing of the elderly: approaches to multidimensional assessment. Geneva: World Health Organization; 1984. (WHO, Offset Publication, 84)

Kane, R.L. The implication of assessment. J. Gerontol., 48 (Sp.Is.): 27-31, 1993

Mann, W.C e col. Assistive devices used by home-based elderly persons with arthrits. Amer. J. Occup. Ther. 49: 810-20, 1995.

Paula JAM e col. Avaliação funcional em gerontologia. Rev. Gerontologia. 1998; 6 (20): 81-88.

World Health Organization. International classification of impairments, disabilities, and handicaps.

A manual of classification relating to the consequences of disease. Geneva; 1980. 
Nome do entrevistado

$N^{\boldsymbol{D}}$ do prontuário

Data de nascimento _

Nome do entrevistador Data de entrevista

\section{Area de investigação Ambiente social e familiar}

Questão 1 -O sr mora com outras pessoas na mesma casa? Sim ( ) Não ( ) Com quem o sr mora? Identificar todas as pessoas que moram, atualmente, com o idoso

\begin{tabular}{|l|c|c|c|c|}
\hline \multirow{2}{*}{ Nome } & $\begin{array}{c}\text { Grau de parentesco/ Tipo de } \\
\text { relacionamento } \\
\text { (cônjuge, irmão, filho, neto, amigo, } \\
\text { etc) }\end{array}$ & Idade & \multicolumn{2}{|c|}{ Sexo } \\
\cline { 3 - 5 } & & & & \\
\hline & & & & \\
\hline & & & & \\
\hline
\end{tabular}

Questão 2 - O sr tem (outros) filhos? Sim ( ) Não ( )

Identificar todos os filhos vivos que não moram com o idoso

\begin{tabular}{|l|l|l|l|l|}
\hline \multirow{2}{*}{ Nome } & \multicolumn{2}{|c|}{ Sexo } & \multirow{2}{*}{ Idade } & \multirow{2}{*}{ Onde reside } \\
\cline { 2 - 5 } & Masculino & Feminino & & \\
\hline & & & & \\
\hline & & & & \\
\hline & & & & \\
\hline
\end{tabular}

Questão 3 - Com que freqüência o sr se relaciona com:

Preencher a coluna correspondente à freqüência segundo Legenda abaixo

\begin{tabular}{|l|l|}
\hline \multicolumn{1}{|c|}{ Tipo de relacionamento } & Freqüência \\
\hline Filhos & \\
\hline Vizinhos & \\
\hline Amigos & \\
\hline Associações/Grupos/Instituições & \\
\hline Outros Parentes & \\
\hline
\end{tabular}

Legenda: Freqüência

Todos os dias A cada 15 dias

Quase todos os dias 1 vez por mês

2 vezes por semana $\quad 1$ vez a cada 2 meses

1 vez por semana
1 vez a cada 6 meses
1 vez por ano

A cada 2 anos

Mais de dois anos

Nunca

Questão 4 - O sr está satisfeito com a freqüência com se relaciona com:

Assinale com um X o grau de satisfação corresponde a cada um dos tipos de relacionamento

\begin{tabular}{|l|c|c|c|}
\hline \multicolumn{1}{|c|}{ Tipos de relacionamento } & \multicolumn{3}{c|}{ Grau de satisfação } \\
\cline { 2 - 4 } & Sim & Mais ou menos & Não \\
\hline Filhos & & & \\
\hline Vizinhos & & & \\
\hline Amigos & & & \\
\hline Associações/Grupos/Instituições & & & \\
\hline Outros Parentes & & & \\
\hline
\end{tabular}


Questão 5 - Como o sr se sente com a relação que mantém com:

Assinale com um $X$ o grau de satisfação correspondente a cada um dos tipos de relacionamento.

Se o idoso mora só não é pertinente perguntar sobre as pessoas que moram com ele, nesse caso assinale com X para a $1^{\text {a }}$ linha somente a coluna Mora só

\begin{tabular}{|l|l|l|l|l|l|}
\hline \multicolumn{2}{|c|}{ Tipos de relacionamento } & \multicolumn{5}{c|}{ Grau de satisfação } \\
\cline { 2 - 6 } & $\begin{array}{c}\text { Muito } \\
\text { satisfeito }\end{array}$ & Satisfeito & Insatisfeito & $\begin{array}{c}\text { Muito } \\
\text { insatisfeito }\end{array}$ & Mora só \\
\hline As pessoas da família que moram com o sr & & & & & \\
\hline Pessoas da família que não vivem com o sr & & & & & \\
\hline Os amigos & & & & & \\
\hline Os vizinhos & & & & & \\
\hline
\end{tabular}

Questão 6 - Tem alguém que cuida do sr quando o sr fica doente? $\operatorname{Sim}($ ) Não ( ).

Quem é ou quais são essa(s) pessoa(s)

Identifique todas as pessoas que cuidam do idoso em caso de doença

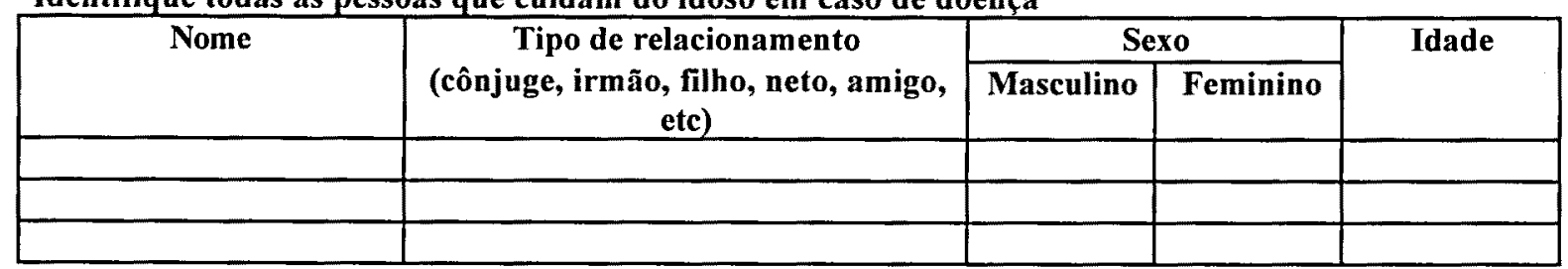

Objetivo das questões $1,2,3,4,5$, e 6 :

Descrever o arranjo doméstico e familiar do idoso e potencial rede de suporte

Questão 7 - O sr freqüentou escola? Até que ano estudou?

Assinale com um $X$ a escolaridade do entrevistado na coluna à direita

\begin{tabular}{|l|l|}
\hline Analfabeto & \\
\hline Sabe ler/escrever ou primário incompleto & \\
\hline Primário completo/ginásio incompleto & \\
\hline Ginásio completo/colegial incompleto & \\
\hline Colegial completo/curso superior incompleto & \\
\hline Superior completo & \\
\hline
\end{tabular}

Questão 8 - Qual sua atividade profissional principal ? Preencha o campo abaixo:

Questão 9 - O sr exerce essa atividade profissional atualmente? ( ) Sim ( ) Não

Se a resposta for negativa, aplicar a questão 10

Questão 10 - O sr tem trabalho remunerado atualmente? ( ) Sim ( ) Não. Qual ?

Após registrar o trabalho remunerado atual, procure transportá-lo para o Quadro 1, classificandoo segundo categorias definidas para Trabalho remunerado. As questões da área Universo Ocupacional deverão informar sobre o significado atribuído pelo idoso a esse trabalho e as suas outras atividades cotidianas, o que possibilitará preencher no Quadro 1 as colunas de caracterização dessas atividades.

Questão 11 - Quais são seus recursos financeiros atualmente?

Assinale com um $X$ os recursos financeiros do entrevistado na coluna à direita (múltipla escolha) - A aplicação financeira é considerada recurso somente se o entrevistado retirar dinheiro da aplicação para as suas despesas

\begin{tabular}{|l|l|}
\hline Salário & \\
\hline Aposentadoria & \\
\hline Pensão & \\
\hline Renda mensal vitalícia & \\
\hline Aluguel & \\
\hline Atividades informais & \\
\hline Aplicação financeira & \\
\hline Recebe ajuda em dinheiro ou espécie & \\
\hline
\end{tabular}


Questão 12 - Com a sua situação econômica atual como o sr satisfaz suas necessidades de alimentação, ${ }^{A-38}$ moradia, saúde, etc?

Assinale com um $X$ a forma com o idoso satisfaz suas necessidades, na coluna à direita

\begin{tabular}{|l|l|}
\hline Muito bem & \\
\hline Bem & \\
\hline Mais ou menos & \\
\hline Mal & \\
\hline Muito mal & \\
\hline
\end{tabular}

Objetivos das questões $7,8,9,10,11$ e12: Traçar um breve perfil social

\section{Área de investigação: Universo ocupacional}

Questão 13 - O que o sr faz todos os dias, desde a hora que acorda até a hora que vai dormir? Procure contar todas as coisas que faz.

Utilize o Quadro 1 para registro das respostas

Objetivo: Conhecer as Atividades cotidianas rotineiras

Questão 14 - Tem alguma coisa que o sr faz só de vez em quando?

Utilize o Quadro 1 para registro das respostas

Objetivo: Conhecer as Atividades cotidianas não-rotineiras

Questão 15-Das coisas que o sr faz, quais o sr acha que são importantes para o sr ? 15.1. Por quê?

Utilize o Quadro 1 para registro das respostas à questão 15 e, o Quadro 2 para registro de respostas à questão 15.1

Objetivo: Conhecer as atividades importantes e as necessidades a que elas correspondem

Questão 16 - Das coisas que o sr faz, quais gosta menos? 16.1 Por quê?

Utilize o Quadro 1 para registro das respostas à questão 16 e Quadro 3 para registro de respostas à questão 16.1

Objetivo: Conhecer as atividades não prazerosas e as necessidades a que elas não atendem 
Quadro1: Quadro resumo para registro de respostas às questões 13,14,15 e16

Identificar atividades que compõe a vida cotidiana do idoso, assinalando com $X$ na(s) coluna(s) correspondente(s) a sua caracterização. São atribuídos códigos numéricos ( 1 a 53 ) às atividades para facilitar seu registro nos quadros seguintes e tabulação futura

Universo ocupacional

\begin{tabular}{|ll}
\hline & \multicolumn{1}{c}{ Atividades de vida diária - Básicas } \\
\hline 1. & Banho \\
\hline 2. & Vestuário \\
\hline 3. & Uso do toalete \\
\hline 4. & Transferências posturais \\
\hline 5. & Continência \\
\hline 6. & Alimentação \\
\hline 7. & Locomoção \\
\hline 8. & Cuidados com pele, cabelos, unhas, dentes e face \\
\hline 9. & Comunicação \\
\hline
\end{tabular}

Atividades de

$11 . \quad$ Uso de meios de transporte

$12 . \quad$ Compras

13. Preparo de comida

14. Tarefas Domésticas

15. Lavagem roupas

16. Tomar medicamentos conforme receitados

17. Comparecer as consultas ou outros tratamentos

18. Receber pagamentos, pagar contas e controlar orçamento

19. Assistir a televisão

$20 . \quad$ Bordar

21. Caminhar

22. Cantar

23. Conversar com amigos/companheiro

24. Cuidar das plantas

25. Cuidar de pequenos animais

26. Dançar

27. Fazer crochê

28. Fazer orações

29. $\quad$ Fazer pequenos consertos em casa

30. Fazer tricô

31. Fazer visitas

32. Freqüentar salão de beleza

33. Ir a missa ou reunião religiosa

34. Ir ao cinema/teatro

$35 . \quad$ Jogar (jogos de salão)

$36 . \quad$ Leituras

37. Ouvir música/radio

38. Participar de cursos (alfabetização, idiomas, outros)

39. Participar de grup os

$40 . \quad$ Pintar

41. Praticar esporte

42. Sair com amigos

$43 . \quad$ Viajar

44. Outras. Especifique

Trabalho remunerado - enquadrar resposta à q. 10 Informal

46. Cargo técnico ou administrativo/profissão libera

$47 . \quad$ Lavrador

48. Empregada domést ica

49. Operário

50. Outro: especifique

$51 . \quad$ Voluntário

52. Dona de casa

53. Outro.especifique
Atividades que.

\begin{tabular}{|l|c|c|c|}
\hline faz todos os dias & faz vez em quando & são importantes & Gosta menos \\
\hline
\end{tabular} 
Quadro 2: Registro de respostas à questão 15.1: Porque o idoso acha determinadas atividades importantes. Preencha a coluna à direita com os códigos numéricos correspondentes às atividades.

$O$ idoso pode atribuir importância a todas as suas atividades por uma ou mais razões, nesse caso ao invés de anotar os códigos, preencha a linha(s) correspondente(s) com a palavra todas.

\begin{tabular}{|l|l|}
\hline \multicolumn{1}{|c|}{ Porque são importantes } & Códigos numéricos das atividades \\
\hline Trazem prazer & \\
\hline Promovem senso de utilidade (incluindo transmissão de cultura) & \\
\hline Através delas as pessoas desempenham comportamentos esperados & \\
\hline Mantêm as pessoas ativas & \\
\hline Distraem & \\
\hline Estimulam o exercicio da independência & \\
\hline Estão relacionadas com a sobrevivência & \\
\hline Diminuem a solidão e a carência afetiva (incluindo oportunidade de interação) & \\
\hline Trazem satisfação espiritual & \\
\hline Trazem oportunidade de descansar & \\
\hline São benéficas à saúde & \\
\hline Ocupam o tempo & \\
\hline Mantém pessoa atualizada & \\
\hline Alimentam a vaidade & \\
\hline Mantêm privacidade & \\
\hline Outras razões : Especifique & \\
\hline
\end{tabular}

Quadro 3: Registro de respostas à questão 16.1: Porque o idoso gosta menos de determinadas atividades.

Preencha a coluna à direita com os códigos numéricos correspondentes às atividades. $O$ idoso pode referir todas as suas atividades como não - prazerosas por uma ou mais razóes, nesse caso ao invés de anotar os códigos, preencha a linha(s) correspondente(s) com a palavra todas.

\begin{tabular}{|l|l|}
\hline \multicolumn{1}{|c|}{ Porque não gosta } & Códigos das atividades \\
\hline Acima das capacidades do idoso & \\
\hline Realizada em condições adversas & \\
\hline Não atende as necessidades do idoso & \\
\hline Outras razões: especifique & \\
\hline
\end{tabular}

\section{Área de investigação: Capacidade funcional}

Questão 17 - O sr tem dificuldade para fazer algumas das coisas que faz? Que tipo(s) de dificuldade?

Utilize o Quadro 4 para registro de respostas

Objetivos: Conhecer as atividades cotidianas para as quais o idoso apresenta dificuldade(s) e alguns

fatores relacionados às dificuldades

Questão 18 - O que o sr faz quanto à dificuldade X: Encontrou um jeito mais fácil de fazer, tem alguém que o ajuda, faz mesmo com dificuldade sem ajuda ou deixou de fazer?

Repita a pergunta 18 para cada dificuldade mencionada e utilize o Quadro 4 para registro de respostas

Questão 19 - Caso tenha encontrado um jeito mais fácil de fazer, como faz? Caso tenha alguém que o ajuda, quem o ajuda ? Repetir a pergunta 19 para cada uma dificuldades mencionada e utilize o Quadro 4 para registro de respostas

Objetivo das questões 18 e 19: Conhecer as formas de compensação adotadas pelo idoso

Seguem:

1. Legenda para preenchimento do Quadro 4

2. Quadro 4: Quadro resumo para registro das respostas às questões 17, 18 e 19 Legenda:

\begin{tabular}{|l|l|l|}
\hline - Tipos de dificuldade & Formas de compensação & $\begin{array}{l}\text { Códigos para tipos de relacionamento (quando houver } \\
\text { alguém que ajude o idoso) }\end{array}$ \\
F:Física & MC:Mudança Comportamental & $1:$ Pai,mãe, sogro(a), tio(a) \\
S:Sensorial & $2:$ Cônjuge \\
E:Emocional & MA:Mudança Ambiental & $3:$ Irmãos, primos, cunhados \\
C:Cognitiva & DA:Dispositivo Auxiliar & $4:$ Filhos, enteados, sobrinhos \\
So:Social & Su: Supervisão & $5:$ Genro, nora \\
EC:Econômica & As: Assistência Fisica & $6:$ Netos \\
R:Restriçōes clínicas & & $7:$ Bisnetos \\
A: Ambiente fisico & & $8:$ Amigo, conhecido \\
O: Outros & $9:$ Cuidador formal \\
& & $10:$ Outros: especifique \\
\hline
\end{tabular}


Quadro 4 : Quadro resumo para registro das respostas às questões 17, 18 e 19

Identifique as atividades para as quais o idoso tenha dificuldades, assinale com $\mathrm{X}$ os tipos de dificuldade (múltipla escolha), se compensa ou não di ficuldades e formas de compensacão adotadas (múltipla escolha).

\begin{tabular}{|l|l|l|l|l}
\hline Atividades para as quais $o$ idoso tem dipo dificuldade & Tipo
\end{tabular}

\begin{tabular}{|l|l|l|l|l|}
\hline \multicolumn{2}{|c|}{$\begin{array}{c}\text { Compensa dificuldades/ } \\
\text { Formas de compensação }\end{array}$} & \multicolumn{2}{c|}{$\begin{array}{c}\text { Não compensa } \\
\text { dificuldades }\end{array}$} \\
\hline $\begin{array}{l}\text { Faz de jeito mais } \\
\text { fácil }\end{array}$ & $\begin{array}{c}\text { Alguém } \\
\text { q.ajude }\end{array}$ & $\begin{array}{l}\text { Faz c/ } \\
\text { Dif. }\end{array}$ & $\begin{array}{l}\text { Deixou } \\
\text { fazer }\end{array}$ \\
\hline
\end{tabular}

\begin{tabular}{|l|l|}
\hline \multicolumn{2}{|c|}{ Atividades básicas de vida diária } \\
\hline 1. & Banho \\
\hline 2. & Vestuário \\
\hline 3. & Uso do toalete \\
\hline 4. & Transferências posturais \\
\hline 5. & Continência \\
\hline 6. & Alimentação \\
\hline 7. & Locomoção \\
\hline 8. & Cuidar pele,cabelos,unhas,dentes,face \\
\hline 9. & Comunicação \\
\hline
\end{tabular}

Atividades Instrumentais de vida diária

10. Uso do telefone

11. Uso de meios de transporte

12. Compras

13. Preparo de comida

14. Tarefas domésticas

15. Lavagem roupas

16. Tomar medicamentos receitados

17. Comparecer as consultas/tratamentos

18. Receber/pagar contas/controlar orca/o

19. Assistir a televisão

20. Bordar

21. Caminhar

22. Cantar

23. Conversar com amigos/companheiro

24. Cuidar das plantas

25. Cuidar de pequenos animais

26. Dançar

27. Fazer crochê

28. Fazer orações

29. Fazer pequenos consertos em casa

30. Fazer tricô

31. Fazer visitas (filhos e amigos)

32. Frequentar salão de beleza

33. Ir a missa ou reunião religiosa

34. Ir ao cinema/teatro

35. Jogar (jogos de salão)

36. Leituras

37. Ouvir música/rádio

38. Cursos(alfabetização,idiomas, outros)

39. Participar de grupos

40. Pintar

41. Praticar esporte

42. Sair com amigos

43. Viajar

44. Outras. Especifique

45. Informal

46. Cargo técnico/administrativo/Liberal

47. Lavrador

48. Empregada doméstica

49. Operário

50. Outro: especifique

51. Voluntário

52. Dona de casa

53 Outro,especifique

No caso de haver restriçōes clínicas, especifique-as:

No caso de haver outro(s) tipo (s) de dificuldade, especifique: 

questão 20

Se idoso precisa de ajuda, faz com dificuldade ou deixou de fazer alguma atividade, aplique a

Questão 20 - Pense nas coisas que o sr faz com ajuda, faz com dificuldade sem ajuda, ou tenha deixado de fazer. O sr imagina algum jeito mais fácil de fazê-las?

Sim, para todas as atividades ( ) Sim, para algumas atividades ( ) Não( )

Se a resposta for afirmativa para todas ou para algumas atividades, aplique a questão 21

Questão 21 - Como poderia ser feito?

Objetivo das questões 20 e 21 : Convidar o idoso a imaginar formas para compensar algumas dificuldades

Quadro 5: Registro das respostas à questão 20 e 21

Nomeie as atividades para as quais o idoso imagina compensações. Assinale com $\mathbf{X}$ as formas de compensação imaginadas (múltipla escolha). Ajuda de alguém pode ser considerada como forma de compensação para atividades que o idoso faz com dificuldade ou deixou de fazer.

\begin{tabular}{|c|c|c|c|c|c|}
\hline \multirow{2}{*}{$\begin{array}{l}\text { Atividades para as } \\
\text { quais apresenta } \\
\text { dificuldade }\end{array}$} & \multicolumn{5}{|c|}{ Formas de compensação imaginadas } \\
\hline & $\begin{array}{l}\text { Mudança de } \\
\text { comportamento }\end{array}$ & $\begin{array}{l}\text { Mudança } \\
\text { ambiental }\end{array}$ & $\begin{array}{c}\text { Dispositivo } \\
\text { Auxiliar }\end{array}$ & $\begin{array}{l}\text { Ajuda de } \\
\text { alguém }\end{array}$ & $\begin{array}{l}\text { Outra forma (especificar } \\
\text { a(s) forma(s) de } \\
\text { compensação na mesma } \\
\text { linha da atividade) }\end{array}$ \\
\hline & & & & & \\
\hline & & & & & \\
\hline & & & & & \\
\hline & & & & & \\
\hline & & & & & \\
\hline & & & & & \\
\hline & & & & & \\
\hline & & & & & \\
\hline
\end{tabular}

Questão 22 - Tem alguma coisa que o sr gostaria de ter feito em sua vida mas nunca fez ou fez há algum tempo atrás e gostaria de voltar a fazer?

Questão 22.1 - Por que não faz?

Questão 22.2 - O sr imagina algum jeito de vir a fazê-las?

Utilize o Quadro 6 para registro das respostas à questão 22, 22.1 e 22.2

Objetivo das questões 22, 22.1 e 22.2 : Conhecer as Atividades desejadas, Fatores de Inibição para essas atividades e Formas imaginadas para realizar as atividades desejadas 
Quadro 6: Registro das Atividades desejadas (resposta à questão 22), dos Por quês o idoso não faz (resposta à questão 22.1) e se imagina algum jeito de vir a fazê-las (resposta à questão 22.2).

Registre as atividades desejadas ( $1^{\text {a }}$ coluna), assinale a(s) coluna(s) correspondente(s) aos fatores de inibição consultando a lista de códigos abaixo (porque não faz) e as formas imaginadas de realização na coluna à direita.

\begin{tabular}{|l|l|l|l|l|l|l|l|l|}
\hline \multirow{2}{*}{$\begin{array}{c}\text { Atividades } \\
\text { desejadas }\end{array}$} & \multicolumn{5}{|c|}{ Porque não faz } & \multicolumn{2}{|c|}{ Formas imaginadas para realização } \\
\cline { 2 - 7 } & PS & FA & ANE & PR & DF & DRS & OR & \\
\hline & & & & & & & & \\
\hline & & & & & & & & \\
\hline & & & & & & & & \\
\hline & & & & & & & & \\
\hline & & & & & & & & \\
\hline & & & & & & & & \\
\hline
\end{tabular}

Legenda: porque não faz (atividades desejadas)

PS : Problemas de saúde

FA: Falta de apoio familiar

ANE: Atitude negativa em relação ao envelhecimento

PR: Preocupação excessiva com atribuições/responsabilidades familiares

DF: Dificuldade financeira

DRS: Desconhecimento de recursos sociais

OR: Outras razões: especifique

observações do entrevistador 


\section{6. $\quad 3^{\text {a }}$ Versão Grupal do Instrumento CICAc}

\section{Orientações gerais para aplicação}

Recomenda-se a aplicação do Instrumento CICAc, pelo Terapeuta Ocupacional, especialmente a idosos usuários de unidades básicas de saúde; uma vez que esse instrumento se propõe a fornecer algumas informações relevantes sobre o idoso que vive na comunidade, onde importam, basicamente, as atividades que o idoso desempenha ou não, fatores compensatórios às incapacidades, o ambiente e o suporte social.

As informações obtidas pela aplicação do Instrumento CICAc deverão contribuir para o processo de avaliação em Terapia Ocupacional, integrando-se a outras informações, provenientes de: prontuários, observações de comportamento e do ambiente, percepções de familiares e cuidadores. Como exemplo da importância da integração de informações podemos citar que os tipos de dificuldade darão pistas para relacionar as incapacidades, designadas pelo idoso - em nossa pesquisa - como "atividades para as quais tem dificuldades" com determinadas doenças registradas em prontuário. Essas informações serão importantes para priorizar condutas em T.O tais como reversão de incapacidades potencialmente reversiveis e compensação de incapacidades irreversíveis.

Ainda que um processo amplo de avaliação deva se dar de forma contínua, recomenda-se a aplicação do Instrumento CICAc em intervalos não superiores a 6 meses, o tempo mínimo de intervalo deverá ser determinado pelas aquisições do idoso, isto é, sempre que o T.O. observar algum progresso no tratamento, deverá conduzir uma nova avaliação, uma vez que a verificação e informação sobre progressos, ainda que sutis (não óbvios) para o idoso, podem promover a sua motivação a prosseguir com o tratamento.

Sugerimos que o Instrumento CICAc seja aplicado ao familiar responsável ou cuidador, especialmente nas seguintes situações: quando as exigências da entrevista superarem as capacidades do idoso e para ampliação da compreensão do profissional acerca da capacidade funcional do idoso. 


\section{Definição de termos}

Arranjo doméstico e familiar do idoso - informações que descrevem com quem o idoso mora e quem compõe sua familia mesmo que não more junto. Essas pessoas deverão ser descritas segundo alguns atributos como grau de parentesco (ou outro tipo de relacionamento) com o idoso, sexo e idade.

Potencial rede de suporte - Algumas informações contempladas pela aplicação do instrumento podem indicar a existência de uma rede de suporte para o idoso, pelo menos em potencial, a saber: frequêencia de contato com familiares, amigos e comunidade, satisfação do idoso em relação às pessoas que compõe sua rede de relações, incluindo aquelas com quem mora e indicação pelo idoso de determinadas pessoas com que pode contar em caso de doença. Algumas destas pessoas poderão, a partir de critérios estabelecidos pelo serviço de saúde, ser orientadas e apoiadas com vistas a formarem uma rede de suporte efetiva.

Breve perfil social - informações que caracterizam de forma sucinta o idoso socialmente. $O$ instrumento reúne sob essa denominação questões sobre escolaridade, atividade profissional principal, trabalho remunerado e outros recursos financeiros do idoso, enquanto fatores que influenciam o Universo Ocupacional do idoso. Atividade profissional, trabalho remunerado e atividades educacionais podem ainda compor esse Universo Ocupacional.

Ajuda em espécie (alternativa de resposta à questão 11): ajuda em mantimentos, roupas, medicamentos, etc

Condições adversas (altemativa de resposta à questão 16.1 , presente no quadro 3) - quando o ambiente físico ou social impõe restrições à autonomia e independência do idoso

Autonomia: termo derivado do grego: autos (eu) e nomos (regra, governo, lei) e significa faculdade para governar a si mesmo. BEAUCHAMP, T.L. e CHILDRESS, J.F. (1985)

Capacidade funcional: $\mathrm{O}$ termo capacidade funcional, é aplicado na área gerontológica para designar a capacidade para as atividades de vida diária (PAULA e col 1998).

Segundo FILLENBAUM (1984), a capacidade funcional relaciona-se à saúde física, mental e bem-estar social e a possibilidade do idoso manter-se na comunidade

De acordo com KANE (1993) a capacidade funcional é produto de três influências básicas: fatores intrínsecos do cliente (incluindo aspectos biológicos e comportamentais), cuidados recebidos (formais e informais) e ambiente do cliente (incluindo o ambiente fisico, psicológico e social).

Tipos de dificuldade: fatores que dificultem ou impeçam a realização de atividades. Esses fatores podem ser intrinsecos do cliente e/ou extrínsecos

- Física: restrição dos movimentos requeridos pela atividade

- Sensorial : restrição dos sentidos requeridos pela atividade

- Emocional: restrição da motivação requerida pela atividade

- Cognitiva: restrição das habilidades mentais requeridas pela atividade

- Social: falta de apoio social para desempenhar a atividade

- Econômica: falta de recursos econômicos que possibilitem a realização da atividade

- Restrições clínicas: doenças referidas pelo idoso ou efeitos dos tratamentos prescritos para essas doenças

- Ambiente físico: desenho arquitetônico do domicílio e/ou disposição de moveis e objetos que dificultem a locomoção do idoso, suas transferências posturais e o uso de objetos e utensílios de forma segura e confortável

- Outros: restrições de ordem cultural entre outras

Dificuldade (para realizar atividades) - termos empregado por alguns idosos para designar incapacidade

Deficiências, incapacidades, desvantagens são conceitos relacionados de acordo com o modelo ICIDH (WHO, 1980).

- deficiência - refere-se a redução das capacidades físicas e/ou mentais. São geralmente distúrbios ao nivel orgânico, podem não ser visíveis ou ainda não ter conseqüências adversas ao individuo, pois podem ser corrigidos

- incapacidade - resulta de patologias ou impedimentos cujos efeitos não foram corrigidos e refere-se a restrição nas habilidades do indivíduo para o desempenho de uma função de uma maneira considerada normal. Pode ser temporária ou permanente, reversivel ou irreversível ou ainda progressiva ou regressiva. Pode ser conseqüência direta de uma doença ou impedimento ou uma resposta, particularmente psicológica do indivíduo, à doença ou impedimento seja ele físico, sensorial ou outro. A incapacidade pode ou não 
limitar a habilidade do indivíduo para preencher um papel social normal - dada sua severidade ou a aquilo que a pessoa deseja fazer.

- desvantagem - resulta de incapacidades, referindo-se a desvantagem social quando essas impedem o desempenho do papel social

Formas de compensação de dificuldades (ou incapacidades): estratégias de autocuidado empregadas por pessoas com distintos niveis de capacidade funcional com a finalidade de reduzir lacunas entre sua capacidade funcional e as demandas do ambiente

- mudança comportamental: mudança na forma de realizar a atividade, ex: evitar escadas, evitar carregar objetos pesados, comprar um pouco a cada vez, fazer coisas menos freqüentemente ou mais vagarosamente etc

- dispositivo auxiliar: "qualquer item, peça de equipamento ou sistema modificado ou customizado, usado para aumentar, manter ou melhorar a capacidade funcional de individuos com incapacidades" (Mann e col, 1995).

- Exemplos de dispositivos auxiliares: adaptações simples nos utensilios e "instrumentos" de uso cotidiano (uso de colher de pau, cabo comprido ao invés de colher de metal, uso de acendedor ao invés de fósforo, óculos, controle remoto para televisão, telefone sem fio, lupa, números maiores para o telefone, amplificador de telefone, abridores de jarra, etc) órteses e próteses substitutivas - dispositivos utilizados junto ao corpo para corrigir disfunções ou deficiências - cadeira de rodas

- mudanças no ambiente físico

- Deslocamento de móveis/obstáculos: remanejamento sem exclusão, com vistas a aumentar a área de circulação e/ou facilitar o acesso de idoso, por exemplo o quarto do idoso pode ser transferido de pavimento - do superior para o inferior (temporária ou permanentemente) - em caso de incapacidade para usar escada.

- Retirada/modificação de barreiras arquitetônicas: modificar o ambiente sem necessitar de reforma arquitetônica

- Alteração na estrutura arquitetônica: colocação de barras, rampas, aumento do tamanho de portas, pintura destacante das portas de ambientes, iluminação diferenciada - no rodapé do corredor, por exemplo, entre outras.

- assistência de outras pessoas:

- Supervisão: observar o idoso para se assegurar que de a atividade está sendo adequadamente realizada; oferecer dispositivos, utensilios utilizados na atividade; lembrá-lo quais passos tomar para completar a atividade.

- Assistência física direta: para iniciar ou completar a atividade.

\section{Referências Bibliográfícas}

Beauchamp, T.L. \& Childress, J.F. Principles of medical ethics. 2nd ed. New York, Oxford University Press, 1985. p. 59-105: The principle of autonomy.

Fillenbaum GG. The wellbeing of the elderly: approaches to multidimensional assessment. Geneva: World Health Organization; 1984. (WHO, Offset Publication, 84)

Kane, R.L. The implication of assessment. J. Gerontol., 48 (Sp.Is.): 27-31, 1993

Mann WC, Hurren D., Machiko T. Assistive devices used by home-based elderly persons with arthrits. Amer. J. Occup. Ther. 1995; 49: 810-20.

Paula JAM, Tavares, MCGF, Diogo MJD. Avaliação funcional em gerontologia. Rev. Gerontologia. 1998; 6 (20): 81-88.

World Health Organization. International classification of impairments, disabilities, and handicaps. A manual of classification relating to the consequences of disease. Geneva; 1980. 
Nome do entrevistado

$N^{n}$ do prontuário

Nome do entrevistador

Data de nascimento __

Data de entrevista

Área de investigação Arranjo doméstico e familiar do idoso e potencial rede de suporte

Questão 1 - O(a) $\operatorname{Sr}($ a) mora com outras pessoas na mes ma casa? Sim ( ) Não ( )

Com quem o(a) $\mathrm{Sr}$ (a) mora?

Identificar todas as pessoas que moram, atualmente, com o idoso

\begin{tabular}{|l|c|c|c|c|}
\hline \multirow{2}{*}{ Nome } & $\begin{array}{r}\text { Grau de parentesco/ Tipo de } \\
\text { relacionamento } \\
\text { (cónjuge, irmão, nilho, neto, amigo, etc) }\end{array}$ & Masculino & Feminino & Idade \\
\hline & & & & \\
\hline & & & & \\
\hline & & & & \\
\hline
\end{tabular}

Questão 2 - O(a) Sr(a) tem (outros) filhos? Sim ( ) Não ( )

Identificar todos os filhos vivos que não moram com o idoso

\begin{tabular}{|l|c|c|c|c|}
\hline \multirow{2}{*}{ Nome } & \multicolumn{2}{|c|}{ Sexo } & Idade & Onde reside \\
\cline { 2 - 5 } & Masculino & Feminino & Ides & \\
\hline & & & & \\
\hline & & & & \\
\hline & & & & \\
\hline
\end{tabular}

Questão 3 - Com que freqüência o sr se relaciona com:

Preencher a coluna correspondente à freqüência segundo Legenda abaixo

\begin{tabular}{|l|l|}
\hline \multicolumn{1}{|c|}{ Tipo de relacionamento } & \multicolumn{1}{c|}{ Freqüência } \\
\hline Filhos & \\
\hline Vizinhos & \\
\hline Amigos & \\
\hline Associações/Grupos/Instituições & \\
\hline Outros Parentes & $\begin{array}{l}\text { l vez por ano } \\
\text { A cada 2 anos }\end{array}$ \\
Legenda: Freqüência & $\begin{array}{l}\text { Mais de dois anos } \\
\text { Nunca }\end{array}$ \\
Todos os dias & $\begin{array}{l}\text { A cada } 15 \text { dias } \\
\text { Quase todos os dias }\end{array}$ \\
2 vezes por semana mês & $\begin{array}{l}\text { l vez a cada 2 meses } \\
\text { l vez por a cada } 6 \text { meses }\end{array}$
\end{tabular}

Questão 4-O(a) Sr(a) está satisfeito com a freqüência com se relaciona com:

Assinale com um X o grau de satisfação corresponde a cada um dos tipos de relacionamento

\begin{tabular}{|l|c|c|c|}
\hline \multirow{2}{*}{\multicolumn{1}{|c|}{ Tipos de relacionamento }} & \multicolumn{3}{|c|}{ Grau de satisfação } \\
\hline & Sim & Mais ou menos & Não \\
\hline Filhos & & & \\
\hline Vizinhos & & & \\
\hline Amigos & & & \\
\hline Associações/Grupos/Instituições & & & \\
\hline Outros Parentes & & & \\
\hline
\end{tabular}


Questão 5 - Como o(a) Sr(a) se sente com a relação que mantém com:

Assinale com um $X$ o grau de satisfação correspondente a cada um dos tipos de relacionamento.

Se o(a) idoso(a) mora só não é pertinente perguntar sobre as pessoas que moram com ele(a), nesse caso assinale com $X$ para a $l^{a}$ linha somente a coluna Mora só.

\begin{tabular}{|l|l|l|l|l|l|}
\hline \multirow{2}{*}{ Tipos de relacionamento } & \multicolumn{5}{|c|}{ Grau de satisfacão } \\
\cline { 2 - 6 } & $\begin{array}{c}\text { Muito } \\
\text { satisfeito }\end{array}$ & Satisfeito & Insatisfeito & $\begin{array}{c}\text { Muito } \\
\text { insatisfeito }\end{array}$ & Mora só \\
\hline $\begin{array}{l}\text { As pessoas da família que moram } \\
\text { com o(a) Sr(a) }\end{array}$ & & & & & \\
\hline $\begin{array}{l}\text { Pessoas da família que não vivem } \\
\text { com o(a) Sr(a) }\end{array}$ & & & & & \\
\hline Os amigos & & & & & \\
\hline Os vizinhos & & & & & \\
\hline
\end{tabular}

Questão 6 - Tem alguém que cuida do(a) Sr(a) quando o sr fica doente? Sim ( ) Não ( ).

Quem é ou quais são essa(s) pessoa(s)

Identifique todas as pessoas que cuidam do(a) idoso(a) em caso de doença

\begin{tabular}{|l|l|l|l|l|}
\hline \multirow{2}{*}{ Nome } & \multirow{2}{*}{ Tipo de relacionamento } & \multicolumn{2}{|c|}{ Sexo } & \multirow{2}{*}{ (cônjuge, irmão, filho, neto, amigo, etc) } \\
\cline { 5 - 5 } & & Masculino & Feminino & Idade \\
\hline & & & & \\
\hline & & & & \\
\hline
\end{tabular}

Objetivo das questões $1,2,3,4,5, \mathrm{e} 6$ :

Descrever o arranjo doméstico e familiar do idoso e potencial rede de suporte

\section{Área de investigação Perfil social}

Questão 7-O(a) $\operatorname{Sr}(a)$ freqüentou escola? Até que ano estudou?

Assinale com um $X$ a escolaridade do entrevistado na coluna à direita

\begin{tabular}{|l|l|}
\hline Analfabeto & \\
\hline Sabe ler/escrever ou primário incompleto & \\
\hline Primário completo/ginásio incompleto & \\
\hline Ginásio completo/colegial incompleto & \\
\hline Colegial completo/curso superior incompleto & \\
\hline Superior completo & \\
\hline
\end{tabular}

Questão 8 - Qual sua atividade profissional principal ? Preencha o campo abaixo:

Questão 9-O(a) Sr(a) exerce essa atividade profissional atualmente? ( ) Sim ( ) Não Se a resposta for negativa, aplicar a questão 10

Questão 10 - O(a) Sr(a) tem trabalho remunerado atualmente? ( ) Sim ( ) Não. Qual?

Após registrar o trabalho remunerado atual, procure transportá-lo para o Quadro 1, classificando-o segundo categorias definidas para Trabalho remunerado. As questões da área "Universo Ocupacional" deverão informar sobre o significado atribuido pelo idoso a esse trabalho e as suas outras atividades cotidianas.

Questão 11 - Quais são seus recursos financeiros atualmente?

Assinale com um $X$ os recursos financeiros do entrevistado na coluna à direita (múltipla escolha)

- A aplicação financeira é considerada recurso somente se o entrevistado retirar dinheiro da aplicação para as suas despesas

\begin{tabular}{|l|l|}
\hline Salário & \\
\hline Aposentadoria & \\
\hline Pensão & \\
\hline Renda mensal vitalícia & \\
\hline Aluguel & \\
\hline Atividades informais & \\
\hline Aplicação financeira & \\
\hline Recebe ajuda em dinheiro ou espécie & \\
\hline
\end{tabular}


Questão 12 - Com a sua situação econômica atual como o(a) $\operatorname{Sr}(a)$ satisfaz suas necessidades de alimentação, moradia, saúde, etc?

Assinale com um X a forma com o idoso satisfaz suas necessidades, na coluna à direita

\begin{tabular}{|l|l|}
\hline Muito bem & \\
\hline Bem & \\
\hline Mais ou menos & \\
\hline Mal & \\
\hline Muito mal & \\
\hline
\end{tabular}

Objetivos das questões $7,8,9,10,11$ e12: Traçar um breve perfil social

Área de investigação : Universo ocupacional

Questão 13 - O que o(a) Sr(a) faz todos os dias, desde a hora que acorda até a hora que vai dormir? Procure contar todas as coisas que faz.

Utilize o Quadro 1 para registro das respostas

Objetivo: Conhecer as Atividades cotidianas rotineiras

Questão 14 - Tem alguma coisa que o(a) Sr(a) faz sỏ de vez em quando ?

Utilize o Quadro 1 para registro das respostas

Objetivo: Conhecer as Atividades cotidianas não-rotineiras

Questão 15 - Das coisas que o(a) $\operatorname{Sr}(a)$ faz, quais o(a) $\operatorname{Sr}(a)$ acha que são importantes para $o(a) \operatorname{Sr}(a)$ ? 15.1. Por quê?

Utilize o Quadro 1 para registro das respostas à questão 15 e, o Quadro 2 para registro de respostas à questão 15.1 Objetivo; Conhecer as atividades importantes e as necessidades a que elas correspondem

Questão 16 - Das coisas que o(a) Sr(a) faz, quais gosta menos? 16.1 Por quê?

Utilize o Quadro 1 para registro das respostas à questão 16 e Quadro 3 para registro de respostas à questão 16.1 Objetivo: Conhecer as atividades não prazerosas e as necessidades a que elas não atendem 
Quadro1: Quadro resumo para registro de respostas às questóes 13,14,15 e16

Identificar atividades que compöe a vida cotidiana do idoso, assinalando com $X$ ma(s) coluna(s) correspondente(s) a sua caracterizagäa. São atribuidos códigos numéricos (1 a 53) dè atividades para facilitar seu registro nos quadros seguintes.

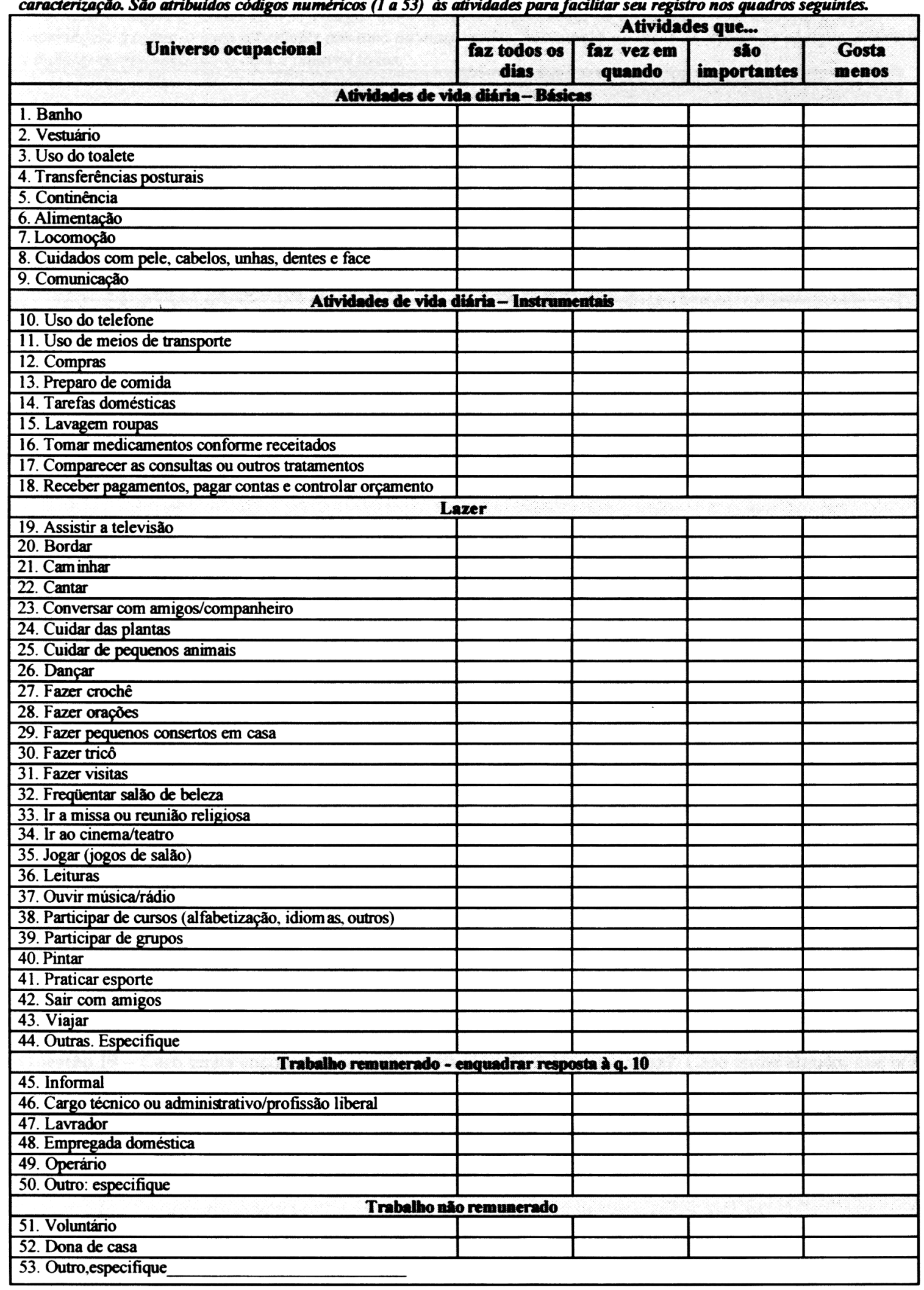


Quadro 2: Registro de respostas à questão 15.1: Porque o(a) idoso(a) acha determinadas atividades importantes.

Preencha a coluna à direita com os códigos numéricos correspondentes às atividades. $O(a)$ idoso(a) pode atribuir importância a todas as suas atividades por uma ou mais razões, nesse caso ao invés de anotar os códigos, preencha a linha(s) correspondente(s) com a palcura todas.

\begin{tabular}{|l|l|}
\hline \multicolumn{1}{|c|}{ Porque são importantes } & \multicolumn{1}{|c|}{$\begin{array}{c}\text { Códigos numéricos das } \\
\text { atividades }\end{array}$} \\
\hline Trazem prazer & \\
\hline Promovem senso de utilidade (incluindo transmissão de cultura) & \\
\hline Através delas as pessoas desempenham comportamentos esperados & \\
\hline Mantêm as pessoas ativas & \\
\hline Distraem & \\
\hline Estimulam o exercício da independência & \\
\hline Estão relacionadas com a sobrevivência & \\
\hline Diminuem a solidão e a carência afetiva (incluindo oportunidade de interação) & \\
\hline Trazem satisfação espiritual & \\
\hline Trazem oportunidade de descansar & \\
\hline São benéficas à saúde & \\
\hline Ocupam o tempo & \\
\hline Mantém pessoa atualizada & \\
\hline Alimentam a vaidade & \\
\hline Mantêm privacidade & \\
\hline Outras razões : Especifique & \\
\hline
\end{tabular}

Quadro 3: Registro de respostas à questão 16.1: Porque o(a) idoso(a) gosta menos de determinadas atividades.

Preencha a coluna à direita com os códigos numéricos correspondentes às atividades. $O(a)$ idoso(a) pode referir todas as suas atividades como não-prazerosas por uma ou mais razões, nesse caso ao invés de anotar os códigos, preencha a linha(s) correspondente(s) com a palavra todas.

\begin{tabular}{|l|l|}
\hline \multicolumn{1}{|c|}{ Porque nlo gosta } & Códigos das atividades \\
\hline Acima das capacidades do idoso & \\
\hline Realizada em condições adversas & \\
\hline Não atende as necessidades do idoso & \\
\hline Outras razões: especifique & \\
\hline
\end{tabular}

\section{Área de investigação: Capacidade funcional}

Questão 17 - $\mathrm{O}(\mathrm{a}) \operatorname{Sr}($ a) tem dificuldade para fazer algumas das coisas que faz? Que tipo(s) de dificuldade?

Utilize o Quadro 4 para registro de respostas

Objetivos: Conhecer as atividades cotidianas para as quais o idoso apresenta dificuldade(s) e alguns fatores relacionados às dificuldades

Questão 18 - O que o(a) $\operatorname{Sr}(a)$ faz quanto à dificuldade X: Encontrou um jeito mais fácil de fazer, tem alguém que o(a) ajuda, faz mesmo com dificuldade sem ajuda ou deixou de fazer?

Repita a pergunta 18 para cada dificuldade mencionada e utilize o Quadro 4 para registro de respostas.

Questão 19 - Caso tenha encontrado um jeito mais fácil de fazer, como faz? Caso tenha alguém que o(a) ajuda, quem o(a) ajuda?

Repetir a pergunta 19 para cada uma dificuldades mencionada e utilize o Quadro 4 para registro de respostas

Seguem:

Objetivo das questões 18 e 19: Conhecer as formas de compensação adotadas pelo idoso

3. Legenda para preenchimento do Quadro 4

4. Quadro 4 : Quadro resumo para registro das respostas às questões 17, 18 e 19 
Legenda para preenchimento do Quadro 4:

\begin{tabular}{|c|c|c|}
\hline Tipos de dificuldade & Formas de compensaciao & $\begin{array}{l}\text { Codigos para tipos de relacionamento (quando } \\
\text { houver algéém que ajude o idoso) }\end{array}$ \\
\hline $\begin{array}{l}\text { F:Física } \\
S: \text { Sensorial } \\
\text { E:Emocional } \\
C: \text { Cognitiva } \\
\text { So:Social } \\
\text { EC:Econômica } \\
R: \text { Restrições clinicas } \\
\text { A: Ambiente fisico } \\
O: \text { Outros }\end{array}$ & $\begin{array}{l}\text { MC:Mudança Comportamental } \\
\text { MA:Mudança Ambiental } \\
\text { DA:Dispositivo Auxiliar } \\
\text { Su: Supervisão } \\
\text { As: Assistência Fisica }\end{array}$ & $\begin{array}{l}\text { 1: Pai,mãe, sogro(a), tio(a) } \\
2: \text { Cônjuge } \\
3: \text { Irmãos, primos, cunhados } \\
4: \text { Filhos, enteados, sobrinhos } \\
5: \text { Genro, nora } \\
6: \text { Netos } \\
7: \text { Bisnetos } \\
8: \text { Amigo, conhecido } \\
9: \text { Cuidador formal } \\
10: \text { Outros: especifique }\end{array}$ \\
\hline
\end{tabular}

Quadro 4 : Quadro resumo para registro das respostas às questões 17, 18 e 19

Identifique as atividades para as quais o(a) idoso(a) tenha dificuldades, assinale com $X$ os tipos de dificuldade (múltipla escolha), se compensa ou não dificuldades e formas de compensação adotadas (múltipla escolha).

\begin{tabular}{|c|c|c|c|c|c|c|c|c|c|c|c|c|c|c|c|c|}
\hline \multirow{3}{*}{$\begin{array}{c}\text { Atividades para as quais o idoso tem } \\
\text { dificuldade }\end{array}$} & \multirow{2}{*}{\multicolumn{9}{|c|}{ Tipo de dificuldade }} & \multicolumn{5}{|c|}{$\begin{array}{c}\text { Compensa dificuldades } \\
\text { Formas de } \\
\text { compensacito }\end{array}$} & \multicolumn{2}{|c|}{$\begin{array}{c}\text { NI0 } \\
\text { compensa } \\
\text { dificuldades }\end{array}$} \\
\hline & & & & & & & & & & \multicolumn{3}{|c|}{$\begin{array}{l}\text { Fan de jeito } \\
\text { mais ffeil }\end{array}$} & \multicolumn{2}{|c|}{$\begin{array}{l}\text { Alguidm } \\
\text { que } \\
\text { giude }\end{array}$} & \multirow{2}{*}{\begin{tabular}{|l|} 
Faz \\
d \\
Dif. \\
\end{tabular}} & \multirow[t]{2}{*}{$\begin{array}{l}\text { Deiro } \\
\text { un } \\
\text { farer }\end{array}$} \\
\hline & $\mathbf{F}$ & $\mathbf{S}$ & $\mathbf{E}$ & $\mathbf{C}$ & So & $\mathbf{E}$ & $\mathbf{R}$ & $\overline{\mathbf{A}}$ & $\mathbf{0}$ & \begin{tabular}{c|}
$\mathbf{M}$ \\
$\mathbf{c}$
\end{tabular} & $\begin{array}{c}\mathbf{M} \\
\mathbf{a}\end{array}$ & $\mathbf{D a}$ & su & AS & & \\
\hline \multicolumn{17}{|l|}{ 1. Banho } \\
\hline \multicolumn{17}{|l|}{ 2. Vestuário } \\
\hline \multicolumn{17}{|l|}{ 3. Uso do toalete } \\
\hline \multirow{2}{*}{\multicolumn{17}{|c|}{$\begin{array}{l}\text { 4. Transferências posturais } \\
\text { 5. Continência }\end{array}$}} \\
\hline & & & & & & & & & & & & & & & & \\
\hline \multicolumn{17}{|l|}{ 6. Alimentacão } \\
\hline \multicolumn{17}{|l|}{ 7. Locomoção } \\
\hline \multicolumn{17}{|l|}{ 8. Cuidar pele,cabelos,unhas,dentes,face } \\
\hline \multirow{2}{*}{\multicolumn{17}{|c|}{$\begin{array}{l}\text { 9. Comunicacăo } \\
\text { Atividades Instrumentais de vida didria }\end{array}$}} \\
\hline & & & & & & & & & & & & & & & & \\
\hline \multicolumn{17}{|l|}{ 10. Uso do telefone } \\
\hline \multicolumn{17}{|l|}{ 11. Uso de meios de transporte } \\
\hline 12. Compras & & & & & & & & & & & & & & & & \\
\hline 13. Preparo de comida & & & & & & & & & & & & & & & & \\
\hline 14. Tarefas domésticas & & & & & & & & & & & & & & & & \\
\hline 15. Lavagem roupas & & & & & & & & & & & & & & & & \\
\hline 16. Tomar medicamentos receitados & & & & & & & & & & & & & & & & \\
\hline 17. Comparecer as consultas/tratamentos & & & & & & & & & & & & & & & & \\
\hline 18. Receber/pagar contas/controlar orça/o & & & & & & & & & & & & & & & & \\
\hline Lazer & & & & & & & & & & & & & & & & \\
\hline 19. Assistir a televisão & & & & & & & & & & & & & & & & \\
\hline 20. Bordar & & & & & & & & & & & & & & & & \\
\hline 21. Caminhar & & & & & & & & & & & & & & & & \\
\hline 22. Cantar & & & & & & & & & & & & & & & & \\
\hline 23. Conversar com amigos/companheiro & & & & & & & & & & & & & & & & \\
\hline 24. Cuidar das plantas & & & & & & & & & & & & & & & & \\
\hline 25. Cuidar de pequenos animais & & & & & & & & & & & & & & & & \\
\hline 26. Dançar & & & & & & & & & & & & & & & & \\
\hline 27. Fazer crochê & & & & & & & & & & & & & & & & \\
\hline 28. Fazer orações & & & & & & & & & & & & & & & & \\
\hline 29. Fazer pequenos consertos em casa & & & & & & & & & & & & & & & & \\
\hline 30. Fazer tricô & & & & & & & & & & & & & & & & \\
\hline 31. Fazer visitas (filhos e amigos) & & & & & & & & & & & & & & & & \\
\hline 32. Freqüentar salăo de beleza & & & & & & & & & & & & & & & & \\
\hline 33. Ir a missa ou reunião religiosa & & & & & & & & & & & & & & & & \\
\hline 34. Ir ao cinema/teatro & & & & & & & & & & & & & & & & \\
\hline 35. Jogar (jogos de salăo) & & & & & & & & & & & & & & & & \\
\hline 36. Leituras & & & & & & & & & & & & & & & & \\
\hline 37. Ouvir músicałádio & & & & & & & & & & & & & & & & \\
\hline 38. Cursos(alfabetizaçào,idiomas, outros) & & & & & & & & & & & & & & & & \\
\hline 39. Participar de grupos & & & & & & & & & & & & & & & & \\
\hline 40. Pintar & & & & & & & & & & & & & & & & \\
\hline
\end{tabular}




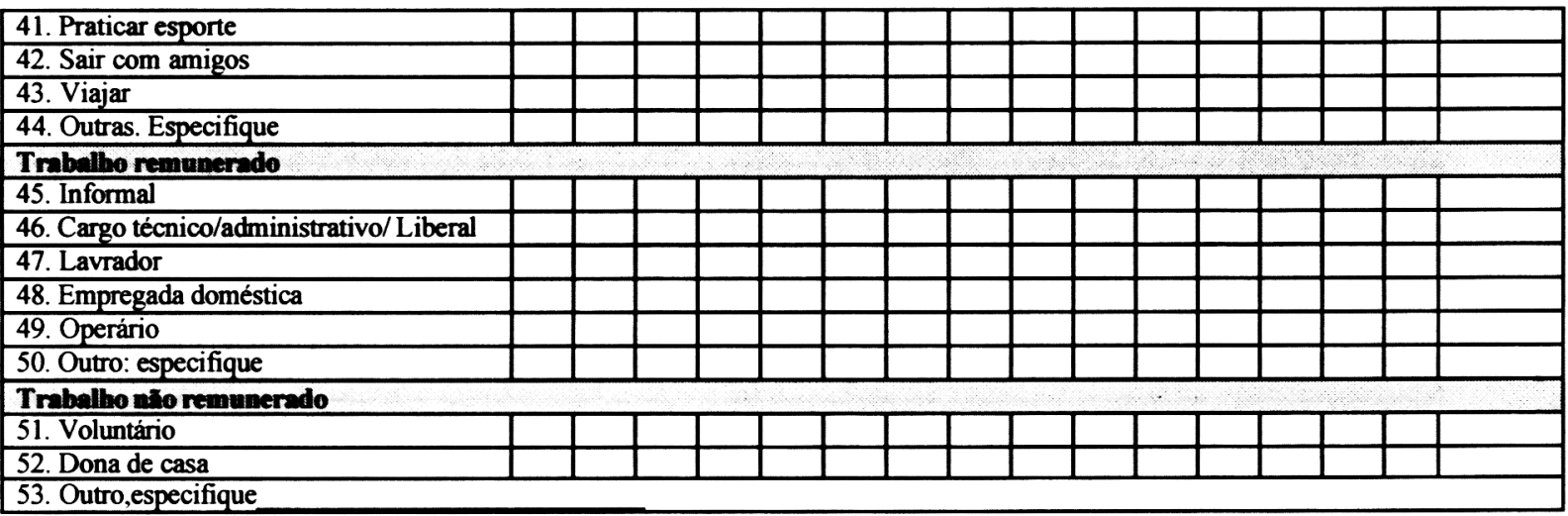

No caso de haver restrições clínicas, especifique-as:

No caso de haver outro(s) tipo (s) de dificuldade, especifique:

Se idoso precisa de ajuda, faz com dificuldade ou deixou de fazer alguma atividade, aplique questão 20

Questão 20 - Pense nas coisas que o(a) Sr(a) faz com ajuda, faz com dificuldade sem ajuda, ou tenha deixado de fazer. $\mathrm{O}(a) \mathrm{Sr}(a)$ imagina algum jeito mais fácil de fazê -las?

Sim, para todas as atividades ( ) Sim, para algumas atividades ( ) Não ( )

Se a resposta for afirmativa para todas ou para algumas atividades, aplique a questão 21

Questão 21 - Como poderia ser feito?

Objetivo das questões 20 e 21 : Convidar o idoso a imaginar formas para compensar algumas dificuldades

Quadro 5: Registro das respostas à questão 20 e 21

Nomeie as atividades para as quais o idoso imagina compensações. Assinale com $X$ as formas de compensação imaginadas (múltipla escolha). Ajuda de alguém pode ser considerada como forma de compensação para atividades que o idoso faz com dificuldade ou deixou de fazer.

\begin{tabular}{|l|l|l|l|l|l|}
\hline \multirow{2}{*}{$\begin{array}{l}\text { Atividades } \\
\text { para as quais } \\
\text { apresenta } \\
\text { dificuldade }\end{array}$} & $\begin{array}{c}\text { Mudança de } \\
\text { comportamento }\end{array}$ & $\begin{array}{c}\text { Mudança } \\
\text { ambiental }\end{array}$ & $\begin{array}{c}\text { Dispositivo } \\
\text { Auxiliar }\end{array}$ & $\begin{array}{l}\text { Ajuda de } \\
\text { alguém }\end{array}$ & $\begin{array}{l}\text { Outra forma } \\
\text { (especificar a(s) } \\
\text { forma(s) de } \\
\text { compensaça na mesma } \\
\text { linha da atividade) }\end{array}$ \\
\hline & & & & & \\
\hline & & & & & \\
\hline & & & & & \\
\hline
\end{tabular}

Questão 22 - Tem alguma coisa que o(a) Sr(a) gostaria de ter feito em sua vida mas nunca fez ou fez há algum tempo atrás e gostaria de voltar a fazer?

Questão 22.1 - Por que não faz?

Questão 22. 2 - $\mathrm{O}(\mathrm{a}) \mathrm{Sr}(\mathrm{a})$ imagina algum jeito de vir a fazê-las?

Utilize o Quadro 6 para registro das respostas à questão 22, 22.1 e 22.2

Objetivo das questões 22, 22.1 e 22.2 : Conhecer as Atividades desejadas, Fatores de Inibição para essas atividades e Formas imaginadas para realizar as atividades desejadas 
Quadro 6: Registro das Atividades desejadas (resposta à questão 22), dos Por quês o(a) idoso(a) não faz (resposta à questão 22.1) e se imagina algum jeito de vir a fazê -las (resposta à questão 22.2).

Registre as atividades desejadas ( $I^{a}$ coluna), assinale a(s) coluna(s) correspondente(s) aos fatores de inibição consultando a lista de códigos abaixo (porque não faz) e as formas imaginadas de realização na coluna à direita.

\begin{tabular}{|c|c|c|c|c|c|c|c|c|}
\hline \multirow{2}{*}{$\begin{array}{l}\text { Atividades } \\
\text { desejadas }\end{array}$} & \multicolumn{7}{|c|}{ Porque nilo faz } & \multirow[t]{2}{*}{ Formas imaginadas para realizacăo } \\
\hline & $\mathbf{F S}$ & $\overline{\mathbf{F A}}$ & ANE & $\overline{\mathbf{P R}}$ & DF & DES & $\overline{\mathbf{O R}}$ & \\
\hline & & & & & & & & \\
\hline & & & & & & & & \\
\hline & & & & & & & & \\
\hline
\end{tabular}

Legenda: porque não faz (atividades desejadas)

PS : Problemas de saúde

FA: Falta de apoio familiar

ANE: Atitude negativa em relação ao envelhecimento

PR: Preocupação excessiva com atribuições/responsabilidades familiares

DF: Dificuldade financeira

DRS: Desconhecimento de recursos sociais

OR: Outras razões: especifique

\section{observações do entrevistador}


ANEXO 2 - DIVERSOS 


\subsection{Matriz de terminologia uniforme em Terapia Ocupacional}

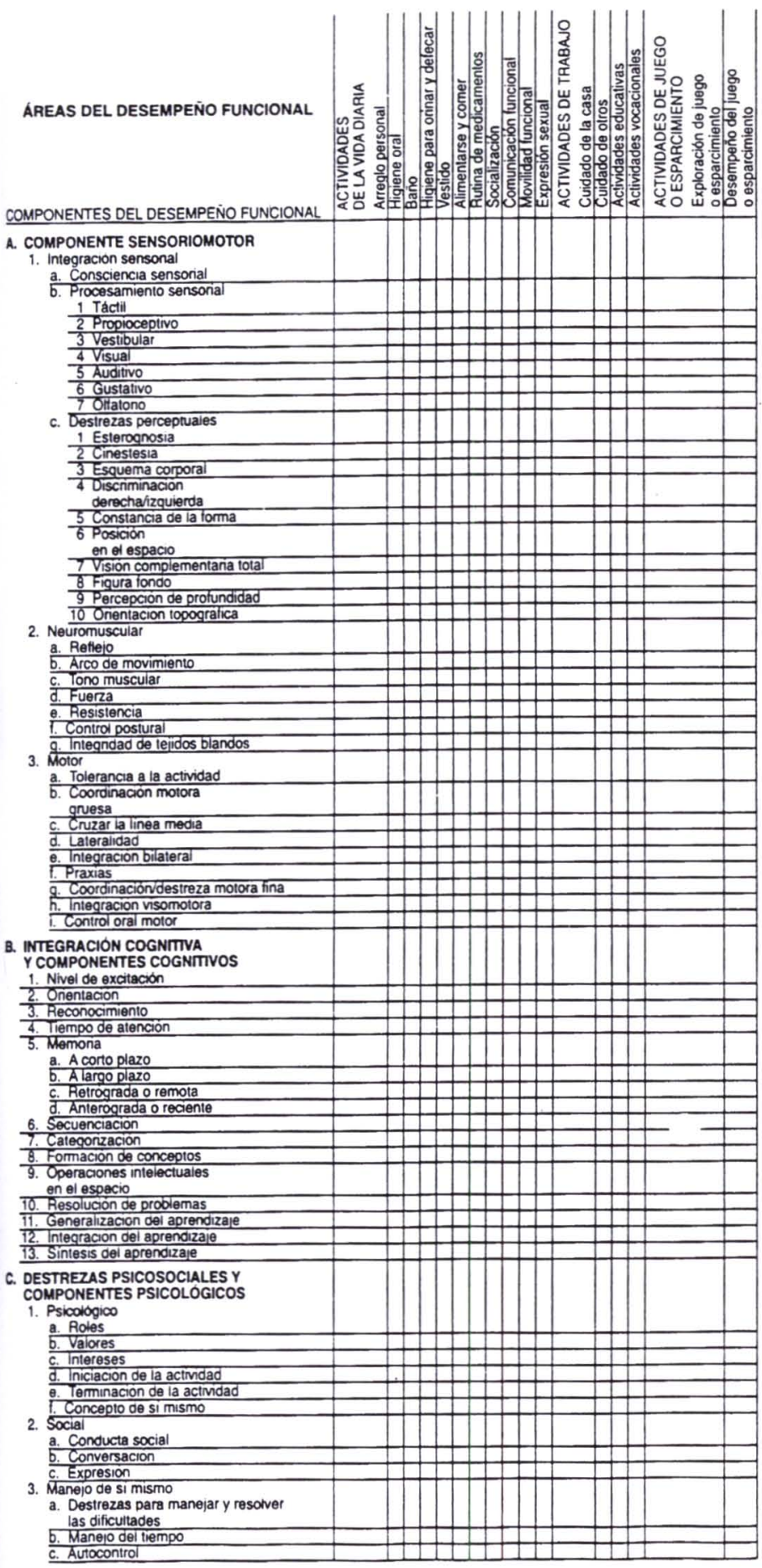

MATRIZ DE TERMINOLOGÍA UNIFORME. Copyright 1988, por Winnie Dunn. Reimpreso con autorización.

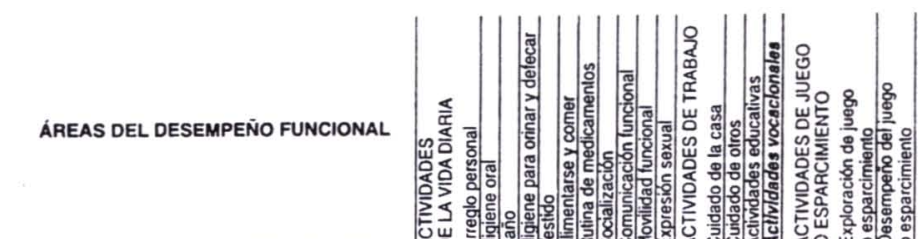

COMPONENTES DEL DESEMPENO FUNCIONAL

A. COMPONENTE SENSORIOMOTOR

1. Integración sensonal

a. Consciencia sensorial

b. Procesam

$\frac{1}{2 \text { Táctil }} \frac{1}{2 \text { Propioceptivo }}$

$\frac{3 \text { Vestibu }}{4}$ Visual

$\frac{5 \text { Auditivo }}{6 \text { Gustativo }}$

c. Destrezas perceptuales

$\frac{1}{2}$ Esterognosi:

$\frac{2 \text { Cinestesia }}{3 \text { Esquema corpo }}$

5 Constancia de

en el espacio

$\frac{7 \text { Vision complementaria lotal }}{8 \text { ifiura }}$

9 Percepcion de profundida

2. Neuromuscutacion lopografica

b. Arcojo de movimient

c. Tono muscula

a. Hesistioncta -

3. ल. Intor

Motor Inegndao de teijdos blandos

a. Tolerancia a la activida

c. gruesa

o. Integracion bilateral

A. Integraras

9. Coordinaciondestreza motora fina

. Control oral molor

B. INTEGRACION COGNITIVA
Y COMPONENTES COGNITVO

1. Nivel de excitación

2. Onentación

4. Tiempo de atencion

5. A cono plazo

a. Alargo plazo

- Aetrograda o remola

6. Secuenciacio

8. Formacion de concepplos

en el espacio

10. Rel el espacio

11. Gesolucion de problemas

$\frac{12 .}{12 .}$ Integracion del aprenoizaia)

C. DESTREZAS PSICOSOCIALESY

COMPONENTES PSICOLOGICOS

1. Psicologico

a. Roles

d. Iniciacion de la actividad

E. Terminacion oe la activid

2. Social

a. Conducta social

c. Expresion

3. Manejo de si mismo

manejar y resolve

las dificultades

c. Autocontrol 


\subsection{Solicitação aos terapeutas ocupacionais para participar do estudo}

\section{Roteiro telefônico}

Os profissionais serão contatados pelo telefone, e brevemente informados sobre o estudo quanto aos seguintes aspectos:

- Objetivo;

- Importância da opinião do profissional sobre o instrumento;

- Descrição sucinta das etapas do processo metodológico;

- Garantia do anonimato;

- Estabelecimento de prazos para devolução dos questionários avaliados;

- Confirmação de endereço do profissional;

- Envio - pelo correio em envelope selado - de:

- Carta convite com proposta detalhada do estudo (Anexo 3);

- Termo de consentimento (Anexo 4);

- questionários de opinião em três etapas. 


\subsection{Solicitação aos terapeutas ocupacionais para participar do estudo}

\section{Carta convite}

Conforme contato prévio, segue proposta de estudo sobre validação de instrumento específico do terapeuta ocupacional a ser aplicado junto à população idosa. Busquei contextualizar a valiosa colaboração do sr (a) nesse estudo

\section{Justificativa do estudo:}

Objetivando sistematizar a prática da terapia ocupacional em unidades básicas de saúde junto à população idosa elaborei um instrumento ao qual denominei CICAc: Classificação de Idosos quanto à Capacidade para o Autocuidado. O CICAc foi construído a partir de referenciais teórico-práticos da terapia ocupacional, concepção teórica do autocuidado e compreensão da população idosa habitualmente atendida em unidades básicas de saúde acerca do autocuidado, sendo objeto de dissertação de mestrado. Esse processo de elaboração tornou o instrumento válido para ser aplicado exclusivamente à população de estudo. Para que forneça resultados válidos para o universo de idosos atendidos em unidades básicas deverá ser submetido a testes de confiabilidade e validade.

\section{Método:}

Em sua primeira versão o CICAc combinou questões abertas e fechadas. Para submetê-lo entretanto a testes de confiabilidade e validade, o CICAc deverá ser estruturado sob a forma de escalas uma vez que, segundo ALMEIDA FILHO (1989), instrumentos estruturados oferecem resultados mais confiáveis.

Estruturei o instrumento, a princípio, sob a forma de escalas nominais. Ao julgar cada um dos itens que compõe as escalas, os especialistas estarão sugerindo uma ordem a ser identificada e estabelecida pelo pesquisador para a elaboração de escalas ordinais. Segundo McDOWELL e NEWELL (1987) essas escalas permitem mensurar características, atribuir pontuações e comparar grupos. 
Critérios para a escolha do júri de especialistas:

- Terapeutas ocupacionais com registro atualizado na Sociedade Brasileira de Geriatria e Gerontologia - Seção São Paulo;

- Com especialização na área de gerontologia por um período igual ou superior a 2 anos;

- Com atuação da referida área por um periodo igual ou superior a 2 anos;

- Residentes e atuantes no Município de São Paulo e/ou Grande São Paulo;

- Interesse expresso em colaborar com o estudo.

Etapas de elaboração de escalas ordinais: o emprego da técnica Delphi:

Optei pela técnica Delphi para a busca de um consenso no que se refere à composição do CICAc Segundo WILLIAMS e WEBB (1994) "a técnica Delphi debruça sobre o julgamento de um grupo de especialistas consistindo essencialmente em questioná-los sobre questões ou assuntos específicos."

Em anexo segue o referido instrumento para que o sr (a) opine acerca de cada questão e respectivas categorias que o compõe, julga ndo se elas informam ou não sobre a capacidade funcional e universo ocupacional do idoso.

O julgamento do conjunto de especialistas será analisado, sumarizado e um novo questionário será elaborado no qual serão incluídos somente os itens aprovados por $55 \%$ ou mais dos especialistas ( $1^{\mathrm{a}}$ versão grupal). Essa versão do Instrumento CICAc será reenviada aos especialistas para que cada um possa, individualmente e a partir da visão do grupo, reconsiderar suas opiniões ( $2^{\mathrm{a}}$ versão grupal). Essas novas ponderações feitas pelos especialistas serão analisadas, sumarizadas e reenviadas aos especialistas, juntamente com a $2^{\mathrm{a}}$ versão grupal do Instrumento CICAc para as considerações finais $\left(3^{\mathrm{a}}\right.$ versão grupal). Nesse processo será assegurado o total anonimato na autoria des respostas.

Solicito que as três versões do questionário sejam julgadas e reenviadas ao pesquisador sempre no prazo de uma semana, em envelope selado que será sistematicamente incluso nas correspondências. 
Segundo ALMEIDA FILHO (1989), o julgamento, pelos especialistas, colabora para a validação de conteúdo das escalas. $O$ autor acrescenta que para ter validade de conteúdo é preciso ainda "verificar se o instrumento foi construído com itens de poder discriminatório aceitável" . Um segundo teste de validade será conduzido com esse propósito, como segue.

Procurarei demonstrar que o conjunto de questões que compõe o Instrumento CICAc informa diferenças entre idosos institucionalizados e não-institucionalizados quanto à capacidade funcional e o universo ocupacional; confirmando distinções já descritas pela literatura especializada. Cada item será avaliado, conforme sua capacidade de discriminar entre os dois grupos, reafirmando valores atribuídos às variáveis e respectivas categorias pelo júri de especialistas.

Pelo exposto, posso afirmar que o resultado positivo da primeira etapa do processo de validação depende da sua colaboração bem como da colaboração dos demais especialistas. Com sua valiosa ajuda, estaremos conduzindo, pela primeira vez, estudo de validação de um instrumento específico de terapia ocupacional a ser empregado junto à população idosa brasileira que, espero, possa embasar o processo de atenção ao idoso pelo terapeuta ocupacional e ainda fundamentar estudos e pesquisas na área de envelhecimento e saúde pública.

Agradecendo antecipadamente sua colaboração, coloco-me a disposição para quaisquer esclarecimentos que se fizerem necessários.

Pesquisador responsável

Maria Helena Morgani de Almeida

Terapeuta ocupacional e aluna de pós-graduação da Faculdade de Saúde Pública/USP

Universidade de São Paulo

Tel.: 30667754 


\subsection{Termo de consentimento livre e esclarecido aos terapeutas ocupacionais}

Estou realizando estudo de doutoramento em Saúde Pública, pela Faculdade de Saúde Pública da Universidade de São Paulo, que resultará em validação de questionário específico do terapeuta ocupacional a ser empregado junto à população idosa em unidades de saúde, com a finalidade de informar sobre sua capacidade para as atividades cotidianas. Para que forneça resultados válidos deverá ser submetido a testes de confiabilidade e validade.

Como parte desses testes, o instrumento deverá ser submetido a julgamento por um júri de especialistas considerado segundo critérios de conhecimento e experiência profissional na área de gerontologia.

Pretendo buscar um consenso entre especialistas, pelo emprego da técnica Delphi, na qual versões do instrumento são apresentadas, modificadas a partir da opinião desses especialistas e reapresentadas aos profissionais que individualmente irão emitir opiniões acerca dos itens que os compõe - em três etapas. Serão incluídos no instrumento os itens aprovados por $55 \%$ ou mais dos especialistas

Sua participação nesse estudo é livre podendo inclusive desligar-se quando julgar conveniente. Pretendo divulgar esse estudo em publicações e eventos científicos assegurando total anonimato na autoria das respostas. Caso o (a) sr (a) decida participar, solicito assinar o presente termo.

$$
\begin{gathered}
\text { Especialista } \\
\text { Pesquisador responsável } \\
\text { Maria Helena Morgani de Almeida } \\
\text { Terapeuta ocupacional }
\end{gathered}
$$

aluna de Pós-graduação pela Faculdade de Saúde Pública da Universidade de São Paulo Tel.: 30667754 


\title{
2.5. Instruções aos terapeutas ocupacionais nas três etapas do estudo Delphi
}

\section{$1^{2}$ Etapa}

\begin{abstract}
Aspectos gerais do Instrumento CICAc a serem considerados na sua apreciação pelos juízes
\end{abstract}

O instrumento é composto por três áreas de investigação: Ambiente sócio-familiar, Universo Ocupacional e Capacidade funcional. As questões que compõe o Instrumento CICAc foram organizadas segundo áreas de investigação, correspondendo a cada uma das questões um objetivo que as acompanha. As questões são acompanhadas ainda de quadros resumos para registro de respostas.

\section{Instruçōes para preenchimento do questionário de opinião}

O questionário para apreciação do Instrumento CICAc foi elaborado no geral em forma de declarações sobre o referido instrumento, em relação as quais peço que o (a) sr (a) procure posicionar-se. Seu posicionamento deverá basear-se na leitura criteriosa do instrumento a partir de experiência e conhecimento acumulados na área de gerontologia.

No questionário foi destinado espaço para comentários ou razões de resposta a cada uma das declarações. Seus comentários são muito importantes pois eles compõem sua resposta. Sua opinião objetiva em relação às questões que compõe o CICAc será fundamental para que possamos confirmar, modificar, introduzir e mesmo excluir questões a fim de que o instrumento venha fornecer informações válidas em seu conteúdo quanto à Capacidade Funcional e o Universo Ocupacional do idoso, especialmente atendido em unidades de saúde. Procurei ainda, reservar um espaço no final do questionário para observações que digam respeito a aspectos do Instrumento CICAc como um todo e que não tenham sido contemplados no questionário. 
Solicito que o questionário seja preenchido e devolvido em 1 semana, pelo correio em envelope selado incluso na correspondência. Após a devolução do questionário será feita a análise de resultados, dando continuidade então ao nosso estudo de validação.

Solicito ainda que enviem junto com o questionário as seguintes informações profissionais: onde fez sua formação profissional, quanto tempo de formado, cursos realizados na área de gerontologia, tempo de experiência na área e em que esferas de atuação (ensino, pesquisa e assistência) e onde trabalha atualmente. Essas informações irão caracterizar o grupo de juízes.

Contando com sua valiosa colaboração, coloco-me a disposição para quaisquer esclarecimentos que se fizerem necessários.

Atenciosamente

Maria Helena Morgani de Almeida

Av do Guacá, 63, Bloco A, apartamento 143, Mandaqui

CEP 02435-000 São Paulo - SP

Tels 62362103 (res.) / 30667754 (coml) / 91637515 (cel.) 


\section{$2^{\mathbf{a}}$ Etapa}

\section{Instruções para apreciação da $1^{a}$ versão grupal do Instrumento CICAc - Classificação de Idosos quanto à Capacidade para o Autocuidado}

Aproveito a oportunidade para agradecer sua valiosa colaboração na $1^{\mathrm{a}}$ etapa do estudo de validação. Graças a sua apreciação sobre o Instrumento CICAc - versão estruturada, pude elaborar a $1^{a}$ versão grupal do referido instrumento. Envio em anexo sumário das respostas, propostas de modificação e a $\mathbf{1}^{\mathbf{a}}$ versão grupal do Instrumento CICAc, para sua apreciação.

Objetivando elaborar uma $2^{\mathbf{a}}$ versão grupal do instrumento que expresse um grau ainda maior de concordância entre especialistas, solicito que o (a) sr (a) julgue a nossa $1^{\text {a }}$ versão grupal da seguinte forma:

- cada questão deverá ser julgada quanto a sua propriedade e clareza para o alcance do objetivo maior do instrumento, qual seja: fornecer informações sobre o universo ocupacional e a capacidade funcional do idoso usuário de unidades básicas de saúde

- .orientações gerais para aplicação do instrumento, instruções para aplicação e preenchimento (no corpo do instrumento) e definição de termos também deverão ser julgadas.

O (a) sr (a) será convidado a expressar suas opiniões em espaços reservados ao longo do próprio Instrumento CICAc $-1^{\text {a }}$ versão grupal, imediatamente após o enunciado de cada questão. Foi reservado ainda espaço para comentários e observações. Críticas e sugestões nortearão o aprimoramento das questões.

Solicito que este julgamento seja enviado ao pesquisador em 15 dias, pelo correio em envelope selado incluso na correspondência, para que possamos dar continuidade ao estudo de validação e entrada em sua fase final.

Contando com sua valiosa colaboração, coloco-me a disposição para quaisquer esclarecimentos que se fizerem necessários.

Atenciosamente

Pesquisador responsável

Maria Helena Morgani de Almeida

Terapeuta ocupacional

aluna de Pós-graduação da Faculdade de Saúde Pública da USP

Tel:: 30667754 


\section{$3^{\mathbf{a}}$ Etapa}

\section{Caro colega}

Agradecemos a devolução de seu questionário preenchido, o que possibilitou a tabulação e análise dos resultados bem como a elaboração da $2^{\mathrm{a}}$ versão grupal do Instrumento CICAc

$\mathrm{Na}$ etapa anterior os itens e tópicos do instrumento foram julgados quanto ao seu conteúdo e enunciado, as respostas dos juízes convergiram para altos índices de concordância - maior ou igual a $70 \%$.

Enfatizamos a alteração do índice de $55 \%$ para $70 \%$ para inclusão de itens ao instrumento, visto que segundo WILLIAMS (1994), FARO (1995) e SPÍNOLA (2002), importantes pesquisas que desenvolveram a técnica DELPHI, inclusive na área de saúde, trabalham com o índice de 0,70 ou 70\%, apontando-o como satisfatório e de concordância. Adotamos esse novo índice ainda por considerarmos, a partir dos dados obtidos, que se o Instrumento - resultante deste estudo - for aprovado por $70 \%$ ou mais dos especialistas terá maior validade de conteúdo e maior aceitação e utilização tanto por parte dos juízes quanto de outros especialistas.

Os itens ou tópicos que obtiveram índices maiores do que $70 \%$ foram considerados validos, serão mantidos no instrumento sem modificações. Caso algum item fosse reprovado em seu conteúdo seria eliminado, não houveram entretanto itens reprovados em seu conteúdo. Os itens ou tópicos que obtiveram índices menores que $70 \%$ em seu enunciado serão reapresentados com novo enunciado, a partir de sugestões feitas por alguns especialistas e deverão ser novamente julgados quanto ao seu conteúdo e enunciado. 
A $2^{\mathrm{a}}$ versão grupal do Instrumento CICAc encontra-se a sua disposição na íntegra. Optamos, no entanto, enviar para apreciação dos especialistas, nesta etapa, somente os ítens ou tópicos a serem julgados, a fim de favorecer a leitura do material.

\section{Atividades propostas aos especialistas para a $3^{\text {a }}$ etapa do Estudo Delphi}

- Acompanhar os resultados da $2^{\mathrm{a}}$ etapa do Estudo Delphi, a partir de:

- Apresentação dos resultados no Quadro 1

Comentários do pesquisador sobre os resultados

- Acompanhar esclarecimentos do pesquisador sobre aos principais referenciais utilizados no instrumento

- Julgar "Definição de termos" visto que foi considerado pelo conjunto dos especialistas apropriado em seu conteúdo mas sem clareza de enunciado. Para essa $3^{\mathrm{a}}$ etapa do Estudo Delphi foram feitas modificações nesse tópico, portanto ele deverá ser julgado novamente em seu conteúdo e enunciado.

- Assinalar SIM ou NÃO conforme julgá-lo apropriado ou não em seu conteúdo

- Assinalar SIM ou NÃO conforme julgá-lo claro ou não em seu enunciado

- Tecer comentários se julgar necessário

- Julgar o Quadro 6. Três especialistas (20\%) consideram que as informações sobre atividades desejadas, fatores de inibição e formas imaginadas de realização devam ser levantadas em seqüência, uma logo após a outra, para evitar que a aplicação do instrumento se torne demorada e repetitiva. O Quadro 6 representa uma tentativa de agrupar todas essas informações logo após a aplicação das questões.

- Assinalar SIM ou NÃO conforme julgá-lo apropriado ou não em seu conteúdo

- Assinalar SIM ou NÃO conforme julgá-lo claro ou não em seu enunciado

- Tecer comentários se julgar necessário 


\section{- Construir uma escala ordinal}

Finalizaremos o Estudo Delphi a partir da devolução das respostas. Os resultados finais serão enviados a cada um de vocês incluindo a $3^{\mathrm{a}}$ versão grupal do Instrumento CICAc Esperamos que o nosso instrumento já possa ser aplicado e os resultados compartilhados por todos nós. Os resultados da $2^{\mathrm{a}}$ fase - aplicação do instrumento a duas populações distintas de idosos - serão compartilhados oportunamente.

Solicitamos envio das respostas em 15 dias, reiterando nossos AGRADECIMENTOS pela sua valiosa colaboração, sem a qual esta pesquisa não teria sido desenvolvida.

Colocamo-nos a disposição para quaisquer esclarecimentos que se fizerem necessários.

Maria Helena Morgani de Almeida

Tels: 30667754/91637515 


\subsection{Questionário de participação em pesquisa}

Caro colega

Agradecemos a devolução de seu questionário preenchido, o que possibilitou a tabulação e análise dos resultados finais de nosso estudo.

Todos os itens e tópicos do Instrumento CICAc foram aprovados em seu:

- Conteúdo: obtendo índice médio de aprovação de 93,3\% (com variação entre $80 \%$ e $100 \%$ )

- $\quad$ Enunciado: obtendo índice médio de aprovação de 86,7\% (com variação entre $73,3 \%$ e $100,0 \%)$

Consideramos que esses resultados confiram ao instrumento validade de conteúdo. Segundo MacDOWELL e NEWELL (1995) para que tenha validade de conteúdo os itens incluídos no instrumento devem refletir uma amostra de itens relevantes para cada domínio, essa amostra podem ser obtida a partir de questionários existentes e sugestões de especialistas. Aspectos de validade de onteúdo incluem propriedade, clareza e abrangência dos itens.

Apresentaremos a seguir:

- $\quad$ Resultados da $3^{a}$ etapa do estudo Delphi - resultados finais

- $\quad$ Instrumento CICAc em sua $3^{\mathrm{a}}$ versão grupal

- Questionário de participação em pesquisa (a ser devolvido se possível)

- $\quad$ Proposta de encontro entre especialistas 


\section{Questionário de participação em pesquisa}

Caro colega

Durante a $1^{\mathrm{a}}$ fase de nosso trabalho, aplicamos a Técnica Delphi com a finalidade de obter o consenso de um grupo de especialistas quanto ao conteúdo do Instrumento CICAc - Classificação de Idosos quanto à Capacidade para o Autocuidado.

Tivemos a grata oportunidade de tê-lo como participante deste grupo durante as três etapas de aplicação da Técnica. O grupo foi composto por 15 Terapeutas Ocupacionais com experiência na assistência, ensino e pesquisa em gerontologia.

Solicitamos, mais uma vez, sua colaboração respondendo ao seguinte questionário:

1. Você já havia participado de alguma pesquisa?

( ) Sim ( ) Não

2. Você já participou, na qualidade de juiz, de outras pesquisas?

( ) $\operatorname{Sim}$ ( ) Não

3. Você conhecia a Técnica Delphi, antes de participar desta pesquisa?

( ) $\operatorname{Sim}$ ( ) Não

4. Você considera a escolha da Técnica apropriada ao objetivo proposto pelo pesquisador: Validar o conteúdo de um instrumento específico para o T.O.?

( ) $\operatorname{Sim}$ ( ) Não

5. Você considera importante a existência de um instrumento especifico para o T.O a ser empregado em Unidades Básicas de Saúde junto à população idosa?

( ) $\operatorname{Sim}$ ( ) Não

6. Descreva em poucas palavras como você se sentiu durante a aplicação da Técnica Delphi

7. Como você percebeu a atuação da pesquisadora durante as três etapas do Estudo Delphi? 


\subsection{Proposta de encontro entre especialistas}

Consideramos que nosso instrumento já possa ser aplicado e os resultados compartilhados por todos nós (reiteramos que estaremos conduzindo a validação operacional do Instrumento CICAc ainda como parte do projeto de doutorado).

Meu desejo de partilharmos da experiência de aplicação do Instrumento CICAc parece somar-se ao desejo expresso por dois juízes: conhecer os T.Os que participaram do júri de especialistas.

Consideramos, pelos resultados obtidos, que a opção pela Técnica Delphi nos conduziu a uma troca de idéias e experiência bastante produtiva sem que houvesse contato entre os especialistas, uma vez que ela se constitui em "processo interativo grupal no qual especialistas são solicitados e tem a oportunidade de expressarem suas opiniões sobre um determinado tema ou assunto, existindo construção participativa sem contato face a face" (SPÍNOLA 1984).

Nos parece que os resultados alcançados nos convidam no entanto a darmos continuidade a troca de experiências.

Pelo exposto, lanço a proposta de agendarmos um encontro entre os especialistas participantes do estudo com a finalidade nos conhecermos pessoalmente, iniciarmos troca de experiências profissionais especialmente com idosos, e discutirmos questões referentes à adoção do Instrumento CICAc entre outros instrumentos, na prática clinica e de pesquisa.

Caro colega, caso você concorde com o agendamento de uma reunião, informe sua disponibilidade (dias, horários, a partir de quando...) por telefone, e-mail ou correio. Se optar por correio, envie, se possível sua resposta no envelope selado que acompanha essa correspondência.

Reiteramos nossos AGRADECIMENTOS pela sua valiosa colaboração, sem a qual esta pesquisa não teria sido desenvolvida.

Atenciosamente

Maria Helena Morgani de Almeida

Tel: 30667754/91637515

hmorgani@usp.br 


\subsection{Considerações sobre o Teste do Relógio [Clock completion Test]}

Tradicionalmente o [Clock completion Test] (CCT) tem sido usado para examinar a apraxia construcional. Considerando que essa disfunção do lobo parietal acompanha com freqüência a demência em seu estado inicial e ainda a praticidade do CCT, estudos atuais têm procurado afirmar sua praticidade e sensibilidade para detectar a presença de demência em idosos (TUOKO e col. 1992; SHERMAN 2001).

Sua validade for testada por SHERMAN (2001), comparando seus resultados com aqueles obtidos a partir de testes padronizados como o "Short Blessed Test". O CCT mostrourse um método confiável para identificar demência com $87 \%$ de sensibilidade e $82 \%$ de especificidade, passando a ser usado como marcador sensível para essa doença.

A administração deste teste consiste em desenhar num papel sem linhas um círculo com aproximadamente oito $\mathrm{cm}$ de diâmetro e pedir ao paciente que escreva números de 1 a 12 dentro do mesmo de modo que represente a face de um relógio.

Após aplicação do teste, deve-se dividir o círculo em quatro partes iguais, a partir do número 12 ou a marca que melhor corresponda e asse número. Cada quadrante deve conter três números ( 12 a 2, 3 a 5,6 a 8 , e 9 a 10), se o número se situar sobre a linha divisória, será incluindo no quadrante seguinte, em sentido horário. Três números em cada quadrante, sejam quais forem, é considerado normal. Resultados normais nos três primeiros quadrantes recebem pontuação zero (0) e resultados anormais recebem pontuação 1. Resultados anormais no quarto quadrante são sugestivos de demência, recebendo pontuação Zero (0) para normal e 4 para anormal. Assim resultados de 4 a 7 são sugestivos de demência, segundo critérios do teste. 


\subsection{Termo de consentimento para aplicação do Teste do Relógio [Clock Completion Test-CCT]}

Prezado (a) sr (a)

Estou realizando um estudo com o objetivo de aperfeiçoar um questionário de avaliação da capacidade de idosos para as atividades do dia-a-dia, a ser utilizado por serviços de saúde.

Por se tratar de um estudo de doutorado, considera-se a necessidade de aplicação aos entrevistados de um instrumento que permita identificar aspectos de memória e orientação dos mesmos.

Optei pelo "Teste do relógio" pela sua simplicidade e rapidez de aplicação.

Pretendo divulgar os resultados obtidos em publicações e eventos, sem no entanto citar o nome daqueles que forneceram as informações.

Sua recusa ou desistência a qualquer momento em participar do estudo não implica, de forma alguma, em prejuízo à sua assistência pelo serviço.

Agradeço antecipadamente sua valiosa colaboração e coloco-me a disposição para quaisquer esclarecimentos que se fizerem necessários.

Caso o sr decida participar, solicito assinar o presente termo.

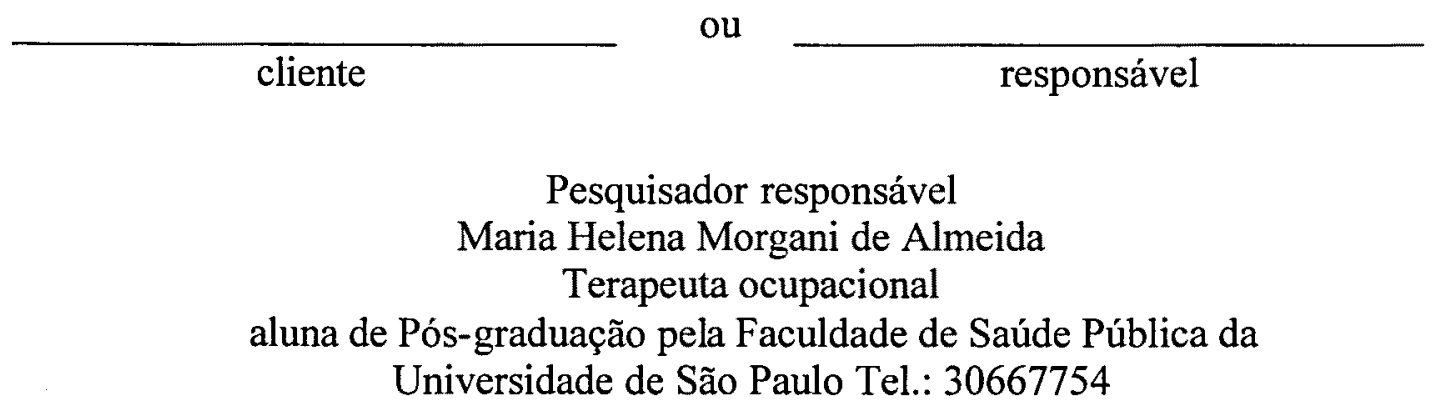


2.10. Protocolo para aplicação do CCT - Teste do relógio

Nome do entrevistado:

Nome do aplicador:

Data do teste:

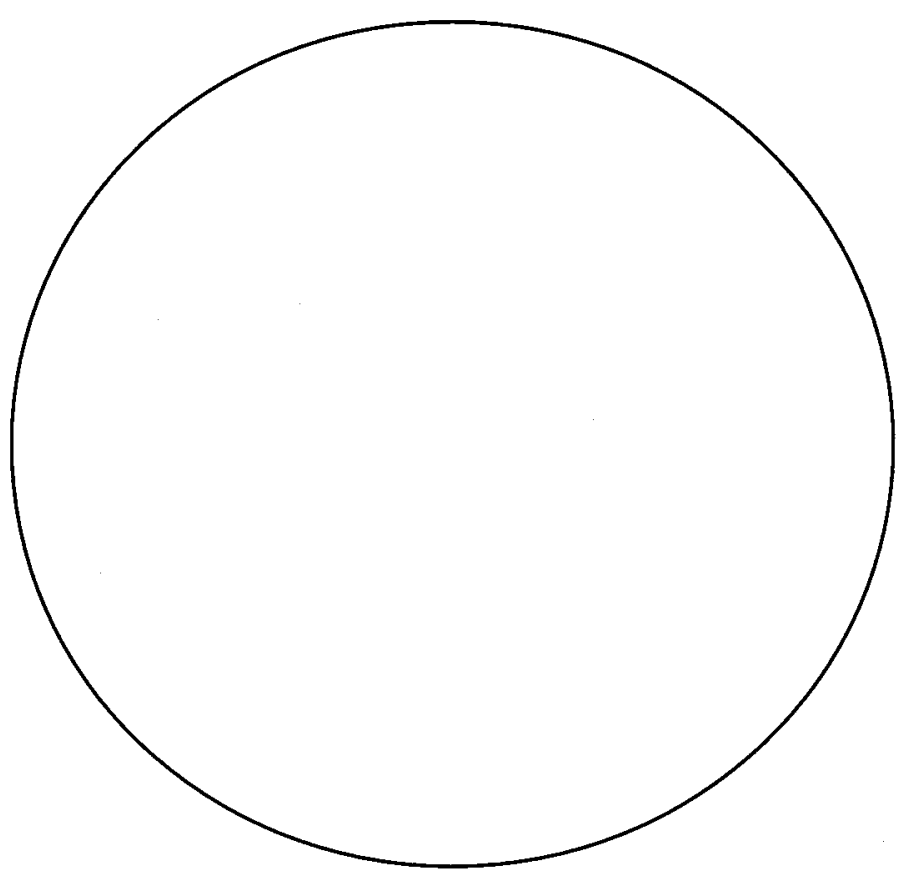




\subsection{Termo de consentimento livre e esclarecido aos idosos -avaliação de confiabilidade}

Prezado (a) sr (a)

Estou realizando um estudo com o objetivo de aperfeiçoar um questionário a ser utilizado por serviços de saúde junto a idosos. Através desse questionário será possível avaliar a capacidade de idosos para as atividades do dia-a-dia e conseqüentemente identificar suas dificuldades, colaborando para a realização de programas de atenção a essa população. Para que esse questionário venha informar a real capacidade de idosos deverá ser testado e sofrer alguns ajustes.

Como parte desses testes ele deverá ser aplicado a idosos residentes em instituições, atendidos em Centro de Saúde/Centros de Convivência.

Serão realizadas duas entrevistas com intervalo de uma semana, por um pesquisador colaborador com duração de 45 minutos até 1 (uma) hora. A partir dessas entrevistas, o (a) sr (a) poderá solicitar orientação quanto à capacidade para as atividades do dia-a-dia. Esclareço que as orientações são inteiramente gratuitas.

Pretendo divulgar os resultados obtidos em publicações e eventos, sem no entanto citar o nome daqueles que forneceram as informações.

Sua recusa ou desistência a qualquer momento em participar do estudo não implica, de forma alguma, em prejuízo à sua assistência pelo serviço.

Agradeço antecipadamente sua valiosa colaboração e coloco-me a disposição para quaisquer esclarecimentos que se fizerem necessários.

Caso o sr decida participar, solicito assinar o presente termo.

ou

cliente

responsável

Pesquisador responsável

Maria Helena Morgani de Almeida

Terapeuta ocupacional

aluna de Pós-graduação pela Faculdade de Saúde Pública da

Universidade de São Paulo Tel.: 30667754 


\subsection{Agendamento de entrevista}

\section{Agendamento de entrevista}

Solicito seu retorno para entrevista

Dia

Horário

Local:

Contando com sua valiosa colaboração, subscrevo - Ine

Maria Helena Morgani de Almeida

Tel $30667754 / 91637515$ 